\title{
The New Second
}

Generation in Switzerland

Youth of Turkish and Former Yugoslav

Descent in Zürich and Basel

ROSITA FIBBI, PHILIPPE WANNER, CEREN TOPGÜL \& DUŠAN UGRINA 
The New Second Generation in Switzerland 


\section{IMISCOE \\ International Migration, Integration and Social Cohesion in Europe}

The IMISCOE Research Network unites researchers from some 30 institutes specialising in studies of international migration, integration and social cohesion in Europe. What began in 2004 as a Network of Excellence sponsored by the Sixth Framework Programme of the European Commission became, as of April 2009, an independent self-funding endeavour. IMISCOE promotes integrated, multidisciplinary and globally comparative research led by scholars from various branches of the economic and social sciences, the humanities and law. The network furthers existing studies and pioneers new scholarship on migration and migrant integration. Encouraging innovative lines of inquiry key to European policymaking and governance is also a priority.

The IMISCOE-Amsterdam University Press Series makes the network's findings and results available to researchers, policymakers and practitioners, the media and other interested stakeholders. High-quality manuscripts are evaluated by external peer reviews and the IMISCOE Editorial Committee. The committee comprises the following members:

Tiziana Caponio, Department of Political Studies, University of Turin / Forum for International and European Research on Immigration (FIERI), Turin, Italy

Michael Collyer, Sussex Centre for Migration Research (SCMR), University of Sussex, United Kingdom

Rosita Fibbi, Swiss Forum for Migration and Population Studies (SFM), University of Neuchâtel, Switzerland / Institute of Social Sciences, University of Lausanne

Agata Górny, Centre of Migration Research (CMR) / Faculty of Economic Sciences, University of Warsaw, Poland

Albert Kraler, International Centre for Migration Policy Development (ICMPD), Vienna, Austria

Jean-Michel Lafleur, Center for Ethnic and Migration Studies (CEDEM), University of Liège, Belgium

Jorge Malheiros, Centre of Geographical Studies (CEG), University of Lisbon, Portugal

Eva Østergaard-Nielsen, Department of Political Science, Autonomous University of Barcelona, Spain

Marlou Schrover, Institute for History, Leiden University, The Netherlands

Patrick Simon, National Demographic Institute (INED), Paris, France

IMISCOE Policy Briefs and more information on the network can be found at www.imiscoe.org. 


\title{
The New Second Generation in Switzerland
}

\author{
Youth of Turkish and Former Yugoslav \\ Descent in Zurich and Basel
}

Rosita Fibbi, Philippe Wanner, Ceren Topgül and Dušan Ugrina

IMISCOE Research 
Cover design: Studio Jan de Boer BNO, Amsterdam

Typesetting: Crius Group, Hulshout

Amsterdam University Press English-language titles are distributed in the US and Canada by the University of Chicago Press.

$\begin{array}{ll}\text { ISBN } & 9789089648433 \\ \text { e-ISBN } & 97890485^{2} 6963 \text { (pdf) } \\ \text { NUR } & 740 \mid 763\end{array}$

(c) Rosita Fibbi, Ceren Topgül, Dušan Ugrina \& Philippe Wanner / Amsterdam University Press B.V., Amsterdam 2015

All rights reserved. Without limiting the rights under copyright reserved above, no part of this book may be reproduced, stored in or introduced into a retrieval system, or transmitted, in any form or by any means (electronic, mechanical, photocopying, recording or otherwise) without the written permission of both the copyright owners and the authors of the book. 


\section{Table of contents}

Preface

1 The new second generation in Switzerland

Youth of Turkish and former Yugoslav descent in Zurich and Basel Rosita Fibbi, Ceren Topgül, Dušan Ugrina and Philippe Wanner

1.1 The old and the new second generation 13

1.2 Research on the second generation in Switzerland

1.2.1 The second generation from Italy and Spain

1.2.2 The new second generation from Turkey

1.2.3 The new second generation from Yugoslavia

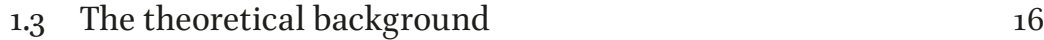

1.3.1 Second generation: Definition and historical processes $\quad 16$

$\begin{array}{lll}1.3 .2 & \text { Structural integration } & 18\end{array}$

1.3.3 Deconstructing the national frame 20

1.4 The TIES study in Switzerland 20

1.4.1 Scope and structure of the book 23

2 Migration history and demographic characteristics of the two second-generation groups

2.1 Immigration in Switzerland: A general overview 29

2.1.1 Admission policies 30

2.1.2 Immigrant policies 33

2.1.3 Naturalisation policies $\quad 35$

2.2 Immigration from Turkey and the successor states of Yugoslavia: A short historical appraisal $\quad 36$

2.2.1 Immigration from Turkey $\quad 36$

2.2.2 Immigration from Yugoslavia and its successor states $\quad 38$

2.3 The agglomerations of Zurich and Basel 42

2.3.1 Demographic characteristics of the cities 42

2.3.2 The Turkish and SSYU populations in the agglomerations of Zurich and Basel 43

2.3.3 Structure of the labour market in the agglomerations of Zurich and Basel 44

2.3.4 Local integration policies in Zurich and Basel 45 
2.4 Demographic characteristics of the second generation in the TIES sample

2.4.1 Age and sex structure of the sample

2.4.2 Civil status of respondents 48

2.5 Living arrangements $\quad 5^{1}$

2.5.1 Living in the parental home $\quad 5^{1}$

2.5.2 Leaving the parental home 53

2.6 The second generation and the institutional environment 57

2.6.1 Naturalisation behaviour 57

2.6.2 Turkish and SSYU communities in Basel and Zurich $\quad 60$

$\begin{array}{lll}2.7 & \text { Conclusions } & 63\end{array}$

3 Socio-demographic characteristics of the parents $\quad 67$

3.1 Immigrant parents' background 67

3.1.1 Regional background $\quad 68$

$\begin{array}{ll}\text { 3.1.2 Linguistic background } & 71\end{array}$

3.1.3 Family's religious background 73

3.2 Educational background of the parents $\quad 75$

3.2.1 Educational situation in Turkey and Yugoslavia in the seventies $\quad 76$

3.2.2 The educational capital of parents $\quad 77$

3.2.3 Parental local-language proficiency $\quad 79$

3.3 Parental migration history and current work situation $\quad 80$

3.3.1 Timing and reason for immigration 80

3.3.2 Naturalisation of Turkish and SSYU parents $\quad 84$

3.3.3 Current status of parents' labour force participation $\quad 87$

3.4 Parental couples and household size $\quad 89$

3.4.1 Couple composition and mixed marriages $\quad 89$

3.4.2 Divorce rate and intact families 90

3.4.3 Household size $\quad 91$

3.5 Conclusions 92

4 Education of the second generation $\quad 97$

4.1 Main features of the Swiss educational systems 97

4.1.1 Pre-school and compulsory education $\quad 97$

4.1.2 Post-compulsory secondary education 99

4.1.3 Tertiary education 100

4.1.4 Education systems in Zurich and Basel 102

4.1.5 Educational equity: An open question 104 
4.2 Children of Turkish and SSYU descent in pre-school and primary education

4.2.1 Entry into the school system

4.2.2 Special classes in primary school

4.2.3 Concentration of immigrant origin children in primary school

4.3 Children of Turkish and SSYU descent in secondary education

4.3.1 Lower secondary schools

4.3.2 Post-compulsory education and training

4.3.3 Perception and experiences at school

4.4 Present educational situation

4.4.1 Currently in education

4.4.2 Training of respondents currently in education

4.4.3 Highest achieved level of respondents currently not in education

4.5 Factors influencing educational achievement

4.5.1 Family involvement in education

4.5.2 Intergenerational social mobility

4.5.3 Naturalisation: A positive selection?

5 Labour market position of the second generation

5.1 Labour market participation of foreigners and the second generation

5.1.1 Labour market position of foreigners

5.1.2 Labour force participation of the second generation $\quad 146$

5.1.3 Factors affecting labour force participation $\quad 154$

5.2 Quality of labour market participation $\quad 156$

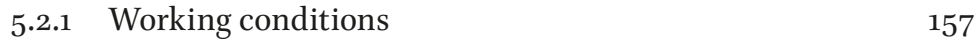

$\begin{array}{lll}5.2 .2 & \text { Occupational level } & 160\end{array}$

$\begin{array}{lll}5.2 .3 & \text { Occupational prestige } & 164\end{array}$

$\begin{array}{ll}5.2 .4 & \text { Evaluation of career and living conditions }\end{array}$

5.3 Barriers to effective labour market integration $\quad 170$

5.3.1 Access to first job $\quad 171$

5.3.2 Access to the public sector $\quad 172$

5.3.3 Mismatch between education level and job requirements 174

5.3.4 Perceived discrimination in the labour market $\quad 176$

$\begin{array}{lr}5.4 \text { Conclusions } & 178\end{array}$ 
6 Identity 183

6.1 Multiple levels of identity $\quad 186$

$\begin{array}{ll}\text { 6.1.1 Present identifications of respondents } & 187\end{array}$

$\begin{array}{lll}\text { 6.1.2 Naturalisation } & 191\end{array}$

6.1.3 Local attachments to city and neighbourhood 193

$\begin{array}{lll}6.2 & \text { Language mastery and use } & 195\end{array}$

6.2.1 Mastery of local language $\quad 195$

6.2.2 Mastery of parental language 195

$\begin{array}{ll}\text { 6.2.3 Language use } & 197\end{array}$

$\begin{array}{ll}6.3 \text { Religion } & 198\end{array}$

6.3.1 Religious upbringing in the family 199

6.3.2 Retention of religious affiliation 201

6.3.3 Current religious affiliation and practice 203

6.3.4 Importance of religion in personal and public life $\quad 205$

6.3.5 Feeling of belonging in Switzerland according to
religious identification

6.3.6 Weak feeling of belonging to Switzerland 209

$\begin{array}{ll}6.4 \text { Conclusions } & 212\end{array}$

$\begin{array}{lll}7 & \text { Social relations } & 217\end{array}$

$\begin{array}{lll}7.1 & \text { Primary group relations } & 219\end{array}$

$\begin{array}{lll}7.1 .1 & \text { Family } & 220\end{array}$

7.1.2 Friendships and dating 223

$\begin{array}{lll}7.2 & \text { Secondary group relations } & 227\end{array}$

$\begin{array}{ll}\text { 7.2.1 Neighbourhood composition } & 227\end{array}$

$\begin{array}{ll}7.2 .2 & \text { School environment } 228\end{array}$

7.2.3 Formal social networks $\quad 231$

7.2.4 Civic participation via voting 233

7.3 Inter-ethnic relations $\quad 234$

7.3.1 Hostility and discrimination $\quad 236$

7.3.2 Attitudes towards multi-ethnic coexistence 244

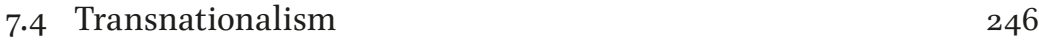

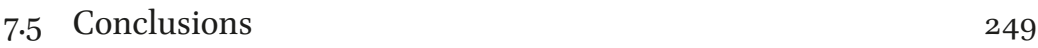

8 Union and family formation of the second generation 255

8.1 Union formation experience 255

8.1.1 Types of current relation $\quad 255$

8.1.2 Age at first marriage $\quad 25^{8}$

8.1.3 Marriage market and family influence $\quad 261$ 
8.2 Partner choice 266

$\begin{array}{lll}\text { 8.2.1 Ethnic endogamy } & 267\end{array}$

$\begin{array}{lll}\text { 8.2.2 Religious endogamy } & 274\end{array}$

8.2.3 Social and educational homogamy 277

$\begin{array}{ll}8.3 \text { Family life } & 279\end{array}$

8.3.1 Labour force arrangements in the couple 279

8.3.2 Parenthood 280

8.3.3 Gender roles $\quad 282$

$\begin{array}{ll}8.4 \text { Conclusions } & 285\end{array}$

9 Assessing the social position of the new second generation $\quad 289$

9.1.1 Socio-economic participation 290

9.1.2 Socio-cultural features $\quad 292$

9.2 Second generation integration: Communities, contexts and outcomes 293

9.2.1 Ethnic settlements $\quad 294$

9.2.2 Second-generation outcomes in Zurich and Basel $\quad 296$

9.3 Old and new second generations in Switzerland: Structural integration and boundary making $\quad 298$

$\begin{array}{ll}9 \cdot 3.1 & \text { Boundary definition } \\ & 301\end{array}$

$\begin{array}{ll}\text { List of contributors } & 307\end{array}$ 



\section{Preface}

This book devoted to the study of children of immigrants in Switzerland is part of a larger project, The Integration of the European Second Generation, known as TIES (www.tiesproject.eu).

The TIES international project gathered researchers from eight countries (Austria, Belgium, France, Germany, the Netherlands, Spain, Sweden and Switzerland) to carry out international comparative research on the structural integration of children of immigrants in Europe. For this purpose it established strictly comparable data based on a common definition of the second generation to be surveyed across all those European countries, i.e. young adults (aged 18 to 35 ) born in the country of immigration to parents coming from Turkey, Morocco and the Successor States of Yugoslavia (SSYU), as compared with young people of native descent. The choice of the groups under study made simultaneous international comparison possible, as immigration from Turkey is present in the whole of Northern Europe, while immigration from the SSYU is mainly present in German-speaking countries and Moroccans in many other European countries.

Since immigration is primarily an urban phenomenon, the TIES project focused on two key agglomerations in each country, where the immigrant groups under scrutiny were strongly represented - Vienna and Linz in Austria, Brussels and Antwerp in Belgium, Paris and Strasbourg in France, Berlin and Frankfurt in Germany, Amsterdam and Rotterdam in the Netherlands, Madrid in Spain and Stockholm in Sweden, as well as Zurich and Basel in Switzerland. The Institute for Migration and Ethnic Studies (IMES) at the University of Amsterdam was entrusted with the coordination of the international project, in collaboration with the Netherlands Interdisciplinary Demographic Institute (NIDI).

The research team of the Swiss Forum for Migration and Population Studies (SFM) at the University of Neuchâtel joined the TIES research network from the beginning and participated in the entire collaborative project. The international project benefitted from seed-money from the Swiss Stiftung für Bevölkerung, Migration und Umwelt (BMU) in 2003. Thereafter, each team financed the local implementation of the project within its national frame.

The international TIES study is particularly original as it combines convergent and divergent models of comparative analysis (Green 1994). The convergent model of comparison, most common in national research, studies various immigrant groups in the same place, either an immigration 
country or a city. In doing so, this design stresses the specificities of each group included in the comparison. The divergent model studies one immigrant group in various countries of residence, thus emphasising the contextual factors that shape opportunities for and barriers to integration.

The publications of the TIES project reflect the dual character of this study. Research teams working on local data produced books reflecting the convergent approach, allowing an in-depth analysis of the immigrant groups and the cities of residence: Crul and Heering (2008), Wilmes and Sürig (2014), Westin (2014) and the present book belong to this category.

The divergent approach was given concrete expression in two edited books focusing on European countries (Crul, Schneider \& Lelie 2012) and on a comparison between Europe and the United States (Crul \& Mollenkopf 2012). Researchers from all teams involved participated in writing various comparative chapters on subjects such as education, the labour market, gender issues and naturalisation. The international dimension is clearly the specific added value of the TIES project.

\section{Rosita Fibbi}

June 2014

\section{References}

Crul, Maurice \& Liesbeth Heering (eds) (2008) The position of the Turkish and Moroccan second generation in Amsterdam and Rotterdam. Amsterdam: Amsterdam University Press.

Crul, Maurice, Jens Schneider \& Frans Lelie (eds) (2012), The European second generation compared. Does the integration context matter? Amsterdam: Amsterdam University Press.

Crul, Maurice \& John Mollenkopf (eds) (2012), The changing face of world cities. Young adult children of immigrants in Europe and the United States. New York: Russell Sage.

Green, Nancy (1994), "The comparative method and post-structural structuralism: New perspectives for migration studies", Journal of American Ethnic History 13(4): 3-22.

Maren, Wilmes \& Sürig Inken (eds) (2014), The second generation in Berlin and Frankfurt: The TIES study in Germany. Amsterdam: Amsterdam University Press.

Westin, Charles (ed.) (2014), The integration of descendants of migrants from Turkey in Stockholm: The TIES study in Sweden. Amsterdam: Amsterdam University Press. 


\section{The new second generation in Switzerland}

Youth of Turkish and former Yugoslav descent in Zurich and Basel

Rosita Fibbi, Ceren Topgül, Dušan Ugrina and Philippe Wanner

\subsection{The old and the new second generation}

During the second half of the $20^{\text {th }}$ century, Switzerland became a true immigration country. By 2010, 22 percent of the resident population did not hold a Swiss passport (1.72 million) and 22.5 percent were foreign born.

Today's situation is the result of the sedimentation of different flows since the Second World War. This period can be divided into two main phases: the first started in 1948 with the first migration agreement signed by Switzerland and ended in 1975 with the recession triggered by the first oil crisis and massive return of migrants, mainly manual workers from Italy and Spain, to their home countries. If the migration regime had been geared to rotation of guest workers, slow consolidation of immigrant status allowed for stabilisation of this foreign population and their offspring in the 1970 s and 1980 s.

The second period started in 1980 as economic recovery triggered a new rise in migrant inflows, this time from Portugal, Turkey and Yugoslavia. The rapprochement between Switzerland and the European Union created a Portuguese migration regime in the image of prior migration flows; however, rules for the Turks and Yugoslavs developed into a regime for third-country nationals. Several pieces of legislation laid down new structural conditions and redesigned the discursive landscape around migration and integration issues. Bilateral agreements between Switzerland and the European Union came into force in 2002, granting free movement of labour, and a new Alien Law was approved in 2005, along with the launch of a federal integration policy and a lively legal debate on naturalisation procedures, scope and purpose. The issue of integration for populations defined by their religious background has been reformulated post-9/11, with long-lasting ramifications. 
It is reasonable to study the offspring of the Turkish and the Yugoslav flows together because of their concurrent immigration and similarity in receiving conditions. Moreover, they share a number of other common characteristics, such as the dual composition of the flow - mainly workers and their families, but also a significant number of refugees - and the introduction of faiths previously unknown in the Swiss religious landscape.

\subsection{Research on the second generation in Switzerland}

\subsubsection{The second generation from Italy and Spain}

The first Swiss studies on the second generation highlight inequality between the children of immigrants and young 'nationals', manifest in the fact that the former group more often end their education on completing compulsory schooling than native-born children (CFE 1980; EckmannSaillant et al. 1994; Gonvers et al. 1980; Wilpert 1988) or are channelled into short training courses for manual work, apprenticeships or vocational training (Borkowsky 1991; Fibbi \& de Rham 1988). These studies also point to the different insertion paths for young men and women. Young men find work as skilled labourers, but often in sectors traditionally set aside for immigrant labour. Young women manage to obtain a qualification and find jobs in the service sector, which until recently would have been barred to immigrant labour, but the majority find themselves relegated to positions similar to those of their mothers due to lack of training (De Rham et al. 1984; Gurny et al. 1984). Thus the central issue for this group is the level and accessibility of education and training opportunities.

The comparison drawn in 1983 between young foreigners aged 25 and those aged 16 (Fibbi et al. 1985) gave rise to hopes of promising development in Switzerland, with the removal of institutional barriers to access to vocational training and young people gradually adhering to the dominant values regarding education and training. An analysis early in the $21^{\text {st }}$ century of migratory adult children of Spanish and Italian immigrants to Switzerland confirms this positive trend (Bolzman et al. 2003) and census data corroborate the finding (Mey et al. 2005).

It is not legitimate to transpose this result to more recent migratory intakes, however, given changes in migration policies, the structure of Switzerland's national economy, the social debate and the characteristics of the immigrant populations themselves. 


\subsubsection{The new second generation from Turkey}

The Turkish presence in Switzerland can be dated to the late 196os, but immigration developed after 1980. Researchers from Zurich University (Hämmig 2000; Sonderegger 2001; Stieger 2000) studied the second generation within the educational and vocational system. Data on school and the transition between school and work paint a highly nuanced picture.

Despite some positive developments in the social and professional position of this group, a comparison with Swiss nationals and secondgeneration Italians - a benchmark for scholars as the largest and oldest immigrant group in the country - highlights a persistent high degree of inequality. Young Turks tend to leave school earlier - often without any qualifications - and are hit by unemployment. Though the professional profile of young Turkish men born in Switzerland is moving closer to that of young second-generation Italians, there remains a substantial gap between young Turkish women and their Italian counterparts. The image of Turks in Switzerland is quite negative. Studies show that those affected react differently to this - some build up sub-cultural identities while others rediscover religious affinities (Juhasz \& Mey 2003).

Turks have often been compared to Italians and natives within the country of residence. The only (indirect) international comparison confirms that Turks in Switzerland face stronger discrimination in accessing the labour market in Switzerland than they do in Germany (Fibbi et al. 2003).

\subsubsection{The new second generation from Yugoslavia}

There are a number of studies on the populations of countries resulting from the break-up of the Socialist Federal Republic of Yugoslavia, although there is a focus on Bosnians and Albanians in Switzerland. The dominant subjects are asylum policy and immigration flows, together with the provision of social services and health care to refugees and asylum-seekers. This should come as no real surprise given that, for the past decade, Switzerland's asylum policy has evolved in response to the Balkan crisis. Authors such as Von Aarburg (2002) or Maillard and Leuenberger (1999) nonetheless uncover the unique interplay between migration driven by the search for asylum and that motivated by the need for work. The general public is almost completely oblivious to this phenomenon, which is characteristic of inflows from the Balkans. Changes in migratory intentions caused by the tragic events there have brought about an increase in family reunion 
which is radically changing the profile of these large communities now established in Switzerland (Von Aarburg \& Gretler 2008; Dahinden 2005).

Studies dealing with the professional, educational and social integration of these populations as a whole, and of young people in particular, are relatively rare, in contrast to the range of studies dealing with traditional labour migration. Statistics on education do, however, show that the school situation of young people from the former Yugoslavia gives cause for concern. In 1980, 38 per cent attended less-demanding lower-secondary schools; ten years later the figure had virtually doubled to 71 per cent (Lischer 2002). In these circumstances, it is useful to explore the extent to which school outcomes lead to differentiated social outcomes.

Census data provided information for the year 2000 on the second generation of Turkish and SSYU descent (Fibbi et al. 2005). However, the nativeborn children of Turkish and SSYU immigrants were, at that time, mainly in compulsory school and assessment of their integration was therefore only partially possible. Almost ten years later, the native-born second generation has reached adulthood, largely left the educational system and is engaged in productive and family life.

The institutional environment has also changed with the passing of the new Alien Law and the new federal integration policy. The time has come for a new assessment of the situation of the Turkish and SSYU second generation in Switzerland.

\subsection{The theoretical background}

This study of the new second generation in Switzerland took place within the framework of a larger international project, The Integration of the European Second Generation (TIES) (www.tiesproject.eu).

The theoretical background to the present study derives from the international project as well as from a national comparison between the old and new second generation in Switzerland.

\subsubsection{Second generation: Definition and historical processes}

According to a strict demographic definition, the second generation includes only those offspring of migrant parentage born in the receiving country. In a broader, more sociological perspective, the second generation may be defined as the offspring of migrant parentage who entered the receiving country before their first year of primary school. Despite the fact that this 
definition is often used in research on educational and labour market status, criteria based on school starting ages vary from country to country and may yield differing research populations. Since a common definition is crucial for an international comparative project, this study is based on the strict demographic definition, which ensures comparability of samples.

Sociological analysis of children of immigrants' future has a long tradition in the United States. Summarising previous research, Alba speaks of a 'canonical synthesis' (Alba 2012) of assimilation outcomes and processes in his theoretical discussion. This paradigm resulted in the analysis of the experience of children of European immigrants whose parents had migrated to the US at the turn of the last century.

Since the 1990s, there has been a revival of interest in the second generation in the US (Gans 1992; Portes \& Zhou 1993). This interest arose from the question of whether the canonical description could still account for the process and the outcomes of the children of new diversified immigrant flows coming from non-European countries which had developed since 1965; these children were negotiating inclusion in a completely different historical period.

One of the major contributions of this strand to theoretical advancement in the US and elsewhere was to highlight the crucial role played by the contextual framework in which migrations develop. No theoretical frame today can overlook this dimension, which points to the historical distinctiveness of the integration process undergone by various migrant flows. Subsequent research has tested various aspects of context which may account for distinctions between populations: economic structure (hourglass economy in Perlmann \& Waldinger 1997), the citizenship-model approach (Brubaker 1992) and immigration and integration policies (Freeman 1995; Freeman 2004), to name the most influential research strands.

The TIES project can be situated with research focusing on context, especially the policy framework. Building on previous research (Crul \& Vermeulen 2003), the project is based on an institutional approach to immigrant integration (Reitz 1998). The very specific design of this project is intended to test the relevance, not of the targeted measures addressed at migrants, but of general policy features and the institutional arrangements which shape migrants' and natives' life chances alike, although possibly to different extents.

Migratory patterns in the first post-war period were based on deep historical links. Over time, however, these 'migratory couples' no longer channelled emigration toward a privileged destination, so people emigrating from the same region settled in various European countries. This 
circumstance now allows international comparisons at the European level of first and second-generation integration patterns in different contexts.

The option of studying the 'same' immigrant group across various countries is intended to allow for the most stringent analysis of the impact of institutional arrangements on migrants by controlling for potential origin effects. Two recent major publications - as well as numerous articles and dissertations - report on extended comparisons and the theoretical implications of those analyses (Crul et al. 2012; Crul \& Mollenkopf 2012).

For obvious reasons, the Swiss study cannot pursue the same goal. Our ambition here is to deliver a detailed account of the living conditions and challenges faced by the second wave of labour migrants and their children and the way they manage to negotiate their place in society. Though these groups have been the object of heated political debate, knowledge about them is fragmented and impressionistic.

The study of the new second generation suggests comparison with the old one. Hence a common thread runs through the various chapters: the comparison insofar as it is possible with previous research concerning the second generation of Italian and Spanish origin in Switzerland aims to underline the historical similarities and differences between their respective incorporation processes.

\subsubsection{Structural integration}

The concept of integration refers to the process by which immigrants and their offspring participate in the society in which they live. Many other terms have been used to denote roughly the same process (e.g., 'assimilation', 'absorption', 'insertion' and 'incorporation'); however, integration is the term that is most often used in social research and social policy, both inside and outside Europe (Alba et al. 2012).

The concept of assimilation - widely used in the American literature - has traditionally linked the structural and cultural dimensions of this process, postulating not only a necessary link between the two dimensions but making the cultural dimension a precondition for the effective structural participation of immigrant groups in their new society. This concept has been increasingly criticised as 'normatively retrograde, analytically disreputable and empirically wrong' (Brubaker 2001: 534). Taking into account such objections, a new 'intransitive' formulation - the process of 'becoming similar' - has been proposed by Brubaker (2001). This reformulation is consistent with the new focus on subject and agency characterising the social sciences today (Wieviorka 2007). 
The traditional concept of assimilation has also been criticised for its implicit view of the receiving society as an undifferentiated ensemble unified by a common national semantics, ignoring deep internal divisions of both a structural and socio-cultural nature (Zhou 1997a). This concept also came to be seen as limited for its view of this process as a unidirectional effort to be made by immigrants whose responsibility it is to adjust to their new society. In the new incorporation approach, the process has been reconceptualised as interactive and structural (Portes \& Böröcz 1989; Schmitter Heisler 200o), highlighting the capacity and willingness of the host society to offer effective integration opportunities. The emphasis is on economic and structural variables - on the functioning of the labour market, school and welfare systems, and on whether they provide social opportunities or reinforce exclusion. In European scholarship, these reformulations converge in the concept of integration (Castles 1993; Crul \& Vermeulen 2003; Faist 1995; Isajiw \& Makabe 1997).

Integration and social cohesion involve the same dimensions, albeit from different perspectives; while integration refers to the process of becoming part of a social unit, social cohesion is characteristic of social units. This notion thus designates the reduction of disparities, inequalities and social exclusion as well as the strengthening of social relations, interactions and ties.

The TIES project focuses on structural integration. After the differential turn that stressed cultural dynamics in society - particularly those shaping the position of immigrants during the last decades of the past century studies on the second generation have experienced a shift towards analysis of their mode of integration in the socio-economic fabric of the host society. The hypothesis of an emerging ethnic underclass in the background of a radical transformation of the productive structure of advanced societies is one example (Crul \& Vermeulen 2003; Massey \& Denton 1993; Wilson 1987; Zhou 1997b). An ethnic underclass consists of a combination of economic marginality - e.g., unemployment, a lack of sufficient income, and dependency on social benefits - and a value orientation that does not promote economic integration. The overlapping of such factors with ethnic features appears especially threatening to the social cohesion of an immigration society.

Structural integration is the degree of participation of individuals in the socio-economic structure of the host society, in turn largely determined by their educational attainment. The literature on migrants' integration discusses whether cultural assimilation is a prerequisite to structural integration (e.g., Gordon 1964) or whether socio-economic integration is a predictor of cultural assimilation (e.g., Hoffmann-Nowotny 1973; see also Hagendoorn et al. 2003; Vermeulen \& Perlmann 2000). The TIES project 
addresses this issue. Based on the assumption that educational attainment and the socio-economic participation of the second generation play a crucial role in their status in society, the project seeks to explain the variability of social outcomes as a consequence of overall contextual factors and, especially, policy options.

\subsubsection{Deconstructing the national frame}

The intergenerational integration process of migrants in society has generally been analysed as a national issue within the frame of the receiving country's nation-state (Wimmer \& Glick Schiller 2002). Such a perspective has two major drawbacks. The local, city-level dimension of integration is overlooked as the national lens seems to homogenise internal variability. Moreover, the uniqueness of the national frame also makes the comparative national perspective more difficult, therefore such perspectives have been largely neglected.

Cities may be a better unit of comparison than nation-states; differences between cities within the same nation-state are often considerable (e.g., Ireland 1994). This may partly be the consequence of different policies at sub-state (regional or city) levels, but other differences such as those in the local economy or political climate may also be relevant.

The debate on integration seems to have had a persistent blind spot up to now regarding the importance of the national and local contexts in which the second generation is trying to move forward. Differences between countries are often overestimated, whereas differences between cities within the same country may be more pronounced than is often realised. The chief focus of the TIES project is therefore on big cities, because that is where, in demographic terms, most second-generation youth live. Another advantage of the city approach is that developments can also be linked more readily to specific (local) integration policies and to local institutional arrangements.

\subsection{The TIES study in Switzerland}

In the US, where research on children of immigrants is well established, as in many European countries and hence in Switzerland, the study of the intergenerational integration process of migrants in society has traditionally been framed as a national issue in an equation which conflated the two concepts of society and the nation-state, one of modernity's major socio-political references. 
Despite the international framework of the overall TIES project, it is useful to submit the data to a preliminary analysis at national level before combining those findings with the more innovative and theoretically demanding international comparative one. This section presents the collection of data in Switzerland. The research team of the Swiss Forum for Migration and Population Studies (SFM) at the University of Neuchâtel joined the TIES research network from the beginning and participated in the entire collaborative project.

The choice of the second-generation groups under study makes sense from a Swiss perspective: the two immigrant groups represent the most important part of recent immigration flows to Switzerland. The need for a focused analysis of groups, present in public debate but relatively rare in the scholarship, together with the opportunity to compare across countries validates this option.

Given the political nature of language, and particularly of categorisation, a clarification of the terminology used to designate the populations under study is needed. The distinction between groups according to origin is generally based on the national criterion. For instance, people from Turkey may have different ethnic backgrounds - for example, they may have Turkish nationality but be of Kurdish ethnicity. In our study we categorised as Turkish all respondents who had at least one parent born in Turkey and who had Turkish nationality. The term 'Turkish' here thus refers to citizenship and not to ethnicity, unless stated otherwise.

We designated the second group as having (or having had) the nationality of one of the Successor States of the Socialist Federal Republic of Yugoslavia (SSYU), mirroring the present political situation of the former Yugoslav territory.

Finally, the non-immigrant group is called the 'comparison group', which avoids reference to their ethnic background. These respondents were born to parents who were themselves born in Switzerland; they are mainly of Swiss descent and nationality but, because of the high percentage of people of immigrant descent in the two selected agglomerations, it cannot be ruled out that the children of immigrants whose origin is not Turkish or SSYU may be included, provided that they satisfy the condition of being born to native-born parents. The preference for the designation 'comparison group' rather than 'Swiss' lies with the fact that a majority of youth of Turkish or SSYU descent have also acquired Swiss nationality and are thus also Swiss. There is another substantial reason for such a designation: the sample of respondents from the comparison group was drawn from the same neighbourhoods as those from which second-generation youth were drawn in 
order to take into account similarities in the structural opportunities made available to the population at the local level.

The local contexts were determined by the relative concentration of the Turkish and SSYU populations; these groups mainly settled in the Germanspeaking part of the country and only the agglomerations of Zurich and Basel could provide a sufficiently large pool of native-born 18 to 35 year-olds from which to draw our sample. The areas cover parts of the canton of Zurich, and the half-cantons of Basel-Stadt and Basel-Land.

Official registers do not show whether a person holds Swiss nationality by birth or by naturalisation. In order to circumvent such constraints imaginative tools were used, such as onomastic sampling, which allows researchers to sample individuals according to the probable national origin of their surnames (Humpert \& Schneiderheinze 2000).

The implementation of the sampling design and the survey strategy designed by the Swiss team in compliance with the international TIES project was carried out by GfK in Hergiswil between 2007 and 2008. The field work was hampered by the difficulties in reaching the target group of young adults not already settled in life. The contacted persons (net sample) represented 35.5 per cent of the delivered addresses (gross sample) in Zurich and 47.2 per cent in Basel. The response rate (successful interviews over net sample) reached 41.4 per cent in Zurich and 37.8 per cent in Basel. Though gender had no influence on the response rate among Turkish origin respondents, women were more responsive than men among native and especially SSYU origin respondents. Refusal among comparison group respondents was the highest. Imbalances in the age and gender structure of the sample were corrected by introducing weights calculated on the basis of the information delivered by the Census 2000 and the Central Register of Foreigners as of 31 December 2006. ${ }^{1}$

Several sources of financing enabled implementation of the survey in Switzerland. The Swiss Foundation Migration Bevölkerung und Umwelt, together with Germany's Volkswagen Stiftung, funded the data collection; the Swiss National Science Foundation (SNSF), in collaboration with the European Science Foundation, subsidised the present country report.

1 For a detailed methodological account of the Swiss study and the whole TIES project see Groenewold and Lessard-Phillips (2012). 


\subsubsection{Scope and structure of the book}

The added value of the TIES project is the international comparison. This book has a different scope: to report the TIES findings for Switzerland and describe the situation for the new second generation of Turkish and SSYU descent, thereby filling a gap in systematic knowledge on the two immigrant groups under study.

The research design is based on within-country comparisons. The first comparison between groups identifies endogenous factors that may account for the specific integrative outcomes of each group; the second between cities identifies exogenous factors that shape opportunities both for the second generation and all young people together. The analyses intend to set the new second generation against the background of knowledge on offspring of previous guest-worker waves in Switzerland.

The structure and content of the present book follow the guidelines agreed upon by the TIES international research teams (Crul \& Heering 2007) and provide a general survey of the main findings of the TIES study in Switzerland, which is far from exhaustive. The first two chapters have an introductory purpose. Chapter 2 sets the stage for the entire study. It outlines the major features of immigration and immigrant policies in Switzerland over the last decades, provides substantial information on the two immigration flows studied in the survey, describes the demographic and economic characteristics of the two agglomerations of Zurich and Basel and provides an insight into the way in which integration has been locally managed over the last 10 to 15 years. The chapter also describes the main demographic traits of the two areas.

Chapter 3 is devoted to an analysis of the parents of TIES respondents, thus providing background information on the immigration flows from Turkey and the Socialist Federal Republic of Yugoslavia described in this report: the parents' regional, linguistic and religious backgrounds, immigration history and educational capital, and the characteristics of the families in which our TIES respondents grew up.

The following two chapters deal with the structural integration of the second generation. Chapter 4 briefly introduces the educational system(s) in Switzerland, focusing on the educational trajectories and performance of the native-born children of immigrants from Turkey and the SSYU. It discusses factors influencing the educational achievement of the second generation. Chapter 5 describes the labour market participation of the second generation, analysing the position they occupy in the Swiss labour hierarchy and the barriers that may hinder their full participation in the labour market. 
The final three chapters concern the identity and the cultural and social incorporation of the second generation. Chapter 6 analyses two major markers of identity - language and religion - to assess the scope and practices of those markers for youth of immigrant descent. It also explores how this group of young people combines various frames of reference in order to build their own personal identities. Chapter 7 maps the breadth and depth of the social networks the individuals are involved in, and their primary and secondary group relations, in the country of residence as well as across transnational fields. It also attempts to assess the majority and minority respondents' perceptions of the quality of their interethnic relations. Chapter 8 addresses the issue of the union and family formation of the second generation. It describes the type of intimate relations in which TIES respondents are engaged and develops more extensively the issue of partner choice, by investigating the ethnic and religious background and the immigration history of the spouse as well. Chapter 8 finally sketches some features of the family life of couples formed by second-generation respondents.

Chapter 9 summarises the main findings of our survey and attempts to paint the bigger picture of the integration trajectories of the Turkish and SSYU second generation in Switzerland.

\section{References}

Aarburg, Hans-Peter von (2002), 'L'émigration albanaise du Kosovo vers la Suisse: l'imprévisible évolution des projets migratoires', Ethnologie française, 32(2): 271-282.

Aarburg, Hans-Peter von \& Sarah Barbara Gretler (2008). Kosova-Schweiz: die albanische Arbeitsund Asylmigration zwischen Kosovo und der Schweiz (1964-20oo). Wien: LIT.

Alba, Richard (2000), “Beyond the Melting Pot": 35 years later: On the relevance of a sociological classic for the immigration metropolis of today', International Migration Review 34(1):243-279.

Alba, Richard, Jeffrey G. Reitz \& Patrick Simon (2012), 'Contrasting national conception of integration and assimilation', in Maurice Crul \& John Mollenkopf (eds), The changing face of world cities. Young adult children of immigrants in Europe and the United States. New York: Russel Sage.

Bolzman, Claudio, Rosita Fibbi \& Marie Vial (2003), 'Secondas Secondos': le processus d'intégration des jeunes issus de la migration espagnole et italienne en Suisse. Zurich: Seismo.

Borkowsky, Anna (1991), Enfants et jeunes d'origine étrangère dans le système de formation en Suisse. Berne: Office fédéral de la statistique.

Brubaker, Rogers W. (1992), Citizenship and nationhood in France and Germany. Cambridge: Harvard University Press.

Brubaker, Rogers W. (2001), 'The return of assimilation? Changing perspectives on immigration and its sequels in France, Germany and the United States', Ethnic and Racial Studies 24(4): $53^{1-548 .}$ 
Castles, Stephen (1993), 'Migrations and minorities in Europe. Perspectives for the 1990s: Eleven hypotheses' in John Wrench and John Solomos (eds), Racism and migration in Western Europe. 17-34 Oxford: Berg Publishers.

CFE (1980), Les jeunes étrangers. La deuxième génération. Problèmes et solutions possibles. Berne: Commission fédérale pour les problèmes des étrangers.

Crul, Maurice \& Liesbeth Heering (eds) (2007), The position of the Turkish and Moroccan second generation in Amsterdam and Rotterdam. Amsterdam: Amsterdam University Press.

Crul, Maurice \& Hans Vermeulen (2003), 'The second generation in Europe: Introduction to the special issue', International Migration Review 37(4): 965-986.

Crul, Maurice, Jens Schneider \& Frans Lelie (eds) (2012), The European Second Generation Compared. Does the Integration Context Matter? Amsterdam: Amsterdam University Press.

Crul, Maurice \& John Mollenkopf (eds), (2012). The changing face of world cities. Young adult children of immigrants in Europe and the United States. New York: Russell Sage.

Dahinden, Janine (2005), Pristina-Schlieren. Zurich: Seismo.

De Rham, Gérard, Rosita Fibbi \& Olivier Virnot (1984), L'entrée dans la formation professionnelle. Rapport de recherche sur la Formation et l'Insertion Professionnelles des jeunes Etrangers et Suisses (FIPES). Lausanne \& Geneva: Programme National de Recherche 'Education et vie active', unpublished document.

Eckmann-Saillant, Monique, Claudio Bolzman \& Gérard de Rham (1994),Jeunes sans qualification. Trajectoires, situations, stratégies. Geneva: Les Editions IES.

Faist, Thomas (1995), Social citizenship for whom? Young Turks in Germany and Mexican Americans in the United States. Aldershot: Avebury.

Fibbi, Rosita \& Gérard de Rham (1988), 'Switzerland: The position of second generation immigrants on the labour market', in C. Wilpert (ed.), Entering the working world. Following the descendants of europe's immigrant labour force, 24-55. Aldershot: Gower.

Fibbi, Rosita, Gérard de Rham \& Olivier Virnot (1985), Différenciation sociale et reproduction des appartenances. Rapport de recherche sur la Formation et l'Insertion Professionnelles des jeunes Etrangers et Suisses (FIPES). Lausanne \& Geneva: Programme National de Recherche 'Education et vie active', unpublished document.

Fibbi, Rosita, Bülent Kaya \& Etienne Piguet (2003), Le passeport ou le diplôme? Etude des discriminations à l'embauche des jeunes issus de la migration. Neuchâtel: Forum suisse pour l'étude des migrations et de la population.

Fibbi, Rosita, Mathias Lerch \& Philippe Wanner (2005), 'Processus de naturalisation et caractéristiques socio-économiques des jeunes issus de la migration', in Office Fédéral de Statistique (ed.) L'intégration des populations issues de l'immigration en Suisse:personnes naturalisés et deuxième génération, 57 . Neuchâtel: OFS.

Freeman, Gary P. (1995), 'Modes of immigration politics in liberal democratic states', International Migration Review 29(4): 881-902.

Freeman, Gary P. (2004), 'Immigrant incorporation in western democracies', International Migration Review 38(3): 945-969.

Gans, Herbert (1979), 'Symbolic ethnicity. The future of ethnic groups and cultures in America', Ethnic and Racial Studies 2(1), 1-20.

Gans, Herbert (1992), 'Second-generation decline: Scenarios for the economic and ethnic futures of the post-1965 American Immigrants', Ethnic and Racial Studies 15(2).

Gonvers, Jean-Pierre, Laurent Monnier, Arlette Mottaz \& Gérard de Rham (1980), Qui sont-ils? Suisses et/ou Espagnols? La deuxième génération d'immigrés espagnols en Suisse. Lausanne: Institut de science politique.

Gordon, Milton (1964), Assimilation in American life. The role of race, religion and national origins. New York: Oxford University Press. 
Groenewold, George \& Laurence Lessard-Phillips (2012). 'Research methodology', in Maurice Crul, Jens Schneider \& Frans Lelie (eds), The European Second Generation Compared. Does the Integration Context Matter? 39-56 Amsterdam: Amsterdam University Press.

Gurny, Ruth, Paul Cassée, Hans-Peter Hauser \& Andreas Meyer (1984), Karrieren und Sackgassen. Wege ins Berufsleben junger Schweizer und Italiener in der Stadt Zürich. Diessenhofen: Ruegger Verlag.

Hagendoorn, Louk, Justus Veenmann \& Wilma Volleberg (eds) (2003), Integrating immigrants in the Netherlands. Cultural versus socio-economic integration. Aldershot: Ashgate.

Hämmig, Oliver (2000), Zwischen zwei Kulturen. Spannungen, Konflikte und ihre Bewältigung bei der zweiten Ausländergeneration. Opladen: Leske+Budrich.

Hoffmann-Nowotny, Hans-Joachim (1973), Soziologie des Fremdarbeitersproblems. Stuttgart: Enke.

Humpert, Andreas \& Klaus Schneiderheinze (2000). 'Stichprobenziehung für telefonische Zuwandererumfragen - Einsatzmöglichkeiten der Namenforschung (Onomastik)', ZUMANachrichten (47): 36-63.

Ireland, Patrick (1994), The policy challenge of ethnic diversity. Cambridge: Harvard University Press.

Isajiw, Wsevolod W. \& Tomoko Makabe (1997), 'Identitätsbewährung und eigenethnische Familie, Schule und Nachbarschaft: der kanadischer Kontext unterschiedlicher Migrantengruppen', in Bernhard Nauck \& Ute Schönpflug (eds), Familien in verschiedenen Kulturen, 285-302. Stuttgart: Enke Verlag.

Juhasz, Anne \& Eva Mey (2003), Die zweite Generation: Etablierte oder Außenseiter? Biographien von Jugendlichen ausländischer Herkunft. Wiesbaden: Westdeutscher Verlag.

Lischer, Rolf (2002), 'Intégration réussie des étrangers? La réponse des statistiques. Les enfants et adolescents étrangers dans le système suisse d'éducation et de formation', in Conférence suisse des Directeurs cantonaux de l'Instruction Publique (ed.) Le parcours scolaire et de formation des élèves immigrés à faibles performances: une présentation du problème, 6-18. Emmetten: CDIP.

Maillard, Alain \& Ueli Leuenberger (1999), Les damnés du troisième cercle: les Albanais de la Kosove en Suisse 1965-1999. Geneva: Les éditions Métropolis.

Massey, Douglas \& Nancy Denton (1993), American apartheid. Segregation and the making of an underclass. Cambridge: Harvard University Press.

Mey, Eva, Miriam Rorato \& Peter Voll (2005), 'Die soziale Stellung der zweiten Generation. Analysen zur schulischen und beruflichen Integration der zweiten Ausländergeneration', in OFS (ed.), L'intégration des populations issues de l'immigration en Suisse: personnes naturalisées et deuxième génération, 61-152. Neuchâtel: Office fédéral de la statistique.

Perlmann, Joel \& Roger Waldinger (1997), 'Second generation decline? Children of immigrants, past and present - a reconsideration', International Migration Review 31(4): 893-922.

Portes, Alejandro \& Josef Böröcz (1989), 'Contemporary immigration: Theoretical perspectives on its determinants and modes of incorporation', International Migration Review 23(3): 606-630.

Portes, Alejandro \& Min Zhou (1993), 'The new second generation: Segmented assimilation and its variants among post-1965 immigrant youth', Annals of the American Academy of Political and Social Science, 530: 74-96.

Portes, Alejandro \& Ruben Rumbaut (eds) (2001), Legacies: The story of the immigrant second generation. Los Angeles and New York: University of California Press.

Reitz, Jeffrey (1998), Warmth of the welcome. The social causes of economic success for immigrants in different nations and cities. Boulder: Westview Press.

Schmitter Heisler, Barbara (2000), 'The sociology of immigration', in Cardine Brettell \& James F. Hollifield (eds.) Migration Theory, 77-96. New York and London: Routledge. 
Sonderegger, Ralph (2001), Der Islam in derwestlichen Diaspora, 1-116. Zürich: Universität Zürich, Soziologisches Institut.

Stieger, Cindy (200o), Ethnizität. Am Beispiel der türkischen und italienischen Zweiten Generation im Kanton Zürich, 1-132. Zurich: Universität Zürich, Soziologisches Institut.

Vermeulen, Hans \& Joel Perlmann (eds.)(2000), Immigrants, schooling and social mobility. Does culture make a difference? London: Macmillan.

Wieviorka, Michel (ed.)(2007), Les sciences sociales en mutation. Auxerre: Editions Sciences Humaines.

Wilpert, Czarina (ed.)(1988), Entering the working world. Following the descendants of Europe's immigrant labour force. Aldershot: Gower.

Wilson, William J. (1987), The truly disadvantaged. Chicago: University of Chicago Press.

Wimmer, Andreas \& Nina Glick Schiller (2002), 'Methodological nationalism and the study of migration', Archives européennes de sociologie XLIII(2): 217-240.

Zhou, Min (1997a), 'Growing up American: the challenge confronting immigrant children and children of immigrants', Annual Review of Sociology 23: 63-95.

Zhou, Min (1997b), 'Segmented assimilation: Issues, controversies, and recent research on the new second generation', International Migration Review 31(4): 975-1008. 



\section{$2 \quad$ Migration history and demographic characteristics of the two second- generation groups}

This chapter describes the demographic characteristics of the survey sample according to the respondents' origin group and the agglomeration in which they live. The age, sex, civil and naturalisation status and position in the household of the second generation of Turkish origin and those whose origins lie in the successor states of Yugoslavia are investigated and compared with the native populations of Zurich and Basel.

\subsection{Immigration in Switzerland: A general overview}

According to official statistics, the total population of Switzerland increased by 7 per cent from 7.2 million in 2000 to 7.7 million in 2008. Among the resident population, 1.67 million (22 per cent) held foreign citizenship, of whom 20 per cent were actually born in Switzerland. The foreign population increased by 18 per cent from 1.42 million in 2000 to 1.67 million in 2008 (2009).

This increase is a direct consequence of the flourishing economic situation and the new immigration regime, as in 2002 the Agreement on the Free Movement of Persons between Switzerland and the European Union came into force. A large majority (1.44 million - 86 per cent) of Switzerland's permanent, foreign, resident population was of European origin, two-thirds of whom were nationals of an EU or European Free Trade Association(EFTA) member state. The largest group of foreigners were Italians (18 per cent), followed by nationals of Germany (14 per cent), Portugal (12 per cent) and Serbia and Montenegro (11 per cent). Turkish citizens accounted for 4 per cent of the foreign resident population (Table 2.1). An increasing number of foreigners come from more distant countries. The proportion of nonEuropean nationals has increased by 8 points since 1980 to reach 13.5 per cent in 2008 (FSO, www.bfs.admin.ch).

Immigrants in Switzerland no longer fit the stereotype of a labour migrant - mainly male and young. Indeed, the 2000 Census documents the ageing of many immigrant groups (Germans, Italians and Turks, for instance) and the feminisation of migration flows. Such changes in the 
Table 2.1 Percentage of national groups in the TIES study in the resident population of Switzerland, 1995-2008

\begin{tabular}{lcrrc}
\hline & $\mathbf{1 9 9 5}$ & $\mathbf{2 0 0 0}$ & $\mathbf{2 0 0 5}$ & $\mathbf{2 0 0 8}$ \\
\hline Serbia and Montenegro & & 13.8 & 12.5 & 11 \\
Croatia & \multicolumn{1}{c}{3.5} & 2.9 & 2.5 & 2.2 \\
Bosnia and Herzegovina & 2.7 & 3.4 & 2.8 & 2.3 \\
Macedonia & 2.7 & 3.7 & 3.7 & 3.6 \\
Ex-Yugoslavia & 14.1 & 0.4 & & \\
Slovenia & 0.2 & 0.2 & 0.1 & 0.1 \\
Turkey & 5.8 & 5.5 & 4.8 & 4.3 \\
SSYU +TR in \% of total foreigners & 28.5 & 29.9 & 26.4 & 23.5 \\
foreigners in \% of total resident population & 20.5 & 20.9 & 21.9 & 21.7 \\
\hline
\end{tabular}

Source: OFS, La population étrangère en Suisse 2008, ESPOP and PETRA, Federal Statistical Office of Switzerland

demographics of resident foreigners are explained by the new immigration policy, the increase in female education in transition and developing countries and the increasing opportunities for family reunification. These policy developments also raised questions about the new imbalance between migrant generations (Wanner 2004).

\subsubsection{Admission policies}

At the end of World War II, Switzerland imported a massive new labour force to meet booming economic reconstruction needs in Europe. The legal frame for this immigration was the 1931 Foreign Nationals' Residence and Settlement Act (Loi sur le séjour et l'établissement des étrangers, LSEE), a general text which was integrated by successive administrative regulations. Migration was then understood as a tool for regulating labour market supply and, as such, was managed by the OFIAMT (Office fédéral de l'industrie, arts et métiers et travail) - the then Ministry of Labour.

The government negotiated bilateral agreements with Italy in 1948 and 1964 as well as with Spain in 1961. The policy behind these agreements became known as the 'rotation of guest-workers', since its aim was to prevent not only the long-term settlement of this foreign labour force, but also a so-called over-foreignisation (Ueberfremdung) in Switzerland, an ideological term dating from the First World War (Arlettaz \& Arlettaz 2004). No migration agreement was signed with Turkey or with Yugoslavia.

At the beginning of the 1960 s, the government put an end to the still very liberal admission policy for workers by adopting measures limiting their 
entry. Various reasons account for this important change: the inefficiency of the rotation model, the tense economic situation and pressure from an increasingly vocal anti-immigrant movement. Over the next ten to fifteen years, many anti-immigrant initiatives were proposed, aimed at drastically reducing the number and the proportion of foreign workers. Even if none of the proposals were approved by popular vote, they nevertheless succeeded in imposing a general ceiling on new entries and in strongly conditioning the admission policy (Mahnig et al. 2005). The oil crisis of the mid-1970s and its repercussions in Switzerland (a 10 per cent reduction in the number of jobs) provoked a significant number of forced return of the labour migrants and the desired reduction in the number of new entries. However, concurrent pressure applied by international organisations such as the United Nations Economic Commission for Europe and the International Labour Organization led to the adoption of a more sensitive family reunification policy (Efionayi et al. 2005).

When the economy recovered during the 1980s, Switzerland called again for new labour migration. Though the global ceiling for immigration was still formally in place, the arrival of labour migrants boomed (some 50,00o new permits were delivered every year between 1989 and 1994). The old migration supplier countries of Italy and Spain were replaced by new ones such as Yugoslavia and Portugal. Immigrants from these countries presented a similar unskilled profile to previous flows and occupied the lowest positions in the labour market, especially in construction and in the hotel and catering industry - sectors deserted by Swiss natives and older migration workers (Piguet 2009). The regulatory frame for this new immigration, however, was largely similar to that of the 1950 and 1960 s, allowing easy access to lowskilled positions in the labour market but restricted access to social rights.

The new geopolitical situation after the fall of the Berlin Wall in 1989 and the internal slowdown of the Swiss economy at the beginning of the $1990 \mathrm{~s}$ induced the Swiss government to reshape its admission policy. In its efforts to negotiate a free movement of labour agreement with the European Union, the new policy, known as the 'three-circles model', foresaw a modulation of admission rights according to the geopolitical origin of the immigrants and their 'cultural distance'. Citizens of EU and EFTA countries enjoyed preferential recruitment, free of quotas (the first circle). Citizens from other 'culturally close' countries in North America and Eastern Europe were to be admitted on a limited basis (the second circle). Finally, citizens of all other states were only to be granted entry permits if highly qualified.

Although Yugoslavia had become an important source of labour in the 1980 s, it was placed in the 'third circle' of countries whose unskilled nationals 
Figure 2.1 Foreign resident population in Switzerland by nationality or geographical origin, 1981-2007

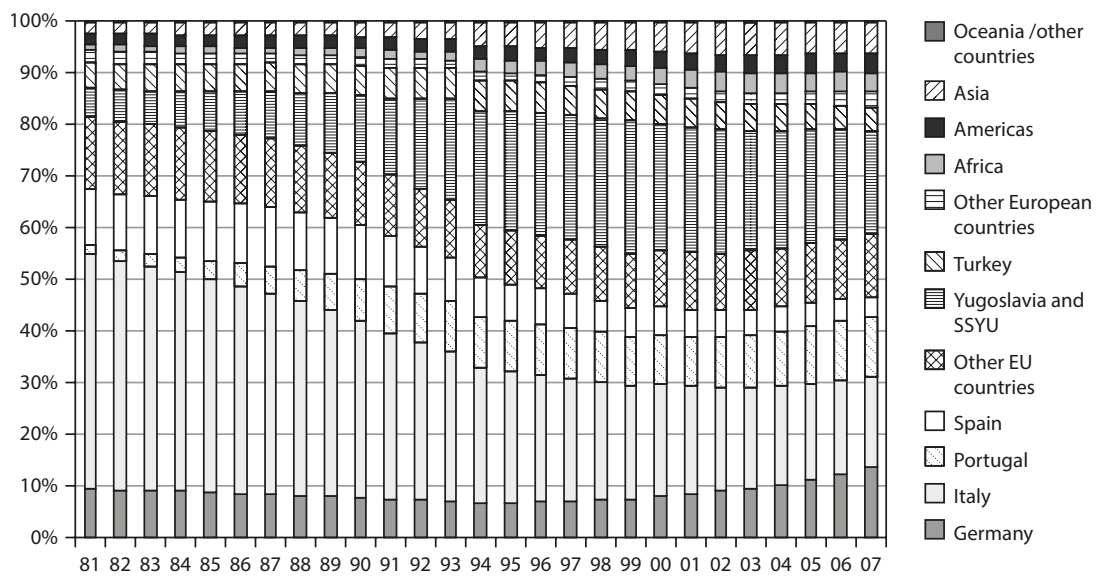

Source: Federal Office for Migration, Bern

were to be given no labour or residence permits because of its precarious record on human rights in 1991. Unfortunately it was the same citizens who mostly suffered from these human-rights violations who bore the brunt of the 'punishment' imposed by Switzerland (Maillard \& Leuenberger 1999). For this maturing migration flow, the only circumstances under which migration could still take place were either family reunification or asylum. The new policy therefore provoked a sudden acceleration of women and young people in these new flows of unwelcome migrants.

The first decade of the $21^{\text {st }}$ century was marked by the adoption of new legal rules for admission. Bilateral agreements (implemented since 2002) between Switzerland and the European Union introduced the free movement of EU and EFTA citizens on the Swiss labour market, while the new Federal Aliens Law (Loi fédérale sur les étrangers or LEtr) - adopted in 2005 and implemented since 2008 - laid down the rules for restricted admission from non EU-EFTA countries, limiting it to highly qualified labour immigrants.

As a consequence, the composition of the foreign resident population significantly changed. The number of EU immigrants, mainly from Germany and Portugal, rose sharply, while the number of citizens from other European countries declined; those from outside Europe increased slightly. Changes brought about by the new migration regime were not only limited to the geographical dimension; labour migration acquired greater importance than family reunification and the overall qualification of the foreign labour force grew markedly. 
Table 2.2 Permanent foreign resident population in Switzerland by country or continent of origin, December 2008

\begin{tabular}{|c|c|c|c|c|c|c|c|}
\hline & & $` 000 s$ & $\begin{array}{c}\text { \% total } \\
\text { foreign } \\
\text { population }\end{array}$ & & & '000s & $\begin{array}{c}\text { \% total } \\
\text { foreign } \\
\text { population }\end{array}$ \\
\hline TOTAL & & 1,669 & & \multicolumn{2}{|c|}{$\begin{array}{l}\text { Other European } \\
\text { countries }\end{array}$} & 406 & 26.4 \\
\hline \multirow{2}{*}{\multicolumn{2}{|c|}{ EUROPE }} & 1,443 & 86.5 & & Serbia & 184 & 11.0 \\
\hline & & & & & Turkey & 72 & 4.3 \\
\hline \multirow[t]{6}{*}{ EU-27 } & & 1,037 & 62.1 & & Macedonia & 59 & 3.5 \\
\hline & Italy & 291 & 17.4 & & Bosnia & 37 & 2.2 \\
\hline & Germany & 234 & 14.0 & & & & \\
\hline & Portugal & 196 & 11.7 & ASIA & & 96 & 5.8 \\
\hline & France & 87 & 5.2 & AMERICAS & & 69 & 4.1 \\
\hline & Spain & 65 & 3.9 & AFRICA & & 54 & 3.2 \\
\hline
\end{tabular}

Source: Federal Office for Migration, Bern

By the end of 2007, the distribution of the permanent resident foreign population was such that the vast majority of immigrants was of European origin - 60 per cent from an EU country and 26 per cent from other European countries.

\subsubsection{Immigrant policies}

Following Hammar (1990), we define 'immigrant policies' as the regulations governing access by immigrants to the labour market, education and housing, as well as to participation in social and political life in the host country. They cover a broad spectrum of purposes ranging from the exclusion of the foreign population to its inclusion in the new society. Integration policies are the result of the close intertwining of admission and immigrant policies of various and changing configurations (Wicker 2003).

With its post-World War II guest-worker rotation model, Switzerland decided on a configuration which allied liberal admission rules with very limited economic and social rights for its foreign labour force until 1964, under the ideological guise of the fight against Ueberfremdung. As this model became economically dysfunctional towards the mid-196os, the liberal admission policy was abandoned in favour of a restrictive one, while the immigrant policy pursued its restrictive track, although family reunification was progressively admitted. Private initiatives were deemed to 
be responsible for any closer relations to be established between immigrants and the host society (Niederberger 2004).

The configuration changed by the time of the first oil crisis; while entry conditions remained restrictive, public authorities recognised their role in ensuring integration by improving conditions for legal resident under the provisions of the 1931 Alien Law. In spite of various attempts to ease naturalisation rules in the 1980s, 1990s and early 200os, they were all overruled by popular vote and Swiss naturalisation provisions thus remained among the most restrictive in Europe. This is just one example of how direct democratic institutions provided opposition (often anti-immigration) movements with considerable opportunities outside the parliamentary arena to influence migratory policy. At the federal level, the issue of integration was reaching a stalemate (Mahnig \& Wimmer 2003).

The initiative on integration policies shifted to the subsidiary level of local authorities, reflecting the federalist structure of the state, vast municipal autonomy and direct democracy. The integration of the second generation was implemented first at cantonal level, with regulations on school access and support, and was later extended to housing and social rights, as well as to access to the political arena through naturalisation (Cattacin \& Kaya 2005). As a consequence of this federalist structure, the different integration policies that were experienced and implemented in the country were often polarised around the linguistic gap between German- and the French-speaking regions.

At the federal level, the initiative was resumed in the 2000s with the launching of a nationwide integration policy, mainly addressing conditions for new arrivals. The Federal Commission for Foreigners (Commission fédérale des étrangers or CFE - today Commission fédérale pour les questions de migration or CFM) successfully contributed to an open debate on this issue, which was shaping a new political climate. As a consequence, the traditional perspective - that integration was the outcome of migrants' good will - was abandoned. The new paradigm entailed decisive and substantial public promotion of integration by the authorities (Prodolliet 2006).

In later years the promotion dimension was complemented by evergrowing requirements toward migrants. The new integration discourse combined liberal and conservative perspectives. From the liberal perspective, the host society's willingness to integrate with migrants is considered necessary only for specific groups; the conservative perspective emphasises compulsory rules to force migrants' compliance with the 'guest' society and to prevent their abuse of its provisions (Wicker 2009). 
The integration policy that has evolved since 2000 is known under the German label of 'Fördern und Fordern' - promotion and firmness (Piñeiro et al. 2009). Its elaboration was linked to the new migration landscape diverse in national origin, migratory status and religious background. The integration dynamics of populations from Turkey and the successor states of Yugoslavia were crucial in this elaboration.

\subsubsection{Naturalisation policies}

Naturalisation policy is a highly significant aspect of integration, as it ensures the political inclusion of immigrants and their offspring. The main feature of Swiss naturalisation policy is that citizenship is acquired either through ius sanguinis or through voluntary application for naturalisation. In other words, there is no automatic acquisition of Swiss citizenship for those born in the country. Therefore the naturalisation procedures and requirements for the second generation differ only slightly from those for the first generation. The first, second and even third generations of immigrant descent have to apply for naturalisation and the procedure appears to be socially selective (Achermann 2003; Fibbi et al. 2007). Even though the legal requirements for residence are more easily met by the children of immigrants who grew up in the country, their naturalisation remains a selective process. With a twelve-year legal residence requirement (Federal Office for Migration 2006), the conditions that must be fulfilled in order to acquire citizenship are the most exacting in Europe (Huddleston \& Niessen 2011).

Among the major consequences of Swiss naturalisation policy are the divergence between the juridical status of nationals and that of foreigners, and the life-experience of migration. In Switzerland, there are two main configurations for the Swiss-born children of immigrants: they may be nationals by birth - born to at least one Swiss parent - or by naturalisation, born to a foreign couple; or they may be foreign citizens who are the non-naturalised offspring of immigrant parents. This last configuration, rarely known in countries which practise the jus soli principle, was the most common status of the second generation in Switzerland in 2000.

The second distinctive feature of Swiss naturalisation policy is the diversity of its implementation models at cantonal and municipal levels, where the authorities are directly responsible for the decision to admit (or refuse entry to) would-be citizens into the political body.

Switzerland has, however, allowed dual nationality since 1992, when the number of naturalisations increased fivefold (Heiniger et al. 2004). The 
average number per year in 1990-1994 was 10,000, rising to 20,000 in 1995-1999 and reaching almost 35,000 in 2000-2005. In 2006, 47,600 naturalisations were registered - an historic peak. Of the 442,500 naturalisations granted between 1986 and 2006, 59 per cent occurred between 2000 and 2006. In 2008 some 45,300 foreigners acquired Swiss citizenship; they came mainly from Kosovo, Italy, Germany and Turkey. This represents a naturalisation rate of only 2.7 per cent, though more than 700,000 of the foreign population would have met the application requirements.

\subsection{Immigration from Turkey and the successor states of Yugoslavia: A short historical appraisal}

The national and ethnic groups studied in the TIES research project belong to the so-called second immigration wave which predominated in the $1980 \mathrm{~s}$ and was characterised by a mix of labour migration and asylum movements. Respondents to the TIES questionnaire were born between 1971 and 1988 and therefore belong to the very first native-born second generation, when labour migrants were featured prominently. They have also experienced a major change in migratory policy in the last twenty years, which represents a significant paradigm shift in the Swiss conceptualisation of the longlasting impact of migration on Swiss society.

\subsubsection{Immigration from Turkey}

The presence of most immigrants from Turkey is relatively recent and quantitatively limited. The Federal Statistical Office has only been studying this group separately since 1965 , when it consisted of about 6,400 people. The Turks migrated to Europe mainly for socio-economic reasons until the end of the 1970s, representing the very image of the guest-worker - a system that developed in German-speaking countries in the 196os (Castles \& Kosack 1973). By the end of the 1960s, some 12,000 Turkish nationals were living in Switzerland, yet they represented barely 1 per cent of the foreign population in 1970; they were mainly unskilled industrial workers from rural Turkey. By 1980 , their number had tripled to reach 38,000 or 4 per cent of the foreign population, though the total foreign population decreased following the two oil crises of the 1970 .

Following the military coup d'état in September in 1980, Turkish emigration became motivated by political as well as economic reasons. Several thousand people thus sought refuge in Western Europe, particularly 
Switzerland. From 1986, the Turkish government's repression of the Kurdish community further increased the wave of refugees into Switzerland. After the guest-workers and political refugees who fled the Turkish regime, the Kurdish refugees formed a third group of Turkish citizens living abroad (Fibbi et al. 2003).

In contrast to the guest-workers, refugees in the late 1980 s were often university and high-school students or university graduates. They came from the larger cities in Turkey and were committed to the political struggle there. Refugees of Kurdish origin differed from these refugees since their exile resulted from ethnic violence against them. Kurdish refugees shared rural origins with the guest-workers and experienced similar conditions of forced exile as refugees who had fled the military regime, although their political motivation was more ethnic than ideological. Thus, the composite social profile of the population of Turkish origin in Switzerland was similar to that observed in Germany (Bozarslan 1990).

The number of Turkish-origin immigrants more than doubled to around 82,000 in 1990 and then stagnated at this level, with some 83,000 residents in 2000 (Wanner 2004). Immigration from Turkey has strongly decreased since the end of the 1980 os due to visa restrictions and changes in Swiss immigration policy. The number of applications lodged for asylum status has steadily dropped: from more than 9,000 at the end of the 1980 s to around 1,500 in 2000. A similar trend characterised labour and family-based immigration during the 1990s. The annual number of asylum requests was in excess of 9,000 at the end of the 1980s, but had stabilised at the much lower level of around 1,400 in 2000. There was no massive inflow of immigrants from Turkey in the first decade of the new century.

The Turkish-origin population accounts for 5.5 per cent of the resident foreign population according to the 2000 figures: they are the fifth-largest group. Some 90 per cent live in the German-speaking part of the country. This group includes a high proportion of young people: 27.3 per cent are aged under 15 (compared with a mean of 19.5 per cent, taking all groups of foreigners together); some 9 per cent are aged between 15 and 19. The Turkish-origin population can now be considered settled and is characterised by stability in terms of status: in 2000, some 72 per cent of young people up to the age of 19 were born in Switzerland, 22 per cent had yearly residence permits and 74 per cent had permanent residence permits, which gave them greater access to social rights.

The naturalisation rate of the Turkish immigrant population has increased since the 1980s, reaching 1.8 per cent by the end of the $1990 \mathrm{~s}$ (Wanner \& Piguet 2002). This is relatively high compared to the national 
Figure 2.2 Age pyramid of the Swiss-born, second generation of Turkish descent, holding or having held a Turkish passport

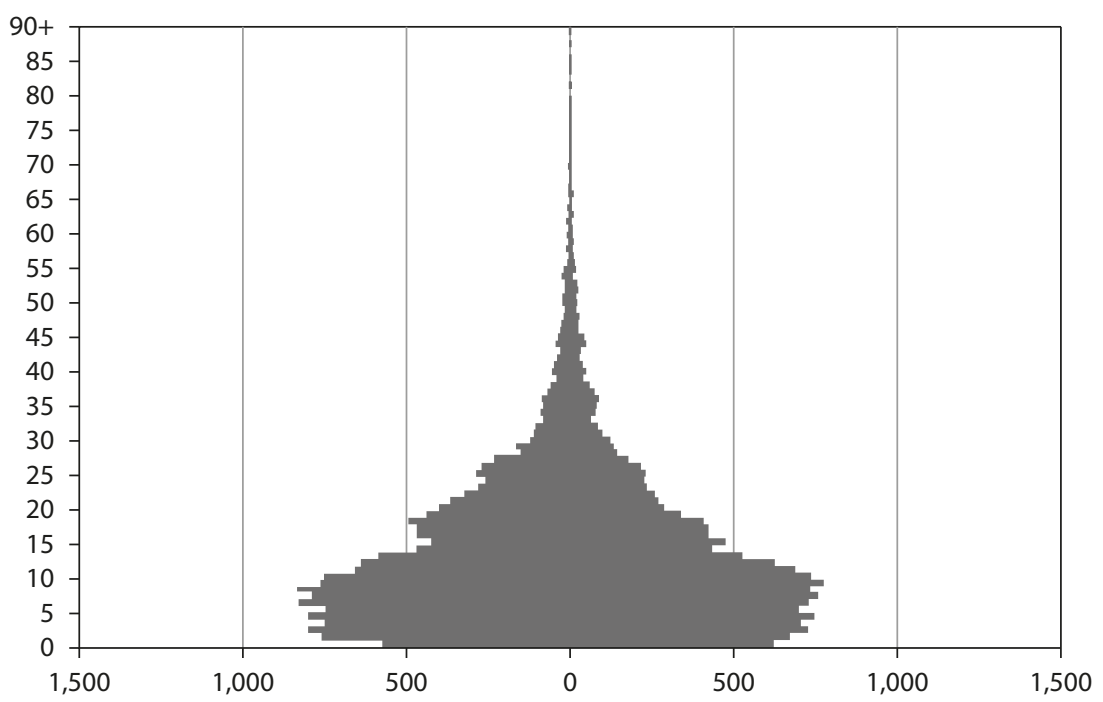

Source: Census 2000

average of 1.02 per cent for all immigrant groups. Since Turkey accepted dual nationality in 1992, applications for naturalisation have risen considerably and relate mostly to second-generation youth.

\subsubsection{Immigration from Yugoslavia and its successor states}

The new Socialist Republic of Yugoslavia under Josip Broz Tito was wary about emigration in the 195 os and actively discouraged it, the labour force being needed in the reconstruction of the country. It was only after 1965 that Yugoslavia changed policy, considering emigration as a way of easing pressure on the labour market, and it was therefore legalised. As a consequence, an important labour emigration started, which headed toward Germany, northern Europe and Switzerland. The movement began in the 1960 s and developed into the 1970 s in spite of the economic slowdown; it boomed in the 199 os with family reunification and, later, asylum flows.

In 1970, some 25,000 Yugoslavs resided in Switzerland and represented around 2 per cent of the foreign resident population. They were mainly qualified workers in the health sector and academia, coming from the Serb Croatian-speaking population living in the northern states of the federation. The majority came from Croatia and a quarter from Serbia; they primarily 
anticipated a return to their country after a few years abroad (Boskovska 2000).

By 1980 , the figure had risen to 61,000 , though this was still less than 5 per cent of the foreign population. Since statistics didn't register the state origin of Yugoslavs, language and religion can be considered as proxies for their ethnic background. The great majority were still mainly Serb-Croatianspeaking: less than 7 per cent had Albanian as their mother tongue; a third of them had a Catholic background and less than a third were Christian Orthodox. The fact that one in six Yugoslavs was aged under 15 indicates that the group was starting to settle. At that time, Yugoslavs enjoyed a very positive image with the local population as they were considered willing to integrate and largely invisible (Mikic 2009).

During the 1980s, immigration from Yugoslavia boomed and its population almost tripled in Switzerland, reaching some 173,000 residents in the 1990 Census. The social position of Yugoslav workers changed during this decade: by 1990 more than half of the Balkan population had an unskilled position on the labour market. The new immigrants were mainly from rural regions and often from Kosovo. Men from this province came first as seasonal workers: they were allowed to stay for nine months, then had to return to their families back home for the next three month and were then obliged to re-apply for a permit. In 1991 half of the seasonal workers from Yugoslavia were Albanian Kosovars. However, migration from Kosovo developed into a politically motivated movement with the loss of the political autonomy of their province in the late 1980s, following Tito's death. The outbreak of war in Croatia, Slovenia and Bosnia in 1991, as well as the Kosovo war in 1998-99, accelerated the family reunification movement that had long been delayed by migrants who had innitially nurtured the myth of returning home (Maillard \& Leuenberger 1999).

Asylum-seekers from the Republic of Serbia (including Kosovo and Montenegro) sought refuge in Switzerland in their thousands as the hostilities reached their peak in 1991 (some 14,00o new entries under this category) and in 1998-99 (around 29,000). Not recognised as statutory refugees, they were granted provisional protection or stayed on in Switzerland as their repatriation could not be enforced. Their children attended local schools but suffered under the restricted social and economic rights granted to those forms of subsidiary protection (Burri Scharani et al. 2010).

The lower qualifications of immigrants from the Western Balkans, the hostile attitude of the Swiss towards asylum-seekers at that time and the growing violent behaviour of immigrants from this group largely 
contributed to the dramatic worsening of the image they held in public opinion (Mikic \& Sommer 2003).

With a total of 364,600 individuals by 2000 , nationals of the successor states of Yugoslavia represented 24 per cent of the resident foreign population. They constituted the second-largest group of immigrants after the Italians and were spread over both the French- and the German-speaking parts of Switzerland, with slightly more in the latter. This group included the largest proportion of young people: 30.7 per cent were younger than 15 years old (compared with a mean of 19.5 per cent for all groups of foreigners taken together) and 9 per cent were aged between 15 and 19. The total number of children and young people from the former Yugoslavia increased by a factor of seven between 1985 and 1997 and by 2000 they represented more than a third of all young foreigners $(137,000)$ (Lischer 2003).

For a long time, the way the statistics were recorded in Switzerland made it impossible to distinguish between the various nationalities of citizens of the former Yugoslavia. The 2000 population census did, however, make the situation more transparent by distinguishing Serbs $(210,000)$ from people who came originally from Macedonia (56,0oo), Bosnia-Herzegovina (51,00o), Croatia $(44,000)$ and Slovenia (3000). As is all too well-known, it is not possible to record the Albanian-speaking minority simply by assessing formal citizenship. Using the languages spoken as their criterion, Albanian speakers were therefore estimated as representing some 45 per cent of all immigrants from Yugoslavia (Haug et al. 2002).

The SSYU-origin population began to settle and by 2000 some 46 per cent of young people aged under 19 had been born in Switzerland. They have a relatively high standardised rate of naturalisation: 2.49 for the period 1992-1998 (Wanner \& Piguet 2002).

There is an ongoing migratory inflow from the countries of the former Yugoslavia; some 9,900 individuals of Yugoslav origin were granted new 'B' or 'C' permits in 2000. The number of requests for asylum amounted to approximately 5,800 in that year. The return flows were also significant around 4,400 in 2000 . This resulted in a net positive international migratory balance of the population in permanent residence of approximately 5,500 individuals. The number of new permits issued on the grounds of family reunion accounted for three-quarters of the total number issued for primary and secondary immigration taken together.

The following table sets out the main demographic dynamic of the two groups for the year 2000 . 
Figure 2.3 Age pyramid of the Swiss-born second generation of SSYU descent, holding or having held an SSYU passport

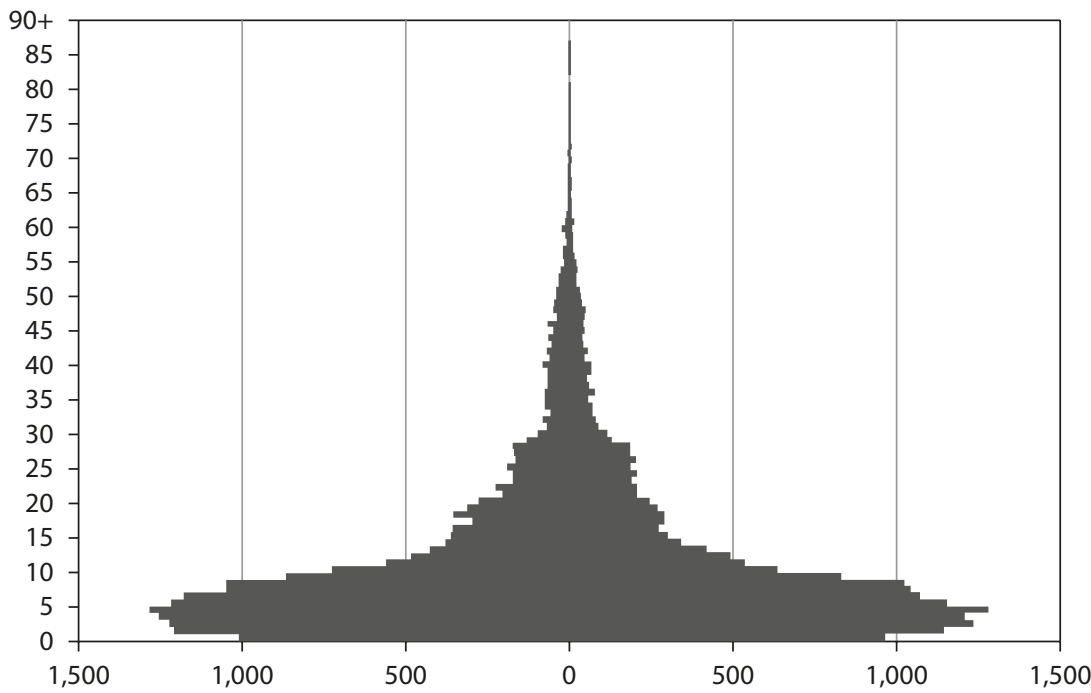

Source: Census 2000

Table 2.3 Key demographic features of Turkish and SSYU citizens in Switzerland, 2000

\begin{tabular}{lrc}
\hline & Turks & SSYU citizens \\
\hline Absolute numbers in 2000 & 83,124 & 364,558 \\
Proportion as a percentage of all foreigners & 5.50 & 23.90 \\
Percentage of increase 1990-2000 & 2.30 & 111.00 \\
Net migration balance in 2000 & 1,075 & 5,502 \\
Percentage of family reunions/total newcomers & 45.00 & 73.00 \\
Absolute numbers of young people (aged 0-19) & 30,270 & 144,120 \\
Dependency ratio of young people (aged 0-19) & 57.80 & 64.70 \\
Percentage in compulsory education & 8.00 & 37.00 \\
Percentage of naturalisation & 1.77 & 2.49 \\
\hline
\end{tabular}

Source: Wanner (2004) Lischer (2002); Piguet \& Wanner (2000) 


\subsection{The agglomerations of Zurich and Basel}

In Switzerland the TIES study was conducted on the Turkish and SSYU second generation born in Switzerland and living in the cities of Zurich and Basel. The choice of the cities - both in the German-speaking part of the country - was determined by the residential patterns of the two groups. In the following section we describe their key socio-demographic characteristics and labour market structures. The educational systems of Zurich and Basel are described in Chapter 4, which covers education.

\subsubsection{Demographic characteristics of the cities}

At the end of 2007, the resident population of Zurich city was about 377,000 (a 2.6 per cent increase over ten years), while its metropolitan area included more than 1.1 million inhabitants. The foreign population of Zurich totalled 113,000 people - about 30 per cent of the total population of Zurich city in 2007 (Zurich City Statistics 2008). The largest groups of foreign nationals were Germans, citizens of the SSYU and Italians; Turks ranked sixth among the immigrant groups.

Table 2.4 Resident foreigners in Zurich and Basel in 2007

\begin{tabular}{lrrrrr} 
& \multicolumn{2}{c}{ Zurich } & & \multicolumn{2}{c}{ Basel } \\
\cline { 2 - 3 } \cline { 5 - 5 } & No. & $\begin{array}{c}\text { \% of foreign } \\
\text { population }\end{array}$ & & No. & $\begin{array}{c}\text { \% of foreign } \\
\text { population }\end{array}$ \\
\cline { 3 - 5 } Germans & 25,164 & 21.9 & & 9,966 & 16.1 \\
SSYU citizens & 19,320 & 16.8 & & 9,700 & 15.6 \\
Italians & 13,946 & 12.1 & & 8,680 & 14.0 \\
Portuguese & 7,850 & 6.8 & & 2,400 & 3.9 \\
Spaniards & 4,800 & 4.2 & & 4,350 & 7.0 \\
Turks & 4,732 & 4.1 & & 7,780 & 12.5 \\
Total foreigners & 115,100 & & 62,000 & \\
\hline Percentage foreigners in & & 30.5 & & 33.0 \\
total population & & & & \\
\hline
\end{tabular}

Source: Statistik Basel-Stadt (2008); Stadt Zürich (2008)

On the other hand, Basel's population had decreased by 5.7 per cent since 1997 to reach 188,00o people in 2007 (by 2009 the trend had reversed and the population rose again to 190,364 ). In 2006 , its metropolitan population was slightly over 720,000 . The foreign population in 2007 - at around 62,000 
- therefore represented about 33 per cent of the total population of Basel city (Statistik Basel-Stadt, 2008), with the largest foreign-national groups again being Germans, SSYU citizens and Italians. With a population of 7,780 , the Turks were the fourth-largest foreign group in Basel (see Table 2.4).

In order to have a large enough sample of native-born second-generation Turks and those of SSYU descent aged between 18 and 35, the agglomerations of Zurich and Basel were also taken into consideration.

\subsubsection{The Turkish and SSYU populations in the agglomerations of Zurich and Basel}

Table 2.5 maps the Turkish and SSYU presence in the two agglomerations based on Census 2000 data. The first generation is defined as those of Turkish or SSYU origin who were 35 years or older and not born in Switzerland; the second generation consisted of people of Turkish or SSYU origin, under 35 and born in Switzerland. Finally, the 1.5 (or in-between) generation were those under 35 not born in Switzerland.

Table 2.5 The composition of the Turkish and SSYU immigrant populations in 2000 (naturalised and non-naturalised)

\begin{tabular}{|c|c|c|c|c|c|c|c|}
\hline & & \multicolumn{2}{|c|}{ Turks } & \multicolumn{2}{|c|}{ SSYU } & \multicolumn{2}{|c|}{ Swiss } \\
\hline & & Number & $\%$ & Number & $\%$ & Number & $\%$ \\
\hline \multirow[t]{4}{*}{ Aggl. ZH } & $1 G$ & 5,115 & 31.46 & 24,314 & 34.56 & & \\
\hline & $1.5 G$ & 6,176 & 37.99 & 31,299 & 44.49 & & \\
\hline & $2 G$ & 4,967 & 30.55 & 14,737 & 20.95 & & \\
\hline & Total & 16,258 & 100.00 & 70,350 & 100.00 & 709,290 & 100.00 \\
\hline \multirow[t]{4}{*}{ Aggl. BS } & $1 G$ & 4,786 & 30.03 & 8,204 & 35.06 & & \\
\hline & $1.5 G$ & 6,444 & 40.44 & 10,367 & 44.31 & & \\
\hline & $2 G$ & 4,706 & 29.53 & 4,827 & 20.63 & & \\
\hline & Total & 15,936 & 100.00 & 23,398 & 100.00 & 321,104 & 100.00 \\
\hline \multirow[t]{4}{*}{$\mathrm{CH}$} & $1 G$ & 27,454 & 30.59 & 121,607 & 32.93 & & \\
\hline & $1.5 \mathrm{G}$ & 33,693 & 37.54 & 170,217 & 46.09 & & \\
\hline & $2 G$ & 28,595 & 31.86 & 77,466 & 20.98 & & \\
\hline & Total & 89,742 & 100.00 & 369,290 & 100.00 & $5,152,559$ & 100.00 \\
\hline
\end{tabular}

The Turkish population in Switzerland is almost equally divided into onethird foreign-born, one-third the 1.5 generation and one-third Swiss-born. Among SSYU citizens around a fifth were Swiss-born, but most of the 
under-35s belong to the 1.5 generation. The distribution observed at the national level is also found in the agglomerations of Zurich and Basel.

The TIES survey was conducted in the agglomerations around Zurich and Basel, and the respective cantons of Zurich, Basel-Stadt and BaselLand. Table 2.6 reports the distribution of the target populations in the two agglomerations.

Table 2.6 Swiss-born population, aged 18-35, naturalised and non-naturalised, of Turkish, SSYU and Swiss origin (2007)

\begin{tabular}{lccccccc}
\hline & \multicolumn{2}{c}{ Turks } & SSYU citizens & \multicolumn{2}{c}{ Swiss } & $\begin{array}{c}\text { Total } \\
\text { population }\end{array}$ \\
\cline { 2 - 8 } & $\mathbf{N}$ & $\begin{array}{c}\text { \% total } \\
\text { population }\end{array}$ & $\mathbf{N}$ & $\begin{array}{c}\text { \% total } \\
\text { population }\end{array}$ & $\mathbf{N}$ & $\begin{array}{c}\text { \% total } \\
\text { population }\end{array}$ & \\
\hline $\begin{array}{l}\text { Aggl. } \\
\text { Zurich }\end{array}$ & 1,290 & 0.67 & 2,458 & 1.27 & 161,308 & 83.31 & 193,628 \\
$\begin{array}{l}\text { Aggl. } \\
\text { Basel }\end{array}$ & 833 & 1.09 & 768 & 1.00 & 64,343 & 83.85 & 76,735 \\
$\begin{array}{l}\text { Total } \\
\text { National }\end{array}$ & 2,123 & 0.79 & 3,226 & 1.19 & 225,651 & 83.46 & 270,363 \\
\hline
\end{tabular}

\subsubsection{Structure of the labour market in the agglomerations of Zurich and Basel}

The two cities are important centres of economic activity. Among the five biggest cities in Switzerland, Zurich and Basel are characterised by a sizable secondary sector, despite a significant reduction in the 1990 (especially in Zurich). In 2007, the unemployment rate in the city of Zurich was 2.8 per cent, while 348,000 people were economically active $(152,000$ women and 196,000 men). Ninety per cent of the employed worked in the tertiary or service sector, while the secondary sector accounted for only 10 per cent of all economically active people (Stadt Zürich 2008).

In Basel, out of the 155,80o people pursuing an economic activity in 2007 , 23.9 per cent were employed in the secondary sector and 75.7 per cent in the service sector (Statistik Basel-Stadt 2009). Traditionally the secondary sector has been more important in Basel, because a number of pharmaceutical and chemical companies have their headquarters and production sites in the city. The unemployment rate in Basel dropped sharply from 5 per cent in 2004 to about 2.9 per cent in December 2007 (Statistik Basel-Stadt 2008). However, by December 2009 the unemployment rate had again reached 
Table 2.7 Structure of the labour market in Basel, Zurich and Switzerland, 2007

\begin{tabular}{lrrrrrrr}
\hline \multirow{2}{*}{ Sectors } & \multicolumn{2}{c}{ Primary } & \multicolumn{2}{c}{ Secondary } & \multicolumn{2}{c}{ Tertiary } & TOTAL \\
\cline { 2 - 8 } & \multicolumn{1}{c}{ No. } & \multicolumn{1}{c}{$\%$} & \multicolumn{1}{c}{ No. } & \multicolumn{1}{c}{$\%$} & \multicolumn{1}{c}{ No. } & \multicolumn{1}{c}{$\%$} & \\
\hline Basel & 600 & 0.4 & 37,200 & 23.9 & 118,000 & 75.7 & 155,800 \\
Zurich & 19,320 & 1.7 & 34,143 & 9.8 & 314,257 & 90.2 & 348,400 \\
SWITZERLAND & 171,000 & 3.9 & $1,050,000$ & 23.8 & $3,192,000$ & 72.3 & $4,412,000$ \\
\hline
\end{tabular}

Source: Stadt Zürich (2008); Statistik Basel-Stadt (2008); FOS (2008)

4.1 per cent (Statistik Basel-Stadt 2009). In this context it is interesting to note that Basel was less affected by the recent economic and financial crisis than most major Swiss cities, because the chemical and pharmaceutical industries fared a lot better during the crisis. However, like Zurich, the unemployment level among foreigners is more than twice that of Swiss nationals because most early immigrants were or are employed in the now-shrinking secondary sector.

\subsubsection{Local integration policies in Zurich and Basel}

Integration policy was implemented at the local level (i.e., cantonal and municipal) long before the issue was politicised at federal level (Niederberger 2004). Educational policy for instance, which is the competence of cantons, has been a priority in the field of integration. A good example of integration measures is the Zurcher 'Quality in Multi-Ethnic Schools' (QUIMS) project, a comprehensive policy design started in 1996 and now institutionalised for the whole canton (Gomolla 2006). It is an area-wide model of quality assurance in multi-ethnic schools, a response to the challenges posed by the unsatisfactory school outcomes of youth of immigrant descent, by growing numbers of middle-class families fleeing inner-city districts with ethnically diverse populations.

Since 2001 the Confederation has had the capacity to finance projects aimed at integration; this new competence has given an impulse to integration measures. Action at federal level was mainly inspired by the largely pragmatic approach developed in cities like Bern and Zurich or cantons like Neuchâtel and Basel (Mahnig \& Wimmer 2003).

In the city of Zurich the first milestone was set with a guideline on integration policy in 1999. Integration was interpreted as a common task for the state, society and individuals. Individuals - of migrant as well as of local backgrounds - were asked to respect the constitution and the rule of 
law but were free, in a liberal approach, to take advantage of the various integrative measures (Meier 2009). Integration was understood as respect for legal order and social practices, commitment to the fundamental values of the constitution and a willingness to take part in economic life, education and local language-learning. Therefore integration policy is based on four pillars: information, linguistic integration, labour market integration and socio-cultural integration. While providing support for migrants needing help in adjusting to the new situation, Zurich pursues a policy of searching for the 'creative classes', actively recruiting highly qualified personnel.

In Switzerland, Basel is seen as one of the pioneers of local integration policy. In 1999 the canton of Basel had already mandated the social anthropology department at the Institute of the University of Basel to define the guidelines of its future integration policy. These guidelines were confirmed in a number of governmental documents. In 2007 Basel was the first canton to adopt a 'law on integration', based on the principle of 'Fördern und Fordern'. It outlines a policy of 'carrots and sticks' through which the canton hopes to encourage the foreign population to 'integrate' (Piñeiro et al. 2009).

In substantive terms the focus has been on the acquisition of the German language. For this purpose the canton has subsidised a number of German courses in which basic written and spoken language skills can be acquired. A second dimension of the policy concerns the implementation of 'integration conventions'; if foreigners fail to attempt to integrate they face non-renewal of their residence permit. A third dimension of the integration policy has been an effort to coordinate further integration in education, health, youth unemployment and other areas. Lastly, a number of pilot projects have been supported that aim to 'bring together people from different countries and regions'. It is hoped that regular interactions with people from foreign countries will reduce prejudice. On the whole, the city has tried to realise ambitious objectives and innovative projects, but it is difficult to judge how effective the policy has been in practice, owing to a number of practical difficulties.

\subsection{Demographic characteristics of the second generation in the TIES sample}

The first two subsections of this chapter introduced the main features of immigration and integration policies as well as the factors that have shaped the two immigration flows which were the particular focus of the TIES study - from Turkey and the republics of the former Yugoslavia. The third 
section briefly presented the key characteristics of the urban environment in which these flows settled.

We now turn to the presentation of the Swiss TIES sample: we first describe our second-generation respondents - their age, gender and geographical distribution. We then discuss the living arrangements of these young people, some of whom live with their parents and some of whom have already established their own household (§ 2.5). We finally sketch out the position of TIES respondents in the institutional landscape and explore their nationality status, which defines their formal relation to their countries of origin and settlement. We then identify the main features of the urban ethnic communities to which the children of immigrants 'belong' because of their specific descent ( $(2.6)$.

\subsubsection{Age and sex structure of the sample}

Respondents of the TIES project in Switzerland are within the age range 18-35 years. The data were weighted to ensure that the age structure of the sample corresponded to the actual population in Zurich and Basel.

In fact, the age structures of respondents with an immigrant background and of native citizens show remarkable intergroup differences, simply because the migratory flows described here are fairly recent and the individuals observed are the very first second-generation group from those countries. While the majority of native-born second-generation Turks and those of SSYU origin are aged under 25, the comparison group is largely concentrated in age categories of 25 years and older. Around 20 per cent of young people of Turkish origin are under 20 and 36 per cent of the Turkish and SSYU second generation are in their early 20 .

The mean age for respondents of Turkish descent is 23 , and for respondents of SSYU origin 25.1; this is lower than the mean age of 26.6 years for the comparison group (Table 2.8).

A different age structure is observed in Zurich and Basel for youth of Turkish origin (Table 2.8). In Zurich, the second generation of Turkish origin is older on average (24.8 years versus 23.2 years) than in Basel. Such differences are mainly due to the survey design. No differences are to be found in the mean age for the SSYU second generation and for comparison-group respondents.

The gender distribution among origin groups reveals a sex ratio for Turkish youth of 104.1 men to 100 women and of 105.3 men to 100 women among comparison-group respondents; these are higher than the sex ratio observed among youth of SSYU origin (98.6:10o). Normally, the sex ratio of 
Table 2.8 Age structure, by origin group and agglomeration

\begin{tabular}{lcccccc}
\hline & \multicolumn{2}{c}{ TR } & \multicolumn{2}{c}{ SSYU } & \multicolumn{2}{c}{ CG } \\
\hline \multicolumn{1}{c}{ Age } & Zurich & Basel & Zurich & Basel & Zurich & Basel \\
\hline Under 25 & 50.5 & 64.4 & 51.7 & 53.6 & 36.6 & 41.4 \\
Over 25 & 49.5 & 35.6 & 48.3 & 46.4 & 63.4 & 58.6 \\
& & & & & & \\
Mean age & 24.8 & 23.2 & 25.1 & 25.1 & 26.9 & 26.4 \\
St. dev. & 5.1 & 4.6 & 5.2 & 5.5 & 5.3 & 5.5 \\
N = & 202 & 247 & 239 & 192 & 202 & 266 \\
\hline
\end{tabular}

TR (Zurich vs. Basel) $\quad X^{2}=8.793 \quad \mathrm{p}=.003$

TR (Zurich vs. Basel) mean age $\quad p=.001$

All other differences are not statistically significant.

Table 2.9 Distribution of respondents by origin group, gender and agglomeration (including mean age and sex ratio by origin group)

\begin{tabular}{lccccccc}
\hline & TR & SSYU & CG & & TR & SSYU & CG \\
\hline Men & 51.0 & 49.7 & 51.3 & Zurich & 45.0 & 55.5 & 43.2 \\
Women & 49.0 & 50.3 & 48.7 & Basel & 55.0 & 44.5 & 56.8 \\
Sex ratio & 104.1 & 98.6 & 105.3 & & & & \\
Mean age & 23.9 & 25.1 & 26.6 & & & & \\
St. dev. & 4.9 & 5.3 & 5.4 & & & & \\
$\mathrm{~N}=$ & 449 & 431 & 468 & $\mathrm{~N}=$ & 449 & 431 & 468 \\
\hline
\end{tabular}

$\begin{array}{lcc}\text { TR-CG } & \text { mean age } & \mathrm{p}=.000 \\ \text { SSYU-CG } & \text { mean age } & \mathrm{p}=.000 \\ \text { TR-SSYU } & \text { mean age } & \mathrm{p}=.001 \\ \text { SSYU-CG (Zurich vs. Basel) } & \mathrm{X}^{2}=13.561 & \mathrm{p}=.000 \\ \text { TR-SSYU (Zurich vs. Basel) } & \mathrm{X}^{2}=9.631 & \mathrm{p}=.002 \\ \text { All other differences are not statistically significant. }\end{array}$

a population aged 18 to 35 with a low mortality rate like that in Switzerland, is about 104 men to 100 women.

\subsubsection{Civil status of respondents}

The age distribution reflects the different civil statuses of the respondents. To study civil status, we focus on those in the older age category ( $>25$ years old), as respondents in the younger age group are still mostly subsumed within family formation. This selection highlights the very distinctive traits 
of the various origin groups, as youth of immigrant descent are more often married than youth from the comparison group.

Table 2.10 Percent of marriage and all unions among respondents aged 25 and over, by origin group, gender and agglomeration

\begin{tabular}{lccccccc}
\hline \multicolumn{1}{c}{ MARRIAGE } & TR & SSYU & CG & & TR & SSYU & CG \\
\hline Men & 40.2 & 40.8 & 27.6 & Zurich & 32.0 & 48.3 & 29.5 \\
Women & 42.4 & 50.5 & 32.9 & Basel & 51.7 & 41.6 & 30.1 \\
Total & 41.3 & 45.6 & 29.9 & Total & 41.3 & 45.6 & 29.9 \\
$\mathrm{~N}=$ & 201 & 175 & 300 & $\mathrm{~N}=$ & 201 & 175 & 300 \\
\hline MARRIAGE and & & & & & & & \\
COHABITATION & & & & & & & \\
\hline Men & 48.5 & 59.2 & 54.5 & Zurich & 39.0 & 62.1 & 51.9 \\
Women & 48.9 & 64.5 & 55.7 & Basel & 59.6 & 60.7 & 57.1 \\
Total & 48.7 & 61.8 & 54.9 & Total & 48.7 & 61.8 & 54.9 \\
$\mathrm{~N}=$ & 201 & 175 & 300 & $\mathrm{~N}=$ & 201 & 175 & 300 \\
\hline
\end{tabular}

$\begin{array}{lcc}\text { TR-CG } & X^{2}=24.712 & \mathrm{p}=.000 \\ \text { SSYU-CG } & X^{2}=13.632 & \mathrm{p}=.001 \\ \text { TR-SSYU } & X^{2}=10.502 & \mathrm{p}=.005 \\ \text { TR (Zurich vs. Basel) } & X^{2}=8.344 & \mathrm{p}=.015 \\ \text { All other differences are not statistically significant. }\end{array}$

Table 2.10 provides information first on married couples and then on all couples, both married and cohabitating, from among TIES respondents in the older age category. Around 40-45 per cent of the second generation of Turkish or SSYU origin are married, compared to only three out of ten respondents in the comparison group.

Marriage patterns of men and women are quite similar for youth of Turkish origin and those of the comparison group. However, in the SSYUorigin group, a higher percentage of women are married than men (half of the women and four out of ten men). Marriage patterns vary in the two agglomerations for the Turkish-origin group; in Basel more than half of those aged 25 and above are married while in Zurich it is only one in three.

If we compare TIES survey data on the marriage status of respondents with similar data from the 2000 Census, at the exact age of 25 (youths born in 1975, Table 2.11), we observe that the prevalence for marriage is markedly higher in the sample than in the Census data both by gender and by origin group.

Census data show that the share of married people among 25-yearold foreign-born youth is significantly higher than for the native-born. 
Table 2.11 Marriage status of Swiss- and foreign-born youth aged 25, holding or having held a Turkish or a Yugoslavian passport, by gender and naturalisation status

\begin{tabular}{|c|c|c|c|c|c|c|}
\hline & & & \multicolumn{2}{|c|}{ Men } & \multicolumn{2}{|c|}{ Women } \\
\hline & & & $\begin{array}{c}\% \\
\text { married }\end{array}$ & No. & $\begin{array}{c}\% \\
\text { married }\end{array}$ & No. \\
\hline \multirow[t]{4}{*}{ Turkey } & Swiss-born & Naturalised & 30.9 & 55 & 45.6 & 90 \\
\hline & & Non-naturalised & 32.9 & 228 & 70.2 & 141 \\
\hline & Foreign-born & Naturalised & 36.1 & 61 & 43.6 & 55 \\
\hline & & Non-naturalised & 63.8 & 646 & 86.5 & 606 \\
\hline \multirow[t]{4}{*}{ Yugoslavia } & Swiss-born & Naturalised & 20.6 & 63 & 25.3 & 79 \\
\hline & & Non-naturalised & 42.2 & 128 & 66.1 & 109 \\
\hline & Foreign-born & Naturalised & 41.2 & 51 & 59.5 & 37 \\
\hline & & Non-naturalised & 73.1 & 1,137 & 86.9 & 1,108 \\
\hline
\end{tabular}

Source: Census 2000

Moreover, married people are more numerous among the non-naturalised than the naturalised; the naturalised foreign-born tend to have a marriage rate similar to that of the non-naturalised native-born. These observations apply also to women, among whom, however, the proportion of those who are married is systematically higher than among men. Finally, among SSYU youth the gap between the non-naturalised foreign-born and the naturalised native-born is more pronounced than for Turkish-origin youth.

Family formation is not synonymous with marriage; quite a number of young people choose simply to live together. In the comparison group, for instance, cohabitation tends to be almost as frequent (24 per cent) as marriage (29 per cent). Such behaviour is relatively common among the SSYU-origin group as well (16 per cent, especially men) but concerns only some 8 per cent of the Turkish-origin group, men and women alike. The bipolarisation of family forms between a conjugal and a non-conjugal sector is considered a consequence of the general movement of individualisation in society and greater equality in the couple (Fux 2005).

When 'cohabiting with a partner' and 'marriage' are considered together, more than half of the respondents aged 25 and above in all origin groups are found to be in a union (Table 2.10), the SSYU-origin group living significantly more often in a union than the two other groups under scrutiny. Differences among immigrant-origin groups and the comparison group pertain more to the degree of formalisation of the union than to the fact of living as a couple. 
The greater importance of the conjugal sector in the two immigrant-origin groups should be seen in the light of the importance of marriage-related migration (see Chapter 8), where formal marriage functions as the entry ticket for migrant spouses.

Do living arrangements across the origin groups differ according to gender? The behaviour of men and women in marriage and cohabitation is quite similar in the Turkish-origin group and the comparison group. Gender differences observed for SSYU youth in marriage behaviour disappear when both types of union are taken into account.

\section{$2.5 \quad$ Living arrangements}

These gender and origin-group patterns of union formation sit alongside quite different models of the way young people gain autonomy from their parents. Timing and reasons for leaving the parental household and setting up a new one differ sharply between respondents in the comparison group on the one hand and among the children of immigrants on the other. In this section certain life-course events, such as leaving parental household, establishing an own household and having children, are studied according to origin groups in two agglomerations.

\subsubsection{Living in the parental home}

One of the key features of the transition from youth to adulthood is the departure from the parental home. The timing and means by which this transition takes place vary according to socio-cultural background. A few decades ago this transition took place earlier in working-class settings than in middle-class milieux (Bourdieu 1980; Held \& Levy 1975). In the meantime, educational expansion, difficulties in entering the labour and housing markets and greater individualisation have postponed residential independence, thus prolonging cohabitation with parents (Déchaux 2007; Lefèvre \& Filhon 2005). Family time-scales are a crucial cultural feature and are key indicators of cultural change.

One aspect of family time-scales is the living arrangements of young adults. How long do they live with their parents? When do they set up their own household? Have the broad changes briefly sketched above affected families of immigrant origin to the same extent as autochthonous ones? Are there diverging patterns among the origin groups or is some convergence to be observed? 
Table 2.12 Household position as 'child', by origin group, agglomeration and age category

\begin{tabular}{|c|c|c|c|c|c|c|c|c|}
\hline & TR & SSYU & CG & & & TR & SSYU & CG \\
\hline Men & 60.0 & 54.2 & 39.6 & & $<25$ & 85.4 & 76.1 & 78.3 \\
\hline Women & 60.9 & 39.2 & 33.8 & & $>=25$ & 26.1 & 14.1 & 9.9 \\
\hline Zurich & 55.7 & 43.5 & 37.1 & & & & & \\
\hline Basel & 64.5 & 50.8 & 36.8 & & & & & \\
\hline Total & 60.6 & 46.9 & 36.8 & & Total & 60.6 & 46.9 & 36.8 \\
\hline $\mathrm{N}=$ & 449 & 431 & 468 & & $N=$ & 449 & 431 & 468 \\
\hline \multicolumn{2}{|l|}{ TR-CG } & \multicolumn{2}{|c|}{$X^{2}=54.009$} & $p=.000$ & & & & \\
\hline \multicolumn{2}{|l|}{ SSYU-CG } & \multicolumn{2}{|c|}{$X^{2}=17.203$} & $p=.000$ & & & & \\
\hline \multicolumn{2}{|l|}{ TR-SSYU } & \multicolumn{2}{|c|}{$X^{2}=17.777$} & $p=.000$ & & & & \\
\hline \multicolumn{2}{|c|}{ SSYU (Men vs. Women) } & \multicolumn{2}{|c|}{$X^{2}=10.874$} & $p=.004$ & & & & \\
\hline \multicolumn{2}{|c|}{$\operatorname{TR}(<25$ vs. $>=25)$} & \multicolumn{2}{|c|}{$X^{2}=161.551$} & $p=.000$ & & & & \\
\hline \multicolumn{2}{|c|}{ SSYU ( $<25$ vs. $>=25)$} & \multicolumn{2}{|c|}{$X^{2}=173.290$} & $p=.000$ & & & & \\
\hline \multicolumn{2}{|c|}{ CG $(<25$ vs. $>=25)$} & \multicolumn{2}{|c|}{$X^{2}=233.258$} & $p=.000$ & & & & \\
\hline
\end{tabular}

Living as a child in the parental household appears more frequent among the adult children (aged 18-35) of Turkish immigrants (61 per cent) than those of SSYU immigrants (47 per cent) and the comparison group (37 per cent) - see Table 2.12. Men tend to live longer with their parents than women in the SSYU-origin group, whereas no such difference is observed in the Turkish and comparison groups.

However, the high percentage of young people living with their parents in the Turkish-origin group is primarily a consequence of the group's age structure. A large majority of respondents aged below 25 live with their parents whatever their origin, so group differences are determined especially by respondents in the older age category. Among those aged over 25, the share of Turkish-origin respondents living with their parents is significantly higher than in other origin groups -26 per cent vs. 14 per cent for the SSYU-origin group and 10 percent for the comparison group (Table 2.12). This result confirms, then, that the cohabitation of parents and their adult children is more frequent among Turkish-origin respondents.

In fact, the higher percentage of Turkish youth in the older age category still living with their parents recalls home-leaving behaviour observed in Turkey. 'The majority of home-leavers are late home-leavers in Turkey' (Koç 2007), moving out of the parental home after the age of 25 . This pattern of parental-home leaving observed in Turkey resembles the pattern which can be found today in Mediterranean and Southern European countries 
(Koç 2007). In Turkey as in many other countries, women leave the parental home earlier than men.

The children of immigrants, especially men, tend to live with their parents longer than autochthonous youth in spite of their more modest social background and school performance. This fact contradicts the expectation of an early working-class path into adulthood. Similar findings were observed among earlier immigrant groups in Switzerland (Bolzman et al. 2003).

\subsubsection{Leaving the parental home}

Let us now consider those respondents who established their own households; as previously explained, the analysis is restricted to respondents aged 25 and above. Respondents were asked to state at what age they left their parents' home to live on their own for the first time and to enumerate the reasons for their departure. Do the timing and reason for leaving differ according to origin group?

Table 2.13 Mean age at leaving the parental home of respondents aged 25 and over, by origin group, gender and agglomeration

\begin{tabular}{lcccccc}
\hline & TR & St. Dev. & SSYU & St. Dev. & CG & St. Dev. \\
\hline Men & 24.0 & 12.4 & 27.5 & 20.7 & 21.3 & 2.8 \\
Women & 22.3 & 9.1 & 20.4 & 2.8 & 20.9 & 2.8 \\
Total & 23.2 & 10.9 & 23.5 & 14.3 & 21.1 & 2.8 \\
$\mathrm{~N}=$ & 151 & & 149 & & 271 & \\
\hline
\end{tabular}

TR-CG

SSYU-CG

mean age at leaving parental home $p=.004$

mean age at leaving parental home $p=.007$

All other differences are not statistically significant.

The timing of leaving the parental home is higher for immigrant-origin groups in both agglomerations: the mean age is 23.2 years for Turkishorigin youth, 23.5 years for those of SSYU origin and only 21.1 years for the comparison group (Table 2.13).

Leaving the parental home occurs at an earlier age for women than for men. Gender difference in this respect is significant in the SSYU second generation, but is in fact limited in the comparison and Turkish secondgeneration groups. This contrasts with de-cohabitation behaviour in Turkey. Studying the Turkey Demographic and Health Survey (TDHS) 2003 data, 
Koç (2007) found that the median age for leaving home was 24.4 years and the timing of leaving the parental home was 27.2 years - notably different from that for women at 21.6 years. The median home-leaving age for Turkishorigin youth in the Swiss TIES survey is 22.0 years for men, thus much closer to the median age of women (21.o years) than is the case in Turkey.

Why leave the parental home? The similar median ages in establishing one's own household appear to be the outcome of very dissimilar processes of transition to adulthood, through marriage and household formation. Reasons for leaving parental home vary from union formation to study, from work to the return migration of parents. Union formation and study are the two most important reasons given (see Table 2.14).

Table 2.14 Reasons for leaving the parental home, by origin group and gender

\begin{tabular}{lrr|r|r|r|r|r|r|r}
\hline & \multicolumn{3}{c}{ TR } & \multicolumn{3}{c}{ SSYU } & \multicolumn{3}{c}{ CG } \\
\cline { 2 - 12 } & M & W & T & M & W & T & M & W & T \\
\hline Marriage & 30.1 & 40.2 & 35.0 & 8.1 & 27.1 & 19.4 & 0.6 & 6.1 & 3.4 \\
Live with a partner & 10.7 & 8.7 & 9.7 & 20.2 & 13.3 & 16.1 & 11.3 & 19.9 & 15.5 \\
Live on one's own & 42.7 & 30.4 & 36.6 & 49.5 & 40.3 & 44.0 & 46.8 & 45.2 & 46.0 \\
Study & 11.7 & 13.7 & 12.7 & 11.1 & 16.7 & 14.0 & 27.2 & 23.0 & 25.1 \\
Work & 5.8 & 6.9 & 6.3 & 13.1 & 6.3 & 9.1 & 8.2 & 12.0 & 10.2 \\
Parents' departure & 2.9 & 3.9 & 3.4 & 1.0 & 0.7 & 0.8 & 0.6 & 0.6 & 0.6 \\
Problems with & 4.9 & 8.8 & 6.8 & 6.1 & 9.8 & 8.6 & 5.7 & 7.8 & 6.8 \\
parents & & & & & & & & & \\
N = & 103 & 111 & 214 & 86 & 137 & 223 & 166 & 171 & 337 \\
\hline
\end{tabular}

Note: As multiple reasons could be given for leaving the parental home, percentages do not total 100. TR-CG Marriage ${ }^{* * *}$, Living with a partner $\left(^{*}\right)$, Living on own*, Study**, Parents' departure*

SSYU-CG

TR-SSYU

TR (Men vs. Women) Marriage ${ }^{* * *}$, Study**

Marriage ${ }^{* * *}$, Living with a partner ${ }^{*}$, Parents' departure ${ }^{*}$ )

Living on own $\left(^{*}\right)$

SSYU (Men vs. Women)

CG (Men vs. Women)

Marriage ${ }^{* * *}$, Work $\left(^{*}\right)$

Marriage ${ }^{* *}$, Living with a partner*

All other differences are not statistically significant/ $\left({ }^{*}\right)=$ p. $>.7$

The most remarkable intergroup difference is observed when the reason for leaving the parental home is marriage. The second generation of Turkish origin establish their own household more often as a result of marriage (35 per cent) than SSYU youth (19 per cent) and the comparison group (3 per cent). As shown in Table 2.10, four or five out of ten children of immigrants (aged 25 and over) are married compared to three out of ten in the comparison group. The association between marriage and leaving the 
parental home is particularly marked in the case of the Turkish second generation and to a lesser extent for the SSYU second generation; youth from the comparison group leave the parental home to live with their partners more often in cohabitation than in marriage.

In all origin groups, marriage is mentioned more frequently by women than men as the reason for leaving. Gender difference is significant for the SSYU second generation (8 per cent of the men; 27 per cent of the women) and for the comparison group (1 per cent and 6 per cent respectively). Men of Turkish origin leave the parental home more often than women in order to live on their own.

In his study on Turkey, Koç (2007) found that the sequence of life-course events for men in Turkey was entry into the labour force, marriage, the birth of the first child and leaving home; in other words, men leave home only after marriage and the birth of a child. On the contrary, women leave home when they marry. However, Koç (2007) argues that the home-leaving experience of women does not mean a real home-leaving in the context of Turkey, but a shifting from their own parental home to their husbands'.

According to the TIES results, the sequence of life-course events of men of Turkish origin living in Switzerland differs from that in Turkey, where married couples may well live under the same roof as the parents of one spouse. Traditional cohabitation between married couples and the parents' generation in Switzerland is very limited ${ }^{1}$ and, as surprising as it may seem, this affects immigrant-origin couples as much as comparison-group couples: 3 per cent of Turkish-origin couples, 5 per cent of SSYU-origin couples and 4 per cent in the comparison group. Equally rare is the cohabitation under the same roof of grandparents and a young married couple with a child - found only in immigrant-descent families: 4 per cent of Turkish-origin couples and 7 per cent of SSYU-descent men and their spouse. Altogether these multigenerational configurations concern some 10 per cent of married couples of immigrant descent.

Study also appears to be an important reason for leaving the parental home; a higher percentage of the comparison group than of immigrantdescent youth gave it as their reason for establishing their own household. Their parents' departure from the country was a relevant reason only for youth of Turkish origin.

1 This circumstance may be the result of family reunion policy in case of marriage migration: in order to secure a residence permit for the newcomer spouse, the resident foreigner has to be able to afford independent accommodation (Achermann 2004). 
Moving out of the parental home may also be a way to avoid tense interpersonal relations. To what extent are intergenerational conflicts given as reasons for leaving by TIES respondents? Are these conflicts more frequent for women, especially in the immigrant-origin groups? Immigrant youth apparently often report higher levels of intergenerational conflict than autochthonous youth, although evidence repeatedly challenges this assumption (Boos-Nünning \& Karakasoglu 2004; Fibbi et al. 2005; SuarezOrozco \& Suarez-Orozco 1995). In the TIES survey, women do mention problems with parents more often than men as a reason for leaving home (Table 2.14); however this occurs across women in all origin groups in equal measure. Again, the evidence contradicts the representation of conflict-torn immigrant families in general and especially Muslim families.

Is there a spatial pattern to why youngsters leave home? This is partially true for the Turkish second generation, where leaving to marry seems more frequent in Basel (four out of ten respondents) than in Zurich (one quarter) ( $p$ $=.065$ ). This concurs with the higher proportion of married people in Basel.

Youth who move out of the parental home go on to establish their own household, either as singles or with other persons - be they partner, spouse or friend(s). What is the average number of these household members?

Table 2.15 Mean number of household members in newly established secondgeneration households, by origin group, gender and agglomeration

\begin{tabular}{lcccccc}
\hline & TR & St. Dev. & SSYU & St. Dev. & CG & St. Dev. \\
\hline Men & 2.4 & 1.3 & 2.5 & 1.5 & 2.0 & 1.0 \\
Women & 2.6 & 1.3 & 2.6 & 1.3 & 2.2 & 1.1 \\
Zurich & 2.4 & 1.3 & 2.6 & 1.5 & 2.1 & 1.0 \\
Basel & 2.6 & 1.2 & 2.6 & 1.3 & 2.1 & 1.1 \\
Total & 2.5 & 1.3 & 2.6 & 1.4 & 2.1 & 1.0 \\
$\mathrm{~N}=$ & 188 & & 208 & & 310 & \\
\hline
\end{tabular}

TR-CG mean number of household members $\quad p=.001$

SSYU-CG mean number of household members $p=.000$

All other differences are not statistically significant.

The household size of young people of immigrant descent is larger than that of the comparison group, as was the case for their parents. This does not imply however, that the size will necessarily be larger than that of the comparison group. Among the respondents who left their parental home, the average household size for the children of immigrants is 2.5 for the 
Turkish group and 2.6 for those from the SSYU, compared to 2.1 for the comparison group. Gender and agglomeration have no effect (Table 2.15).

A majority of Turkish and, to a lesser extent, SSYU respondents still live with their parents, the difference with the comparison group being especially pronounced among respondents aged 25 and older. This is undoubtedly because of their younger average age in relation to the comparison group. However this behaviour also reflects the situation observed in Mediterranean countries, where the age of residential autonomy of young people tends to be higher than in Switzerland.

The majority of the SSYU second-generation and comparison-group members live in their own household, while a lower percentage of youth of Turkish origin do so. This difference is very noticeable in the younger age group, but is still significant among respondents aged 25 and above.

\subsection{The second generation and the institutional environment}

In this last subsection we change perspective; we leave the family environment and move on to describe relations between the second generation, the Swiss institutional environment and the ethnic community in which the children of immigrants find themselves due to their background.

\subsubsection{Naturalisation behaviour}

Because of the lack of any jus soli provision (see $\S 2.1 .3$ ), the acquisition of local citizenship is a choice that the children of immigrants have to make at some point in their lives. This decision and its eventual acceptance by the authorities have both a strong personal resonance and clear public repercussions. We observed (see $§ 2.1$ ) that immigrants and their offspring from non-EU countries contributed significantly to the increase in naturalisations in the first decade of the twenty-first century; in 2008, 45 per cent of naturalised people were previously nationals of Turkey and of the successor states of Yugoslavia.

In the TIES survey, naturalisation behaviour is similar for the second generation of both Turkish and SSYU origin. Seventy per cent of males have Swiss nationality; the proportion is higher for women at around 80 per cent. SSYU youth are more often naturalised in Basel than in Zurich (79 vs. 72 per cent respectively) whereas Turkish youth are more often naturalised in Zurich than in Basel (77 vs. 68 per cent respectively), but agglomeration differences are significant only for the children of Turkish immigrants. 
Table 2.16 Percentage of naturalised second-generation youth (with a Swiss passport), by origin group, gender and agglomeration

\begin{tabular}{lccccc}
\hline & TR & SSYU & & TR & SSYU \\
\hline Men & 65.5 & 68.7 & Zurich & 77.2 & 71.7 \\
Women & 78.6 & 81.1 & Basel & 68.0 & 79.2 \\
Total & 72.2 & 74.9 & Total & 72.2 & 74.9 \\
$\mathrm{~N}=$ & 449 & 431 & $\mathrm{~N}=$ & 449 & 431 \\
\hline
\end{tabular}

TR (Men vs. Women) $\quad X^{2}=9.588 \quad \mathrm{p}=.002$

TR (Zurich vs. Basel) $\quad X^{2}=4.694 \quad p=.030$

SSYU (Men vs. Women) $\quad X^{2}=8.843 \quad p=.003$

Other differences are not statistically significant.

The gender gap in the naturalisation behaviour of young people has already been observed in other groups of immigrant descent in Switzerland, based, for instance, on data from the Federal Census 2000 (Fibbi et al. 2005). But the high rate of naturalisation of Turkish and SSYU respondents contrasts with previous findings on the naturalisation behaviour of second-generation youth in the study by Wanner \& Piguet (2002), probably undertaken at a time when the second generation was too young.

Two factors may account for the high percentage of naturalised youth in the TIES second generation: first, TIES respondents are native-born and this fact was found to have a positive impact on naturalisation; secondly, during the 2000s the status and rights of non-EU citizens in Switzerland deteriorated, while EU citizens experienced a clear improvement. Naturalisation may indeed be a strategy to bridge this divide on an individual basis. An analysis of the average age at naturalisation by origin group, gender and agglomeration allows a deeper investigation of the naturalisation process of TIES respondents of Turkish and SSYU origin (see Table 2.17).

Table 2.17 Mean age at naturalisation, by origin group, gender and agglomeration

\begin{tabular}{lcccc}
\hline & TR & St. Dev. & SSYU & St. Dev. \\
\hline Men & 18.4 & 6.1 & 17.5 & 5.6 \\
Women & 17.8 & 4.9 & 17.8 & 5.7 \\
Zurich & 17.6 & 5.2 & 17.9 & 5.4 \\
Basel & 18.5 & 5.7 & 17.3 & 6.0 \\
Total & 18.1 & 5.5 & 17.7 & 5.7 \\
N $=$ & 288 & & 279 & \\
\hline
\end{tabular}

All other differences are not statistically significant. 
For both second-generation groups, the mean age at naturalisation is eighteen, with no noticeable gender difference (Table 2.17). The age at naturalisation drops to fifteen when the father is also naturalised (see Chapter 3 on parents), implying that this is a family procedure. Naturalisation at fifteen means that the application was filed when the child was aged twelve or thirteen, or as soon as the lengthy residence requirement (twelve years) were met by the child. The average age at naturalisation is similar in the two agglomerations for SSYU youth, while Turkish youth in Basel seem to naturalise later (18.5 years on average) than in Zurich (17.6 years).

The introduction of dual citizenship in 1992 halted the decline in naturalisations during the 1980 s. The possibility of holding citizenship of both the origin and the host country has proved not only institutionally but also subjectively crucial in taking the highly symbolic step represented by the voluntary acquisition of nationality (Frauenfelder 2007). Dual nationality is an institutionalised way of signifying multiple subjective identities.

Since all countries of origin in the survey opted for a dual nationality policy, we may question whether the naturalised second generation among the Swiss TIES respondents have taken advantage of this opportunity and hold dual nationality. Have they kept the nationality of their parents' country of origin while acquiring the Swiss one? Does this practice differ in the two migrant groups, by gender or agglomeration?

Table 2.18 Percentage of second generation with a Swiss passport only, by origin group, gender and agglomeration

\begin{tabular}{lrcccc}
\hline & TR & SSYU & & TR & SSYU \\
\hline Men & 8.3 & 19.2 & Zurich & 9.9 & 22.2 \\
Women & 12.3 & 26.3 & Basel & 10.5 & 23.4 \\
Total & 10.2 & 22.7 & Total & 10.2 & 22.7 \\
$\mathrm{~N}=$ & 449 & 431 & $\mathrm{~N}=$ & 449 & 431 \\
\hline
\end{tabular}

TR-SSYU $\quad X^{2}=25.078 \quad \mathrm{p}=.000$

All other differences are not statistically significant.

Among those respondents who naturalised, many also hold citizenship of Turkey or a successor state of Yugoslavia. However, 23 per cent of SSYU youth only have a Swiss passport, twice as many as the 10 per cent of the second generation of Turkish origin (Table 2.18). This high percentage of respondents of SSYU origin who only have Swiss nationality might be explained by difficulties in matching personal trajectories with institutionalised belonging (in the case of children born to 'mixed' couples) as well as by 
practical difficulties in holding the nationality of the country of origin in the war-troubled successor states of Yugoslavia. Because of subjective resonance of double citizenship, this issue will be further developed in the chapter on identity. There is no influence of the father's language on dual nationality among the naturalised Turkish and SSYU second generation.

Table 2.19 Holders of a Swiss passport only, by origin group and parents' naturalisation

\begin{tabular}{|c|c|c|c|c|c|}
\hline & \multicolumn{3}{|c|}{ Father } & \multicolumn{2}{|c|}{ Mother } \\
\hline & Naturalised & \multicolumn{2}{|c|}{ Non-naturalised } & Naturalised & Non-naturalised \\
\hline $\begin{array}{l}\text { TR with Swiss } \\
\text { passport only }\end{array}$ & 14.2 & & 8.1 & 16.0 & 6.2 \\
\hline$N=$ & 159 & & 287 & 185 & 261 \\
\hline $\begin{array}{l}\text { SSYU with Swiss } \\
\text { passport only }\end{array}$ & 28.8 & & 18.0 & 28.9 & 14.7 \\
\hline$N=$ & 194 & & 230 & 239 & 190 \\
\hline \multicolumn{3}{|c|}{ TR (Father naturalised vs. non-naturalised) } & $X^{2}=4.148$ & $p=.042$ & \\
\hline \multicolumn{3}{|c|}{ SSYU (Father naturalised vs. non-naturalised) } & $X^{2}=6.900$ & $p=.009$ & \\
\hline \multirow{2}{*}{\multicolumn{3}{|c|}{$\begin{array}{l}\text { TR (Mother naturalised vs. non-naturalised) } \\
\text { SSYU (Mother naturalised vs. non-naturalised) }\end{array}$}} & $X^{2}=11.190$ & $\mathrm{p}=.001$ & \\
\hline & & & $X^{2}=12.084$ & $p=.001$ & \\
\hline
\end{tabular}

When the parents are naturalised, their children are more likely to abandon the nationality of their parents' country of origin (Table 2.19). This is the case for 29 per cent of SSYU youth, a much higher percentage than the children of non-naturalised parents ( 15 per cent). For Turkish youth the pattern is the same -15 per cent of those with naturalised parents versus 7 per cent of those with non-naturalised parents. Women of both origin groups have a higher likelihood of having only Swiss nationality compared to men, but gender difference is not significant.

\subsubsection{Turkish and SSYU communities in Basel and Zurich}

So far, respondents have been grouped according to the 'national origin' of the parents. The national category is a convenient one, largely used in migration studies to classify migrants into groups; but it has the treacherous shortcoming of suggesting underlying commonalities. A closer investigation allows us to tackle this issue of diversity inside 'origin groups', and explore to what extent such diversity appears territorially organised in the country of immigration. We do this in each of the two agglomerations. Chain migration, time of settlement and labour market features might account 
for local singularities. We therefore analyse the national/ethnic origins of the second generation in Zurich and Basel by describing differences in the internal set-up of the groups. Both groups are composite as a result of diversified ethnic and religious settings in the sending countries. The criteria for analysing ethnic composition in the two agglomerations will be fathers' childhood language and family religion, passed down from parents to children. In the case of the SSYU, national origin will be determined by the country of birth of their parents in what are today's successor states of Yugoslavia.

Sixteen per cent of Turkish youth in the two cities combined have a father who learned to speak Kurdish at home; this is a lower percentage than that estimated for Turkey, where Kurdish people are thought to represent a fifth of the population (Courbage \& Todd 2007). In Basel, however, one in four of those with a Turkish background speak Kurdish - three times as many as in Zurich. The percentage of other minority languages is very limited; while Armenian is never mentioned, 8 per cent of Turkish respondents mentioned 'other language' (e.g., Arabic, Bulgarian, Circassian) as their father's childhood language.

The major religious divide among immigrants from Turkey is Sunni versus Alevi; both, however, are to be found within the Turkish- and Kurdish-speaking groups.

Table 2.20 Turkish families' religious affiliation, by agglomeration

\begin{tabular}{lrrr}
\hline & \multicolumn{3}{c}{ TR } \\
\cline { 2 - 4 } & Zurich & Basel & Total \\
\hline Families with no religious affiliation & 16.8 & 34.4 & 26.5 \\
Christian & 4.0 & 1.2 & 2.4 \\
Sunni Muslims & 52.5 & 38.5 & 44.8 \\
Shiite Muslims & 2.0 & 3.6 & 2.9 \\
Alevi Muslims & 9.9 & 19.0 & 14.9 \\
Other Muslim & 13.9 & 2.4 & 7.6 \\
Other & 1.0 & 0.8 & 0.9 \\
N $=$ & 202 & 247 & 449 \\
\hline
\end{tabular}

TR (Zurich vs. Basel) $\quad X^{2}=48.475 \quad \mathrm{p}=.000$

Is the distribution of these denominations similar in the two agglomerations or is there a concentration of one or the other in one area? The religious landscape of Turkish descendants differs in the two areas. In Basel, a third of respondents have no family religious affiliation, while Alevi families are better represented 
in Basel (19 per cent) than in Zurich (10 per cent). The concentration of Kurds and Alevi Muslims in Basel is not just a coincidence but the result of the high proportion of Alevi families among Kurds (3o per cent vs. 15 per cent of Turkish families). In Turkey, Alevi Kurds form a significant minority group which has had a changing and confrontational relationship with both Sunni Kurds and Alevi Turks (Karimova \& Deverell 2001). In Zurich, on the other hand, half of the respondents were brought up in the Sunni tradition, the proportion of non-religious families is more limited and the representation of other Muslim branches (such as Sufism) is significantly higher than in Basel.

For the SSYU group, national categories are prominent. Like the Turkish origin group, the language spoken by the father and parental religious affiliation will be used in order to identify the ethnic group.

Table 2.21 Country of birth of SSYU fathers and mothers, by agglomeration

\begin{tabular}{lrrrr}
\hline & \multicolumn{2}{c}{ Father } & \multicolumn{2}{c}{ Mother } \\
\cline { 2 - 5 } & Zurich & Basel & Zurich & Basel \\
\hline Switzerland & 0.8 & 1.6 & 1.7 & 5.3 \\
Bosnia & 23.0 & 20.3 & 21.4 & 22.2 \\
Yugoslavia & 7.1 & 10.9 & 6.3 & 7.9 \\
Kosovo & 17.6 & 8.3 & 17.6 & 8.5 \\
Croatia & 16.7 & 19.3 & 20.2 & 16.4 \\
Macedonia & 9.6 & 8.9 & 10.9 & 9.0 \\
Montenegro & 1.7 & 2.1 & 0.8 & 0.5 \\
Serbia & 22.2 & 25.5 & 18.5 & 24.9 \\
Slovenia & 1.3 & 3.1 & 1.3 & 2.1 \\
Other & \multicolumn{4}{c}{3.2} \\
N $=$ & 239 & 192 & 1.2 & 190 \\
\hline SSYU (Zurich vs. Basel) & father's country of birth & n.s. & 238 & \\
SSYU (Zurich vs. Basel) & mother's country of birth & $X^{2}=18.840$ & $\mathrm{p}=.042$ &
\end{tabular}

National groups from the three larger successor states of Yugoslavia - Bosnia, Croatia and Serbia - are similar in size in the two agglomerations, each representing 20-25 per cent of SSYU families (Table 2.21). However, families from Kosovo are more often settled in Zurich than in Basel.

Three-quarters of SSYU youth have fathers who speak Serbian/Croatian/ Serbo-Croatian; 13 per cent of the fathers speak Albanian/Macedonian. The language distribution is similar in Basel and in Zurich.

The only criterion drawing a somewhat different local profile of the SSYU population is religious affiliation. Once again there is a higher share 
of non-religious families in Basel (37 per cent vs. 20 per cent in Zurich), whereas there is a concentration of Muslim families of SSYU origin in Zurich (30 per cent vs. 15 per cent in Basel). This reflects the relative concentration of Kosovars in Zurich.

Table 2.22 SSYU families' religious affiliation, by agglomeration

\begin{tabular}{lccc}
\hline & \multicolumn{3}{c}{ SSYU } \\
\cline { 2 - 4 } & Zurich & Basel & Total \\
\hline Family with no religious affiliation & 20.4 & 37.3 & 27.9 \\
Catholic Christians & 25.0 & 24.4 & 24.7 \\
Protestant Christians & 0.8 & 1.0 & 0.9 \\
Orthodox Christians & 23.3 & 21.2 & 22.4 \\
Sunni Muslims & 17.1 & 6.2 & 12.2 \\
Alevi / Shiite / Other Muslim & 12.9 & 8.8 & 11.2 \\
Other & 0.4 & 1.0 & 0.7 \\
$\mathrm{~N}=$ & 239 & 192 & 431 \\
\hline
\end{tabular}

SSYU (Zurich vs. Basel) $\quad X^{2}=27.513 \quad \mathrm{p}=.001$

National categories hide the diversified composition of what is often considered 'the' (homogeneous) immigrant community - often characterised, in fact, by significant ethnic and religious divisions, so that the local landscapes may differ substantially from each other. TIES respondents are no exception. For the Turkish-origin population, Basel features an ethnic and religious pluralism as it hosts more Kurds, Alevi Muslims and non-religious respondents than Zurich. For the very diverse SSYU-origin population, there is less of a polarisation between the two agglomerations, though Zurich exhibits a concentration of Muslim families and Kosovars.

\subsection{Conclusions}

Migrants from Turkey and the SSYU are the largest European immigrant groups coming from non-EU-member countries. These flows date back to the late 1960s and 1970s: the presence of an adult, Swiss-born second generation is witness to almost 40 years of their history in the country. However, they tend to be regarded as 'new' immigration waves, as they come from countries outside the EU and are characterised by the intertwining of labour and asylum-related migration. Many of the changes in Swiss admission, integration and naturalisation policies that have occurred in the last twenty 
years have significantly affected flows from countries outside the EU, but not specifically the generation of TIES survey respondents, whose parents mainly correspond to the early labour-migrant profile and settled quite early in the country, benefitting from the easing of family reunification provisions in the 1970 s.

These origin groups are ethnically and religiously quite diverse. Among Turkish nationals there is a substantial minority of Kurds (16 per cent); though the majority is of Muslim Sunni tradition, a significant minority belongs to the Alevi tradition and a similar share of Turkish nationals has no religious affiliation whatsoever. Basel has the most diverse Turkishorigin immigration, as it hosts more Kurds and Alevi Muslims as well as non-religious respondents than Zurich.

Among SSYU-origin families, the share of parents from Bosnia, Croatia and Serbia is about equal; Albanian- and Macedonian-speaking parents are a minority at just 13 per cent. A majority of SSYU-origin families have no religious affiliation, whereas the various denominations have equal shares of followers. Zurich has a higher share than Basel of SSYU-origin families with a Muslim or a Kosovar background.

Turkish and SSYU respondents are considerably younger than those of the comparison group, therefore most still live with their parents. The difference between them and the comparison group is especially pronounced among respondents aged 25 and over. Women tend to leave home earlier than men. Marriage and cohabitation are the most frequent reasons for leaving home among immigrant-origin youth, while residential autonomy and study are the prevailing reasons for youth of Swiss descent.

The share of youth of Turkish and SSYU origin who hold Swiss citizenship is especially high, with three people in four holding a Swiss passport, disproportionate in comparison with other second-generation youth, even when native-born. The reason may lie with the relative worsening of the legal status of immigrant third-country nationals, while EU immigrant groups have experienced a clear improvement in their status.

\section{References}

Achermann, Alberto (2004), Integration und Habitat. Bern: Eidgenössiche Ausländerkommission. Achermann, Christin (2003), Ein- und Ausschluss im Einbürgerungsprozess. Zürich: Seismo. Arlettaz, Gerald \& Silvia Arlettaz (2004), La Suisse et les étrangers. Immigration et formation nationale (1848-1933). Lausanne: Editions Antipodes.

Bolzman, Claudio, Rosita Fibbi \& Marie Vial (2003), 'Secondas - Secondos': Le processus d'intégration des jeunes issus de la migration espagnole et italienne en Suisse. Zurich: Seismo. 
Boos-Nünning, Ursula \& Yasemin Karakasoglu (2004), Viele Welten Leben. Lebenslagen von Mädchen und jungen Frauen mit griechischem, italienischem, jugoslawischem, türkischem und Aussiedlerhintergrund. Berlin: Bundesministerium für Familien, Senioren, Frauen und Jugend.

Boskovska, N. (2000), 'Jugoslawen in der Schweiz', Schweizerische Aertzezeitung 81(47): 2647-2651.

Bourdieu, Pierre (1980), Questions de sociologie. Paris: Éditions de Minuit.

Bozarslan, Hamit (1990), 'Une communauté et ses institutions: Le cas des Turcs en RFA', Revue européenne des migrations internationales 6(3): 63-82.

Burri Scharani, Barbara et al. (eds) (2010), Die Kosovarische Diaspora in der Schweiz. Bern: Bundesamt für Migration.

Castles, Stephen \& Godula Kosack (1973), Immigrant workers and class structure in Western Europe. London: Oxford University Press.

Cattacin, Sandro \& Bülent Kaya (2005), 'Le développement des mesures d'intégration de la population migrante sur le plan local en Suisse', in Hans Mahnig et al. (eds), Histoire de la politique de migration, d'asile et d'intégration en Suisse depuis 1948. Zurich: Seismo. Courbage, Youssef and Emmanuel Todd (2007). Le rendez-vous des civilisations. Paris: Le Seuil.

Déchaux, Jean-Hugues (2007), Sociologie de la famille. Paris: La Découverte.

Efionayi, Denise, Josef Martin Niederberger \& Philippe Wanner (2005), 'Switzerland faces common European challenges'. Washington, DC: Migration Information Source, Migration Policy Institute. See. <http://www.migrationinformation.org/Profiles/display.cfm?ID=284>.

Federal Office for Migration (2006), Rapport concernant les questions en suspens dans le domaine de la nationalité. Bern: Federal Office for Migration.

Fibbi, Rosita, Mathias Lerch \& Philippe Wanner (2007), 'Naturalisation and socio-economic characteristics of youth of immigrant descent in Switzerland', Journal of Ethnic and Migration Studies 33(7): 1121-1144.

Fibbi, Rosita, Mathias Lerch \& Philippe Wanner (2005), 'Processus de naturalisation et caractéristiques socio-économiques des jeunes issus de la migration', in OFS (ed.), L'intégration des populations issues de l'immigration en Suisse: Personnes naturalisés et deuxième génération, 57. Neuchâtel: Office fédéral de statistique.

Fibbi, Rosita et al. (2003), 'Second generation immigrants from Turkey in Switzerland', Zeitschrift für Türkeistudien, Journal for Studies on Turkey 16(1-2): 217-239.

Frauenfelder, Arnaud (2007), Les paradoxes de la naturalisation. Enquête auprès de jeunes issus de l'immigration. Paris: L'Harmattan.

Fux, Beat (2005), Evolution des formes de vie familiale. Neuchâtel: Office fédéral de la statistique.

Gomolla, Mechtild (2006), 'Tackling underachievement of learners from ethnic minorities: A comparison of recent policies of school improvement in Germany, England and Switzerland', Current Issues of Comparative Education 9(1): 46-59. New York: Teachers College, Columbia University.

Hammar, Thomas (1990), Democracy and the nation-state. Aliens, denizens and citizens in a world of international migration. Aldershot: Avebury Gower.

Haug, Werner, Martin Schuler \& Philippe Wanner (2002), La dynamique spatiale et structurelle de la population de la Suisse de 1990 à 2000. Neuchâtel: OFS.

Heiniger, Marcel, Enrico Moresi \& Fabienne Rausa (2004), La population étrangère en Suisse. Neuchâtel: Swiss Federal Statistical Office.

Held, Thomas \& René Levy (1975), Femme, famille et société, Enquête sociologique sur la femme en Suisse. Vevey: Delta.

Huddleston, Thomas \& Jan Niessen (2011), Migrant Integration Policy Index III. Brussels: British Council Migration Policy Group.

Karimova, Nigar \& Edward Deverell (2001), Minorities in Turkey, Occasional Papers, No. 19. Stockholm: Swedish Institute of International Affairs. 
Koç, İsmet (2007), 'The timing of leaving the parental home and its linkages to other life course events in Turkey', Marriage and Family Review 42(1): 29-47.

Lefèvre, Cécile \& Alexandra Filhon (2005), Histoires des familles, histoires familiales. INED.

Lischer, R. (2003), 'Integrierte Fremde? Eine statistische Antwort. Ausländische Kinder und Jugendliche im schweizerischen Bildungssystem', in EDK/CDIP (ed.) Schul- und Bildungslaufbahn von immigrierten «leistungsschwachen» Schülerinnen und Schülern. Bern.

Mahnig, Hans \& Andreas Wimmer (2003), 'Integration without immigrant policy: The case of Switzerland', in Friedrich Heckmann \& Dominique Schnapper (eds), The Integration of Immigrants in Europe Societies, 135-165. CITY: Lucius.

Mahnig, Hans et al. (eds)(2005), Histoire de la politique de migration, d'asile et d'intégration en Suisse depuis 1948. Zurich: Seismo.

Maillard, Alain \& Ueli Leuenberger (1999), Les damnés du troisième cercle: Les Albanais de la Kosove en Suisse 1965-1999. Genève: Les éditions Métropolis. Meier, Christoph (2009), 'Lokale und nationale Integrationspolitiken. Zürich im Spiegel von 1o Jahren schweizerischen Integrationspolitik', Stadtblick 20: 14-15.

Mikic, Dejan (2009), 'Serbische Migration in die Schweiz: Einige Aspekte', Migration 2: 12-15.

Mikic, Dejan \& Erika Sommer (2003), 'Als Serbe warst du plötzlich nichts mehr wert': Serben und Serbinnen in der Schweiz. Zürich: O. Füssli.

Niederberger, Josef Martin (2004), Ausgrenzen, Assimilieren, Integrieren: die Entwicklung einer schweizerischen Integrationspolitik. Zürich: Seismo.

ODM (2009), Rapport sur la migration 2008. Berne: Office fédéral des migrations.

Piguet, Etienne (2009), L'immigration en Suisse. 60 ans d'entreouverture. Lausanne: PPUR.

Piñeiro, Esteban, Isabelle Bopp \& Georg Kreis (2009), Fördern und Fordern im Fokus. Zürich: Seismo.

Prodolliet, Simone (2006), "Nachholende Integrationspolitik" - eine Herausforderung für die gesellschafltchen Institutionen', Schweizerische Zeitschrift für Asylrecht und -praxis 21(3):1-7.

SFSO, Census 2000, Neuchâtel.

Stadt Zürich (2008). See http://www.stadt-zuerich.ch/prd/de/index/statistik/bevoelkerung/ bevoelkerungsstand.html. Accessed 28.01.2010.

Statistik Basel-Stadt (2008). See http://www.statistik.bs.ch/themen/o1. Accessed 28.01.2010.

Statistik Basel-Stadt (2009). See http://www.statistik.bs.ch/themen/o3/arbeitslose_0911. Accessed 28.01.2010.

Suarez-Orozco, Carola \& Marcelo Suarez-Orozco (1995), Transformations: Immigration, family life, and achievement motivation among Latino adolescents. Stanford: Stanford University Press. Wanner, Philippe (2004), Migration et intégration. Neuchâtel: Office fédéral de la Statistique.

Wanner, Philippe \& Etienne Piguet (2002), 'La pratique de la naturalisation en Suisse: Un aperçu statistique', Population 57(6): 913-922.

Wicker, Hans Rudolph (2003). 'Introduction', in Hans Rudolph Wicker, Rosita Fibbi \& Werner Haug (eds), Les migrations et la Suisse. Résultats du PNR 'Migrations et relations interculturelles', Zürich: Seismo.

Wicker, Hans Rudolph (2009), 'Die neue schweizerische Integrationspolitik', in Esteban Piñeiro, Isabelle Bopp \& Georg Kreis (eds), Fördern und Fordern im Fokus, 23-47. Zürich: Seismo. 


\section{Socio-demographic characteristics of the parents}

Many social scientists researching the second generation single out the socio-economic characteristics of the parents as one of the crucial variables influencing future patterns of their children's integration (Bankston \& Zhou 1994; Crul \& Doomernik 2003; Fibbi \& Wanner 2009; Stepick \& Stepick 2003). This chapter therefore examines the cultural, social and financial capital of the parents of TIES survey respondents. As Bourdieu (1994) pointed out, these three main forms of capital are intimately connected and can easily be transmuted from one form to another. Moreover, material possessions, money (financial capital), education, class distinctions (cultural capital), and social networks (social capital) can all be transmitted from one generation to another and thus intimately affect the integration processes of all children into a given society (Bommes 2005). Migration processes, however, interfere with the valorisation of these types of capital and may disrupt their transmission while at the same time opening the way for new opportunities and pitfalls (Esser 2001; Waters et al. 2004).

We begin with a discussion of parental background, examining the region of origin where parents grew up, the language(s) they spoke, the religion they practised and the type of socialisation (urban vs. rural) they were exposed to in childhood. In order to discuss the levels of cultural capital among the parents of our respondents, we examine their educational background and achievements before looking at the reasons for and timing of migration and naturalisation patterns. We also address the basic structures of the families that the parents established - inter-ethnic mixing, divorce rates and household size. To assess the levels of financial capital on which the children of immigrants can rely, we look at the parents' labour-market participation and work status. In the concluding section, we sketch out the background of our second-generation respondents by summarising the socio-cultural characteristics of their parents.

\subsection{Immigrant parents' background}

National categories are dominant in any analysis of migration flows and immigrant integration; however, it is worth going beyond the uniformity created by the national label and examining internal socio-cultural 
heterogeneity. Region of origin, language(s) spoken and religious affiliation are all crucial markers of ethnicity. We observe whether, among Turkish and SSYU parents, the boundaries of region, language and religion overlap, enabling a construction of bright boundaries among different ethnic groups; alternatively, if they do not overlap, whether firm inter-ethnic boundaries might be blurred by cross-cutting commonalities in the variables used (Alba 2005).

\subsubsection{Regional background}

Around 5 per cent of Turkish and 3 per cent of SSYU fathers grew up in Switzerland, compared to 9 per cent for Turkish and 8 per cent for SSYU mothers. There are two reasons for this: first, the earlier waves of guest-worker immigrants from Turkey and the Social Federal Republic of Yugoslavia (SFRY) were predominantly male, some of whom married Swiss women; second, the immigration of these groups to Switzerland has a relatively long history, so that some respondents' parents are already second generation.

In the case of Turkish parents, around 30 per cent grew up in the highly developed and industrialised Marmara region, which has received a large share of Turkish internal migrants since the 1950s (Gedik 1997). Two-thirds of them actually grew up in Istanbul Province, for which reason we single it out for more detailed analysis.

One in six Turkish parents came from the Aegean region and a similar share from East Anatolia, while a slightly smaller number came from Central Anatolia (Table 3.1). However, there are important interregional differences in terms of socio-economic development. The Aegean region displays similar characteristics to Marmara in terms of industrial development; together with Marmara and the Mediterranean regions, it has been the main destination of internal migration from the East due to better employment opportunities in the former and political instability in the latter. By contrast, Central and Eastern Anatolia are the two least-developed regions and the source of much internal migration towards the West (Munro 1974). This mobility is largely rural to urban: between 1965 and 1970 population growth in Turkey was 2.5 per cent while the urbanisation rate was 6.03 per cent (Filiztekin \& Gökahn 2007).

About 20 per cent of fathers and 17 per cent of mothers of Turkish origin reported coming from Istanbul Province. This is understandable given Istanbul's historic role as a destination for diverse migrant populations. Until the 1950s, the heterogeneity of its population was thought to derive from its religious and confessional diversity. 'After the 1950s, when Istanbul began 
Table 3.1 Region in Turkey of parents' upbringing until the age of 15

\begin{tabular}{|c|c|c|c|c|c|c|c|c|}
\hline & \multicolumn{4}{|c|}{ Father } & \multicolumn{4}{|c|}{ Mother } \\
\hline & $<1970$ & $1970 \mathrm{~s}$ & $>1979$ & Total & $<1970$ & $1970 \mathrm{~s}$ & $>1979$ & Total \\
\hline TR Marmara & 41.8 & 33.3 & 15.0 & 28.5 & 64.7 & 29.4 & 20.0 & 27.9 \\
\hline Of which Istanbul: & 24.6 & 22.4 & 11.5 & 19.6 & 41.2 & 17.5 & 13.4 & 16.5 \\
\hline TR Aegean & 14.5 & 22.0 & 15.0 & 17.6 & 11.8 & 13.5 & 17.9 & 15.7 \\
\hline TR Central Anatolia & 12.7 & 12.1 & 20.4 & 15.1 & 5.9 & 15.1 & 13.8 & 13.6 \\
\hline TR Mediterranean & 7.3 & 6.4 & 10.6 & 8.7 & 5.9 & 5.6 & 14.5 & 10.4 \\
\hline TR Black Sea & 10.9 & 14.2 & 17.7 & 12.4 & 5.9 & 20.6 & 15.9 & 14.1 \\
\hline TR South-East Anatolia & 0.0 & 2.1 & 2.7 & 2.5 & 0.0 & 0.0 & 2.1 & 1.8 \\
\hline TR East Anatolia & 12.7 & 9.9 & 18.6 & 15.3 & 5.9 & 15.9 & 15.9 & 16.4 \\
\hline $\mathrm{N}=$ & $56^{*}$ & $147^{*}$ & $108^{*}$ & $405^{* *}$ & $17^{*}$ & $130^{*}$ & $140^{*}$ & $383^{* *}$ \\
\hline
\end{tabular}

* Data for cases where we know the year of parent's immigration

** Among Turkish people who grew up in Turkey

Father (decade of immigration) $X^{2}=24.701 \quad \mathrm{p}=.016$

Mother (decade of immigration) $X^{2}=25.799 \quad \mathrm{p}=.011$

to rapidly gain population, the composition and diversity of its population started to change radically' (Erder 1999). On the one hand, the forced and voluntary emigration of the non-Muslim population and, on the other, the vast wave of immigration from Anatolia, rendered Istanbul's population qualitatively different. From the 1980s, when Turkey experienced economic restructuring, Istanbul's involvement in the capitalist world economy has intensified. This brought even more migrants from rural Turkey and its neighbouring countries to Istanbul, today a multicultural global city. The Istanbul metropolitan area had nearly 1.2 million inhabitants in 1950; this figure reached 4.7 million in 1980 and 10 million in 2000 (Geymen \& Baz 2007). In our sample, however, those parents (and especially mothers) who came to Switzerland in later waves usually did not come from Istanbul (or the Marmara region), but from other Turkish provinces in the east of the country.

Among those who grew up in Yugoslavia, most of the parents were born in Croatia, Serbia and Bosnia (Table 3.2). Among the population in 1971, Croatia appears to be under-represented, Serbia proportionally represented and Bosnia, Macedonia and Kosovo over-represented (Statistisches Bundesamt, cited in Džambo \& Haberl 1982). This can be explained by internal differences in emigration rates between regions of the SFRY (Baučić 1973) and by the preference of certain groups (Albanians from Kosovo and Macedonians) for Switzerland as a destination country, in comparison to other German-speaking countries which are the most frequent destinations for SFRY migrants. 
Table 3.2 Region of upbringing of SSYU parents until the age of 15

\begin{tabular}{|c|c|c|c|c|c|c|c|c|}
\hline & \multicolumn{4}{|c|}{ Father } & \multicolumn{4}{|c|}{ Mother } \\
\hline & $<1970$ & 1970s & $>1980$ & Total & $<1970$ & 1970s & $>1980$ & Total \\
\hline Bosnia & 17.8 & 27.6 & 24.7 & 25.0 & 20.8 & 27.7 & 23.5 & 24.7 \\
\hline Kosovo & 8.9 & 14.2 & 21.6 & 15.9 & 4.2 & 4.3 & 26.2 & 16.5 \\
\hline Croatia & 31.1 & 14.9 & 17.5 & 18.5 & 33.3 & 23.4 & 12.8 & 18.4 \\
\hline Macedonia & 8.9 & 11.2 & 12.4 & 11.2 & 4.2 & 9.6 & 16.1 & 12.7 \\
\hline Montenegro & 2.2 & 3.0 & 0.0 & 1.8 & 0.0 & 1.1 & 0.7 & 0.7 \\
\hline Serbia & 28.9 & 26.9 & 23.7 & 26.1 & 29.2 & 33.0 & 20.1 & 25.5 \\
\hline Slovenia & 2.2 & 2.2 & 0.0 & 1.4 & 8.3 & 1.1 & 0.7 & 1.5 \\
\hline $\mathrm{N}^{*}=$ & 40 & 134 & 108 & 282 & 21 & 88 & 162 & 271 \\
\hline $\begin{array}{ll}\text { Father } & \text { (dec } \\
\text { Mother } & \text { (de }\end{array}$ & $\begin{array}{l}\text { le of } \mathrm{imm} \\
\text { de of } \mathrm{imm}\end{array}$ & gration) & $\begin{array}{l}X^{2}=15 \\
X^{2}=45\end{array}$ & $\begin{array}{l}98 \\
12\end{array}$ & .215 & & & \\
\hline
\end{tabular}

Analysis of the regional origin of SFRY parents according to the decade in which they migrated to Switzerland reveals an interesting shift. While the relative percentage of parents from Croatia and Serbia decreases with time, that of parents from Bosnia, Kosovo and Macedonia increases. In the case of the last two countries, this increase is particularly significant for mothers, reflecting the changing ethnic and gender structure of the guest-worker population over time.

A further significant dimension of parental background is the type of social environment the parents were exposed to as children. The majority of Turkish parents came from an urban background similar to that of the comparison-group parents. Around 6o per cent of Turkish parents who spent their childhood in the Marmara region were brought up in a city - most probably Istanbul; around three-quarters of the parents from East Anatolia spent their youth in a village. The parents of SSYU-origin respondents in our sample mostly spent their childhood in villages, and only a minority lived in a town or city. Thus, in contrast to the parents of Turkish respondents, SSYU parents more often immigrated to Switzerland from rural areas of the country. Only parents who spent their youth in Serbia reported a significantly higher percentage of people living in a city - most of them in Belgrade. Parents from Bosnia, Kosovo and Croatia reported growing up mainly in a village. Over time, the dominance of an urban socialisation environment is a constant for Turkish fathers, while the importance of the rural environment appears to increase for SFRY emigrants. 


\subsubsection{Linguistic background}

Another way of approaching the issue of family background is to examine the childhood language(s) of the parents of TIES respondents, a feature somewhat independent of regional origin. Both immigrant groups in our study are characterised by internal language differences. Parents of Turkishorigin respondents mostly spoke Turkish or Kurdish in their childhood. Given that Turkish was the official language, we expect to find a significant number of people whose native language is Kurdish also speaking Turkish.

Among Turkish-origin respondents, one father in six grew up speaking Kurdish; Table 3.3 shows that the percentage increased over time. Among fathers who came before the 1970s, Kurdish-speakers represented about 5 per cent and all grew up speaking Turkish; this rises to 24 per cent (around 5 per cent of whom spoke only Kurdish) among Turkish fathers who came in the 1980s. This reflects the second phase of Turkish immigration to Switzerland, with its inflow of refugees and asylum-seekers (see Chapter 2). Most Kurdish-speaking fathers settled in Basel, with only a small minority deciding to settle in Zurich.

Table 3.3 Turkish fathers' childhood language, by year of immigration and agglomeration

\begin{tabular}{lccrrrr}
\hline & \multicolumn{7}{c}{ TR } \\
\cline { 2 - 7 } & <1970s & 1970s & 1980s & Zurich & Basel & Total \\
\hline Turkish & 91.9 & 89.3 & 71.6 & 89.4 & 75.4 & 81.5 \\
Kurdish & 0.0 & 1.3 & 4.7 & 0.5 & 4.8 & 3.1 \\
Turkish-Kurdish & 4.8 & 8.9 & 18.9 & 5.8 & 17.7 & 12.3 \\
Other & 3.2 & 0.6 & 4.7 & 4.4 & 2.0 & 3.1 \\
$\mathrm{~N}=$ & $63^{*}$ & $162^{*}$ & $121^{*}$ & 206 & 248 & 454 \\
\hline
\end{tabular}

${ }^{*}$ Calculated for cases where the year of immigration is available.

TR (Zurich vs. Basel) $\quad X^{2}=27.334 \quad \mathrm{p}=.000$

TR $(<1970 s, 1970 s, 1980 s) \quad X^{2}=23.793 \quad p=.002$

Interestingly, Kurdish-speaking parents came from provinces in the Mediterranean region (mostly from Kahramanmaraş Province), East and South-East Anatolia (Erzincan and Tunceli Provinces), and the Marmara region (mostly from Istanbul Province) (Table 3.4). These data reflect the important internal migrations that took place during the 1960 s and 1970 s which brought many rural peasants from Eastern Turkey to its Western industrialising regions (Gedik 1996). As a consequence of this stepwise 
migration and the subsequent changes in the capital city and the Marmara area more generally, the regional origin of the TIES respondents only partially reflects their ethnic/linguistic background.

Table 3.4 Fathers' childhood language(s) by province of upbringing and gender

\begin{tabular}{lccccc}
\hline & Turkish & Kurdish & Turkish-Kurdish & Other & N = \\
\hline TR Marmara & 93.8 & 0.9 & 5.3 & 0.0 & 114 \\
TR Aegean & 98.6 & 0.0 & 1.4 & 0.0 & 73 \\
TR Central Anatolia & 88.3 & 1.7 & 8.3 & 1.7 & 60 \\
TR Mediterranean & 40.0 & 20.0 & 40.0 & 0.0 & 36 \\
TR Black Sea & 96.1 & 2.0 & 2.0 & 0.0 & 50 \\
TR South-East Anatolia & 40.0 & 10.0 & 50.0 & 0.0 & 10 \\
TR East Anatolia & 63.5 & 3.2 & 30.2 & 3.2 & 62 \\
\hline Total & 80.2 & 3.2 & 12.6 & 0.7 & 405 \\
\hline Istanbul & 91.1 & 1.3 & 7.6 & 0.0 & $80^{*}$ \\
\hline
\end{tabular}

*Out of Turkish parents who grew up in Istanbul Province

TR (Turkish vs. Kurdish) region level $\quad X^{2}=105.242 \quad p=.000$

TR (Turkish vs. Kurdish) province level $\quad X^{2}=156.970 \quad p=.000$

Let us now consider the linguistic landscape of the country from where today's SSYU citizens come. The Socialist Federal Republic of Yugoslavia was a multiethnic state, with Serbo-Croatian - as its name implies a purposeful combination of Serbian and Croatian - as its administrative language. Other languages such as Slovenian, Macedonian, Albanian or Hungarian were also officially recognised as minority languages. Thus, many parents grew up speaking both the official language and the language of their ethnic group. Furthermore, with the possible exception of ethnically homogeneous Slovenia, in Yugoslavia the different linguistic groups were not spatially isolated; intimate contact between them offered opportunities for the parents of our respondents to learn the language of another group. Last but not least, a strong emphasis on the non-ethnic Socialist identity of the Yugoslav people, propagated by the regime of President Tito, enabled more ethnic mixing, which influenced the languages to which those growing up in the SFRY in the 1950s and 1960s were exposed. Therefore we expect SFRY parents to display an even greater heterogeneity of childhood languages than Turkish parents.

While around two-thirds of SSYU parents grew up speaking SerboCroatian (i.e. Croatian, Serbian, Bosnian and Yugoslavian), just under a third spoke more than one childhood language (Table 3.5). This high percentage confirms the high levels of linguistic diversity and mixing in the SFRY, 
as described above. In terms of spatial distribution in Switzerland, one interesting feature is that people who were brought up speaking several languages settled in Zurich more often than in Basel.

Table 3.5 SSYU fathers' childhood language(s), by year of immigration and agglomeration

\begin{tabular}{lcrrrrr}
\hline & \multicolumn{7}{c}{ SSYU } \\
\cline { 2 - 7 } & \multicolumn{1}{c}{ 1970s } & 1970s & 1980s & Zurich & Basel & Total \\
\hline Albanian & 4.1 & 7.4 & 12.9 & 7.6 & 6.8 & 7.5 \\
Serbo-Croatian & 59.2 & 55.7 & 51.6 & 51.3 & 64.6 & 57.4 \\
Macedonian & 4.1 & 3.4 & 3.2 & 2.5 & 3.6 & 11.8 \\
Other & 4.0 & 3.3 & 2.1 & 2.5 & 6.3 & 4.3 \\
Mixed & 30.0 & 31.1 & 31.6 & 36.0 & 18.8 & 28.1 \\
$\mathrm{~N}=$ & $44^{*}$ & $149^{*}$ & $106^{*}$ & 239 & 192 & 431 \\
\hline
\end{tabular}

*Based on a total of 299 SSYU respondents (118 missing for fathers' age at migration) SSYU (Zurich vs. Basel) $\quad X^{2}=20.052 \quad \mathrm{p}=.003$

Looking at the distribution of languages across different regions of what has been known, since the 1990s, as the SSYU, we note that most of the republics that composed the SFRY were themselves multilingual. Thus, in Kosovo, we find people speaking Serbian and Albanian; both of these languages are also spoken in Macedonia, alongside Macedonian. In Bosnia, the label Serbo-Croatian hides the linguistic differences between Croatian and Serbian - differences that, despite being muted in the SFRY, never really disappeared. Moreover, in most republics (Croatia and Montenegro being the exceptions), a large percentage of people reported that their parents grew up speaking more than one language.

Fathers of second-generation TIES respondents display a great heterogeneity of languages and frequently a bilingual background (Table 3.6). Analysis of parental language distribution according to the decade in which the parents immigrated to Switzerland allowed us to map the shift towards the linguistically ever-more-diverse populations included in the recruitment of Turkish and SSYU immigrants to Switzerland.

\subsubsection{Family's religious background}

In order to continue the analysis of parents' background, we now examine data on the religious education of our TIES survey respondents as a proxy for their parents' religious affiliation. As expected, a majority of Turkish 
Table 3.6 SSYU fathers' childhood language(s) by region of upbringing

\begin{tabular}{|c|c|c|c|c|c|c|c|}
\hline & Albanian & $\begin{array}{l}\text { Serbo- } \\
\text { Croatian }\end{array}$ & Macedonian & Slovenian & Other & Mixed & $\mathbf{N}=$ \\
\hline Switzerland & 0.0 & 38.5 & 7.7 & 0.0 & 38.5 & 15.4 & 12 \\
\hline Bosnia & 0.0 & 75.6 & 0.0 & 0.0 & 0.0 & 24.4 & 93 \\
\hline Yugoslavia & 5.1 & 66.7 & 2.6 & 2.6 & 2.6 & 20.5 & 35 \\
\hline Kosovo & 37.0 & 11.1 & 0.0 & 0.0 & 1.9 & 50.0 & 57 \\
\hline Croatia & 0.0 & 87.3 & 0.0 & 0.0 & 0.0 & 12.7 & 68 \\
\hline Macedonia & 21.1 & 2.6 & 26.3 & 0.0 & 0.0 & 50.0 & 41 \\
\hline Montenegro & 0.0 & 85.7 & 0.0 & 0.0 & 0.0 & 14.3 & 7 \\
\hline Serbia & 1.0 & 71.7 & 0.0 & 0.0 & 0.0 & 27.3 & 96 \\
\hline Slovenia & 0.0 & 11.1 & 0.0 & 55.6 & 0.0 & 33.3 & 8 \\
\hline Other & 0.0 & 33.3 & 0.0 & 0.0 & 33.3 & 33.3 & 3 \\
\hline Of total SSYU & 7.8 & 56.9 & 3.1 & 1.2 & 2.4 & 28.7 & 422 \\
\hline
\end{tabular}

parents are Muslim; however, a considerable 26 per cent display no intimate affiliation to any religion. The figure for Kurdish-speaking parents is twice as high - as Table 3.7 shows, they are either non-religious or Alevi - while Turkish parents predominantly practise the Sunni faith. Thus, for the Turkish and Kurdish parents in our sample, the boundaries of language and religion tend to be aligned.

Table 3.7 Religious affiliation of the family by the Turkish-origin father's childhood language(s)

\begin{tabular}{lrrrrrr}
\hline & $\begin{array}{c}\text { Christian } \\
\text { Muslim } \\
\text { Alevi }\end{array}$ & $\begin{array}{c}\text { Muslim } \\
\text { Sunni }\end{array}$ & Other & $\begin{array}{c}\text { No religious } \\
\text { affiliation }\end{array}$ & N \\
\hline Turkish & 1.4 & 11.4 & 64.6 & 0.5 & 22.1 & 370 \\
Kurdish & 0.0 & 42.9 & 0.0 & 0.0 & 57.1 & 14 \\
Turkish-Kurdish & 0.0 & 30.4 & 19.6 & 3.6 & 46.4 & 56 \\
Other & 50.0 & 7.1 & 28.6 & 0.0 & 14.3 & 14 \\
Total & 2.6 & 14.5 & 60.0 & 0.9 & 26.0 & 449 \\
\hline
\end{tabular}

On the other hand, with parents of SSYU-origin respondents, the boundaries of the different religious and linguistic groups do not coincide, and people speaking the same language are often found practising different religions and vice versa (see Table 3.8). Thus, Macedonian-speaking parents are most often Muslim or Orthodox, although just fewer than 10 per cent of them are practising Catholic/Protestants. Serbo-Croatian parents are practising Catholics, Orthodox or Muslims, as are those whose parents grew up 
speaking more than one language. Like Switzerland (Kriesi 1995), SFRY was then characterised by cross-cutting cleavages.

Table 3.8 Family's religion by father's childhood language(s)

\begin{tabular}{lccccr}
\hline & $\begin{array}{c}\text { Catholic } \text { I } \\
\text { Protestant }\end{array}$ & Orthodox & Muslim & $\begin{array}{c}\text { No religious } \\
\text { affiliation }\end{array}$ & N \\
\hline Albanian & 6.5 & 0.0 & 74.2 & 19.4 & 31 \\
Serbo-Croatian & 29.8 & 27.8 & 7.8 & 34.7 & 245 \\
Macedonian & 8.3 & 25.0 & 33.3 & 33.3 & 12 \\
Slovenian & 83.3 & 0.0 & 0.0 & 16.7 & 6 \\
Mixed & 23.3 & 20.0 & 37.5 & 19.2 & 120 \\
Total of SSYU & 26.3 & 22.9 & 22.0 & 28.7 & 414 \\
\hline
\end{tabular}

In terms of the spatial distribution of Turkish and SSYU parents in Switzerland, we note that people with no religious affiliation settled more often in Basel than Zurich (see § 6.3). While the share of Catholics and Orthodox is similar in the two agglomerations, SSYU Muslims settled more often in Zurich. Similarly, those Turkish parents practising the Alevi denomination moved to Basel, while those practising other Muslim faiths (mostly Sunni) settled more often in Zurich.

\subsection{Educational background of the parents}

We now come to the last key dimension of parental background: educational achievement. As this dimension is also relevant to comparison-group parents, they are included in our consideration.

Some knowledge of the main features of the educational situation in the country where our respondents' immigrant parents grew up gives us a better understanding of the data concerning them. Therefore, we first sketch out the educational systems of the two emigration countries and examine the statistics on educational attainment during the period when the parents of TIES respondents were emigrating. We then turn our attention to the educational background of the parents before discussing their proficiency in the Swiss-German language. 


\subsubsection{Educational situation in Turkey and Yugoslavia in the seventies}

Until August 1997 the formal education system in Turkey consisted of primary, middle and high school, followed by university. Primary school lasted for five years and was compulsory for all Turkish children. In August 1997 the five years of compulsory primary education was extended to eight years, to include three years of middle school (Tansel 2004). Thus, for about 90 per cent of Turkish parents in our sample who received their highest level of education in Turkey, only five years of primary school were compulsory.

Table 3.9 presents the educational attainment of the Turkish population in the period 1970-2000 and shows that just under 6o per cent of women and a third of men were still illiterate in 1970. In the same year, only a quarter of women and about 45 per cent of men earned a primary school diploma or higher. While these figures improved significantly throughout the 1970s, just under 50 per cent of women and 20 per cent of men were still illiterate ten years later (Tunali 1996).

Table 3.9 Educational status of the Turkish population aged six years and over, 19702000

\begin{tabular}{lcccccc}
\hline & \multicolumn{3}{c}{ WOMEN } & \multicolumn{3}{c}{ MEN } \\
\cline { 2 - 7 } & $\mathbf{1 9 7 0}$ & $\mathbf{1 9 7 5}$ & $\mathbf{1 9 8 0}$ & $\mathbf{1 9 7 0}$ & $\mathbf{1 9 7 5}$ & $\mathbf{1 9 8 0}$ \\
\hline Illiterate & 58.2 & 49.5 & 45.3 & 29.7 & 23.8 & 20.0 \\
$\begin{array}{l}\text { Literate w/o } \\
\text { diploma }\end{array}$ & 16.6 & 15.5 & 14.7 & 24.5 & 20.8 & 18.4 \\
$\begin{array}{l}\text { Primary school } \\
\text { only }\end{array}$ & 20.7 & 29.1 & 31.4 & 36.1 & 42.9 & 44.2 \\
$\begin{array}{l}\text { Secondary school } \\
\text { High school }\end{array}$ & 2.2 & 3.1 & 3.7 & 4.9 & 6.3 & 7.6 \\
\hline Higher education & 1.8 & 2.4 & 3.7 & 3.4 & 4.7 & 6.4 \\
\hline
\end{tabular}

Source: TR State Institute of Statistics, cited by Kaya Çabuk (2007)

In the Socialist Federal Republic of Yugoslavia the formal education system consisted of eight years of compulsory primary education, followed either by two to four years of technical education, or four years of gymnasium, leading to higher education. A diploma from a four-year technical school or gymnasium guaranteed a place on a higher-school programme (2-4 years) followed by university studies at BA, MA or PhD level.

The eight years of obligatory schooling was officially introduced in 1929. However, it was not really enforced on a wider scale; hence school 
attendance (especially in the southern republics) remained quite low until the 196os, when compulsory schooling was progressively extended to all the republics. Its implementation - in terms of school materials, classrooms and teachers - varied so much between the republics composing the SFRY that it can hardly be regarded as unitary. Thus, by the end of War World II, the northern member-states had eight years of compulsory schooling, whereas the southern and central member-states only had four (Haberl \& Bach 1977). Illiteracy, again very unevenly distributed, concerned 12 per cent of the population - reaching 18 per cent among women in 1971 (Džambo \& Haberl 1982).

\subsubsection{The educational capital of parents}

We now analyse the educational attainment of the parents of the TIES survey respondents (Table 3.10). The modal value for the highest level of education for first-generation immigrants is primary school for Turks, both men and women: about 34 and 41 per cent, respectively, only had primary education, while 2 per cent of fathers and 6 per cent of mothers had no formal education at all and were illiterate.

The parents of SSYU respondents present a significantly higher level of education: the modal value for men is upper-secondary education and lower- secondary for women, while 0.2 per cent of fathers and 1.4 per cent of mothers were illiterate. Immigrant illiteracy and educational levels prove to be better on average than those observed among non-migrants in the home countries of origin in 1970; in other words, migrants represent a positive selection in comparison to the native population in Turkey and Yugoslavia.

The modal value for comparison-group parents is also upper-secondary education - as for SSYU parents - but the share of parents having tertiary education is about a third for fathers, significantly higher than for the two immigrant groups. All in all, parental educational levels appear to reflect the development of the education system in their respective countries of origin.

If we consider differences within each origin group (Table 3.10), we see that Turkish-speaking fathers have, on average, a significantly higher educational level than Kurdish-speaking fathers, a majority of whom only attended primary school; 12 per cent of Turkish parents reached tertiary education compared to only 6 per cent of Kurdish parents.

Among parents of SSYU respondents, those speaking Albanian are significantly less educated than those speaking other languages; 15 per cent have only primary education, compared to 4-6 per cent for the other language groups of the SFRY. Overall, it appears that parents growing up 
Table 3.10 Fathers' and mothers' highest education level, by origin group

\begin{tabular}{lrrrrrc}
\hline & \multicolumn{3}{c}{ Father } & \multicolumn{5}{c}{ Mother } \\
\cline { 2 - 7 } & TR & SSYU & CG & TR & SSYU & CG \\
\hline No education & 2.2 & 0.3 & - & 6.1 & 0.8 & - \\
ISCED 1 & 33.9 & 4.9 & - & 41.4 & 8.8 & - \\
ISCED 2 & 23.1 & 37.5 & 4.0 & 23.7 & 44.2 & 9.6 \\
ISCED 3 & 28.7 & 44.5 & 59.0 & 22.8 & 37.0 & 81.0 \\
ISCED 5 & 11.3 & 12.1 & 35.4 & 5.6 & 8.5 & 9.4 \\
Other & 0.7 & 0.8 & 1.6 & 0.5 & 0.8 & - \\
N $=$ & 410 & 371 & 430 & 414 & 386 & 425 \\
\hline TR-CG & (father) $X^{2}=308.386 \mathrm{p}=.000$ & (mother) & $X^{2}=370.158 \mathrm{p}=.000$ & \\
SSYU-CG & (father) $\mathrm{X}^{2}=189.444 \mathrm{p}=.000$ & (mother) & $X^{2}=203.185 \mathrm{p}=.000$ & \\
TR-SSYU & (father) $\mathrm{X}^{2}=114.159 \mathrm{p}=.000$ & (mother) & $\mathrm{X}^{2}=140.072 \mathrm{p}=.000$ &
\end{tabular}

Table 3.11 Father's education level by country of origin and childhood language(s)

\begin{tabular}{lcccccc}
\hline \multicolumn{3}{c}{ TURKEY } & \multicolumn{5}{c}{ SSYU } \\
\hline Language & Turkish & Kurdish & Albanian & $\begin{array}{c}\text { Serbo- } \\
\text { Croatian }\end{array}$ & Macedonian & Mixed \\
\hline No education & 2.7 & 1.6 & - & - & - & 0.9 \\
ISCED 1 & 30.4 & 54.7 & 15.4 & 3.7 & - & 5.6 \\
ISCED 2 & 24.4 & 17.2 & 53.8 & 35.6 & 50.0 & 36.4 \\
ISCED 3 & 29.9 & 20.3 & 23.1 & 48.6 & 50.0 & 41.1 \\
ISCED 5 & 12.4 & 6.3 & 7.7 & 12.0 & - & 15.9 \\
N = & 336 & 64 & 29 & 211 & 8 & 108 \\
\hline
\end{tabular}

TR (Turkish vs. Kurdish) $\quad X^{2}=14.911 \quad p=.011$

All other differences are not statistically significant.

bilingual and the Serbo-Croatian-speaking parents of SSYU-origin respondents show the highest levels of educational achievement.

The educational background of immigrant parents changed along with regional shifts in recruitment area, as mentioned earlier (Table 3.12). The share of Turkish fathers holding tertiary education grew between the $1960 \mathrm{~s}$ and the 1980s; on the other hand, parents of SSYU respondents, who came in the 1970s, were significantly less educated than those who came before or after them.

The difference between agglomerations is significant only for Turkish parents, as Zurich hosts better-qualified parents, with a higher percentage of upper-secondary and tertiary-level graduates. 
Table 3.12 Change in the composition of migrants: father's highest education level by year of immigration and origin group

\begin{tabular}{lcccccc}
\hline & \multicolumn{3}{c}{ TR } & \multicolumn{3}{c}{ SSYU } \\
\cline { 2 - 7 } & $<1970$ s & 1970s & 1980s & $<1970$ s & 1970s & 1980s \\
\hline Less than compulsory education & 44.6 & 34.0 & 38.7 & 2.2 & 8.9 & 4.5 \\
Compulsory education & 21.4 & 27.7 & 17.9 & 34.8 & 48.4 & 31.8 \\
Higher than compulsory education & 33.9 & 38.3 & 43.4 & 63.0 & 42.7 & 63.6 \\
$\mathrm{~N}=$ & 58 & 146 & 102 & 41 & 125 & 98 \\
\hline
\end{tabular}

TR (<1970s, 1970s, 1980s) n.s.

SSYU (<1970s, 1970s, 1980s) $\quad X^{2}=12.104 \quad p=.017$

\subsubsection{Parental local-language proficiency}

Another important characteristic of parents' cultural assets, which closely interacts with educational levels and personal assertiveness in the receiving society, is their knowledge of the Swiss-German language. To assess this, we examined their children's perception of how well their parents speak the local language (Table 3.13).

Table 3.13 Children's perception of parents' command of spoken Swiss-German

\begin{tabular}{lrrrr}
\hline & \multicolumn{2}{c}{ TR } & \multicolumn{2}{c}{ SSYU } \\
\cline { 2 - 5 } & Father & Mother & Father & Mother \\
\hline Good knowledge & 51.2 & 43.3 & 65.4 & 63.7 \\
Reasonable knowledge & 45.0 & 50.4 & 30.6 & 33.1 \\
Very little knowledge & 3.6 & 6.0 & 2.1 & 2.5 \\
Don't know & 0.2 & 0.2 & 1.9 & 0.7 \\
N = & 449 & & 431 & \\
\hline
\end{tabular}

TR-SSYU (father) $X^{2}=26.999 \quad \mathrm{p}=.000 \quad$ (mother) $\quad \mathrm{X}^{2}=40.073 \quad \mathrm{p}=.000$

As we can see, two-thirds of SSYU children think their parents have a good knowledge of Swiss-German, with no significant difference between mothers and fathers; this compares positively with just 50 per cent for Turkish parents, with mothers perceived to lag behind fathers in their knowledge of the local language. A similar trend was observed in relation to the educational attainment of the parents - there is a much greater gender imbalance in the educational profiles of Turkish parents than among SSYU parents. 
The guest-workers who immigrated to Europe between 1960 and 1990 displayed generally low educational capital, mirrored in the educational profile of the parents of our TIES respondents. Migrants represent a positive selection in relation to the native population of their country of origin; nevertheless, they also reflect the level of development of the educational system in the country they came from. Even if from urban regions, Turkish parents have, on average, low levels of education and are frequently illiterate in their native language; hence only half are proficient in the spoken local language of the host society. Parents of the respondents of SSYU descent show higher levels of education. Both groups display a degree of internal heterogeneity in terms of educational attainment. Thus, among parents from Turkey, Kurdish-speaking parents are significantly less educated than those who speak Turkish; Albanian-speaking parents are significantly less educated than the rest of the SSYU group.

\subsection{Parental migration history and current work situation}

In this sub-section we sketch the family migration history of TIES respondents by exploring two milestones - parents' date of arrival and parents acquisition of Swiss citizenship - before outlining their fathers' and mothers' current work situation.

\subsubsection{Timing and reason for immigration}

Most parents of TIES second generation respondents were born in the 1950s, while comparison-group parents are slightly older on average, which explains the significant imbalance in age structure between second-generation respondents and the comparison group (see Chapter 2). SSYU parents are significantly older than Turkish parents, with fathers significantly older than mothers. This trend is especially clear among Turkish parents, where fathers are, on average, 4.3 years older than mothers (3.4 years for SSYU parents and 2.7 for parents in the comparison group).

Most parents arrived while still quite young. About half the mothers and almost two-thirds of the fathers were in their 20 s, while another 25 per cent of fathers and 40 per cent of mothers were in their teens. Parents of Turkish-origin respondents were significantly younger than those of SSYU respondents at the time of their migration.

Turkish immigrants were first singled out in Swiss immigration statistics in 1965 . Table 3.14 shows that roughly 20 per cent of TIES-respondent parents 
from Turkey and SFRY arrived during this initial phase of immigration. The median period of immigration for fathers (coming mostly for employment) is exactly that of the first oil crises (1973 and 1979), which produced substantial outflows of foreigners from Switzerland (Mahnig 2005). In other terms, those parents belong to the very first flow of immigrants from Turkey and Yugoslavia and not to the more consistent successive ones which took place in the 1980 ond 1990 s and gave a SSYU immigration (and to a lesser extent Turkish immigration) its present prominence among the foreign population in Switzerland.

Table 3.14 Parents' year of migration

\begin{tabular}{lcccc}
\hline & \multicolumn{2}{c}{ Father } & \multicolumn{2}{c}{ Mother } \\
\cline { 2 - 5 } & TR & SSYU & TR & SSYU \\
\hline$<1970$ & 18.0 & 17.1 & 7.6 & 12.7 \\
$1970 \mathrm{~s}$ & 46.8 & 50.7 & 45.5 & 39.6 \\
$1980 \mathrm{~s}$ & 35.1 & 32.2 & 46.8 & 47.8 \\
& & & & \\
Mean & 1976.3 & 1976.4 & 1979.0 & 1979.1 \\
St. Dev & 7.6 & 7.2 & 6.6 & 8.1 \\
N = & 334 & 303 & 314 & 271 \\
\hline
\end{tabular}

TR-SSYU Mother $\quad X^{2}=11.892 \quad \mathrm{p}=.008$

In terms of spatial distribution within Switzerland, Table 3.15 shows that Turkish immigration to Zurich started significantly earlier than that to Basel, though Basel currently has a higher percentage of Turkish-origin people in its resident population - 1.1 vs. 0.7 per cent, according to Census 2000 (Fibbi \& Pecoraro 2003). However, parents from the SFRY initially settled more often in Basel, while Zurich gained in importance as the decades went by.

Some 40 per cent of fathers from the SFRY and almost half of those from Turkey were unemployed before their migration. This figure rises to 65 per cent for mothers from the SFRY and 80 per cent for those from Turkey. Table 3.16 shows this variable over time; the level of unemployment before migration of Turkish fathers remains more or less the same, whereas it drops significantly for fathers of SSYU respondents arriving in the 1980s. For SFRY mothers, unemployment before emigration remains roughly 60 per cent over the years, whereas it increases sharply for Turkish mothers during the $1970 \mathrm{~s}$ and 1980s. The type of migration observed in the TIES study is traditional labour migration, taking place during a major economic downturn. 
Table 3.15 Parents' year of immigration, by origin, gender and agglomeration

\begin{tabular}{|c|c|c|c|c|c|c|c|c|}
\hline & \multicolumn{4}{|c|}{ FATHER } & \multicolumn{4}{|c|}{ MOTHER } \\
\hline & \multicolumn{2}{|c|}{ TR } & \multicolumn{2}{|c|}{ SSYU } & \multicolumn{2}{|c|}{ TR } & \multicolumn{2}{|c|}{ SSYU } \\
\hline & Zurich & Basel & Zurich & Basel & Zurich & Basel & Zurich & Basel \\
\hline$<1970$ & 22.1 & 14.8 & 14.3 & 20.3 & 9.6 & 6.1 & 8.0 & 17.1 \\
\hline $1970 s$ & 55.2 & 40.7 & 52.8 & 48.6 & 50.4 & 41.9 & 38.4 & 41.1 \\
\hline $1980 \mathrm{~s}$ & 22.8 & 44.4 & 32.9 & 31.2 & 40.0 & 52.0 & 53.6 & 41.9 \\
\hline Mean & 1974.6 & 1977.7 & 1976.6 & 1976.1 & 1977.8 & 1979.8 & 1980.4 & 1977.6 \\
\hline St. Dev & 7.4 & 7.5 & 7.1 & 7.3 & 6.8 & 6.3 & 8.0 & 8.0 \\
\hline$N=$ & 145 & 189 & 163 & 140 & 136 & 178 & 139 & 132 \\
\hline \multicolumn{2}{|c|}{ TR (Zurich vs. Basel) } & Father & & & & $X^{2}=17.054$ & & \\
\hline \multicolumn{2}{|c|}{ TR (Zurich vs. Basel) } & \multicolumn{4}{|c|}{ mean of father's year of migration } & & $p=.000$ & \\
\hline \multicolumn{2}{|c|}{ TR (Zurich vs. Basel) } & \multicolumn{4}{|c|}{ mean of mother's year of migration } & & \multicolumn{2}{|l|}{$p=.007$} \\
\hline \multicolumn{2}{|c|}{ SSYU (Zurich vs. Basel) } & \multicolumn{4}{|c|}{ Mother } & $X^{2}=6.496$ & \multicolumn{2}{|l|}{$p=.039$} \\
\hline \multicolumn{2}{|c|}{ SSYU (Zurich vs. Basel) } & \multicolumn{4}{|c|}{ mean of mother's year of migration } & & \multicolumn{2}{|l|}{$p=.003$} \\
\hline
\end{tabular}

Table 3.16 Parental employment situation before migration by decade and group

\begin{tabular}{|c|c|c|c|c|c|c|c|c|c|}
\hline & & \multicolumn{4}{|c|}{ Father } & \multicolumn{4}{|c|}{ Mother } \\
\hline & & $<1970$ s & $1970 s$ & $\begin{array}{l}\text { After } \\
1979\end{array}$ & Total & $<1970$ s & 1970 s & $\begin{array}{c}\text { After } \\
1979\end{array}$ & Total \\
\hline \multirow[t]{4}{*}{ TR } & Employed & 51.7 & 47.7 & 48.8 & 48.8 & 41.7 & 11.9 & 14.7 & 15.5 \\
\hline & Unemployed & 41.7 & 45.8 & 46.4 & 45.3 & 50.0 & 82.5 & 81.4 & 79.6 \\
\hline & Don't know & 6.7 & 6.5 & 4.8 & 5.9 & 8.3 & 5.6 & 3.8 & 5.0 \\
\hline & $N=$ & 61 & 161 & 119 & 341 & 24 & 143 & 156 & 323 \\
\hline \multirow[t]{4}{*}{ SSYU } & Employed & 46.2 & 49.7 & 66.0 & 54.7 & 32.4 & 26.7 & 30.6 & 29.4 \\
\hline & Unemployed & 46.2 & 42.4 & 28.3 & 38.2 & 64.7 & 65.7 & 63.8 & 64.5 \\
\hline & Don't know & 7.7 & 7.9 & 5.7 & 7.1 & 2.9 & 7.6 & 5.6 & 6.0 \\
\hline & $N=$ & 46 & 150 & 117 & 313 & 34 & 105 & 160 & 299 \\
\hline
\end{tabular}

Thus, it is not surprising that gaining employment was the main reason for migration among Turkish and Yugoslavian fathers, while mothers (especially those from Turkey) more often came for family reasons (Table 3.17). Yet, family migration (marriage or reunification with the family or partner) is still significantly higher for fathers of Turkish descent (almost 30 per cent) compared to those of SSYU origin (13 per cent). A significantly higher percentage of SSYU mothers (32 per cent) migrated for work compared to mothers of Turkish respondents (11 per cent). The share of parents who came to Switzerland to seek asylum is very low, implying that the Turkish 
and SSYU respondents in our sample are indeed mainly the children of guest-workers.

Table 3.17 Parents' reasons for migration

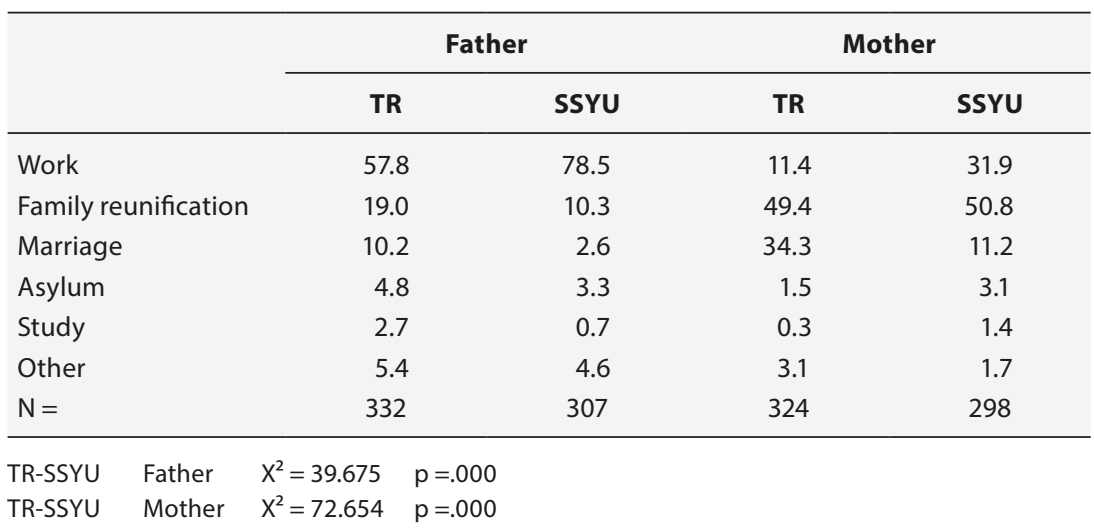

The data show that while work was the fathers' main reason for migration in earlier flows from Turkey and the SSYU, first family reunification and later marriage became increasingly important (Table 3.18). Asylum from political prosecution appeared still later, in the $1980 \mathrm{os}$, and was especially important for Turkish parents. While 80 per cent of parents who migrated before the 1970s came for work reasons, this percentage dropped to 45 per cent for Turkish fathers and 70 per cent for SSYU fathers in the 1980 .

Table 3.18 Change in the reasons for migrating among fathers, by origin group and period of immigration

\begin{tabular}{lcccccc}
\hline & \multicolumn{3}{c}{ TR } & \multicolumn{3}{c}{ SSYU } \\
\cline { 2 - 7 } & $<$ 1970s & 1970s & 1980s & $<$ 1970s & 1970s & 1980s \\
\hline Work & 78.3 & 62.0 & 45.6 & 86.3 & 84.9 & 69.8 \\
Family reunification & 13.3 & 20.7 & 20.2 & 9.8 & 7.5 & 12.5 \\
Marriage & 1.7 & 6.0 & 19.3 & 2.0 & - & 7.3 \\
Asylum & - & 0.7 & 9.6 & - & 0.7 & 5.2 \\
Study & - & 5.3 & 0.9 & - & 1.4 & - \\
Other & 6.7 & 5.3 & 4.4 & 2.0 & 5.5 & 5.2 \\
$\mathrm{~N}=$ & 61 & 155 & 109 & 46 & 145 & 106 \\
\hline
\end{tabular}

TR (<1970s, 1970s, 1980s) $\quad X^{2}=50.988 \quad \mathrm{p}=.000$

SSYU (<1970s, 1970s, 1980s) $\quad X^{2}=26.626 \quad p=.009$ 
We now turn to mothers' reasons for migrating (Table 3.19): family reunification and marriage. While half of SFRY mothers arriving in the early phases of guest-worker migration came in search of work, of those who came in the 1980 only 18 per cent came for work; nearly 80 per cent came for family reasons. This number is similar for Turkish mothers in the 1980s, but in their case the change from work-related to family-related migration never happened because, even in the early phases of Turkish guest-worker migration, they did not come to Switzerland with the explicit purpose of finding work, but for marriage or family reunification.

Table 3.19 Change in the reasons for migrating among mothers, by origin group and period of immigration

\begin{tabular}{lcccccc}
\hline & \multicolumn{3}{c}{ TR } & \multicolumn{3}{c}{ SSYU } \\
\cline { 2 - 7 } & $\mathbf{2}$ <1970s & 1970s & 1980s & $<1970 s$ & 1970s & 1980s \\
\hline Family reunification & 57.2 & 59.1 & 40.6 & 37.5 & 41.3 & 63.1 \\
Marriage & 28.6 & 29.2 & 41.8 & 3.1 & 9.6 & 14.8 \\
Work & 14.3 & 18.8 & 13.1 & 50.0 & 47.1 & 18.1 \\
Study & - & 0.7 & - & 9.4 & 1.0 & - \\
Asylum & - & - & 4.6 & - & 1.0 & 4.0 \\
$\mathrm{~N}=$ & 23 & 148 & 147 & 29 & 98 & 161 \\
\hline
\end{tabular}

TR (<1970s, 1970s, 1980s) $\quad X^{2}=18.319 \quad p=.050$

SSYU (<1970s, 1970s, 1980s) $\quad X^{2}=52.727 \quad p=.000$

Thus, parents of TIES second-generation respondents immigrated quite young, mainly during the economic downturn in the 1970s and later recovery in the 1980 s. The increasing importance of family reunification and marriage indicates the progressive stabilisation of these flows. Family reunification and marriage were the main reasons for mothers of TIES respondents; however, a large percentage of Turkish fathers also came for marriage. Among the parents of SSYU respondents, family reasons became increasingly important over time, though labour migration was dominant until the 1980 .

\subsubsection{Naturalisation of Turkish and SSYU parents}

Chapter 2 described the increasing importance of naturalisation for secondgeneration respondents of Turkish and SSYU descent and discussed the possible reasons for this behaviour in contrast to 'old' second-generation groups. The great interest in naturalisation for first-generation parents from 
Turkey and the SFRY appears to be a new phenomenon in Swiss migrants' integration history and is probably common to all immigrants from non-EU countries in search of stability.

In particular, SSYU parents are naturalised more often than Turkish parents (roughly 50 vs. 40 per cent), with women naturalising more than men in both groups (Table 3.20). Intriguingly, naturalisation tends to be more frequent in the agglomeration where the group is smaller: it is more frequent in Zurich for Turkish parents and in Basel for SSYU parents.

Table 3.20 Parents with Swiss citizenship, by origin group and gender

\begin{tabular}{|c|c|c|c|c|c|c|}
\hline & \multicolumn{3}{|c|}{ TR } & \multicolumn{3}{|c|}{ SSYU } \\
\hline & Zurich & Basel & Total & Zurich & Basel & Total \\
\hline Fathers & 37.0 & 36.2 & 36.4 & 37.0 & 55.3 & 45 \\
\hline$N=$ & 200 & 246 & 446 & 234 & 190 & 424 \\
\hline Mother & 47.5 & 37.8 & 42.2 & 46.4 & 67.2 & 55.7 \\
\hline$N=$ & 200 & 246 & 446 & 237 & 192 & 429 \\
\hline TR-SSYU & & Father & $X^{2}=6.724$ & $p=.010$ & & \\
\hline TR-SSYU & & Mother & $X^{2}=16.089$ & $p=.000$ & & \\
\hline TR (Zurich & & Mother & $X^{2}=4.252$ & $\mathrm{p}=.039$ & & \\
\hline SSYU (Zur & Basel) & Father & $X^{2}=14.115$ & $p=.000$ & & \\
\hline SSYU (Zur & Basel) & Mother & $X^{2}=18.552$ & $p=.000$ & & \\
\hline
\end{tabular}

It has been observed for second-generation groups that naturalisation is associated with a higher level of education (Fibbi et al. 2005), but this question has not been analysed in detail for the first generation. Census 2000 on elderly Italians showed a positive correlation, but the share of naturalised individuals in this immigrant group was much smaller than among Turks and SSYU respondents (Fibbi \& Wanner 2008).

How does the educational background of naturalised Turkish and SSYU first-generation respondents compare with those currently registered as Turks in the official statistics? A clear picture appears among parents of TIES respondents. Among Swiss-Turkish fathers, 17 per cent are university graduates versus 9 per cent among non-naturalised; 50 per cent have a post-compulsory qualification as compared to 34 among non-naturalised; one fourth have earned only a primary school diploma, against one third among non-naturalised fathers. Among Swiss-Turkish mothers, 9 per cent are university graduates versus 3 among non-naturalised; 42 per cent have a post-compulsory qualification versus 18 among non-naturalised; one third have only a primary school diploma compared with half among 
non-naturalised, and 2 per cent have no education versus 9 per cent among non-naturalised. Among Swiss-SSYU fathers, 18 per cent are university graduates, against 8 per cent among non-naturalised; 66 per cent have a postcompulsory qualification compared with 49 among non-naturalised fathers. Among Swiss-SSYU mothers, 12 per cent are university graduates versus 4 among non-naturalised; $5^{2}$ per cent have a post-compulsory qualification versus 36 among non-naturalised; 4 per cent have only a primary school diploma as against 5 per cent among non-naturalised, and 2 per cent have no education versus 9 per cent among non-naturalised. It therefore appears that naturalisation represents a positive selection of Turks and SSYU migrants.

Table 3.21 Naturalisation of parents by origin and religious affiliation

\begin{tabular}{lcccc}
\hline & \multicolumn{2}{c}{ Father } & \multicolumn{2}{c}{ Mother } \\
\cline { 2 - 5 } & \% Naturalized & N $=$ & \% Naturalized & N $=$ \\
\hline TR Sunni & 32.8 & 201 & 35.0 & 201 \\
TR Alevi & 43.3 & 67 & 49.3 & 67 \\
SSYU Catholics & 36.6 & 113 & 44.1 & 113 \\
SSYU Orthodox & 41.8 & 97 & 55.1 & 97 \\
SSYU Muslims & 53.0 & 106 & 51.0 & 106 \\
TR Non-religious & 36.1 & 119 & 46.6 & 119 \\
SSYU Non-religious & 45.8 & 114 & 68.6 & 114 \\
\hline
\end{tabular}

It was further analysed whether religious background has an influence on naturalisation behaviour among parents of both Turkish and SSYU origin respondents (Table 3.21). Among Turkish parents, Alevi fathers and mothers more frequently acquired Swiss citizenship, while about one third of Sunni and non-religious Turkish parents did so. Among SSYU parents, Catholics naturalised the least while Muslims and non-religious did so the most.

Looking more closely at differences in naturalisation among parents from different republics of the SFRY (Table 3.22), we note that parents from Macedonia acquire Swiss citizenship significantly more often than parents from other republics. On the other hand, parents of Bosnian and Croatian origin naturalised less often.

Parents of TIES respondents, particularly mothers, have a strong tendency to naturalise, and SSYU more than Turkish parents. So far analysis of naturalisation behaviour has focused mainly on the second generation; the TIES findings document an increased interest in naturalisation among first-generation immigrants prompting the need for a better understanding of their naturalisation behaviour and determinants. 
Table 3.22 Naturalisation of SSYU parents by country of upbringing

\begin{tabular}{lcccc}
\hline & \multicolumn{2}{c}{ Father } & \multicolumn{2}{c}{ Mother } \\
\cline { 2 - 5 } & \% Naturalized & $\mathbf{N}=$ & \% Naturalized & $\mathbf{N}=$ \\
\hline Switzerland & 76.9 & 12 & 90.6 & 33 \\
Bosnia & 36.7 & 92 & 49.4 & 90 \\
Yugoslavia & 48.6 & 34 & 60.9 & 21 \\
Kosovo & 46.3 & 57 & 51.7 & 60 \\
Croatia & 40.6 & 67 & 48.8 & 76 \\
Macedonia & 60.5 & 41 & 65.8 & 40 \\
Montenegro & 66.7 & 6 & 100 & 3 \\
Serbia & 54.1 & 95 & 54.4 & 87 \\
Slovenia & 50.0 & 8 & 50 & 6 \\
Total & 46.0 & 412 & 56.4 & 416 \\
\hline
\end{tabular}

\subsubsection{Current status of parents' labour force participation}

The last issue we address in this subchapter is the question of parents' employment status and labour force participation. Since gender differences are very relevant in labour market issues, we present the findings separately for fathers and mothers.

Despite being older, comparison group fathers are more often working than immigrant fathers, as they are less affected by unemployment and forced retreat from the labour market. Significantly more parents of secondgeneration respondents are unemployed (especially Turkish parents) or out of work due to illness or disability (almost 15 per cent of Turkish fathers and almost 20 per cent of SSYU fathers). This finding corresponds with data on high rates of disability allowances beneficiaries observed among first-generation immigrants from Turkey and SSYU, attributed to the type of industrial work immigrant parents performed (Burri Sharani et al. 2010; Haab et al. 2010).

Self-employment (either working alone or owning a business) plays an important role among working fathers: 21 per cent of Turkish fathers are self-employed, a share comparable to that of comparison group fathers (2o per cent), but this drops to 11 per cent among SSYU fathers. The similarity in self-employment between the autochthonous population and Turkish immigrants, like the lower rate of self-employment among SSYU immigrants (14, 12 and 8 per cent respectively), had already been observed in Census data (Piguet \& Besson 2005) (Table 3.23). Compared to fathers, mothers are less likely to be employed. The gender gap is especially marked among Turkish 
Table 3.23 Fathers' current work situation, by origin group and agglomeration

\begin{tabular}{lccrrrrrrrr}
\hline & \multicolumn{3}{c}{ TR } & \multicolumn{3}{c}{ SSYU } & \multicolumn{3}{c}{ CG } \\
\cline { 2 - 11 } & Zurich & Basel & Total & Zurich & Basel & Total & Zurich & Basel & Total \\
\hline Working & 56.1 & 65.8 & 61.5 & 62.3 & 56.8 & 59.6 & 69.7 & 73.9 & 72.1 \\
Unemployed & 3.2 & 3.8 & 3.6 & 1.4 & 1.2 & 1.3 & 0.5 & & 0.2 \\
Retired & 21.9 & 16.7 & 19.0 & 17.7 & 20.7 & 19.3 & 26.5 & 21.2 & 23.5 \\
Sick/Disabled & 15.5 & 12 & 13.5 & 17.3 & 20.7 & 18.8 & 3.2 & 3.7 & 3.5 \\
Other & 3.2 & 1.7 & 2.4 & 1.4 & 0.6 & 1.0 & & 1.2 & 0.7 \\
$\mathrm{~N}=$ & 186 & 234 & 420 & 220 & 171 & 391 & 185 & 245 & 430 \\
\hline
\end{tabular}

TR-CG $\quad \mathrm{X}^{2}=47.437 \quad \mathrm{p}=.000$

SSYU-CG $\quad X^{2}=54.186 \quad p=.000$

TR-SSYU $\quad X^{2}=9.938 \quad p=.041$

CG (Zurich vs. Basel) $\quad X^{2}=10.325 \quad p=.035$

All other differences are not statistically significant.

parents, but is smaller for SSYU parents than for parents of the comparison group. In fact, mothers of SSYU respondents are just as often employed as mothers of the comparison group; they differ, however, since comparison group mothers are often retired or housewives whereas SSYU mothers are frequently prevented from working by health problems (Table 3.24).

Table 3.24 Mothers' current work situation, by origin group and agglomeration

\begin{tabular}{lrrrrrr|r|r|r}
\hline & \multicolumn{3}{c}{ TR } & \multicolumn{3}{c}{ SSYU } & \multicolumn{3}{c}{ CG } \\
\cline { 2 - 11 } & Zurich & Basel & Total & Zurich & Basel & Total & Zurich & Basel & Total \\
\hline Working & 38.8 & 41 & 39.9 & 57.3 & 58.9 & 58.0 & 62 & 59.1 & 60.4 \\
Unemployed & 1.5 & 2.1 & 1.8 & 0.4 & & 0.2 & 0.5 & 1.5 & 1.1 \\
Retired & 10.2 & 5.4 & 7.8 & 7.7 & 10.8 & 9.1 & 12.5 & 12.4 & 12.4 \\
Sick/Disabled & 12.8 & 14.6 & 13.8 & 14.1 & 13.5 & 13.8 & 1.6 & 2.7 & 2.2 \\
Household, & 30.1 & 31.4 & 6.0 & 19.2 & 11.9 & 2.9 & 21.4 & 18.5 & 4.2 \\
care tasks & & & & & & & & & \\
Other & 6.6 & 5.4 & 30.7 & 1.3 & 4.9 & 16.0 & 2.1 & 5.8 & 19.7 \\
N = & 197 & 238 & 435 & 235 & 187 & 422 & 192 & 260 & 452 \\
\hline
\end{tabular}

TR-CG $\quad X^{2}=73.616 \quad p=.000$

SSYU-CG $\quad X^{2}=45.238 \quad p=.000$

TR-SSYU $\quad X^{2}=44.289 \quad \mathrm{p}=.000$

Differences between cities are not statistically significant.

Turkish mothers report similar levels of disability as SSYU mothers, but are more often housewives than both SSYU and autochthonous mothers. As a consequence, the labour force participation of Turkish mothers is 
low compared to other groups. This reflects the group's official reason for entering Switzerland (Table 3.17).

Today, the two immigration flows under study are characterised by the mixing of labour and asylum migration. However, the Turkish and SSYU fathers of TIES respondents largely came as guest-workers in the late sixties and seventies; the share of fathers entering Switzerland on asylum grounds was limited to the eighties and in total very small. Migration of Turkish mothers was largely induced by family from the seventies onward. Migration of mothers from SSYU up to the seventies was clearly work-led and only later became mainly family-driven.

Parents of TIES respondents have high rates of naturalisation, unusual in the integration history of guest-workers. Half of SSYU origin parents and more than a third of Turkish origin parents acquired Swiss citizenship, with women naturalising more often than men in both groups. Naturalised parents generally have higher qualifications than non-naturalised parents.

Finally, labour force participation for Turkish fathers is lower than for SSYU fathers who, in turn, show lower participation than in the comparison group, mainly due to frequent health problems. Turkish mothers display the lowest rates of participation in the labour market, while SSYU mothers resemble comparison group mothers.

\subsection{Parental couples and household size}

This subsection gives an overview of our respondents' family environments. We discuss the ethnic background of the parents as well as the stability of parental couples and finally touch on parental household size.

\subsubsection{Couple composition and mixed marriages}

A large majority of parents of TIES survey respondents married a partner from their country of origin (Table 3.25), the case for more than go per cent of Turkish parents and SFRY parents. Among the latter, three quarters have a spouse from the same republic and another 20 per cent married a partner from another republic of the SFRY. They therefore might have married across ethnic lines, but, given that most of them married before the breakup of the former Yugoslavia, they married a person of the same nationality. Parents of our Turkish and SSYU respondents that married a Swiss national represent 3 and 4 per cent respectively. 
Table 3.25 Mixed marriages

\begin{tabular}{lclc}
\hline \multicolumn{1}{c}{ Parents' country of birth } & TR & SSYU \\
\hline TR & 93.4 & Same country of former YU & 74.2 \\
& & Mixed countries of former YU & 19.5 \\
Mother or Father CH & 3.4 & Mother or Father CH & 4.2 \\
Mother or Father Other & 3.2 & Mother or Father Other & 2.1 \\
N = & 442 & N = & 428 \\
\hline
\end{tabular}

The prevalence of mixed marriages among Turkish parents is 10 per cent in Zurich and 4 per cent in Basel, while among SSYU parents it is 2 per cent in Zurich and 10 per cent in Basel. In other words, mixed couples involving first-generation migrants are more common where the group is less dominant.

\subsubsection{Divorce rate and intact families}

Literature on immigration to the US often points to the quality of intact versus non-intact families in explaining second-generation outcomes (Pessar 1999; Portes et al. 1999). Among TIES second-generation respondents, intact families are the rule; immigrant parents show significantly lower divorce rates than parents in the comparison group (Table 3.26).

Table 3.26 Divorced/separated parents, by gender, origin group, naturalisation status and agglomerations

\begin{tabular}{|c|c|c|c|c|}
\hline & & TR & SSYU & CG \\
\hline \multicolumn{5}{|l|}{ FATHER } \\
\hline Swiss citizen & & 9.3 & 12.6 & \\
\hline Foreign citizen & & 14.5 & 19.3 & \\
\hline \multicolumn{5}{|l|}{ MOTHER } \\
\hline Swiss citizen & & 12.8 & 22.2 & \\
\hline Foreign citizen & & 13.2 & 10.0 & \\
\hline Zurich & & 14.4 & 13.8 & 26.7 \\
\hline Basel & & 11.3 & 20.3 & 28.9 \\
\hline Total & & 12.9 & 16.7 & 28.0 \\
\hline$N=$ & & 449 & 431 & 468 \\
\hline TR-CG & & $X^{2}=32.005$ & $\mathrm{p}=.000$ & \\
\hline SSYU-CG & & $X^{2}=16.348$ & $\mathrm{p}=.000$ & \\
\hline SSYU (Swiss vs. Not Swiss) & Father & $X^{2}=3.508$ & $p=.061$ & \\
\hline SSYU (Swiss vs. Not Swiss) & Mother & $X^{2}=11.236$ & $p=.001$ & \\
\hline
\end{tabular}


Examining the relation between divorce rates and naturalisation status, a curious gender pattern appears: naturalised fathers have a lower divorce rate than foreign fathers, but naturalised mothers are significantly more often divorced.

\subsubsection{Household size}

What is the size of the parental household where our respondents live? Does it differ among origin groups and between agglomerations? The analysis concerns only respondents living with their parents - six Turkish and five SSYU-descent youth in ten in the TIES sample (see Chapter 2). The number of members in migrant households is significantly higher than in comparison group households: 4.1 and 4.0 members respectively for Turkish and SSYU families vs. 3.7 members (Table 3.27). Respondents from migrant groups, especially of Turkish origin, are more likely to have a sibling. Being an only child is exceptional among Turkish youngsters (2 per cent), rare in SSYU families (6 per cent) and more frequent for comparison group respondents (10 per cent).

Table 3.27 Mean number of household members in parents' household, by origin group and agglomerations

\begin{tabular}{lcccccc}
\hline & TR & St. Dev. & SSYU & St. Dev. & CG & St. Dev. \\
\hline Zurich & 4.2 & 1.1 & 4.3 & 1.0 & 3.6 & 0.9 \\
Basel & 4.1 & 0.9 & 3.7 & 1.0 & 3.8 & 0.9 \\
Total & 4.1 & 1.0 & 4.0 & 1.0 & 3.7 & 0.9 \\
$\mathrm{~N}=$ & 261 & & 223 & & 158 & \\
\hline
\end{tabular}

TR-CG

SSYU-CG

mean number of household members

$\mathrm{p}=.000$

SSYU (Zurich vs. Basel) mean number of household members

$\mathrm{p}=.002$

mean number of household members $\quad p=.000$

All other differences are not statistically significant.

Household size observed in migrant families corresponds to the average size found in their respective countries of origin. The size of the Turkish family coincides with that observed in Turkey in 2003 (TDHS 2003). Household Budget Survey of Kosovo estimates an average household size of 6.1 members in 2005-2006, a decrease from 6.8 in 2002-2003 (World Bank 2007), while the average number of household members is 3.8 in Serbia (Bodewig \& Sethi 2005) (Table 3.28). 
Table 3.28 Mean number of household members by SSYU country

\begin{tabular}{lccc}
\hline Father's country of birth & Total & Std. Deviation & N \\
\hline Switzerland & 3.0 & 0.0 & 1 \\
Bosnia & 4.1 & 0.8 & 53 \\
Yugoslavia & 3.8 & 1.1 & 13 \\
Kosovo & 4.4 & 1.2 & 32 \\
Croatia & 4.0 & 0.9 & 30 \\
Macedonia & 4.4 & 1.2 & 20 \\
Montenegro & 5.0 & 0.0 & 1 \\
Serbia & 3.6 & 1.0 & 51 \\
Slovenia & 2.0 & 0.0 & 1 \\
\hline Total & 4.0 & 1.1 & 201 \\
\hline SSYU mean number of household members & $\mathrm{p}=.006$ &
\end{tabular}

The parental household size of Turkish second-generation and comparison group respondents is similar. By contrast, SSYU second-generation respondents live in larger parental households in Zurich (4.3 members) than in Basel (3.7 members) (Table 3.27). This difference is due to the different composition of the SSYU group in the two agglomerations: Kosovar families, characterised by a larger number of members, are more common in Zurich (18 per cent) than in Basel (8 per cent). Only in this case is average parental household size is only in this case significantly higher in Zurich (4.8 members) than in Basel (3.7 members).

Immigrant parental couples are largely endogamous couples, a feature consistent with the importance of family-related motives for migrating. Parents of TIES respondents remained married, to a large extent, despite the challenges of adjusting to life in a new environment. The size of their household, similar to that observed in their country of origin, is larger than that of comparison group families.

\subsection{Conclusions}

This chapter outlined the cultural, social and financial capital of parents of TIES respondents, a useful exercise given that general knowledge on these immigration flows is still not consolidated and there is limited familiarity with their countries of origin. 
The migrant groups under study are characterised by a striking ethnic, linguistic and religious diversity. In the case of Turkish emigrants, regional, linguistic and religious lines are tangled as a consequence of the massive internal mobility that brought the Kurdish population to live in the western part of the country before migrating abroad. Bilingualism is even more pronounced in the case of migration from SFRY, so that the ethnic group boundaries appear characterised by cross-cutting cleavages of language, religion and regional origin. In both groups, one family in four is non-religious.

Migrant parents show a higher level of education than their compatriots. Reflecting the differences in development of the educational system in their respective country of origin, SFRY emigrants have higher levels of attainment than Turkish emigrants. SFRY mothers are in a more favourable position in terms of level of education, local language proficiency and labour market participation than Turkish mothers. However, migrant parents are at a clear disadvantage in relation to comparison group parents.

Though immigration from Turkey and SSYU is considered mixed - comprised of labour and asylum migration - the parents of TIES respondents are, to a large extent, guest-workers who came in the sixties and seventies. Migration of mothers from Turkey was mainly family-related; migration of mothers from the SFRY was first guest-worker migration and later familydriven. Accordingly, Turkish mothers tend not to engage in the labour market while SSYU mothers are similar in this respect to comparison group mothers. Labour market participation of emigrant fathers is impaired by considerable health problems leading to disability. Almost half of the TIES respondents' parents acquired Swiss citizenship; such rates are unusual in the integration history of labour migrations.

\section{References}

Alba, Richard (2005), 'Bright vs. blurred boundaries: Second generation assimilation and exclusion in France, Germany and the United States', Ethnic and Racial Studies 28(1): 20-49.

Bankston, Carl L. III \& Min Zhou (1994), 'Social capital and the adaptation of the second generation: The case of Vietnamese youth in New Orleans', International Migration Review 28(4): 821-845.

Baučić, Ivo (1973), 'Yugoslavia as a country of emigration', Options Méditerranéennes 22: 56-66. Bodewig, Christian \& Akshay Sethi (2005), Poverty, Social Exclusion and Ethnicity in Serbia and Montenegro: The Case of the Roma. World Bank's Programmatic Poverty Assessment for Serbia and Montenegro.

Bommes, Michael (2005), 'Transnationalism or Assimilation?' Journal of Social Science Education 4(1): 14-30.

Bourdieu, Pierre (1994), Raisons pratiques. Paris: Seuil. 
Burri Scharani, Barbara et al. (eds) (2010), Die Kosovarische Diaspora in der Schweiz. Bern: Bundesamt für Migration.

Kaya Çabuk, Nilay (2007), The Position of Women in the Public Sphere in Turkey after the 1980 s. Gendering Transformations. Rethymno, Papageorgiou.

Crul, Maurice \& Jerome Doomernik (2003), 'The Turkish and Moroccan second generation in the Netherlands: Divergent trends between and polarization within the two groups', International Migration Review 37(4): 1039-1064.

Džambo, Jozo \& Othmar Nikola Haberl (1982), 'Jugoslawien, ein sozialistischer Emigrationsland', Deutsch Lernen. Zeitschrift für den Sprachunterricht mit ausländischen Arbeitnehmern 7(4): 3-54.

Erder, Sema (1999), 'Where do you hail from? Localism and networks in İstanbul', in Caglar Keyder (ed.), Istanbul: Between the global and the local. İstanbul: Rowman \& Littlefield.

Esser, Hartmut (2001). Integration und Ethnische Schichtung, MZES.

Fibbi, Rosita \& Marco Pecoraro (2003), Well-argued proposal Switzerland: Zurich and Basel. Neuchatel: SFM.

Fibbi, Rosita, Mathias Lerch \& Philippe Wanner (2005), 'Processus de naturalisation et caractéristiques socio-économiques des jeunes issus de la migration, in OFS (ed.), L'intégration des populations issues de l'immigration en Suisse: personnes naturalisés et deuxième génération, 57. Neuchâtel: Office fédéral de statistique.

Fibbi, Rosita \& Philippe Wanner (2008), Condizioni di vita degli Italiani anziani in Svizzera. Neuchâtel: Forum suisse pour l'étude des migrations et de la population.

(2009), 'Children in immigrant families in Switzerland: on a path between discrimination and integration', Innocenti Working Paper. Florence, UNICEF.

Filiztekin, Alpay \& Ali Gökhan (2007), 'The Determinants of Internal Migration In Turkey', Tuzla Istanbul, Sabanci University.

Geymen, A. \& I. Baz (2007), 'Istanbul metropolitan alanindaki arazi kullanim degisimi ve nufus artisinin izlenmesi', Ulusal Cografi Bilgi Sistemleri Kongresi. Trabzon.

Haab, Katharina et al. (eds) (2010), Die Türkische Diaspora in der Schweiz. Bern: Bundesamt für Migration.

Haberl, Othmar Nikola \& Uwe Bach (1977), 'Jugoslawien', in U. Boos-Nünning and M. Hohmann (eds), Ausländische Kinder - Schule und Gesellschaft im Herkunftsland, 144-193. Düsseldorf: Schwann.

Kriesi, Hanspeter (1995), Le système politique suisse. Paris: Economica.

Mahnig, Hans et al. (eds) (2005), Histoire de la politique de migration, d'asile et d'intégration en Suisse depuis 1948. Zurich: Seismo.

Munro, John (1974), 'Migration in Turkey', Economic Development and Cultural Change 22(4): 634-653.

Pessar, Patricia (1999), 'The role of gender, households and social networks in the migration process: A review and appraisal', in Charles Hirschman, Philip Kasinitz \& Josh DeWind (eds), The Handbook of International Migration, 53-70. New York: Russell Sage.

Piguet, Etienne \& Roger Besson (2005), 'L'emploi indépendant des personnes d'origine étrangère', in Werner Haug \& Philippe Wanner (eds), Migrants et marché du travail, 111-148. Neuchâtel: Office fédéral de statistique.

Portes, Alejandro \& Dag MacLeod (1999), 'Educating the second generation: Determinants of academic achievement among children of immigrants in the United States',Journal of Ethnic and Migration Studies 25(3): 373-396.

Stepick, Alex \& Carol Stepick-Dutton (2003), 'Becoming American: Immigration, identity, intergenerational relations, and academic orientation', in Nancy Foner (ed.), American 
arrivals: Anthropology engages the new immigration, 129-162. Santa Fe: School of American Research Press.

Tansel, Aysit (2004), 'Education and labour market outcomes in Turkey', World Bank Report: Background papers and studies for Turkey. Washington: World Bank.

TDHS-2003 (2003), 'Turkey Demographic and Health Survey', see http://www.measuredhs.com/ pubs/pdf/SR115/SR115.pdf. 04.10.2010.

Tunali, İnsan (1996), Education and work: Experiences of 6-14 year old children in Turkey. Istanbul: Koç University.

Waters, Mary, John Mollenkopf \& Philip Kasinitz (2004), 'Worlds of the second generation', in Mary Waters, John Mollenkopf \& Philip Kasinitz (eds), Becoming New Yorkers. New York: Russell Sage.

World Bank (2007), 'Kosovo Poverty Assessment Report', Volume II: Estimating Trends from Non-comparable Data, Report No. 39737-XK. Unit, Poverty Reduction and Economic Management. Washington: World Bank. 



\section{Education of the second generation}

The educational career of young adults determines aspects of their future lives such as labour market outcome and family formation. Moreover, young people's attainment in education compared to their parents' shows upward intergenerational social mobility and is a driving force for social development and change. We would expect this experience to be different from that of comparison group youth, as it reflects not only individual and family characteristics, but also opportunities available in the educational system.

This chapter investigates the educational opportunities of TIES respondents in light of kindergarten enrolment, attendance in special classes in primary education, school segregation and post-compulsory qualifications. It also takes a detailed look at the present educational situation as well as the current and highest achieved educational level of second-generation immigrant youth and comparison group youth. It examines not only the path followed by the children of immigrants compared with comparison group youth, but also explores the factors affecting their educational careers; individual factors (such as naturalisation) and family/contextual factors (such as parents' highest education level) are investigated. In order to study this, it is crucial to understand the characteristics of the Swiss system; in particular, respondents experienced quite different educational systems depending on where they live.

\subsection{Main features of the Swiss educational systems}

Most children go to state schools run by the cantons, which are in charge of educational services (kindergarten, schools and universities). Despite recent efforts to coordinate at the federal level, education may vary significantly from canton to canton, notably in terms of the school tracks, subjects, the starting age of students and duration of the various curricula. In order to give an overview of such a fragmented school landscape, ISCED (International Standard Classification of Education) categories are used, as they are common both in the scholarly literature and in the public debate.

\subsubsection{Pre-school and compulsory education}

In most cantons compulsory education does not include pre-school, so we single this out. Compulsory or elementary school is for children aged 
seven to sixteen years old and is divided into primary (ISCED 1 ) and lower secondary school (ISCED 2).

\subsubsection{Pre-school and primary school}

Though pre-school education (ISCED o) is not compulsory, many children go to kindergarten, which may last one or two years. The duration of primary school varies from four to six years, according to canton. In primary school, selection involves special classes or schools for children with learning difficulties. In 2007, these special curriculum classes were attended by 8.6 per cent of primary pupils in Basel-Land, 3.2 per cent in Zurich ${ }^{1}$ and 2 per cent in Geneva (DIP 2010).

\subsubsection{Lower secondary education}

In almost all cantons, selection takes place when entering lower secondary schools. Children usually attend secondary school for three years, but this is longer in some cantons. While children are all in the same type of classes during primary school, they are divided into different levels in secondary schools based on three different models:

- Separated paths: children are clearly separated into different paths, sometimes in different schools, according to academic ability. Usually, there are three ability-based sections: one with elementary requirements, one with extended requirements and one with high requirements.

- Cooperative paths: there are 'common-core classes' differentiated according to level of academic challenge. For some subjects, children are again separated into different courses with different levels of difficulty. The level of the common-core class and the level of the specific subjects do not need to be the same.

- Integrative classes: there is no distinction between the paths and all children receive the same education, except for some subjects, where they are separated according to ability.

The decision regarding each child's path is based on results in primary school, the opinion of the teacher and the opinion of the parents. Additionally, a selection exam needs to be passed in some cantons or in case of disagreement between teachers and parents.

1 For Basel-land see www.statistik.bl.ch/stabl_data/stabl_generator/titel.php?unterthema_ $\mathrm{id}=65$ \& thema_id=16 (Accessed 31.01.2010); for Zurich see www.bista.zh.ch/vs/VS_Stufen.aspx (accessed 31.01.2010). 
Some schools offer an additional year (a so-called 'tenth year') for children who have not decided what to do after compulsory school, found an apprenticeship place or reached the age or the required level of knowledge to start the training they would like to do. Other bridging solutions are available in some cantons, such as preparation courses for specific vocational schools. According to the inter-cantonal coordination centre Conférence des Directeurs de l'Instruction Publique (CDIP), 15-30 per cent of all children choose such a bridging class. The Swiss Federal Statistical Office (SFSO) considers this level as part of compulsory education (ISCED 2). The SFSO classifies all types of schools and classes of the compulsory secondary level as ISCED 2, as the different types of the Swiss system do not correspond to the categories $2 \mathrm{~A}, 2 \mathrm{~B}$ and $2 \mathrm{C}$.

To give an overview of the fragmented lower secondary school situation to be found in the 26 cantons, Swiss school statistics group the various types into two categories: those with basic requirements and those with extended requirements.

\subsubsection{Post-compulsory secondary education}

\subsubsection{Upper secondary education}

After compulsory school, students may either go to higher secondary education ('general schools') or vocational training (ISCED 3). The two types of vocational training include fully-fledged training and another form with lower requirements.

\section{General schools}

Gymnasia generally lead to tertiary education and students can choose between different types according to their main subjects. Students at gymnasia earn the federal graduation diploma or Matura, which is recognized at all universities in Switzerland and at most universities in foreign countries.

Vocational colleges (Diplommittelschule) last two to three years and prepare students for higher vocational education (technical colleges or vocational baccalaureate leading to higher vocational schools).

\section{Vocational education}

Vocational education can be done either through a full-time school or through a dual system (apprenticeship) taking two to four years, depending on the profession. Apprentices are trained at a company or organization, but also attend school for one or two days a week. In the latter case the apprentice enters the labour market on a specific apprenticeship contract with the employer. 
Created in 1994, vocational baccalaureate school (Berufsmaturität) combines general and vocational education. It lasts three to four years and gives access to all higher vocational schools (Fachhochschulen).

\section{Teachers' training}

Students who want to become teachers now need to attend the Pedagogical University, which is classified $5 \mathrm{~A}$ according to ISCED.

Until recently, however, they went to the teaching school (Lehrerseminar), which was considered education of secondary level II and classified as ISCED 3 A for the first three years (teacher training I) and as tertiary education for the two remaining years, classified as ISCED ${ }_{5} \mathrm{~B}$ (teacher training II).

\subsubsection{Post-secondary non-tertiary education}

Adults who want to attend higher education but do not hold the necessary qualifications to do so may earn them by attending gymnasia for adults (leading to a federal Matura) or obtaining a vocational baccalaureate (Berufsmaturität), after an apprenticeship. Schools of this type are grouped under ISCED 4.

\subsubsection{Tertiary education}

Tertiary education (ISCED 5) includes different types of schools and the conditions to access them vary.

- Higher vocational colleges (Höhere Fachschulen) include technical schools as well as other vocational schools (businesses, tourism, etc.). They usually last two years full-time or three years part-time and are mainly attended by persons who have finished an apprenticeship and want to attend further education. They are classified ${ }_{5} \mathrm{~B}$ in the ISCED system.

- Universities of applied science (Fachhochschulen) exist for different professions (engineers, social workers, nurses, economists, musicians, etc.) and last three to four years. Depending on the profession and the educational background of the student, an admission exam may be required. Students can attend three to four years full-time or four years part-time. These institutions are classified ${ }_{5} \mathrm{~A}$ in the ISCED system.

- Universities and polytechnic schools can only be attended with a Matura. However, people who have followed another path may change by attending a gymnasium for adults leading to a Matura. They are classified $5 \mathrm{~A}$ in the ISCED system. 
Figure 4.1 The Swiss educational system (simplified)

\section{THE SWISS EDUCATION SYSTEM}

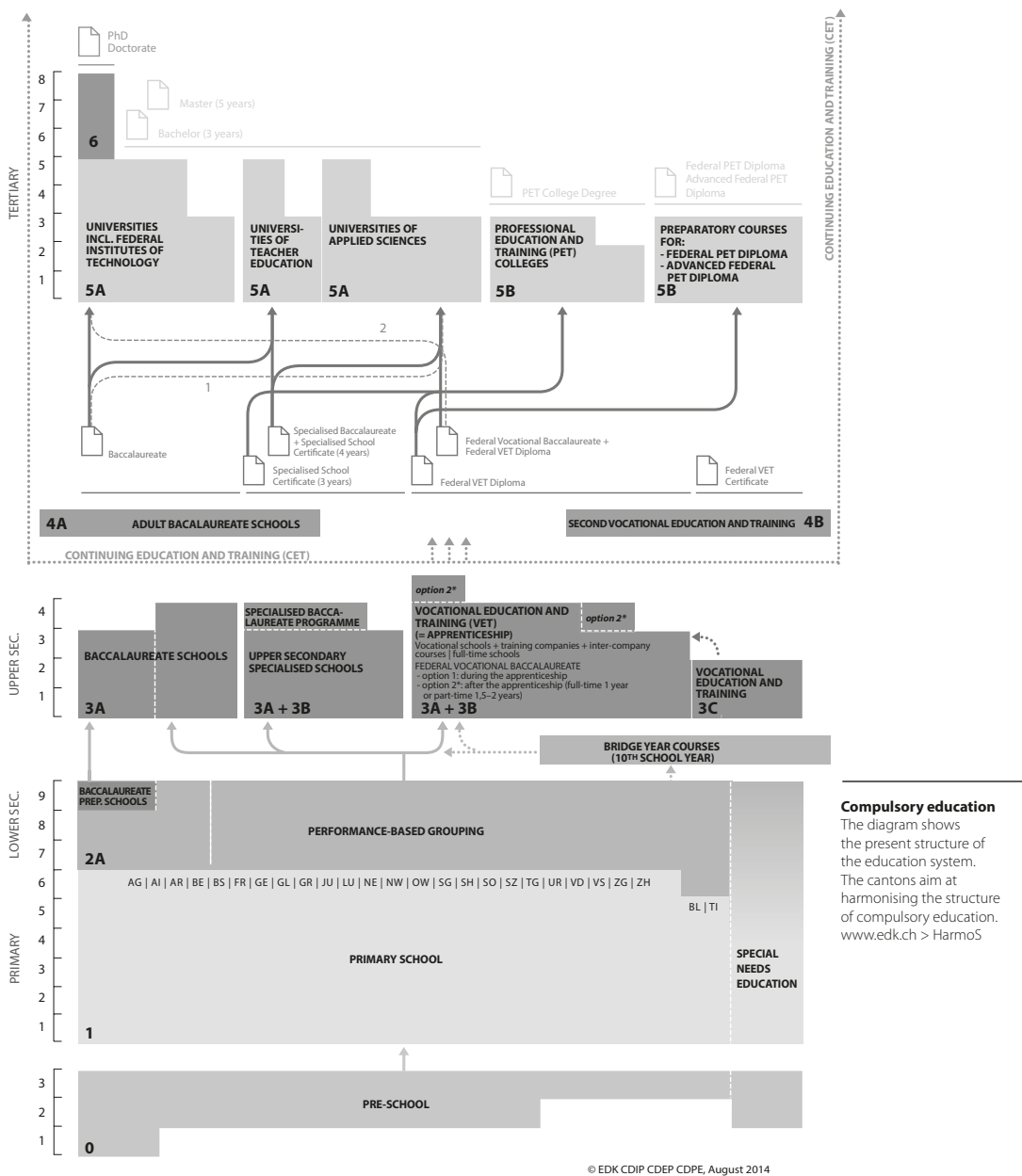

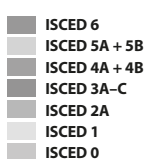

10 EDK CDIP CDEP CDPE, August 2014

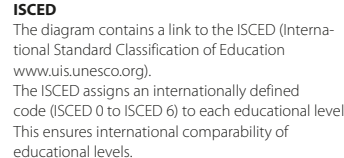

educational levels.

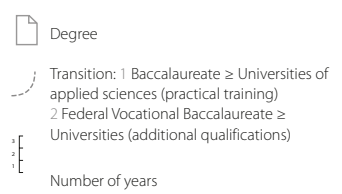

Number of years

National statistics on school attendees (Table 4.1) give a general picture of how the educational system is used by students. Private schools are not 
significant, especially during the compulsory school years. The proportion of foreign students at each level bears special importance for this study as it provides clues about the educational careers of children of immigrants. Two points stand out: foreign students are underrepresented in upper secondary schools (16 per cent) compared to lower secondary (23 per cent) and are concentrated in the least qualifying type of upper secondary schools. In the 2007-2008 academic year, foreign students represented 35 per cent of the students at ISCED ${ }_{3} \mathrm{C}$ level (who received vocational education lasting one or two years). The high percentage of foreigners at tertiary II level is largely due to incoming migrants for doctoral or postdoctoral studies.

Table 4.1 Number of students in different education levels and proportion of foreign nationals and private school students at each level, 2007-2008

\begin{tabular}{lccc}
\hline & Total & \multicolumn{2}{c}{ Percentage of } \\
\hline \multicolumn{1}{c}{ Level of education } & & Foreigners & Private schools \\
\hline ISCED 0 - Pre-school & 151,699 & 26.5 & 9.4 \\
ISCED 1 - Primary school & 505,382 & 24.3 & 2.9 \\
ISCED 2 - Lower secondary level & 295,227 & 22.6 & 4.9 \\
ISCED 3 - Upper secondary level & 303,730 & 15.6 & 4.1 \\
ISCED 3A & 91,844 & 12.7 & 6.3 \\
ISCED 3B & 201,746 & 16 & 2.7 \\
ISCED 3C & 10,140 & 34.6 & 10.8 \\
ISCED 4 - Post secondary level & 15,019 & 13 & 37.9 \\
ISCED 4A & 8,256 & 10.4 & 6 \\
ISCED 4B & 6,763 & 16.1 & 76.8 \\
ISCED 5 - Tertiary level & 206,314 & 18.1 & 6.4 \\
ISCED 5A & 159,563 & 17.9 & - \\
ISCED 5B & 46,751 & 18.5 & 28.1 \\
ISCED 6 - Tertiary II Level & 18,152 & 45.9 & - \\
Non-attributable & 11,295 & 85.4 & 100 \\
\hline TOTAL & $1,506,818$ & 22.2 & 5.9 \\
\hline
\end{tabular}

Source: Swiss Federal Statistical Office, Statistics on pupils and students, 2007-2008 http://www.bfs.admin.ch/bfs/portal/fr/index/themen/15/02/data/blank/01.html

\subsubsection{Education systems in Zurich and Basel}

The indicators presented in this section give a sense of the diversity of school systems in the areas under study. The agglomeration of Basel stretches over four cantons: only the two which are fully encompassed in the agglomeration, Basel-Stadt and Basel-Land, were considered in this study. 
Table 4.2 Selected indicators of diversity in school systems in Zurich, Basel-Stadt and Basel-Land, 2008²

\begin{tabular}{|c|c|c|c|}
\hline & $\mathrm{ZH}$ & BS & $B L$ \\
\hline $\begin{array}{l}\text { Percentage of foreign pupils in } \\
\text { compulsory school }\end{array}$ & 25.4 & $43^{*}$ & 23 \\
\hline Compulsory Kindergarten & no & 2 years & 1 year \\
\hline Years of Primary school & 6 & 4 & 5 \\
\hline Years of Lower Secondary & 3 & 6 & 5 \\
\hline $\begin{array}{l}\text { Overall duration of compulsory } \\
\text { school }\end{array}$ & 9 & 12 & 11 \\
\hline Main feature of Lower Secondary & separated & integrative & $\begin{array}{l}\text { Separated + } \\
\text { cooperative }\end{array}$ \\
\hline $\begin{array}{l}\text { Academic diplomas among } \\
\text { 19-years-olds }\end{array}$ & 17.8 & 26.1 & 20.2 \\
\hline
\end{tabular}

* pupils with a foreign mother tongue, 2006

Source: Zurich State Department of Education, Division of Educational Planning and Evaluation; Statistical Office of the Canton of Basel-Stadt; Statistical Office of the Canton of Basel-Land

Table 4.2 compares the education systems in three cantons using selected indicators to capture their distinctiveness. Though the first indicator is not strictly comparable, Basel-Stadt appears to have a higher level of diversity in its student body (four out of ten pupils in compulsory schooling have a foreign mother tongue) than the two other cantons concerned. In Zurich and Basel-Land, the proportion of foreign nationals among compulsory school attendees is closer to the overall country average (see Table 4.1).

Many differences are observed at the level of educational structures. Kindergarten attendance of one to two years is compulsory in Basel-Stadt and Basel-Land, while no such regulation exists in Zurich. As a consequence, duration of compulsory education varies across the agglomerations studied from nine years in Zurich (six primary + three lower secondary) to eleven years in Basel-Land (six primary + five lower secondary) and twelve years in Basel-Stadt (six primary + six lower secondary).

As already mentioned, lower secondary school is characterised by a first differentiation of school tracks. The degree of differentiation in lower secondary school tracks varies significantly across the cantonal systems considered:

2 The present educational situation is described in order to show the diversity of the school systems. Many changes have occurred in the structure of education systems in the agglomerations under study in the last twenty years. Thus, no single year or period can be representative for all respondents. 
in Zurich children are channelled into a separated paths model according to ability. In Basel-Stadt, all children follow the same path during the two first years, but in the third year they are divided into two levels for German, French and Maths classes according to an integrative model. Lower secondary education in Basel-Land is a combination of separated and cooperative path models.

Besides the overall duration, it is important to note the number of compulsory school years spent in a comprehensive type of school (before selection) and those spent in a selective type of school. In spite of the different structure, the comprehensive part represents two thirds of compulsory school, both in Zurich and Basel-Stadt; it is not possible to analyse this difference in Basel-Land.

\subsubsection{Educational equity: An open question}

Today, educational policy aims at reaching educational equity. This concept was defined in the 2004 Swiss Report as:

[a]n educational and learning environment in which individuals can consider options and make choices throughout their lives based on their abilities and talents, not on the basis of stereotypes, biased expectations or discrimination.

Yet evidence from the same Report shows that the path is still fraught, due to insufficient use of means, such as childcare facilities, to overcome drawbacks. In addition, children of immigrants face different forms of inequity in the education system. Lack of equity in initial school experience and during the transition to compulsory school, over-representation of children with migrant backgrounds in special classes/schools, disadvantages caused by concentrations of young immigrants in certain schools and unequal access to post-compulsory education programmes are the main issues affecting the education of the children of immigrants in Switzerland (Coradi Vellacott \& Wolter 2004).

The proportion of children in each path at primary and secondary level, according to their nationality, reveals clearly that children coming from Serbia-Montenegro and Turkey are represented at kindergarten level in the same relative proportion as their Swiss classmates, where there is no selection at all (Moret \& Fibbi 2010). At primary level, they are over-represented in small classes designated for children with special needs (including migrants needing to learn the local language). At secondary level, the overrepresentation of these migrant children in less academically challenging 
classes is even more striking, while they are clearly under-represented in the classes with higher academic requirements.

The description of the school systems has portrayed structural opportunities and constraints confronted by students during their school career. We now assess the position of second-generation Turkish and SSYU students in educational achievement and thus in educational equity by considering it against comparison group respondents. In the next subsections we look at pre-school and primary school enrolment $(\$ 4.2)$ and then describe lower secondary performance and experience $(\S 4.3)$. We further assess the present school achievement of those respondents who still attend school as well as of those who are presently out of school (§ 4.4). We end this chapter by discussing major factors influencing school trajectories and achievement for second-generation immigrant children (§4.5).

\subsection{Children of Turkish and SSYU descent in pre-school and primary education}

In this subsection we analyse various issues concerning the first steps of children of immigrants in the school system: kindergarten enrolment, age at first schooling, attendance of special classes in primary education and school segregation.

\subsubsection{Entry into the school system}

In 2007-2008, non-Swiss nationals constituted almost one quarter (24 per cent) of students in compulsory education. The proportion was even higher in schools following a special curriculum; four out of ten students (44 per cent) were foreign citizens (SFSO 2008). In such an educational environment, pre-school education received more attention, since these complementary care facilities were seen as an opportunity for early language and cultural integration for children of immigrants (Lanfranchi 2002; Coradi Vellacott \& Wolter 2004).

The significance of pre-school education is explained by the fact that children who, starting in their third year of life, are cared for and receive encouragement in other institutions in addition to their family (including kindergartens) get better assessment results in their cognitive, language and social skills by their teaching personnel than children who grow up solely within family bounds (Lanfranchi 2002). 
Moreover, by attending pre-school institutions, children of immigrants experience an easier transition to school compared to their peers who did not receive this kind of education. Comparing child-care institutions in three medium size Swiss towns, Lanfranchi (2002) found that the majority (more than 70 per cent) of four-year-old Swiss children attended some form of institutionalised child care compared to half of children with migrant backgrounds. It may be that those educational opportunities are more readily available in bigger agglomerations than in medium size towns.

According to the current TIES survey, a high proportion of Turkish and SSYU origin children (some 90 per cent) attended a pre-school institution; such attendance rates are exceptionally high, well over the average observed by Lanfranchi. The result is especially remarkable as it concerns children who were of kindergarten age in the 1970 s and 1980 s. Nevertheless, there is still a difference in kindergarten attendance between second-generation children and the comparison group; among the latter the attendance reaches virtually 100 per cent, whereas among the former, some ten per cent of children of immigrants were not enrolled in educational institutions. There is no difference by gender as the trend in kindergarten enrolment is the same for boys and girls. There are no special classes at pre-school level; however, special courses to learn German are offered to children of immigrants.

Is there a difference in kindergarten attendance by age? The answer is affirmative: younger respondents of immigrant descent attended a pre-school institution to a greater extent compared to the older age group (the attendance rate is 86 per cent for youth aged 25 and over vs. 96 per cent for those younger than 25 among the Turkish second generation; 84 per cent vs. 94 per cent, respectively, among SSYU origin group), whereas age does not affect attendance in the comparison group. Hence, pre-school attendance has improved over time, probably under the double effect of greater availability of such services and readier willingness on the part of immigrant families to take advantage of them.

In Swiss-German Switzerland, compulsory school starts quite late, at age seven, according to Coradi Vellacott and Wolter (2004). Thanks to relatively high enrolment in pre-school institutions, all respondents in Zurich and Basel started their educational career on average at an earlier age than official age provisions would suggest (Table 4.3). The mean age on starting school is still significantly higher for children of immigrants ( 5.2 years and 5.1 years for youth of Turkish and of SSYU origin, respectively), however, than for the comparison group (five years). 
Table 4.3 Mean age on entering an educational institution

\begin{tabular}{lcccccc}
\hline & TR & St. Dev. & SSYU & St. Dev. & CG & St. Dev. \\
\hline Men & 5.1 & 0.7 & 5.2 & 0.8 & 5.0 & 0.7 \\
Women & 5.2 & 0.8 & 5.1 & 1.0 & 5.0 & 0.7 \\
\hline$<25$ & 5.1 & 0.7 & 5.1 & 0.9 & 4.9 & 0.8 \\
$>=25$ & 5.3 & 0.8 & 5.3 & 0.9 & 5.1 & 0.7 \\
\hline Zurich & 5.2 & 0.7 & 5.3 & 0.8 & 5.0 & 0.7 \\
Basel & 5.1 & 0.9 & 5.0 & 0.9 & 5.0 & 0.7 \\
Total & 5.2 & 0.8 & 5.1 & 0.9 & 5.0 & 0.8 \\
\hline $\mathrm{N}=$ & 449 & & 431 & & 465 & \\
\hline
\end{tabular}

TR-CG

SSYU-CG

TR (Zurich vs. Basel)

SSYU (Zurich vs. Basel)

TR $(<25$ vs. $>=25)$

SSYU (<25 vs. $>=25)$

CG (<25 vs. $>=25)$ mean age at starting to go to school mean age at starting to go to school mean age at starting to go to school mean age at starting to go to school mean age at starting to go to school mean age at starting to go to school mean age at starting to go to school $\mathrm{p}=.008$

$\mathrm{p}=.017$

$\mathrm{p}=.030$

$\mathrm{p}=.000$

$\mathrm{p}=.002$

$\mathrm{p}=.020$

$p=.001$

An agglomeration difference is observed for second-generation children, who on average started school enrolment at a higher age in Zurich (5.2 years and 5.3 years) than in Basel (5.1 years and 5.0 years for youth of Turkish and of SSYU origin respectively). The fact that Basel introduced compulsory attendance of two years' kindergarten in 2005 (Moret \& Fibbi 2007), for example, three years earlier than Zurich (2008), showing greater attention to pre-school, can perhaps explain the diverging second-generation result in the two localities.

Though kindergarten attendance is frequent among children of immigrants and has improved over time, age at school entrance remains high compared to immigrant groups in other countries, so that early socialisation takes place mainly in the family and community context. In the literature, there are associated benefits of kindergarten attendance and thus early entry to the education system on school performance, particularly for children of immigrants. Unexpectedly widespread kindergarten attendance makes it difficult to test its impact on the primary school experience of youth of Turkish and SSYU origin.

\subsubsection{Special classes in primary school}

The standard curriculum in compulsory school (primary and lower secondary levels) runs parallel to particular curriculum classes. The most relevant ones 
for migrant children are the so-called 'integration classes' designed for newly arrived children and attended for one year before joining mainstream classes. Migrant children can also be enrolled in special courses in German as a second language and additional support lessons. While integration classes are not relevant for the Swiss-born population, the second type were mentioned as special classes by the respondents who attended them. Other special support measures are offered in some cantons (double-counting of migrant children for the class size, courses taught in the mother language, etc.); those measures are not usually identified as special classes (Moret \& Fibbi 2007).

There are, however, other particular-curriculum classes at primary level designated as special classes but not aimed at addressing the special needs of immigrant children. These are special schools, designed for children with a mental or physical handicap, introductory courses for children who need support in local language learning and properly termed 'special classes', for children with learning impediments or behavioural problems.

Official statistics show higher representation of foreigners in special classes compared to Swiss nationwide (2 per cent of Swiss versus 7 per cent of foreigners) as well as in all three cantons under study; the difference is particularly striking in Basel-Land (6 per cent of Swiss versus 14 per cent of foreigners). Coradi Vellocatt \& Wolter (2004) confirm over-representation of children of migrant origin in special classes. More than half (54 per cent) of children in small classes for pupils with learning impediments were not of Swiss nationality in the 1997-1998 school year. ${ }^{3}$

Although distinctive from an organisational and pedagogical point of view, the different types of special classes are not easily identified, either by pupils or families. Therefore, the results relating to 'special classes' in the TIES survey inevitably conflate the three types of classes. On this basis, the TIES survey revealed low special classes attendance in primary school for youth of Turkish (2.7 per cent) and SSYU origin (2.1 per cent) in Zurich and Basel. There are significant differences between the former groups and the comparison group (1.7 per cent) (Table 4.4).

How can the differences between our findings and the official statistics be accounted for? A strict comparison with official statistics is inaccurate, as a large proportion of TIES respondents are naturalised, hence included in the 'native' group in official statistics, whereas they are counted as 'immigrant origin youth' in TIES research. Moreover, TIES respondents represent a positive selection in comparison to a population defined only by foreign nationality,

3 OFS, Statistique des élèves et étudiants, see www.bfs.admin.ch/bfs/portal/fr/index/ themen/15/02/key/ind5.indicator.51323.513.html?open=507\#507. Accessed 31.01.2010. 
Table 4.4 Attendance at special classes in primary school by origin group

\begin{tabular}{lccc}
\hline & TR & SSYU & CG \\
\hline Attended special classes & 2.7 & 2.1 & 1.7 \\
$\mathrm{~N}=$ & 449 & 431 & 468 \\
\hline
\end{tabular}

TR-CG $\quad X^{2}=10.975 \quad p=.012$

All other differences are not statistically significant.

since they were born in Switzerland; thus, even when they hold a foreign passport, they differ from newcomers, notably in respect of local language proficiency. In the official statistics, however, these two groups are classified together as foreigners, as long as they have not acquired Swiss citizenship.

Different cantonal practices of placing children in special classes also have an impact on children of immigrants. Lischer (2003) states that for a foreign pupil the probability of being assigned to a special class is highest in those cantons where the proportion of pupils in special classes is highest. If the percentage of foreign pupils is high in a canton then significantly fewer of them are placed in special classes.

Do we find similar patterns in the TIES survey? Consider Table 4.2, concerning foreign pupils' enrolment in the three cantons under scrutiny: 23 per cent in canton Basel-Land, ${ }^{4} 25$ per cent in Zurich ${ }^{5}$ in 2008 and 43 per cent of foreign-language-speaking students in Basel-Stadt in 2006. ${ }^{6}$ According to Lischer, we should expect to find the lowest special classes enrolment in Basel-Stadt, which has the highest percentage of foreign-language-speaking students; this is indeed the case for children of SSYU immigrants who are less numerous in special classes than in Zurich ( 1 vs. 3 per cent). But Basel-Stadt has higher special classes enrolment for Turkish origin pupils than Zurich (4 vs. 3 per cent).

In all, the TIES results do not show as high a prevalence of special classes attendance among children of immigrants as documented in official statistics. This can be explained by the fact that TIES respondents born in Switzerland enjoy more stable living conditions and long-standing socialization in

4 Statistical Office of the Canton of Basel-Stadt, see www.statistik.bl.ch/stabl_data/stabl_generator/unterthema.php?thema_id=16\&unterthema=1. Accessed 31.01.2010.

5 Zurich State Department of Education, Division of Educational Planning and Evaluation, see www.statistik.zh.ch/themenportal/themen/jb.php?mt=2\&k=A5\&kn=Bildung. Accessed 31.01.2010.

6 Statistical Office of the Canton of Basel-Land, see www.statistik-bs.ch/themen/15/ schueler_muttersprache07. Accessed 31.01.2010. 
this country than the average foreign pupil. However, second generation Turkish children are more likely to attend special curriculum classes than comparison group and second-generation SSYU children.

\subsubsection{Concentration of immigrant origin children in primary school}

The concentration of students of immigrant origin in primary school is particularly notable in schools in disadvantaged geographic areas. Two aspects are underlined in this respect by Coradi Vellacott et al. (2003): 'Pupils whose first language is not a national language perform less well in a school where they account for a high proportion of the total compared with a school where they would form only a small proportion.'

Since the general rule about primary school enrolment in Switzerland is that pupils are to be registered in the district of their residence, the concentration of immigrant origin children in primary school mirrors neighbourhood segregation in the urban setting. This general principle, known as the 'carte scolaire', contrasts vividly with the rule dominant in other countries where families have latitude in choosing the school of their child, so that school concentration and neighbourhood segregation may be quite different.

We tested the issue of social and geographical concentration of Turkish and SSYU pupils by asking TIES respondents to estimate the average prevalence of immigrant origin children in their primary school: a presence of 75 per cent and above of immigrant origin pupils in the school is defined as a high concentration (Table 4.5). Turkish and SSYU second-generation (13 and 12 per cent, respectively) students attended schools with a high share of immigrant origin children more often than the comparison group (5 per cent).

Migrant origin pupils' concentration at primary school has sharply increased over time, as it seems to be a more relevant issue for respondents under 25. A higher percentage of youth of Turkish and SSYU origin (16 and 18 per cent, respectively) in the younger age category attended primary schools with a high share of children of immigrants compared to those in the older age category ( 9 and 6 per cent, respectively). The same pattern of age group difference is observed for the comparison group (9 per cent versus 3 per cent). This result can be explained by the overall increase in the immigrant population in the country in the last two decades: according to official statistics, the proportion of foreign students in compulsory education increased from 16 per cent in the 1980-1981 school year to 22 per cent in the 1996-1997 school year. ${ }^{7}$

7 Swiss Federal Statistical Office, Statistics on pupils and students. http://www.bfs.admin. ch/bfs/portal/fr/index/themen/15/o2/data/blank/o1.html. 
Table 4.5 Respondents' estimate of immigrant origin pupils' concentration in primary school by origin and age group

\begin{tabular}{lcccccccccc}
\hline & \multicolumn{3}{c}{ TR } & \multicolumn{4}{c}{ SSYU } & \multicolumn{3}{c}{ CG } \\
\cline { 2 - 10 } & Total & $\mathbf{< 2 5}$ & $\mathbf{> = 2 5}$ & Total & $\mathbf{< 2 5}$ & $>\mathbf{= 2 5}$ & Total & $<\mathbf{2 5}$ & $>\mathbf{= 2 5}$ \\
\hline $\begin{array}{l}\text { Concentration } \\
\text { of immigrant } \\
\text { origin pupils * }\end{array}$ & 13.1 & 16.0 & 9.1 & 12.0 & 17.6 & 6.2 & 5.2 & 9.4 & 2.5 \\
$\mathrm{~N}=$ & 449 & 244 & 200 & 418 & 251 & 167 & 463 & 165 & 298 \\
\hline
\end{tabular}

* More than 75 per cent of the children were of immigrant origin

TR-CG $\quad X^{2}=45.723 \quad \mathrm{p}=.000$

SSYU-CG $\quad X^{2}=41.276 \quad \mathrm{p}=.000$

TR $(<25$ vs. $>=25) \quad X^{2}=16.272 \quad \mathrm{p}=.000$

SSYU $(<25$ vs. $>=25) \quad X^{2}=24.227 \quad \mathrm{p}=.000$

CG $(<25$ vs. $>=25) \quad X^{2}=14.132 \quad p=.001$

All other differences are not statistically significant.

Second-generation pre-school and primary education were mapped in this section. Kindergarten attendance is very high in all origin groups; the vast majority of the second generation in the younger age category (significantly higher than their group members aged 25 and over) attended a kindergarten or pre-school institution. Due to this high prevalence, the average age on beginning pre-school or school is five years, lower than the compulsory school age, for example (which is seven in the agglomerations under study). Special classes are attended more often by the second generation (of Turkish origin); yet the figure is not as high as found in the official statistics. Youth with a migrant background attend primary schools with a high concentration of children of immigrants more often. The proportion is higher for the younger age category, signalling an increasing concentration of children of migrants in these schools over time.

\subsection{Children of Turkish and SSYU descent in secondary education}

At the end of primary school pupils move away from small comprehensive schools, which cater for all children living in a neighbourhood, to larger schools with diversified curricula. This subsection deals with the qualifications trajectories through the various tracks of lower and upper secondary school. It finally tackles the school experience of TIES respondents and the overall perception of school in society. 


\subsubsection{Lower secondary schools}

Pupils undergo a selection process at several stages of their educational trajectory. The first selection takes place at the end of primary level, between the ages of ten and twelve. Students are channelled into various tracks with elementary or extended requirements at lower secondary level (§ 4.1.1.2) preparing them for vocational, academic or intermediate training in post-compulsory education.

In spite of the common characteristics of lower secondary school, education systems may vary from canton to canton, since each differs in how they define the number of tracks and the requirements to enter them. In Zurich, lower secondary school is structured according to the separated path model, in Basel-Stadt according to the integrated path and in Basel-Land according to a combination of the separated and cooperative paths (see $§$ 4.1.1.2). In line with the features of the local education systems, pupils are channelled to the path that corresponds to their supposed academic capabilities. The decision is made by teachers and families, taking pupils' performance into consideration.

Studies have repeatedly demonstrated that working-class children, and among them immigrant origin children, are clearly over-represented in the type of school with elementary requirements compared to young Swiss (Hutmacher 1987; Coradi Vellacott \& Wolter 2004). Using a random sample of children in their sixth year of primary school in the German-speaking part of Switzerland, Haeberlin et al. (2004) demonstrated empirically an 'unfair' allocation of youth in this first stage of the selection process by youth displaying the same average skill level, especially at the expense of foreign boys.

What types of lower secondary school did the TIES respondents attend? To what extent do educational tracks at lower secondary differ according to the origin group? As expected, children of immigrants are over-represented in elementary requirements tracks and under-represented in extended requirements tracks (Table 4.6). Seven out of ten follow the former path, almost twice the proportion of the comparison group. Youth of Turkish origin are systematically over-represented in elementary requirements tracks compared to SSYU youth.

Cantonal differences are clear: the educational systems in Basel, especially Basel-Land, appear more selective for all students and particularly for immigrant origin pupils.

Equally sharp are the gender differences: girls perform better in lower secondary than boys in all origin groups (Table 4.7). The gap is widest with Turkish descent girls, who are 1.6 times more likely to attend extended 
Table 4.6 Type of lower secondary school attended by origin group and canton

\begin{tabular}{|c|c|c|c|c|c|c|c|c|c|c|c|c|}
\hline & \multicolumn{4}{|c|}{ TR } & \multicolumn{4}{|c|}{ SSYU } & \multicolumn{4}{|c|}{ CG } \\
\hline & Total & $\mathbf{Z H}$ & BS & BL & Total & $\mathbf{Z H}$ & BS & BL & Total & $\mathbf{Z H}$ & BS & BL \\
\hline $\begin{array}{l}\text { Elementary } \\
\text { requirements }\end{array}$ & 74.2 & 58.2 & 80.8 & 95.1 & 67.6 & 59.4 & 73.8 & 89.1 & 40.3 & 28.0 & 34.6 & 62.7 \\
\hline $\begin{array}{l}\text { Extended } \\
\text { requirements }\end{array}$ & 25.8 & 41.8 & 19.2 & 4.9 & 32.4 & 40.6 & 26.2 & 10.9 & 59.7 & 72.0 & 65.4 & 37.3 \\
\hline $\mathrm{N}=$ & 378 & 178 & 92 & 108 & 354 & 218 & 68 & 68 & 314 & 159 & 52 & 103 \\
\hline \multicolumn{2}{|l|}{ TR-CG } & \multicolumn{3}{|c|}{$X^{2}=82.346$} & $\mathrm{p}=.000$ & & & & & & & \\
\hline \multirow{2}{*}{\multicolumn{2}{|c|}{$\begin{array}{l}\text { SSYU-CG } \\
\text { TR-SSYU }\end{array}$}} & \multicolumn{2}{|c|}{$X^{2}=50.030$} & \multicolumn{2}{|c|}{$\mathrm{p}=.000$} & & & & & & & \\
\hline & & \multicolumn{2}{|c|}{$X^{2}=3.815$} & \multicolumn{2}{|c|}{$p=.051$} & & & & & & & \\
\hline \multicolumn{2}{|c|}{ TR (ZH vs. BL vs. BS) } & \multirow{2}{*}{\multicolumn{2}{|c|}{$\begin{array}{l}X^{2}=49.483 \\
X^{2}=21.214\end{array}$}} & \multicolumn{2}{|c|}{$p=.000$} & & & & & & & \\
\hline \multicolumn{2}{|c|}{ SSYU (ZH vs. BL vs. BS) } & & 21.214 & & $=.000$ & & & & & & & \\
\hline \multicolumn{2}{|c|}{ CG (ZH vs. BL vs. BS) } & \multicolumn{2}{|c|}{$X^{2}=32.300$} & & $=.000$ & & & & & & & \\
\hline
\end{tabular}

Table 4.7 Type of lower secondary school attended by origin group and gender

\begin{tabular}{lcccccccccc}
\hline & \multicolumn{3}{c}{ TR } & \multicolumn{4}{c}{ SSYU } & \multicolumn{3}{c}{ CG } \\
\cline { 2 - 11 } & Total & M & W & Total & M & W & Total & M & W \\
\hline $\begin{array}{l}\text { Elementary } \\
\text { requirements }\end{array}$ & 74.2 & 80.1 & 68.3 & 67.6 & 70.2 & 65.3 & 40.3 & 45.4 & 35.0 \\
$\begin{array}{l}\text { Extended } \\
\text { requirements } \\
\mathrm{N}=\end{array}$ & 25.8 & 19.9 & 31.7 & 32.4 & 29.8 & 34.7 & 59.7 & 54.6 & 65.0 \\
\hline
\end{tabular}

\begin{tabular}{lll}
\hline TR (Men vs. Women) & $X^{2}=6.971$ & $\mathrm{p}=.008$ \\
CG (Men vs. Women) & $X^{2}=3.572$ & $\mathrm{p}=.059$ \\
Men (TR-CG) & $X^{2}=46.047$ & $\mathrm{p}=.000$ \\
Men (SSYU-CG) & $X^{2}=21.579$ & $\mathrm{p}=.000$ \\
Men (TR-SSYU) & $X^{2}=4.841$ & $\mathrm{p}=.028$ \\
Women (TR-CG) & $X^{2}=38.015$ & $\mathrm{p}=.000$ \\
Women (SSYU-CG) & $\mathrm{X}^{2}=29.600$ & $\mathrm{p}=.000$
\end{tabular}

All other differences are not statistically significant.

requirements tracks than Turkish descent boys, whereas the gap is much smaller for SSYU origin and comparison group youth (1.2).

The ranking of groups defined by both gender and background in the TIES survey is the same as the one identified by Haeberlin et al. (2004): Swiss girls are more likely to attend extended requirements classes than Swiss boys, followed by foreign girls and finally foreign boys. The gaps between comparison group girls and second-generation girls in the TIES survey are 
markedly wider, however. Turkish second-generation boys have a distinctly lower level of achievement.

Selection at the end of primary school consolidates during lower secondary into quite differentiated school capital endowments at the end of compulsory school, when pupils reach the second step of the selection process, access to upper secondary school and later labour market participation. A number of studies have shown the crucial importance of the first selection, as it demarcates the scope of opportunities open to pupils both in their school career (Meyer 2003; Rastoldo et al. 2007) and later in labour market participation.

Let us finally consider the strength of influence of parental qualifications on the performance of the child at the end of compulsory school (Table 4.8): children's tracks are analysed in relation to a dichotomised variable accounting for parental school assets.

Table 4.8 Type of lower secondary school attended by origin group and parents' highest achieved education level

\begin{tabular}{lcccccc}
\hline & \multicolumn{2}{c}{ TR } & \multicolumn{2}{c}{ SSYU } & \multicolumn{2}{c}{ CG } \\
\cline { 2 - 7 } & $\begin{array}{l}\text { Compul- } \\
\text { sory and } \\
\text { lower }\end{array}$ & $\begin{array}{c}\text { Higher } \\
\text { than } \\
\text { compul- } \\
\text { sory }\end{array}$ & $\begin{array}{c}\text { Compul- } \\
\text { sory and } \\
\text { lower }\end{array}$ & $\begin{array}{c}\text { Higher } \\
\text { than } \\
\text { compul- } \\
\text { sory }\end{array}$ & $\begin{array}{c}\text { Compul- } \\
\text { sory and } \\
\text { lower }\end{array}$ & $\begin{array}{c}\text { Higher } \\
\text { than } \\
\text { compul- } \\
\text { sory }\end{array}$ \\
\hline $\begin{array}{l}\text { Elementary } \\
\text { requirements }\end{array}$ & 83.2 & 64.6 & 78.1 & 59.6 & 50.0 & 40.6 \\
$\begin{array}{l}\text { Extended } \\
\text { requirements }\end{array}$ & 16.8 & 35.4 & 21.9 & 40.4 & 50.0 & 59.4 \\
$\mathrm{~N}=$ & 163 & 162 & 107 & 188 & $(6)$ & 260 \\
\hline $\begin{array}{l}\text { TR (education levels) } \\
\text { Compulsory edu. and lower (TR-CG) } \\
\text { Higher than compulsory edu. (TR-CG) }\end{array}$ & $\begin{array}{l}\mathrm{X}^{2}=14.546 \\
\mathrm{X}^{2}=4.334 \\
\mathrm{X}^{2}=23.438 \\
\mathrm{X}^{2}=15.609\end{array}$ & $\begin{array}{l}\mathrm{p}=.000 \\
\mathrm{p}=.037\end{array}$ & & & \\
$\begin{array}{l}\mathrm{p}=.000 \\
\mathrm{p}=.000\end{array}$ & & & \\
All other differences are not statistically significant. & & & & \\
\hline
\end{tabular}

It is no surprise that family background impacts on the educational achievement of TIES respondents. In all origin groups, the higher the parental qualifications, the higher the proportion of pupils in the extended requirement tracks. In compulsory schooling, the level of qualification of the parents still makes a difference within the origin group. Although among the SSYU group the difference according to parental background is not significant, it points, however, in the same direction as in the other groups. 


\subsubsection{Post-compulsory education and training}

The Conférence des Directeurs de l'Instruction Publique (CDIP) defined as one of its goals for the period 2008-2014 that 95 per cent of students complete postcompulsory education (2009). Setting this target indicates, of course, that this is not yet the case; at the same time, however, it shows that post-compulsory qualification is already a widespread and accepted social norm. Statistics describing the qualifications of youth aged 20 in the school year 2007-2008 show the absence of post-compulsory education in 13 per cent of this cohort, that is, among 6 per cent of men and 17 per cent of women (Table 4.9).

Table 4.9 Educational achievement of 20-year-old youth in Switzerland (in per cent), 2007-2008

\begin{tabular}{lccc}
\hline & Total & Men & Women \\
\hline Vocational qualification & 69 & 78 & 60 \\
Federal graduation diploma (Matura) & 19 & 16 & 23 \\
No post-compulsory education & 13 & 6 & 17 \\
& 100 & 100 & 100 \\
\hline
\end{tabular}

Source: OFS, Statistique de l'éducation, 2009

Working on a panel study of the first Programme for International Student Assessment(PISA) cohort in Switzerland in 2000, Meyer and his team found that almost all students comply with the social norm prescribing some sort of certified post-compulsory education (Meyer 2004). Within two years after the end of compulsory school, some 99 per cent of students were engaged in education or training. Three fourths of this cohort succeeded in entering post-compulsory education right after lower secondary school; 18 per cent did so after a year, while some 8 per cent had not reached this goal after two years (Hupka 2003).

What is the situation for TIES respondents? How many second-generation students managed to enrol in post-compulsory education and training? How many instead found it difficult to do so and were therefore channelled into some sort of bridging facility? It is notable that the most popular form of post-compulsory education in Switzerland is vocational training (two thirds of post-compulsory qualifications, Table 4.9). Moreover, this takes place mainly in the dual system, entailing the signing of a working contract with an employer. Access to education for those who take up vocational training therefore means at the same time finding a position in this special segment of the labour market. 
Table 4.10 describes the tracks entered by TIES compulsory school leavers. About half of compulsory school leavers entered vocational training (ISCED ${ }_{3}$ B) leading to a fully-fledged vocational qualification, a Federal Vocational Education Training (VET) Diploma (three years or more). Others managed only to enter a lower qualifying vocational track (ISCED ${ }_{3} \mathrm{C}$ ) leading to a Federal VET Certificate (two years): second-generation youth are overrepresented in this track with some 8 to 10 per cent, almost three times more than the comparison group. Altogether, vocational training was taken up by 59 per cent of Turkish origin respondents, 67 per cent of SSYU respondents and 49 per cent in the comparison group. A sixth of second-generation respondents found their way into the most prestigious track of general education (ISCED $3 \mathrm{~A}$ ); however, there are proportionately 2.5 times fewer of them than in the comparison group.

The most important threshold for second-generation youth is access to postcompulsory education: almost one in four Turkish second generation youth, one in six SSYU origin youth and one in eleven comparison group youth could not pass this hurdle. They were channelled into one of the various forms of bridging solutions, meant to ease the transition between lower secondary and upper secondary education and to keep the young person on track.

Table 4.10 Post-compulsory educational attendance for those who completed compulsory education, by origin group and gender

\begin{tabular}{|c|c|c|c|c|c|c|c|c|c|}
\hline & \multicolumn{3}{|c|}{ TR } & \multicolumn{3}{|c|}{ SSYU } & \multicolumn{3}{|c|}{ CG } \\
\hline & M & $\mathbf{w}$ & Total & M & $\mathbf{W}$ & Total & $\mathbf{M}$ & $\mathbf{w}$ & Total \\
\hline $\begin{array}{l}\text { ISCED } 2 \text { (Bridge year } \\
\text { Brückenangebot) }\end{array}$ & 21 & 25.7 & 23.4 & 13.4 & 17.9 & 15.6 & 9 & 7.8 & 8.5 \\
\hline ISCED 3A & 17.1 & 18.3 & 17.7 & 12.3 & 22.9 & 17.6 & 41 & 44 & 42.5 \\
\hline ISCED 3B & 51.4 & 46.9 & 49 & 68.2 & 48.6 & 58.4 & 47.1 & 45 & 46.1 \\
\hline ISCED 3C & 10.5 & 9.1 & 9.9 & 6.1 & 10.6 & 8.4 & 2.9 & 2.9 & 2.9 \\
\hline $\mathrm{N}=$ & 181 & 174 & 355 & 180 & 179 & 359 & 209 & 205 & 414 \\
\hline SSYU (Men vs. Women) & \multicolumn{2}{|c|}{$X^{2}=14.868$} & $\mathrm{p}=.002$ & \multicolumn{2}{|c|}{ TR-CG } & \multicolumn{2}{|c|}{$X^{2}=80.949$} & $p=.000$ & \\
\hline Men (TR-CG) & \multicolumn{2}{|c|}{$X^{2}=37.189$} & $p=.000$ & \multirow{2}{*}{\multicolumn{2}{|c|}{$\begin{array}{l}\text { SSYU-CG } \\
\text { TR-SSYU }\end{array}$}} & \multicolumn{2}{|c|}{$X^{2}=63.067$} & $p=.000$ & \\
\hline Men (SSYU-CG) & \multicolumn{2}{|c|}{$X^{2}=40.156$} & $p=.000$ & & & \multicolumn{2}{|c|}{$X^{2}=8.815$} & $p=.032$ & \\
\hline Men (TR-SSYU) & \multicolumn{2}{|c|}{$X^{2}=10.724$} & $\mathrm{p}=.013$ & & & & & & \\
\hline Women (TR-CG) & \multicolumn{2}{|c|}{$X^{2}=45.121$} & $p=.000$ & & & & & & \\
\hline Women (SSYU-CG) & \multicolumn{2}{|c|}{$X^{2}=29.547$} & $p=.000$ & & & & & & \\
\hline
\end{tabular}


Unexpectedly, gender differences are not statistically significant, with the exception of second-generation SSYU pupils, where the gap is prominent. SSYU women appear more successful than male compatriots in accessing general education, since they are twice as often represented as SSYU men. This performance does not, however, compensate for the higher proportion of SSYU women in low-qualifying VET certificate tracks and in bridging solutions. SSYU women show a stronger polarisation between success and difficulty than men.

In the case of second-generation Turkish pupils, it is worth noting the similarity of school destiny for girls and boys, despite the high proportion of women - one in four - in bridging solutions. This finding tends to refute the hypothesis that there is a specific gender issue among second-generation Turkish pupils. Broad similarity between genders is also notable in the comparison group.

Our findings tally with the results of Meyer (2004), which idently access to post-compulsory education and training as the most crucial juncture for youth of immigrant descent. However, he identifies the main challenge in this respect with immigrant children (e.g., first generation) whereas secondgeneration students, born in the residence country, have careers similar to locals. TIES results tend to show, however, that even native-born secondgeneration youth belonging to more recent immigrant flows are confronted with serious difficulties in entering the vocational training segment of the labour market. TIES findings point at rather limited gender differences; this shows a generalized acceptance of the social norm of post-compulsory enrolment and what is probably effective supervision of this transition.

\subsubsection{Perception and experiences at school}

School is not only important for cognitive transmission, performance and social selection, but also as a place of socialisation and social bonding. It is therefore worth exploring how the second generation perceive their educational environment for their origin group and whether they experienced discrimination at school as individuals.

TIES respondents were asked to give their opinion on the overall reception climate dominating their lower secondary school toward their origin group in relation to locals. Comparison group respondents were asked to give their opinion on how second-generation pupils of Turkish and SSYU descent were welcomed in school. Table 4.11 synthesises these perceptions.

School seemed a sheltered environment to second-generation pupils ofboth immigrant origin and autochthonous youth. Children of immigrants felt as 
Table 4.11 Immigrant groups' sense of being welcome, compared to Swiss students, in lower secondary school, by origin group and agglomeration

\begin{tabular}{lrrrrrrrrrr}
\hline & \multicolumn{3}{c}{ TR } & \multicolumn{3}{c}{ SSYU } & \multicolumn{3}{c}{ CG } \\
\cline { 2 - 10 } & Total & ZH & BS & Total & ZH & BS & Total & ZH & BS \\
\hline Less welcome & 22.5 & 17.3 & 26.7 & 17.8 & 22.9 & 11.5 & 20.0 & 22.8 & 17.7 \\
Just as welcome & 72.6 & 77.7 & 68.4 & 77.8 & 73.8 & 82.8 & 75.9 & 74.3 & 77.4 \\
More welcome & 4.9 & 5.0 & 4.9 & 4.4 & 3.3 & 5.7 & 4.1 & 3.0 & 4.9 \\
$\mathrm{~N}=$ & 449 & 202 & 247 & 431 & 239 & 192 & 468 & 202 & 266 \\
\hline
\end{tabular}

SSYU (ZH vs. BS) $\quad X^{2}=10.376 \quad p=.006$

All other differences are not statistically significant.

welcome as the comparison group at the lower secondary level for the majority of the respondents; some 4 per cent even thought they were more appreciated than locals. Nevertheless, 20 per cent of second-generation pupils felt that their origin group at school was less appreciated. This feeling is stronger in those agglomerations where the migrant group is better represented -Basel for the Turkish origin group and Zurich for the SSYU origin group.

TIES respondents were also asked to state whether they personally experienced hostility and unfair treatment in school (Table 4.12). Half reported such situations; roughly 5 per cent felt frequently targeted. Group, gender and agglomeration differences are statistically irrelevant; however, as for the previous question, it can be noted that those experiences are more frequent in the places where the group is more numerous.

Table 4.12 Frequency of personal experience of hostility or unfair treatment in school, by origin group and agglomeration

\begin{tabular}{lrrrrrr}
\hline & \multicolumn{3}{c}{ TR } & \multicolumn{3}{c}{ SSYU } \\
\cline { 2 - 7 } & Total & ZH & BS & Total & ZH & BS \\
\hline Often & 6.7 & 5.4 & 7.7 & 4.2 & 4.6 & 3.6 \\
Sometimes & 44.8 & 40.4 & 48.2 & 42.5 & 41.8 & 43.2 \\
Never & 48.6 & 54.2 & 44.1 & 53.4 & 53.6 & 53.1 \\
$\mathrm{~N}=$ & 449 & 202 & 247 & 431 & 239 & 192 \\
\hline
\end{tabular}

Agglomeration and group differences are not statistically significant.

School-mates represent the main source of hostility perceived by secondgeneration respondents (Table 4.13), comparable to the perception of secondgeneration Italian and Spanish pupils in a similar study on their experience 
at school (Bolzman et al. 2003). We may therefore assume that this level of unfriendliness among peers is quite common for all second-generation pupils. However, just as many TIES respondents - some two-thirds of those mentioning perceived hostility - report perceived hostility coming from professional figures having institutional power over them as pupils. This proportion is nearly double that observed in the study of second-generation Italian and Spanish pupils. This uncomfortable situation is likely to undermine a young person's confidence in important authority figures and the institution they represent.

Table 4.13 Sources of perceived hostility or unfair treatment in school

\begin{tabular}{lrr}
\hline & TR & SSYU \\
\hline Students & 65.4 & 66.7 \\
Teachers & 55.4 & 52.2 \\
Principal & 6.9 & 4.5 \\
Supervisor or headmaster & 6.5 & 4.0 \\
Others & 3.0 & 4.0 \\
$\mathrm{~N}=$ & 228 & 202 \\
\hline
\end{tabular}

No difference is statistically significant.

Schools develop a meritocratic argument to legitimise their selection functions and decisions. It is interesting to see whether pupils in general and children of immigrants in particular share this view and hence accept their position in the social hierarchy as designated by the school system; in other words, do they find the system equitable? We asked the TIES respondents whether, on the basis of their personal experience, they agreed with the statement that the education system grants 'equal opportunities to everybody'.

Half of the second-generation respondents - but only a third of the comparison group - were convinced that the school system is equitable. About 20 per cent of immigrant descent children were sceptical in this respect, while approximately 30 per cent of respondents felt the same in the comparison group. Neither gender, nor age category nor agglomeration affected respondents' opinions regarding equal educational opportunities.

Overall, the second generation seems confident in the function of the school system as a lever for social promotion. This view represents an essential attitude allowing the individual to envisage possible avenues for change into more desirable conditions; it defines the stage on which they can act 
as individuals. Similar meritocratic opinions were observed among secondgeneration Italian and Spanish pupils (Bolzman et al. 2003).

Lower secondary is a crucial stage in the school career of children, as it represents the first selective screening in their course at quite an early age, between ten and twelve years old. TIES second-generation respondents are over-represented in low qualifying school tracks; more than two thirds attended those tracks in lower secondary school, almost twice as many as in the comparison group.

In all origin groups, girls manage better than boys at this level of education. Turkish girls score especially well in comparison to their male compatriots. In post-compulsory education, however, these gender 'advantages' fade away, so girls tend to enrol in comparable types of education as boys; they end up more often than boys in bridge solutions, a fact that indicates their greater difficulties in accessing vocational training or any other form of upper secondary education.

In spite of those difficulties appearing in lower secondary for boys and in upper secondary for girls, second-generation pupils of Turkish and SSYU descent tend to perceive the school system as giving everybody equal chances. One child in four or five reports scepticism about equity in school, a lower share among children of immigrants than among comparison group youth.

\subsection{Present educational situation}

So far, we have analysed the school career of respondents: the results concerning educational opportunities at the beginning of students' careers showed significant differences between children of immigrants and the native Swiss comparison group. It is worth noting, however, that they are less clear cut than those appearing in the literature.

In this section we present current school outcomes, as the educational situation of TIES respondents beyond compulsory school age is examined. We will first deal with those young people who are now enrolled in an educational path and then examine the situation of those respondents who entered the labour market and are presently not in education.

\subsubsection{Currently in education}

A consistent minority of immigrant and native origin respondents aged 18-35 years old are still in school. Table 4.14 gives an overview of the present 
situation for the two groups and shows the frequency and percentage distribution of TIES respondents according to their enrolment in an educational path.

Table 4.14 Present enrolment in education, by origin group

\begin{tabular}{lcrrrrr}
\hline & \multicolumn{2}{c}{ TR } & \multicolumn{2}{c}{ SSYU } & \multicolumn{2}{c}{ CG } \\
\cline { 2 - 7 } & N & \% & N & \% & N & $\%$ \\
\hline Still in education & 182 & 42.0 & 162 & 35.7 & 182 & 40.7 \\
Out of education & 263 & 58.0 & 266 & 64.3 & 285 & 59.3 \\
$\mathrm{~N}=$ & 445 & 100.0 & 428 & 100.0 & 467 & 100.0 \\
\hline
\end{tabular}

Differences are not statistically significant.

In the TIES survey, migrant origin groups display a younger profile: if the age structure were the same across all origin groups, then $3^{6}$ per cent of second-generation Turkish youth would still be in education, as would 34 per cent SSYU descent youth and 46 per cent of youth in the comparison group.

Younger $(<25)$ respondents are more often in school, as in the case of six out of ten Turkish and comparison group youth and almost half of secondgeneration SSYU youth. One fourth of the comparison group youth over 25 years of age are still in education, compared to one fifth of youth of immigrant background (Table 4.15).

Table 4.15 Proportion of youth still in school, by origin group, age and gender

\begin{tabular}{lccccccc}
\hline & TR & SSYU & CG & & TR & SSYU & CG \\
\hline Men & 39.5 & 33.3 & 42.9 & $<25$ & 57.8 & 48.9 & 63.0 \\
Women & 44.7 & 38.1 & 38.3 & $>=25$ & 20.3 & 21.2 & 26.1 \\
Total & 42.0 & 35.7 & 40.7 & Total & 42.0 & 35.7 & 40.7 \\
$\mathrm{~N}=$ & 445 & 428 & 467 & $\mathrm{~N}=$ & 445 & 428 & 467 \\
\hline
\end{tabular}

TR $(<25$ vs. $>=25) \quad X^{2}=62.348 \quad \mathrm{p}=.000$

SSYU $(<25$ vs. $>=25) \quad X^{2}=35.667 \quad p=.000$

CG $(<25$ vs. $>=25) \quad X^{2}=63.341 \quad p=.000$

All other differences are not statistically significant.

However the overall proportion of respondents currently in education is similar for youth of Turkish origin (42 per cent) and the comparison group (41 per cent). Despite the similar age structure among children of 
immigrants, second-generation SSYU youth are less numerous in school (36 per cent) than is the case for youth of Turkish origin.

Remarkably, second-generation immigrant women tend to be engaged in post-compulsory education as much as their male compatriots: this evidence seems to contradict the assumption that traditional conceptions of gender roles (Kasinitz et al. 1997) prevent women from engaging in training beyond the minimum of compulsory schooling.

Table 4.16 Proportion of respondents still in school, among people under 25, by agglomerations

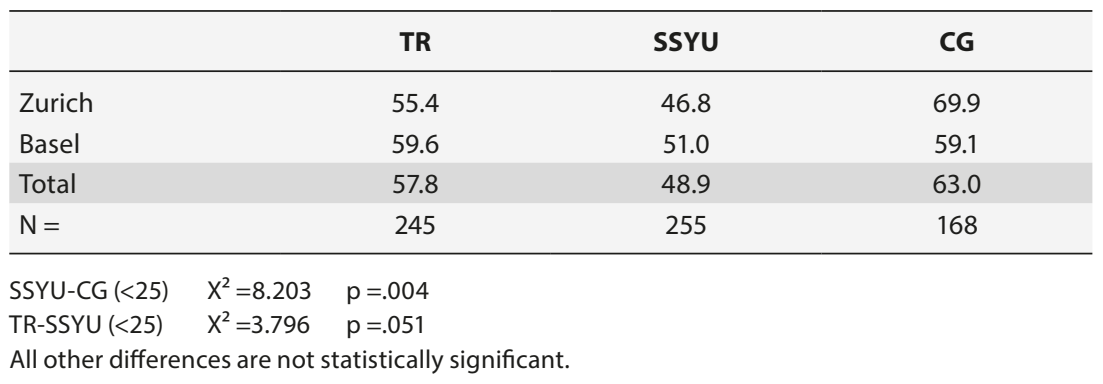

Differences by origin group are especially prominent in Zurich (Table 4.16), where a majority of SSYU origin respondents have already left school, whereas more than two thirds of youth in the comparison group have continued their education, with Turkish origin youth occupying an intermediate position. In Basel, on the contrary, school attendance is less polarised by origin.

\subsubsection{Training of respondents currently in education}

Relatively high school enrolment is an encouraging finding, as it indicates that youth stay on their educational path. In order to understand the relevance of this enrolment properly, the type of schools attended needs to be closely analysed and benchmarked against the extant literature. Which type of training do youngsters still enrolled in school pursue? Does it differ according to the origin group? Because of the significant differences in school paths according to origin at lower secondary level, described in $\S$ 4.3.1, we expect further differentiation at upper secondary level.

The various origin groups may display similar enrolment proportions at upper secondary level; nevertheless they differ sharply in type of school presently attended. Whereas some 40 per cent of the comparison group 
Table 4.17 Current level of education among respondents still in school, by origin group and age

\begin{tabular}{lcccccc}
\hline & \multicolumn{2}{c}{ TR } & \multicolumn{2}{c}{ SSYU } & \multicolumn{2}{c}{ CG } \\
\cline { 2 - 7 } & Mean age & $\begin{array}{c}\text { std. } \\
\text { deviation }\end{array}$ & Mean age & $\begin{array}{c}\text { std. } \\
\text { deviation }\end{array}$ & Mean age & $\begin{array}{c}\text { std. } \\
\text { deviation }\end{array}$ \\
\hline ISCED 2 & 22.5 & 3.0 & 24.0 & 4.0 & 29.8 & 5.3 \\
ISCED 3A & 20.4 & 2.3 & 21.6 & 4.3 & 23.2 & 5.1 \\
ISCED 3B & 20.2 & 3.2 & 20.8 & 4.2 & 22.3 & 4.5 \\
ISCED 3C & 21.1 & 4.6 & 21.6 & 3.2 & 19.7 & 1.2 \\
ISCED 4A & 22.2 & 3.4 & 21.3 & 2.5 & 22.2 & 4.0 \\
ISCED 5A & 24.9 & 4.9 & 25.6 & 5.0 & 25.5 & 4.4 \\
ISCED 5B & 26.7 & 4.9 & 27.1 & 6.3 & 26.8 & 2.7 \\
Total & 21.3 & 4.0 & 22.1 & 4.8 & 23.9 & 4.8 \\
\hline N = & 163 & \multicolumn{7}{c}{} & 141 & & 162 & \\
\hline
\end{tabular}

concentrate in tertiary education, this is the case for only 22 per cent of SSYU origin and 17 per cent of Turkish origin respondents. For all young people still in education, differences at the tertiary level fade in the older age category.

More than half the TIES respondents with migrant backgrounds (whether of SSYU or Turkish origin) who are still in education are enrolled in vocational training (ISCED ${ }_{3} \mathrm{~B}$ and ${ }_{3} \mathrm{C}$ ), versus a third of comparison group respondents. Moreover, the proportion of immigrant origin youth involved in quite low-level vocational training (ISCED ${ }_{3} \mathrm{C}$ ) is twice as big as the comparison group youth; it represents 6 to 7 per cent of those respondents who are still attending school. The predominance of vocational training is a characteristic of the Swiss school system (see Table 4.1); the distribution of TIES respondents aged up to 25 reflects this preponderance, and is especially strong among children of immigrants (seven out of ten immigrant origin youth vs. one third of the comparison group) (Table 4.17).

Let us now consider alternatives to VET. While a few students are still attending classes at lower secondary level (ISCED 2) (be they compulsory school or more often a bridge year), the proportion of students enrolled in an academic track at upper secondary level (ISCED $3 \mathrm{~A}$ ) is limited to one in six among children of immigrants (14 per cent of Turkish and SSYU descent youth) but includes almost one in four respondents in the comparison group.

In other countries, youth of immigrant descent are somewhat concentrated in ISCED 4 types of tracks (Crul \& Heering 2007). This has been interpreted as a way for them to compensate for lower attendance in academic tracks at an earlier stage of their school career; these 'second 
chance schools' allow them to reach more prestigious tracks by taking the 'long route' to higher education (Zweiter Bildungsweg). This does not seem to be the case in Zurich and Basel, since such classes are attended by all origin groups in the same proportion. The compensatory function may be there, but seems equally important for all groups.

Table 4.18 Current level of education among school attendees, by origin group and gender

\begin{tabular}{|c|c|c|c|c|c|c|c|c|c|}
\hline & \multicolumn{3}{|c|}{ TR } & \multicolumn{3}{|c|}{ SSYU } & \multicolumn{3}{|c|}{ CG } \\
\hline & Total & M & $\mathbf{w}$ & Total & $\mathbf{M}$ & w & Total & $M$ & w \\
\hline ISCED 2 & 1.8 & 1.3 & 2.2 & 3.1 & 4.7 & 1.5 & 1.2 & & 2.5 \\
\hline ISCED 3A & 14.4 & 12.7 & 15.7 & 13.8 & 9.4 & 18.2 & 24.9 & 21.1 & 28.8 \\
\hline ISCED 3B & 56.9 & 57.0 & 57.3 & 53.8 & 62.5 & 45.5 & 27.2 & 28.9 & 25.0 \\
\hline ISCED $3 C$ & 6.6 & 6.3 & 6.7 & 5.4 & 4.7 & 6.1 & 3.0 & 4.4 & 1.3 \\
\hline ISCED 4A & 3.6 & 2.5 & 4.5 & 2.3 & 1.6 & 3.0 & 3.0 & 3.3 & 3.8 \\
\hline ISCED 5 & 16.8 & 20.2 & 13.5 & 21.5 & 17.2 & 25.8 & 40.9 & 42.2 & 38.8 \\
\hline$N=$ & 163 & 79 & 84 & 141 & 72 & 69 & 162 & 83 & 79 \\
\hline Women & $\begin{array}{l}\text { (TR-CG) } \\
\text { (SSYU-CG) } \\
\text { (TR-CG) }\end{array}$ & $\begin{array}{l}\hat{x} \\
X^{2} \\
X^{2}\end{array}$ & $\begin{array}{l}30.018 \\
26.436 \\
27.574\end{array}$ & $\begin{array}{l}p=.000 \\
p=.000 \\
p=.000\end{array}$ & & & & & \\
\hline
\end{tabular}

It is notable that men and women in each origin group are enrolled in the same type of schools. Women may be slightly more numerous in ISCED 3A-type schools and boys in VET, but their overall performance is rather similar to that of men (Table 4.18).

To what extent do local educational structures impact on the performance of those who are still enrolled in school? If we consider the comparison group youth, then achievement clearly appears higher in Basel; however, this pattern is not to be found among second-generation youth. There is absolutely no local polarisation in the case of second-generation SSYU youth, and the proportion of Turkish origin youth reaching tertiary education is higher in Zurich than in Basel.

Respondents in the younger age category prevail among youth still enrolled in school. They are mainly in VET tracks, whereas older respondents are more often in tertiary education. Within each origin group, men and women are to be found in similar types of schools. Origin group differences appear to reflect differences in social background. No systematic local 
effect is to be observed on the performance level of respondents who are completing their education.

\subsubsection{Highest achieved level of respondents currently not in education}

Slightly less than two thirds of respondents have completed their education (see Table 4.14); on average for the whole sample, $5^{8}$ per cent among Turkish origin youth, 64 per cent among those of SSYU origin and 59 in the comparison group. Such proportions are higher for respondents over 25: 79-80 per cent of Turkish and SSYU origin youth and 74 per cent of the comparison group.

Before looking at the highest level of education achieved by those who have already left the educational system, let us consider those lacking school qualification beyond compulsory school. Few youth have no or incomplete compulsory education; according to a survey in the Canton of Zurich, the quota for temporary or definite exclusion from school is estimated to be around 5 per cent (Mettauer \& Szaday, 2005). Such cases do not appear in the TIES survey. Using the OECD definition of youth 'at risk' as children who are failing at school and unsuccessful in making the transition to work (Keck et al. 2005; OECD 1996), we consider at risk those young persons who did not enrol in any education after compulsory school or did not complete any upper secondary education they had enrolled in.

In fact, TIES respondents who completed only ISCED level 2 are 'at risk' in OECD terms (Table 4.19). Turkish second-generation youth stand out as the group with the lowest level of post-compulsory qualification, since 17 per cent managed to complete only compulsory school. This is more than twice of the percentage for SSYU youth (eight out of ten) and almost five times the percentage for the comparison group. In all groups, the absence of post-compulsory qualifications affects men more than women. This is especially pronounced among Turkish origin youth, where one man out of five is in this situation versus one woman out of ten.

Turning to a comparison of our findings on low qualifications with available data on the labour force, the Swiss Labour Force Survey (SLFS) (Enquête suisse sur la population active, ESPA) provides interesting benchmarking data. SLFS distinguishes between Swiss and foreigners (independent of their birthplace) and does not provide distinct information on foreigners by nationality. The figures for youth of Turkish origin and comparison group youth roughly correspond to those of SLFS for 2007, which estimates that 5.1 per cent of Swiss and 21.2 per cent of foreign youth aged 18 to 24 quit 
school without any post-compulsory education and are no longer enrolled in school (ESPA 2009). In other words, second-generation Turkish youth are affected by a lack of post-compulsory qualifications to a similar extent as the average foreigner, a category including at least in part first-generation immigrants. SSYU youth in the TIES survey instead run a significantly lower risk of lacking post-compulsory education than the average foreigner in the SLFS.

Table 4.19 Highest achieved level of education among those not in school, by origin group and gender

\begin{tabular}{lrrrrrrrrrr}
\hline & \multicolumn{3}{c}{ TR } & \multicolumn{3}{c}{ SSYU } & \multicolumn{3}{c}{ CG } \\
\cline { 2 - 10 } & M & W & Total & M & W & Total & M & W & Total \\
\hline ISCED 2 & 21.8 & 11.3 & 17.1 & 8.1 & 7.3 & 7.8 & 5.1 & 3.2 & 3.8 \\
ISCED 3A & 4.5 & 7.5 & 5.8 & 5.2 & 8.1 & 6.6 & 13.0 & 16.9 & 14.4 \\
ISCED 3B & 47.4 & 58.5 & 52.1 & 71.9 & 63.4 & 68.4 & 36.2 & 45.2 & 42.0 \\
ISCED 3C & 12.8 & 12.3 & 12.9 & 4.4 & 11.4 & 7.4 & 2.9 & 2.4 & 3.4 \\
ISCED 5 & 13.5 & 10.4 & 12.1 & 10.3 & 9.7 & 9.8 & 42.7 & 32.3 & 36.4 \\
N = & 134 & 110 & 244 & 126 & 122 & 248 & 136 & 135 & 271 \\
\hline
\end{tabular}

TR-CG $\quad X^{2}=82.619 \quad \mathrm{p}=.000$

SSYU-CG $\quad X^{2}=72.032 \quad p=.000$

TR-SSYU $\quad X^{2}=19.272 \quad p=.002$

Other differences are not statistically significant.

Let us now consider the whole spectrum of positions relating to the highest level of education achieved by TIES respondents who have completed their education (Table 4.19). In all origin groups, fully-fledged vocational training (ISCED $3_{3}$ B) lasting three or more years with a Federal VET diploma is the most frequently achieved educational level both among immigrant origin youth (68 per cent for SSYU second generation, 52 per cent for Turkish origin youth) and for the comparison group (42 per cent). The low-requirement VET (ISCED ${ }_{3} \mathrm{C}$ ) lasting one to two years with a Federal VET certificate is much more common for second-generation youth than for the comparison group: among youth of Turkish origin, attendance at this lesser level of vocational training is four times higher than in the comparison group; it is twice as frequent for second-generation SSYU youth than for the comparison group. General education in upper secondary school is more frequent in the comparison group than among second-generation students (14 vs. 6-7 per cent). 
Conversely, the comparison group reached tertiary education (four out of ten) roughly four times more often than migrant origin groups (one out of ten). Half of the Turkish second generation that reached tertiary education attended a university, polytechnic or university of applied science, whereas half went to higher vocational colleges ( 6 vs. 6 per cent respectively). A similar distribution (6 and 4 per cent) is observed among second-generation SSYU youth. In the comparison group, however, 75 per cent attended ISCED $5 \mathrm{~A}$ tertiary education and only 25 per cent attended higher vocational colleges.

Table 4.20 Mean years of schooling, by origin group, agglomerations and gender

\begin{tabular}{lcccccc}
\hline & TR & St. Dev. & SSYU & St. Dev. & CG & St. Dev. \\
\hline Men & 11.8 & 2.3 & 12.1 & 1.7 & 14.0 & 2.9 \\
Women & 12.2 & 2.1 & 12.2 & 2.1 & 13.9 & 2.8 \\
Zurich & 12.1 & 2.1 & 12.0 & 1.7 & 14.0 & 2.8 \\
Basel & 11.9 & 2.3 & 12.4 & 2.1 & 13.9 & 3.0 \\
Total & 12.0 & 2.2 & 12.2 & 1.9 & 14.0 & 2.9 \\
$\mathrm{~N}=$ & 240 & & 245 & & 271 & \\
\hline
\end{tabular}

TR-CG mean year of schooling $p=.000$

SSYU-CG mean year of schooling $p=.000$

All other differences are not statistically significant.

The gender gap in the highest level of achieved education is statistically irrelevant in all origin groups. Exploring this issue through the average number of (theoretical) school years. While there is no gender gap among SSYU youth and the comparison group, women of Turkish origin have a longer educational career - though statistically not significant - (12.2 years) compared to men (11.8 years) (Table 4.20). In fact, they appear to perform better than men in compulsory and upper secondary levels, but they are underrepresented at university (Table 4.19).

A quite worrying finding concerns the intra-generational situation: against the general assumption that achievement of immigrant origin groups improves over time, younger age groups are more affected by a lack of post-compulsory education (Table 4.21) than older respondents. This is the case for both immigrant and autochthonous origin youth.

Finally, there is no evidence of an agglomeration effect for secondgeneration youth and the comparison group, even if youth in Basel are more often affected by lack of post-compulsory qualifications than those in Zurich. 
Table 4.21 Highest achieved level of education among those not in school, by age group and agglomeration

\begin{tabular}{|c|c|c|c|c|c|c|c|}
\hline & \multicolumn{3}{|c|}{ TR } & \multicolumn{2}{|c|}{ SSYU } & \multicolumn{2}{|c|}{ CG } \\
\hline & & $<25$ & $>=25$ & $<25$ & $>=25$ & $<25$ & $>=25$ \\
\hline ISCED 2 & & 21.1 & 13.9 & 12.0 & 4.7 & 13.8 & 0.5 \\
\hline ISCED 3A & & 4.2 & 6.9 & 8.3 & 5.4 & 26.2 & 10.5 \\
\hline ISCED 3B & & 51.6 & 52.8 & 74.1 & 63.8 & 52.3 & 39.0 \\
\hline ISCED $3 C$ & & 17.9 & 9.7 & 3.7 & 10.1 & 1.5 & 4.0 \\
\hline ISCED 5 & & 5.3 & 16.6 & 1.8 & 16.1 & 6.2 & 46.0 \\
\hline \multirow[t]{3}{*}{$N=$} & & 92 & 152 & 121 & 127 & 60 & 211 \\
\hline & & \multicolumn{2}{|l|}{ TR } & \multicolumn{2}{|c|}{ SSYU } & \multicolumn{2}{|c|}{ CG } \\
\hline & & $\mathbf{Z H}$ & BS & $\mathbf{Z H}$ & BS & $\mathbf{Z H}$ & BS \\
\hline ISCED 2 & & 12.7 & 21.3 & 6.4 & 10.8 & & 6.4 \\
\hline ISCED $3 \mathrm{~A}$ & & 5.9 & 5.7 & 4.5 & 9.8 & 13.9 & 15.4 \\
\hline ISCED 3B & & 56.8 & 47.5 & 71.2 & 62.7 & 47.2 & 38.5 \\
\hline ISCED $3 C$ & & 12.7 & 13.1 & 9.6 & 3.9 & 2.8 & 3.8 \\
\hline ISCED 5 & & 11.8 & 12.3 & 8.3 & 12.8 & 36.1 & 35.9 \\
\hline $\mathrm{N}=$ & & 116 & 128 & 149 & 99 & 116 & 155 \\
\hline TR-CG & $(<25)$ & $X^{2}=33.713$ & $p=.000$ & $(>=25)$ & $X^{2}=56.238$ & & \\
\hline SSYU-CG & $(<25)$ & $X^{2}=16.694$ & $p=.005$ & $(>=25)$ & $X^{2}=48.826$ & & \\
\hline TR-SSYU & $(<25)$ & $X^{2}=21.829$ & $\mathrm{p}=.001=$ & & & & \\
\hline
\end{tabular}

This analysis of achievement distinguished between respondents still enrolled in school and those who - for the time being - have completed their education; of course, the former are on average younger than the latter. Over a third of respondents are still in school; this share is similar across gender and origin groups. A majority of second-generation youth are on VET tracks while the comparison group is mainly in tertiary education.

Yet the majority of respondents have completed their education. Their qualifications are noticeably lower than the level reported for youth still in education. Young Turkish men represent quite a high share of youth 'at risk', with no qualification beyond compulsory school. SSYU youth seem able to concentrate on fully-fledged vocational training, similar to the type of qualifications prevailing among SSYU parents.

We do not find support for the hypothesis that second-generation girls achieve higher levels of education than their male compatriots, but there is similarly no support for the competing hypothesis of girls retreating 
from school very early and thus presenting lower levels of achievement. It appears that girls perform better in compulsory school and possibly in upper secondary, but this advantage vanishes at subsequent levels of education.

\subsection{Factors influencing educational achievement}

So far we have described the main features of the school trajectory and achievement of second-generation youth by considering both those who are still enrolled in school and those who have completed their training. In this subsection we examine some of the factors which, according to the literature, are likely to influence educational achievement. For this purpose we singled out parental support, family background and naturalisation.

\subsubsection{Family involvement in education}

Independent of parental educational background, parents and family may affect the educational achievement of children in various ways, for example through valorisation of school achievement and the degree of parental emotional investment. In the TIES survey, respondents were asked about certain aspects of parental or familial involvement in education: assistance of parents and older siblings in homework, practices expressing the importance attributed to school matters by parents (through contact with teachers and discussion of school and training in the family) and respondents' availability in terms of time, beyond household tasks.

The issue of parental involvement in education has been given increasing attention as the role of cultural capital in the dynamics of reproduction has been theorized (Bourdieu 1970). School alone does not bring children academic success; this can better be reached by children who benefit from an advantaged family educational background and effective family support. In Epstein's theory of overlapping spheres of influence (2006) the congruence between the three spheres of school, home and local community produces a mutual fortification of effort which creates educational success, which in turn enhances development for children.

How do these aspects vary across origin groups and between men and women in each group? Are immigrant parents actively involved in the homework process (either by helping or checking the time), at least in their children's view?

For some 30 per cent of youth with immigrant backgrounds, parents often check the time their children spend on homework. This is only the case for 
Table 4.22 Children's perception of parental involvement: Parents check time spent on homework, by origin group and gender

\begin{tabular}{lcccccccccc}
\hline & \multicolumn{3}{c}{ TR } & \multicolumn{3}{c}{ SSYU } & \multicolumn{3}{c}{ CG } \\
\cline { 2 - 10 } & Total & M & W & Total & M & W & Total & M & W \\
\hline Often & 28.6 & 26.0 & 31.3 & 31.7 & 31.9 & 31.6 & 22.5 & 26.2 & 18.3 \\
Sometimes & 41.5 & 45.4 & 37.4 & 35.0 & 42.4 & 27.4 & 37.6 & 40.1 & 35.3 \\
Never & 29.9 & 28.6 & 31.3 & 33.3 & 25.7 & 41.0 & 40.0 & 33.8 & 46.4 \\
N $=$ & 440 & 227 & 213 & 423 & 211 & 212 & 462 & 237 & 225 \\
\hline TR-CG & & $X^{2}=10.663$ & $\mathrm{p}=.005$ & & & & & \\
SSYU-CG & & $\mathrm{X}^{2}=10.034$ & $\mathrm{p}=.007$ & & & & & \\
SSYU (men vs. women) & $\mathrm{X}^{2}=14.252$ & $\mathrm{p}=.001$ & & & & & \\
CG (men vs. women) & $\mathrm{X}^{2}=8.523$ & $\mathrm{p}=.014$ & & & & & \\
All other differences are not statistically significant. & & & & &
\end{tabular}

23 per cent of the comparison group; here the proportion of parents who never check the time spent is the highest (40 per cent) (Table 4.22). SSYU and comparison group boys are more often the target of homework control from their parents than girls; however, in Turkish families, no significant gender gap is to be observed in this respect. This finding is consistent with results of specific research in this field (Gouyon \& Guérin 2006).

Comparison group children can count on frequent help from their parents (22 per cent), whereas only some (14-15 per cent) of Turkish and SSYU youth benefit from this type of support, a significant but not huge difference. However, a third of second-generation youth get no help from their parents, as against a sixth in comparison group families, possibly due to the weaker educational background in immigrant families.

When there are older siblings in the family, they tend to compensate and assume the supporting role of the immigrant parents; this is often the case among youth of Turkish origin (Table 4.23). The need for an enlarged concept of family, not merely parental support, for the achievement of the second generation, has been effectively demonstrated by Crul \& Doormenik (2003) in their study of Turkish and Moroccan second-generation youth in the Netherlands.

Another way of showing support for a child's school career is the interest shown in educational matters. Do immigrant parents discuss educational issues with their children or the educational progress of their children with teachers? Three students in five, across origin groups, talk with their parents about education (Table 4.24): 63 per cent of youth of Turkish origin 
Table 4.23 Older siblings helped with homework, by origin group (selecting respondents with older siblings)

\begin{tabular}{lccc}
\hline & TR & SSYU & CG \\
\hline Often & 29.1 & 20.4 & 6.6 \\
Sometimes & 51.7 & 51.3 & 61.8 \\
Never & 19.1 & 28.3 & 31.5 \\
$\mathrm{~N}=$ & 231 & 228 & 243 \\
\hline
\end{tabular}

TR-CG $\quad X^{2}=42.995 \quad \mathrm{p}=.000$

SSYU-CG $\quad X^{2}=19.192 \quad p=.000$

TR-SSYU $\quad X^{2}=7.610 \quad \mathrm{p}=.022$

often find this opportunity against 59 per cent of SSYU youth and the comparison group. The proportion of parents who never discuss educational prospects with their children is very low, but still more than twice as high in immigrant families ( 5 per cent) than in the comparison group (2 per cent).

Table 4.24 Parents talk about school and training, by origin group

\begin{tabular}{lrrr}
\hline & TR & SSYU & CG \\
\hline Often & 62.6 & 59.0 & 58.8 \\
Sometimes & 32.4 & 35.8 & 39.5 \\
Never & 4.9 & 5.2 & 1.7 \\
$\mathrm{~N}=$ & 447 & 428 & 468 \\
\hline
\end{tabular}

TR-CG $\quad X^{2}=10.951 \quad \mathrm{p}=.004$

SSYU-CG $\quad X^{2}=8.707 \quad \mathrm{p}=.013$

Discussions on education are the rule in immigrant families, as well as contact with school, at least in the child's perception; Turkish parents ( 38 per cent) also talk more often to teachers about their children's educational progress than parents of SSYU youth (26 per cent) and are nearly twice as likely to do so than comparison group parents (20 per cent) (Table 4.25). Almost 11 per cent of respondents in the SSYU and comparison groups reported that their parents never spoke with teachers.

The general picture of parental involvement in the school career of children does not indicate that immigrant parents are less attentive to school matters than the parents of the comparison group; the only point of difference lies with the lower engagement in direct help, which is somewhat compensated for by older siblings. This contradicts the impression that immigrant parents do not support their children and show a lack of interest 
Table 4.25 Parents talk to teachers, by origin group

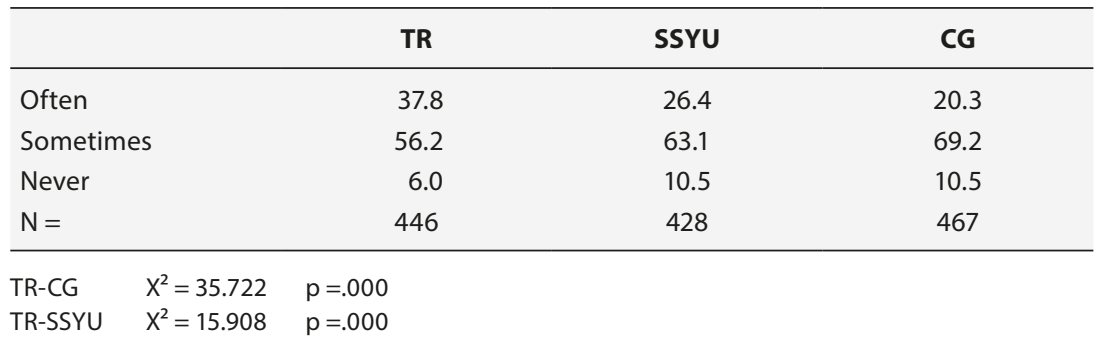

in their children's educational performance. Although such behaviour exists among some immigrant parents, their interest is largely comparable with the interest manifested by autochthonous parents, at least according to their children's perception.

This finding may be unexpected, as it challenges the image of immigrant parents' presence in school. Two reasons may explain this result: desirability bias in children's responses on parental behaviour might have played a role. However, long-standing socialisation of the whole family to the residence country may account for greater convergence in behaviour than the one implied in an oversimplified, undifferentiated image of immigrant families.

It should be stressed that parental involvement in children's education is similar for boys and girls. In fact, in immigrant families, girls more often get help from their parents with homework than second-generation boys. However, the proportion of immigrant parents that never help their daughters is still twice as high as for reference group parents.

Are daughters more constrained by household tasks than sons or do they face the same demands? Gender differences in time allocation for household tasks do not affect all origin groups: the burden of household chores is similar for second-generation Turkish sons and daughters. This finding may challenge commonly held ideas about Turkish families, yet it does not contradict scholarly results (Kohlmann 2000; Nauck 1985). For SSYU and comparison group youth, time allocation varies substantially along gender lines, as girls allocate more time than boys: overall, three out of ten girls carry out household tasks frequently in all origin groups (Table 4.26).

We have tried to explore the degree of supportiveness of immigrant families in their children's schooling, as this type of involvement is expected to play a role in school achievement. In line with this idea, unsatisfactory achievement among children of immigrants is attributed to lack of family backing. Overall, the results do not show strong polarisations in expression of family interest in school matters: second-generation 
Table 4.26 Respondents perform household chores by origin group and gender

\begin{tabular}{lccccccccc}
\hline & \multicolumn{3}{c}{ TR } & \multicolumn{3}{c}{ SSYU } & \multicolumn{3}{c}{ CG } \\
\cline { 2 - 10 } & Total & M & W & Total & M & W & Total & M & w \\
\hline Often & 26.9 & 27.9 & 25.7 & 20.9 & 15.3 & 26.6 & 25.6 & 21.9 & 29.7 \\
Sometimes & 42.8 & 39.2 & 46.7 & 45.1 & 44.3 & 45.8 & 46.5 & 45.2 & 47.8 \\
Never & 30.3 & 32.9 & 27.6 & 34.0 & 40.4 & 27.6 & 27.9 & 32.9 & 22.5 \\
N = & 432 & 222 & 210 & 408 & 204 & 204 & 437 & 227 & 210 \\
\hline
\end{tabular}

SSYU (men vs. women) $\quad X^{2}=11.171 \quad \mathrm{p}=.004$

CG (men vs. women) $\quad X^{2}=6.943 \quad p=.031$

All other differences are not statistically significant.

children felt that parental control was exerted on them, and parental interest is largely comparable with the attention manifested by autochthonous parents, at least in the children's perception. Immigrant parents, however, are perceived as less likely than autochthonous parents to offer concrete support, a shortcoming partially compensated by older siblings, especially in Turkish families. Finally, there is a notable absence of gender difference in family support for school matters in immigrant families, just as in comparison group families. Instead, the findings tend to support the hypothesis of converging messages between family and school in valorising school achievement.

\subsubsection{Intergenerational social mobility}

Sociological research has consistently shown the crucial role played by parents' educational level and socio-economic status in the educational career of their children. More recently, the OECD-inspired PISA study has managed to carry out comparisons across countries on the role of family background: across the 31 participating countries, the impact of parents' socio-economic status on children's educational outcomes was the highest in Switzerland (OECD 2002; Bauer \& Riphahan 2004).

The next tables analyse the highest level of education attained by the respondents out of school and by respondents still attending education (Table 4.28) in relation to parental educational background. For statistical reasons, parental education was collapsed into two categories: only compulsory education and upper secondary (post-compulsory) education. In order to make the origin groups as comparable as possible, 'extreme' examples are omitted: parents with lower than compulsory education are not considered as they are not to be found among the comparison group, 
while parents with tertiary education are not taken into account since they are rare among the immigrant groups.

TIES results show the impact of parental education on school achievement among children who have already left school. The expected relationship between higher parental cultural capital and higher children's performance is confirmed in the case of second-generation SSYU youth: children born to better educated parents have, as adults, lower risks of being unqualified and higher chances of achieving a tertiary education (Table 4.27). This relationship cannot be properly tested in the case of the comparison group because of the clear imbalance in the number of observations in the two categories of parental education. However, the link between parental and youth school achievement is not found among second-generation Turkish youth, as the risks of missing or poor post-compulsory education are similar, whatever the background of the parents. A distinct performance gap based on origin group is observed among children of parents with upper secondary education.

Table 4.27 Highest achieved level of education among respondents not in school, by parents grouped by level of education* and origin group

\begin{tabular}{lllllllllll}
\hline & \multicolumn{3}{c}{ TR } & \multicolumn{3}{c}{ SSYU } & \multicolumn{3}{c}{ CG } \\
\cline { 2 - 11 } & $\begin{array}{c}\text { Com- } \\
\text { pul- } \\
\text { sory }\end{array}$ & $\begin{array}{c}\text { Upper } \\
\text { sec- } \\
\text { ond- } \\
\text { ary }\end{array}$ & Total & $\begin{array}{c}\text { Com- } \\
\text { pul- } \\
\text { sory }\end{array}$ & $\begin{array}{c}\text { Upper } \\
\text { sec- } \\
\text { ond- } \\
\text { ary }\end{array}$ & Total & $\begin{array}{c}\text { Com- } \\
\text { pul- } \\
\text { sory }\end{array}$ & $\begin{array}{c}\text { Upper } \\
\text { sec- } \\
\text { ond- } \\
\text { ary }\end{array}$ & Total \\
\hline ISCED 2 & 17.0 & 18.6 & 18.0 & 9.9 & 2.9 & 5.7 & 16.7 & 4.1 & 4.6 \\
ISCED 3A & 1.9 & 5.1 & 3.6 & 7.0 & 5.8 & 6.3 & 16.7 & 12.3 & 12.5 \\
ISCED 3B & 62.3 & 52.5 & 57.7 & 64.8 & 76.9 & 72.0 & 50.0 & 54.1 & 53.9 \\
ISCED 3C & 11.3 & 13.6 & 12.6 & 15.5 & 1.9 & 7.4 & 0.0 & 4.8 & 4.6 \\
ISCED 5 & 7.6 & 10.2 & 8.1 & 2.8 & 12.5 & 8.5 & 16.7 & 24.6 & 24.4 \\
N= & 52 & 60 & 112 & 69 & 102 & 171 & 6 & 150 & 156 \\
\hline
\end{tabular}

* Selecting only parents with compulsory and upper secondary education

$\begin{array}{llll}\text { SSYU (education levels) } & & X^{2}=20.376 & p=.001 \\ \text { Upper secondary } & \text { TR-CG } & X^{2}=21.593 & p=.001 \\ & \text { SSYU-CG } & X^{2}=15.275 & p=.009 \\ & \text { TR-SSYU } & X^{2}=23.335 & p=.000\end{array}$

Other differences are not statistically significant.

Let us now consider the intergenerational mobility of youth who are still enrolled in school (Table 4.28). As before, within group differences are not statistically significant, as parental educational background - at least 
restricted to the two meaningful categories for comparison purposes - does not seem to have a notable influence on school outcomes in any origin group.

Table 4.28 Highest achieved level of education among respondents attending education, by parents' grouped level of education* and by origin group

\begin{tabular}{lcccccccccc}
\hline & \multicolumn{3}{c}{ TR } & \multicolumn{3}{c}{ SSYU } & \multicolumn{3}{c}{ CG } \\
\cline { 2 - 11 } & $\begin{array}{c}\text { Com- } \\
\text { pul- } \\
\text { sory }\end{array}$ & $\begin{array}{c}\text { Upper } \\
\text { sec- } \\
\text { ond- } \\
\text { ary }\end{array}$ & Total & $\begin{array}{c}\text { Com- } \\
\text { pul- } \\
\text { sory }\end{array}$ & $\begin{array}{c}\text { Upper } \\
\text { sec- } \\
\text { ond- } \\
\text { ary }\end{array}$ & & $\begin{array}{c}\text { Total } \\
\text { Com- } \\
\text { pul- } \\
\text { sory }\end{array}$ & $\begin{array}{c}\text { Upper } \\
\text { sec- } \\
\text { ond- } \\
\text { ary }\end{array}$ & Total \\
\hline ISCED 2 & 69.0 & 69.4 & 69.2 & 63.6 & 68.4 & 67.0 & 33.3 & 51.9 & 51.2 \\
ISCED 3A & 17.2 & 6.5 & 9.9 & 6.1 & 14.0 & 10.2 & 33.3 & 23.5 & 23.8 \\
ISCED 3B & 13.8 & 19.4 & 17.6 & 24.2 & 12.3 & 17.0 & 33.3 & 17.3 & 17.9 \\
ISCED 3C & 0.0 & 4.8 & 3.3 & 3.0 & 0.0 & 1.1 & 0.0 & 2.5 & 2.4 \\
ISCED 5 & & & & 3.0 & 5.3 & 4.5 & 0.0 & 5.0 & 4.8 \\
N= & 28 & 60 & 88 & 35 & 60 & 95 & 3 & 77 & 80 \\
\hline
\end{tabular}

* Selecting only parents with compulsory and upper secondary education

Education level differences are not statistically significant

$\begin{array}{llll} & \text { TR-CG } & X^{2}=11.917 & \mathrm{p}=.036 \\ \text { Upper secondary } & \text { TR-CG } & X^{2}=11.833 & \mathrm{p}=.037 \\ & \text { SSYU-CG } & \text { n.s } & \end{array}$

Other differences are not statistically significant.

Origin group differences appear more salient among children of better educated parents: youth of Turkish descent appear to have particular difficulty in attaining tertiary education.

\subsubsection{Naturalisation: A positive selection?}

In the absence of jus soli in Switzerland (see § 2.1.3), second-generation youth willing to acquire country of immigration citizenship have to engage in a naturalisation procedure. Therefore, as previous studies on secondgeneration youth show, naturalised youth represent a selected group in comparison to non-naturalised youth (Bolzman et al. 2003: Fibbi et al. 2005).

Census data in 2000 showed this trend for all groups, whether belonging to long established migration flows or more recent ones (Fibbi et al. 2007). However, ten years ago naturalisation was not the phenomenon it has since become, that is, related to a minority of the second generation: today it affects the vast majority of Swiss-born youth from the two non-EU areas 
under study. Turkish and SSYU groups have shown unprecedentedly high naturalisation rates in the last ten years (see $§$ 2.1.3). Is naturalisation always selective when three young persons in four in the second generation hold a Swiss passport (see § 2.5)?

Naturalisation retains the selective character identified in previous studies on the second generation in the case of youth of Turkish descent: in fact, the education levels of naturalised youth are higher than those of youth without Swiss nationality (Table 4.29). Non-naturalised youth with no education beyond compulsory school outnumber naturalised youth by five to one. Swiss youth of Turkish descent are three times more likely to have tertiary education than Turkish citizens born in Switzerland. However, this disparity does not materialise in the case of second-generation SSYU youth in any statistically significant way, though the share of youth who have completed tertiary education among naturalised youth is 1.6 times higher than among those not naturalised.

Table 4.29 Highest achieved education of respondents out of education by Swiss citizenship and by origin group

\begin{tabular}{lcccc}
\hline & \multicolumn{2}{c}{ TR } & \multicolumn{2}{c}{ SSYU } \\
\cline { 2 - 5 } & CH Citizen & Non-CH citizen & CH Citizen & Non-CH citizen \\
\hline ISCED2 & 8.5 & 41.0 & 7.1 & 9.3 \\
ISCED3 & 76.8 & 54.1 & 81.9 & 84.0 \\
ISCED5 & 14.7 & 4.9 & 11.0 & 6.7 \\
N $=$ & 182 & 62 & 178 & 70 \\
\hline
\end{tabular}

TR (naturalisation status) $\quad \mathrm{X}^{2}=35.384 \quad \mathrm{p}=.000$

Naturalisation and educational career are undoubtedly associated, but it is hard to identify whether educational achievement influences citizenship acquisition or if the link runs in the opposite direction. The average age at naturalisation is 18 (see $\S 2.5$ ). At this age critical decisions related to the educational career of the second generation have already been made, as channelling of pupils into different educational paths has already taken place. Naturalisation may be one step in the construction of a life for the young candidate, whereas education is probably a criterion under scrutiny during the application procedure.

A meaningful test of educational achievement must take into account the educational capital of the family, along with naturalisation status. We therefore compared naturalised youth of Turkish and SSYU descent to 
Swiss-by-birth youth by selecting the children of parents who attended compulsory and upper secondary education, a selection which brings the profile of the parents closer together.

Table 4.30 Highest achieved level of education among naturalised respondents $(a 8 a=1)$ attending school, by parents grouped by level of education* and by origin group

\begin{tabular}{lcccccccccc}
\hline & \multicolumn{3}{c}{ TR } & \multicolumn{3}{c}{ SSYU } & \multicolumn{3}{c}{ CG } \\
\cline { 2 - 11 } & $\begin{array}{c}\text { Com- } \\
\text { pul- } \\
\text { sory }\end{array}$ & $\begin{array}{c}\text { Upper } \\
\text { sec- } \\
\text { ond- } \\
\text { ary }\end{array}$ & Total & $\begin{array}{c}\text { Com- } \\
\text { pul- } \\
\text { sory }\end{array}$ & $\begin{array}{c}\text { Upper } \\
\text { sec- } \\
\text { ond- } \\
\text { ary }\end{array}$ & & $\begin{array}{c}\text { Total } \\
\text { Com- } \\
\text { pul- } \\
\text { sory }\end{array}$ & $\begin{array}{c}\text { Upper } \\
\text { sec- } \\
\text { ond- } \\
\text { ary }\end{array}$ & Total \\
\hline ISCED 2 & 65.0 & 63.8 & 64.2 & 52.2 & 63.3 & 60.6 & 33.3 & 51.9 & 51.2 \\
ISCED 3A & 15.0 & 8.5 & 10.4 & 4.3 & 16.3 & 12.7 & 33.3 & 23.5 & 23.8 \\
ISCED 3B & 20.0 & 21.3 & 20.9 & 34.8 & 14.3 & 19.7 & 33.3 & 17.3 & 17.9 \\
ISCED 3C & 0.0 & 6.4 & 4.5 & 4.3 & 0.0 & 1.4 & 0.0 & 2.5 & 2.4 \\
ISCED 5 & & & & 4.3 & 6.1 & 5.6 & 0.0 & 5.0 & 4.8 \\
N= & 19 & 46 & 65 & 23 & 51 & 74 & 3 & 77 & 80 \\
\hline
\end{tabular}

* Selecting only parents with compulsory and upper secondary education Within group differences are not statistically significant.

None of the observed differences appear to be statistically significant when comparing family education background within each origin group or when comparing origin groups within the lower and higher level of parental education. Naturalised youth of the two immigrant groups have very similar performances and the gap with the autochthonous youth has markedly narrowed to not-statistically-significant differences (Table 4.30). This remarkable catch-up effect of the non-EU youth of immigrant descent is not acknowledged in public opinion. In fact, official statistics based on formal citizenship conceal part of the achievement of children of immigrants and nourish a stereotypical image of a persisting gap between second-generation and autochthonous youth. Recall the findings relative to youth of Italian and Spanish descent, which challenged even more strongly such perceptions of the second generation; once family educational background was taken into account, native-born youth of Mediterranean origin succeeded in closing the performance gap with Swiss-by-birth, whereas the naturalised second generation outperformed autochthonous young people (Bolzman et al. 2003).

The notion that that cultural difference may account for the lack of out-performance between Mediterranean and Balkan youth should be 
avoided. Naturalisation is much higher in the present non-EU second generation $(75 \%)$ than for the previous, EU second-generation groups (41\%). Naturalisation continues to be selective, but not to the same extent as before. Moreover, the differential length of stay in Switzerland may have influenced the somewhat different outcome, the latter group having accumulated fewer social resources to mobilise in order to achieve more ambitious results in school.

In this subsection we tackled the factors influencing educational achievement and singled out three: parental support, family background and naturalisation.

Filtered by children's perception of their parents' behaviour, no striking polarisation in parental involvement in school matters was found, although the meagre school capital of immigrant parents is reflected in lower concrete support in daily homework practices. This parental involvement concerns both sons and daughters, however. This finding may be unexpected, as it challenges the image of immigrant parents' presence in school. This result may be explained in two ways. Desirability bias in children's response on parental behaviour might have played a role. However, long-standing socialisation of the whole family to the residence country may account for greater convergence in behaviour than the one imputed to an oversimplified, undifferentiated image of immigrant families.

The general rule that parental education has a decisive impact on children's achievement is not contradicted in our results. However, it does not find systematic confirmation within each origin group: in the new social environment, better educated Turkish origin parents do not seem to succeed as well in transmitting their cultural assets to their children.

Finally, the positive selection effect of naturalisation that is well established in the literature is only partially corroborated by the present finding: it is borne out among Turkish but not second-generation SSYU youth.

\subsection{Conclusions}

This chapter described the educational trajectory and the achievement of second-generation Turkish and SSYU youth. The vast majority attend kindergarten, a practice that is increasing, reducing the gap in kindergarten attendance between second-generation and comparison group children. Despite this progressive conforming to local standards, the average age at first contact with school occurs at the age of five. In primary school, 
second-generation children are channelled into special curriculum classes more often than comparison group children; yet this share is lower than the one observed in official statistics, where pupils are analysed by nationality and not also by place of birth. This contrast shows the advantage of nativeborn second-generation children over immigrant children.

The first selection takes place at the end of primary school, when pupils are aged between ten and twelve; this determines which type of lower secondary track is open to them. Second-generation youth are overrepresented in low-qualifying school tracks: more than two thirds attend these tracks, almost twice as many as in the comparison group.

During compulsory school, girls in all origin groups do better than boys; this is especially the case for Turkish girls in comparison to their male compatriots. In post-compulsory education, however, these 'advantages' fade away. Second-generation young women end up more often than young men in bridge solutions. This finding points to their difficulty in accessing vocational training or other forms of upper secondary education. SSYU origin women show a stronger polarisation between high and low achievement than SSYU men, whereas Turkish origin and comparison group women are confronted with similar chances of success and failure as their male compatriots.

The analysis of achievement has to differentiate between youth still enrolled in education - generally younger - and those who have completed it. Over a third of respondents are still enrolled in school; this share is similar across gender and origin groups. Here we find again the expected cleavage between origin groups, with second-generation youth mainly engaged in VET tracks and the comparison group mostly in tertiary education. However, the share of older respondents in tertiary education is similar across groups.

For now, the majority of respondents have completed their education. Their qualifications are noticeably lower than the level reported for youth still in training. Turkish youth, especially men, represent a rather high share of youth 'at risk', with no qualifications beyond compulsory school. SSYU youth appear more concentrated on fully-fledged vocational training, reproducing the high frequency of vocational qualifications observed among their parents.

The findings do not support the hypothesis that second-generation women achieve higher levels of education than their male compatriots, although they seem better able to avoid dead-ends such as lack of postcompulsory education or meagre post-compulsory qualifications. These results clearly refute the competing hypothesis of women retreating from school very early and thus presenting lower levels of achievement than men. 
We found no evidence of an agglomeration effect on the achievement of second-generation youth or the comparison group, though the Basel youth appear more affected by lack of post-compulsory qualifications than Zurich youth.

Two issues are worth noting in the relations between school and families: the perception of equity and family involvement. Children of immigrants appear more confident than comparison group children in the role of school in granting equal chances to everybody. This confidence, despite perceptible hostility suffered in school, mirrors the family mobilization for school success during compulsory education. Parents show interest in the school behaviour of their children and exert control over them; older siblings mobilise together with parents in supporting school efforts in immigrant families to a similar extent as in comparison group families, although control is stronger than help.

Among the factors influencing educational achievement, we analysed family background and naturalisation. As expected, our results reflect the norm that parental education has a decisive impact on children's achievement. However, we find signs of downward intergenerational school mobility in the Turkish group, since better educated Turkish parents do not seem to succeed as well in transmitting their cultural assets to their children. The well-established hypothesis of an association between naturalisation and higher educational achievement finds only support among secondgeneration Turkish youth, but not for second-generation SSYU youth.

\section{References}

Bauer, Thomas, John Haisken-DeNew \& Christoph Schmidt (2004), 'International labor migration, economic growth and labor markets: The current state of affairs', RWI Discussion Paper 20: 50 .

Bauer, Philipp \& Regina T. Riphahn (2004). 'Heterogeneity in the Intergenerational Transmission of Educational Attainment: Evidence from Switzerland on Natives and Second Generation Immigrants.' Institute for the Study of Labor (IZA), (Discussion Paper No. 1354).

Bolzman, Claudio, Rosita Fibbi \& Marie Vial (2003), 'Secondas - Secondos': Le processus d'intégration des jeunes issus de la migration espagnole et italienne en Suisse. Zurich: Seismo.

Bourdieu, Pierrre \& Jean-Claude Passeron (1970), La reproduction. Paris: Éditions de Minuit.

CDIP (2009), Stratégie 2008-2014 de la CDIP. Programme de travail 2008-2014. Version actualisée 2009, Conférence des Directeurs de l'Instruction Publique, adoptée par l'Assemblée plénière, Bern, le 18 juin 2009.

Coradi Vellacott, Maja, Judith Hollenweger, Michel Nicolet \& Stefan C. Wolter (2003), Soziale Integration und Leistungsförderung. Thematischer Bericht der Erhebung PISA 2000. Bern and Neuchâtel: EDK/BFS. 
Coradi Vellacott, Maja \& Stefan C. Wolter (2004), 'Equity in the Swiss education system:Dimensions, causes and policy responses', national report from Switzerland contributing to the OECD's review, 'Equity in Education'. Aarau: Swiss Coordination Centre for Educational Research.

Crul, Maurice \& Jeroen Doomernik (2003), 'The Turkish and Moroccan second generation in the Netherlands: Divergent trends between and polarization within the two groups', International Migration Review 37(4): 1039-1064.

Crul, Maurice \& Liesbeth Heering (eds) (2007), The position of the Turkish and Moroccan second generation in Amsterdam and Rotterdam. Amsterdam: Amsterdam University Press.

DIP Genève (2010), 'L'enseignement à Genève: Edition 2009', Service de la recherche en education. Geneva: Département de l'instruction publique.

Epstein, Joyce L. (2006), 'Connecting home school and community', in Maureen T. Hallinan (ed.), Handbook of the sociology of education. New York: Springer.

ESPA (2009),Jeunes quittant prématurément l'école selon la nationalité, de 2003 à 2009. Neuchâtel: Office fédéral de la Statistique. http://www.bfs.admin.ch/bfs/portal/fr/index/themen/15/o2/ key/ind 5 .indicator.51325.html?open $=507 \# 507$

Fibbi, Rosita, Mathias Lerch \& Philippe Wanner (2005), 'Processus de naturalisation et caractéristiques socio-économiques des jeunes issus de la migration', in Office fédéral de statistique (OFS) (ed.), L'intégration des populations issues de l'immigration en Suisse:Personnes naturalisées et deuxième génération, 1-57. Neuchâtel: OFS.

Fibbi, Rosita, Mathias Lerch \& Philippe Wanner (2007), 'Naturalisation and socio-economic characteristics of youth of immigrant descent in Switzerland', Journal of Ethnic and Migration Studies 33(7): 1121-1144.

Gouyon, Marie \& Sophie Guérin (2006), 'L'implication des parents dans la scolarité des filles et des garçons: Des intentions à la pratique', Economie et Statistique (398-399): 59-84.

Haeberlin, Urs, Christian Imdorf \& Winfried Kronig (2004), Von der Schule in die Berufslehre: Untersuchungen zur Benachteiligung von ausländischen und von weiblichen Jugendlichen bei der Lehrstellensuche. Bern: Haupt Verlag.

Hupka, Sandra (2003), 'Ausbildungssituation und -verläufe', in EDK/CDIP \& BFS/OFS (eds), Wege in die nachobligatorische Ausbildung. Die ersten zwei Jahre nach Austritt aus der obligatorischen Schule. Zwischenergebnisse des Jugendlängsschnitts TREE. Neuchâtel: BFS/OFS.

Hutmacher, Walo (1987), 'Le passeport ou la position sociale? Quelques données sur la réussite et l'orientation scolaire d'enfants suisses et étrangers compte tenu de la position sociale des familles', 228-256, in Les enfants de migrants à l'école. Paris: CERI OCDE.

Kasinitz, Philip, John Mollenkopf, Mary Waters, Nancy Lopez \& Dae Young Kim (1997), 'The school to work transition of second generation immigrants in metropolitan New York: Some preliminary findings', paper presented to the Levy Institute Conference on the Second Generation, Bard College, Annandale-on-Hudson, 25 October 1997.

Keck, Andrea, Anna-Verena Fries, Bernard Favre, Jacqueline Lurin \& Kai Felkendorff (2005), 'Cross-sectoral partnership for youth at risk - Country report Switzerland', Cross-Sectoral Partnerships Country Representatives, organized by the OECD within the current CERI programme of work 'Partnerships for Inclusion'. Seoul: CERI, OCDE.

Kohlmann, Annette (2000), 'Entscheidungsmacht und Aufgabenallokation in Migrantenfamilien', in Empirische Beiträge zur Familienentwicklung und Akkulturation. Familien ausländischer Herkunft in Deutschland. Opladen: Leske + Budrich.

Lanfranchi, Andrea (2002), Schulerforlg von Migrationskindern. Die Bedeutung familienergänzender Betreueung in Vorschulalter. Opladen: Leske + Budrich.

Lischer, Rdf. (2003), 'Integrierte Fremde? Eine statistische Antwort. Ausländische Kinder und Jugendliche im schweizerischen Bildungssystem', in EDK/CDIP (ed.), Schul- und Bildungslaufbahn von immigrierten 'leistungsschwachen' Schülerinnen und Schülern. Bern. 
Mettauer, Belinda \& Christopher Szaday (2005), 'Befragung der Zürcher Oberstufengemeinden zum Thema Schulausschluss. Bericht über die Ergebnisse'. http://www.bildungsdirektion. zh.ch/internet/bi/de/publikationen/evaluationen. SubContainerList.SubContainerı.ContentContainerList.o061.DownloadFile.pdf. Accessed 30.06.2008

Meyer, Thomas (2003), Jugendliche mit Migrationshintergrund. Wege in die nachobligatorische Ausbildung. Die ersten zweiJahre nach Austritt aus der obligatorischen Schule. Zwischenergebnisse des Jugendlängsschnitts TREE, EDK/CDIP, BFS/OFS. Neuchâtel: BFS/OFS.

Meyer, Thomas, (2004), 'Lécole... et après? Résultats intermédiaires de l'étude longitudinale TREE', 1-35, TREE, EDK/CDIP, BFS/OFS. Neuchâtel: BFS/OFS

Moret, Joëlle \& Rosita Fibbi (2007), 'The educational system in the cantons BS, BL and ZH. Structures and issues of international codification for comparability purposes'. 1-22, Neuchâtel: Swiss Forum for Migration and Population Studies.

Moret, Joëlle \& Rosita Fibbi (2010), Enfants migrants de o à 6 ans: quelle participation pour les parents? Berne: Conférence suisse des directeurs cantonaux de l'instruction publique.

Nauck, Bernhard (1985), Arbeitsmigration und Familienstruktur. Eine soziologische Analyse der mikrosozialen Folgen von Migrationsprozessen. Frankfurt: Campus.

Rastoldo, François, Annick Evrard \& Jacques Amos (2007), Les jeunes en formation professionnelle. Rapport I: Entrée en formation professionnelle et parcours de formation des diplômés. Geneva: Service de la recherche en éducation.

OECD (2002), 'Education at a Glance', OECD Indicators 2002. Paris: OECD.

OFS (2009), Statistique de l'éducation. Neuchâtel: OFS.

OFS (2009) Statistique des élèves et des étudiants. Neuchâtel: OFS. 


\section{Labour market position of the second generation}

The labour market integration of immigrants and their children is a key issue both in public debate and scientific research. Together with educational issues, labour market outcomes are a fundamental measure of the degree of integration of immigrant groups. Research has shown that the upward mobility and socio-cultural integration of the first generation often remains modest. The most important changes occur at the transition between generations, hence the interest in second-generation outcomes.

Entering the labour market is the litmus test of the inclusion of foreign origin groups as they settle permanently in their immigration country. Conditions and opportunities for integration, as well as individual and group characteristics, are crucial in determining the outcomes of youth of immigrant descent. The literature focuses on structural integration and intergenerational occupational/earnings mobility between first and second generations as the crucial indicator of the loss over time of the distinctive position of minority groups in their new society.

Studies of the social mobility of second-generation youth are deeply rooted in the assimilation strand encapsulated in the old notion of moving up in three generations 'from peddler to plumber to professional' (Suro 1998), an individual path out of ethnic and ascriptive identities favouring the advancement in the labour market. A similar optimism underlies the immigrant advantage theory of Kasinitz, Mollenkopf and Waters (2008), which stresses motivational factors in explaining the powerful resilience of second-generation children and hence their capacity to avoid the pitfalls of social reproduction.

The unfulfilled promise of assimilation theory for certain immigrant groups undermines its assumptions. The structuralist approach focuses on labour market segmentation for first-generation immigrants and suggests that open or covert discrimination limits the second generation to similar structural positions to their parents. The theory of segmented assimilation is a good example in point (Zhou 1997).

Insightful theoretical advancements in this field come from the new economic sociology, with the concept of social construction of economic processes. This embeddedness (Tilly \& Tilly 1994) entails attention to social ties and cultural belonging, in which economic behaviour is rooted. 
The labour market outcomes of children of immigrant descent is considered here as reflecting the opportunities in the immigration society (especially at the educational level), family condition, cultural orientation and individual preferences. In this chapter, the main features of labour market outcomes of youth of Turkish and SSYU origin will be described with the help of selected indicators, and patterns of their labour market position will be identified relative to the comparison group.

The labour force participation rate is indicative of the degree of integration into the formal labour market. With the unemployment rate, it is possible to gain a general overview of the level of labour market activity; these rates will be broken down by gender, agglomeration and age categories. Further research questions related to the position of youth with migrant background in the labour market are whether they are working under fixed contracts, supervising other employees, have access to public sector employment opportunities and whether they are over- or under-qualified for their current jobs.

Discrimination in the labour market affects the second generation and their labour market position together with other individual and contextual factors.

\subsection{Labour market participation of foreigners and the second generation}

An overview of statistical information on the presence of foreigners in the labour market constitutes the backdrop to the description of Turkish and SSYU second-generation participation.

\subsubsection{Labour market position of foreigners}

To understand the labour market in the period of the TIES survey, coinciding with a phase of economic prosperity, we refer to the Swiss Labour Force Survey (SLFS) data. We observe the low prevalence of unemployment in the permanent resident population on average for 2008 (Table 5.1).

Foreign nationals represent a high share of the 4.3 million employed permanent residents, reaching more than a fifth in the second quarter of 2008 (22.6 per cent or 989,000). Between the second quarter of 2007 and the second quarter of 2008 , the number of unemployed fell from 156,000 to 147,000 persons $(-5.9$ per cent). The unemployment rate reached 3.36 per cent of the economically active population in 2008 (2007:3.6 per cent), with 
Table 5.1 Composition of permanent resident population aged 15 and over by employment status, 2008 (in thousands)

\begin{tabular}{lrrrrrrc}
\hline & \multicolumn{2}{c}{ Total } & \multicolumn{2}{c}{ Swiss } & \multicolumn{2}{c}{ Foreign } \\
\cline { 2 - 7 } & \multicolumn{1}{c}{ N } & \multicolumn{1}{c}{$\%$} & \multicolumn{1}{c}{ N } & \multicolumn{1}{c}{$\%$} & N & $\%$ \\
\hline Economically active population & $\mathbf{4 3 7 5}$ & $\mathbf{6 8 . 2}$ & $\mathbf{3 3 8 6}$ & $\mathbf{6 7 . 6}$ & $\mathbf{9 8 9}$ & $\mathbf{7 4 . 4}$ \\
Self-employed and family workers & 671 & 10.5 & 594 & 11.7 & 77 & 5.8 \\
Salaried workers and apprentices & 3557 & 55.4 & 2707 & 54.2 & 851 & 64 \\
Unemployed persons & 147 & 2.3 & 85 & 1.7 & 61 & 4.6 \\
& & & & & & \\
Economically inactive population & $\mathbf{2 0 4 2}$ & $\mathbf{3 1 . 8}$ & $\mathbf{1 7 0 1}$ & $\mathbf{3 3 . 4}$ & $\mathbf{3 4 1}$ & $\mathbf{2 5 . 7}$ \\
People undergoing training & 299 & 4.7 & 239 & 4.7 & 60 & 4.5 \\
Housewives/house husbands & 271 & 4.2 & 191 & 3.8 & 80 & 6 \\
Retirees, pensioners and other & 1472 & 22.9 & 1271 & 24.9 & 201 & 15.2 \\
Population over 15 & 6417 & 100 & 5087 & 101 & 1330 & 100.1 \\
\hline
\end{tabular}

Source: FSO, SLFS 2008 http://www.bfs.admin.ch/bfs/portal/fr/index/themen/03/22/lexi.html

foreigners more affected than the autochthonous population (6.2 per cent vs. 2.5 per cent) (SLFS 2009).

Official statistics systematically document the autochthonous and foreign population separately but not according to nationality, though foreigners differ markedly in employment status on this basis. Workers holding a foreign passport are under-represented among the self-employed and pensioners, but are over-represented as housewives, the unemployed and other inactive persons, and also as employees.

To grasp unemployment among the various nationality groups, it is necessary to look at census data from 2000. This shows that employment activity rates for men and women vary according to origin group. High activity rates (93.7 per cent) are observed for Swiss men and men from older migration flows; men from Turkey and the Federal Republic of Yugoslavia have lower rates (88.6 and 88.9 per cent, respectively). In all groups, women present lower activity rates than men. The gap between men and women is, however, similar in the groups of concern in this study: some 15 per cent lower activity rates are observed among Swiss women as well as among women from Turkey and the Federal Republic of Yugoslavia (77.9; 72.5; 73.3 per cent, respectively) (Wanner et al. 2005).

Activity rates also increase with age in all groups (Table 5.2). The employment activity rate for Swiss men and foreign men aged 15-24 is similar, although Swiss men aged 25-39 have higher rates. Women's rates are consistently lower than men's; only in the younger age category do Swiss women 
and men show similar activity rates. Activity rates for foreign women are lower than for Swiss women; the gap between these groups aged 25-39 seems to narrow from 2005 to 2008.

Table 5.2 Employment activity rate of Swiss and permanent resident foreigners according to gender and age, 2005 and 2008

\begin{tabular}{llll}
\hline & & $\mathbf{2 0 0 5}$ & $\mathbf{2 0 0 8}$ \\
\hline MEN & & & \\
Swiss & Age 15-24 & 60.8 & 63.0 \\
& Age 25-39 & 94.1 & 95.2 \\
Foreigners & & & \\
& Age 15-24 & 61.6 & 65.7 \\
WOMEN & Age 25-39 & 89.4 & 92.5 \\
Swiss & Age 15-24 & & \\
& Age 25-39 & 60.4 & 62.4 \\
Foreigners & Age 15-24 & 80.3 & 83.8 \\
& Age 25-39 & 53.1 & 56.6 \\
& & 66.4 & 71.3 \\
\hline
\end{tabular}

Source: FSO, SLFS 2008 http://www.bfs.admin.ch/bfs/portal/fr/index/themen/03/02/blank/ data/03.html

It is difficult to find statistics based on nationality providing general trends relating to the labour market position of foreign residents. The TIES survey, however, describes the condition of the second generation with a focus on two immigrant groups and their children, who are at the centre of public debate but relatively unknown. Given the labour market situation of immigrants or foreigners, what is the position of the second generation relative to the comparison group? In the next section indicators related to position at work and trend in current work status and labour force participation are used to differentiate between the comparison group and children of immigrants.

\subsubsection{Labour force participation of the second generation}

Two major indicators describe the participation of the second generation in the labour market: labour force participation and unemployment.

Labour force participation expresses the percentage of total population that is either employed or seeking employment, called 'economically active persons' in Swiss statistics. In the TIES survey origin groups show 
quite similar labour force participation rates; more than 80 per cent of respondents are economically active. The second generation of SSYU origin has significantly higher labour force participation than the comparison group (89 per cent vs. 83 per cent) while Turkish origin youth occupy an intermediate position (Table 5.3).

The unemployment rate expresses the percentage of the economically active population not gainfully employed nor actively looking for work. Here origin group differences become more apparent: youth of Turkish origin have the highest unemployment rate (roughly 6 per cent), three times the comparison group (lower than 2 per cent) while second-generation SSYU youth have an unemployment rate higher than the comparison group but half that of second-generation Turkish youth.

Table 5.3 Labour force participation and unemployment rate by origin group

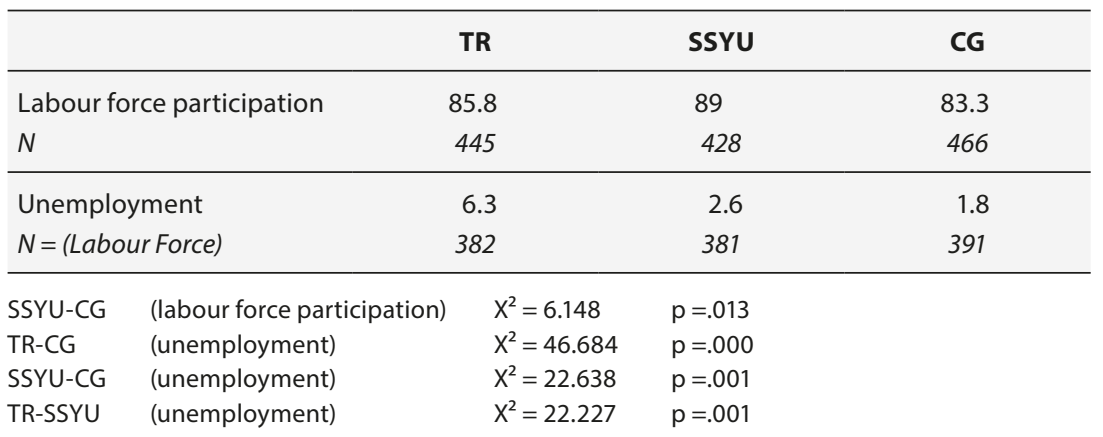

It is worth emphasising the higher labour force participation by secondgeneration youth as against the comparison group. This contrasts with the census data from 2000, where foreigners of Turkish and SSYU origin of all generations showed lower labour force participation in relation to the Swiss. In this respect the second generation is clearly more like their local contemporaries than their parents' generation. Labour force participation through the special segment of the labour market represented by dual apprenticeship may account for this result.

Unemployment among second-generation youth is several times that of the comparison group; however, the gap between these groups is narrower than that between their respective parents (3.5 per cent versus 18 per cent for the first-generation Turkish population and 1.4 per cent versus 6.5 per cent for the previous SSYU generation, see $\S 3.3 .3)$. The labour market position of the second generation is clearly framed between these two poles: clear improvement compared to their parents' position in terms of labour 
market participation but a persistent lag in unemployment rate as against autochthonous contemporaries.

A closer investigation of the current work status of TIES respondents uncovers distinct traits for the second generation.

Table 5.4 Current work status, by origin group

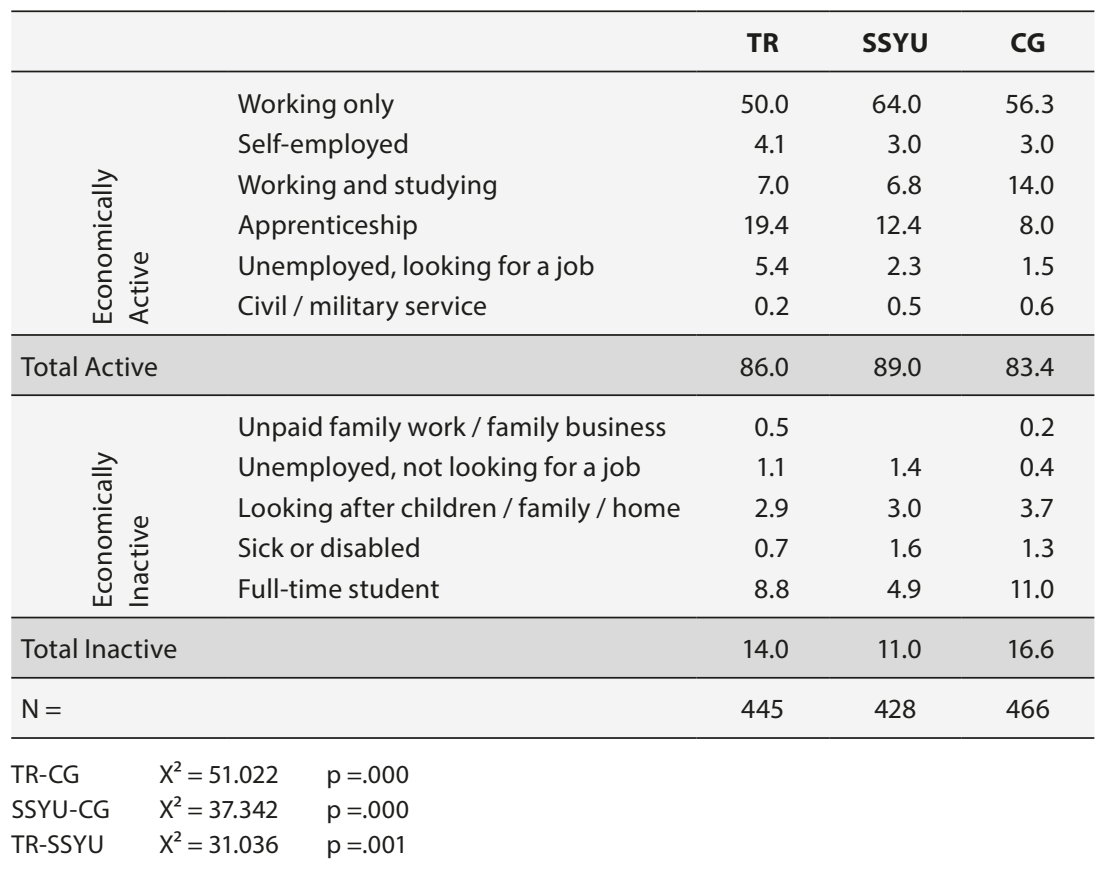

Let us first consider the economically active population (Table 5.4). For at least half of respondents in all origin groups, working is their exclusive activity. The percentage of youth whose only activity is working is higher for SSYU youth (seven out of ten), whereas this is the case for six out of ten comparison group natives and slightly over five out of ten second-generation Turkish youth. Youth of Turkish origin are younger than origin groups (see chapter 2) and therefore more often in education, especially vocational training: one fifth attends apprenticeship as against one in ten SSYU youth and comparison group natives. Some 20 per cent of respondents are engaged in both learning and working.

If all engagement in the labour market is counted together (work only, self-employment, working and studying, apprenticeship) then 80 per cent of Turkish origin respondents are already employed, nearly the same as 
the comparison group ( 81 per cent), while SSYU origin respondents exceed both with an 86 per cent economically active population. Self-employment is more frequent among the employed Turkish second generation (4 per cent) with slightly lower rates observed for SSYU youth and the comparison group (3 per cent).

In the inactive population, the share of respondents in education is worth highlighting. Comparison group members are often still in education but generally at tertiary level (see Chapter 4). Full-time students constitute a large percentage of the comparison group, more than twice as many as SSYU youth. They are also twice as likely as children of immigrants to combine work and study (15 per cent versus 7 per cent).

The similar share of housewives and house husbands across origin groups invites more detailed enquiry into the specific situation of men and women.

Table 5.5 Current work status, by origin group and gender

\begin{tabular}{|c|c|c|c|c|c|c|c|c|}
\hline & & & \multicolumn{2}{|c|}{ TR } & \multicolumn{2}{|c|}{ SSYU } & \multicolumn{2}{|c|}{ CG } \\
\hline & & & $M$ & w & $M$ & $\mathbf{w}$ & $M$ & w \\
\hline \multirow{6}{*}{ 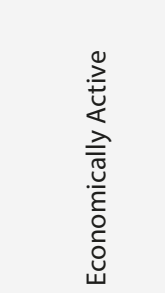 } & \multicolumn{2}{|c|}{ Working only } & 52.2 & 47.4 & 64.8 & 63.4 & 53.8 & 58.8 \\
\hline & \multicolumn{2}{|c|}{ Self-employed } & 6.1 & 1.9 & 4.7 & 0.9 & 3.8 & 2.2 \\
\hline & \multicolumn{2}{|c|}{ Working and studying } & 6.1 & 7.9 & 5.6 & 7.9 & 14.3 & 13.6 \\
\hline & \multicolumn{2}{|c|}{ Apprenticeship } & 20.2 & 18.6 & 12.7 & 12.0 & 10.5 & 5.7 \\
\hline & \multicolumn{2}{|c|}{$\begin{array}{l}\text { Unemployed, looking for } \\
\text { a job }\end{array}$} & 5.3 & 5.1 & 2.8 & 1.9 & 2.5 & 0.4 \\
\hline & \multicolumn{2}{|c|}{ Civil / military service } & 0.4 & & 0.9 & & 1.3 & \\
\hline \multicolumn{3}{|l|}{ Total Active } & 90.4 & 80.9 & 91.5 & 86.1 & 86.1 & 80.7 \\
\hline \multirow{5}{*}{ 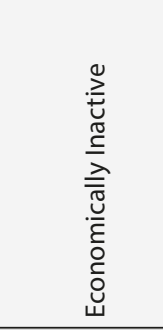 } & \multicolumn{2}{|c|}{$\begin{array}{l}\text { Unpaid family work / } \\
\text { family business }\end{array}$} & & 0.9 & & & & 0.4 \\
\hline & \multicolumn{2}{|c|}{$\begin{array}{l}\text { Unemployed, not looking } \\
\text { for a job }\end{array}$} & 2.2 & & 0.9 & 1.9 & 0.8 & \\
\hline & \multicolumn{2}{|c|}{$\begin{array}{l}\text { Looking after children / } \\
\text { family / home }\end{array}$} & & 6.0 & 0.9 & 5.6 & 0.8 & 6.6 \\
\hline & \multicolumn{2}{|c|}{ Sick or disabled } & 0.9 & 0.9 & 2.3 & 0.9 & 1.7 & 0.9 \\
\hline & \multicolumn{2}{|c|}{ Full-time student } & 6.6 & 11.2 & 4.2 & 5.6 & 10.5 & 11.4 \\
\hline \multicolumn{3}{|l|}{ Total Inactive } & 9.6 & 19.1 & 8.5 & 13.9 & 13.9 & 19.3 \\
\hline \multicolumn{3}{|l|}{$\mathrm{N}=$} & 229 & 216 & 212 & 216 & 238 & 228 \\
\hline TR (Men vs. Wo & & $X^{2}=32.290$ & & & & & & \\
\hline SSYU (Men vs. V & men) & $X^{2}=18.388$ & & & & & & \\
\hline CG (Men vs. Wo & en) & $X^{2}=26.729$ & & & & & & \\
\hline
\end{tabular}


As expected, gender differences among economically active and inactive respondents are significant, but they display a similar pattern in all origin groups (Table 5.5). Women are often less active than men; the gap is more pronounced in the Turkish second generation (10 per cent less) than in the SSYU second generation and comparison group (6 per cent less). The difference lies with self-employment, dominated by men across all groups, and the working-only situation, where men outnumber women except in the comparison group. It is interesting to note that in the two second-generation groups there are no differences between men and women when forms of associating work and study activities are combined (apprenticeship as well as working and studying): 26 per cent among second-generation Turkish youth and some 19-20 per cent among second-generation SSYU youth. However, in the comparison group, women are engaged less often than men in this double track.

Among the economically inactive, family and childcare are done largely by women in all origin groups. The proportion of women engaged in caregiving is similar in all origin groups (6 per cent) although second-generation women are more likely to have children than comparison group women (see Chapter 2). More women than men are full time students in all origin groups, especially among second-generation Turkish youth, where they are proportionally just as numerous as women of the comparison group. In the SSYU second generation the gender gap in labour market participation is limited to caregiving activities.

Let us further consider the impact of age categories on labour market participation (Table 5.6). Age is an important factor affecting the type and status of economic activity in all origin groups. As expected, the proportion of economically active respondents in the older age category is higher than in the younger age category: this is indeed the case for youth of Turkish origin and in the comparison group but not for SSYU youth. Remarkably, age category does not influence unemployment.

Finally, we turn to local differences in labour market participation patterns (Table 5.7). Labour force participation tends to be systematically higher in Zurich. However, the current work situation of children of immigrants is quite similar in Zurich and Basel. In the comparison group, the proportion of economically active persons is higher in Zurich; the combination of working and studying is more common there than in Basel, where full-time students are proportionally more numerous.

We close this description of labour market participation by discussing self-employment in greater detail and calculating the self-employment rate, 
Table 5.6 Current work status, by origin group and age category

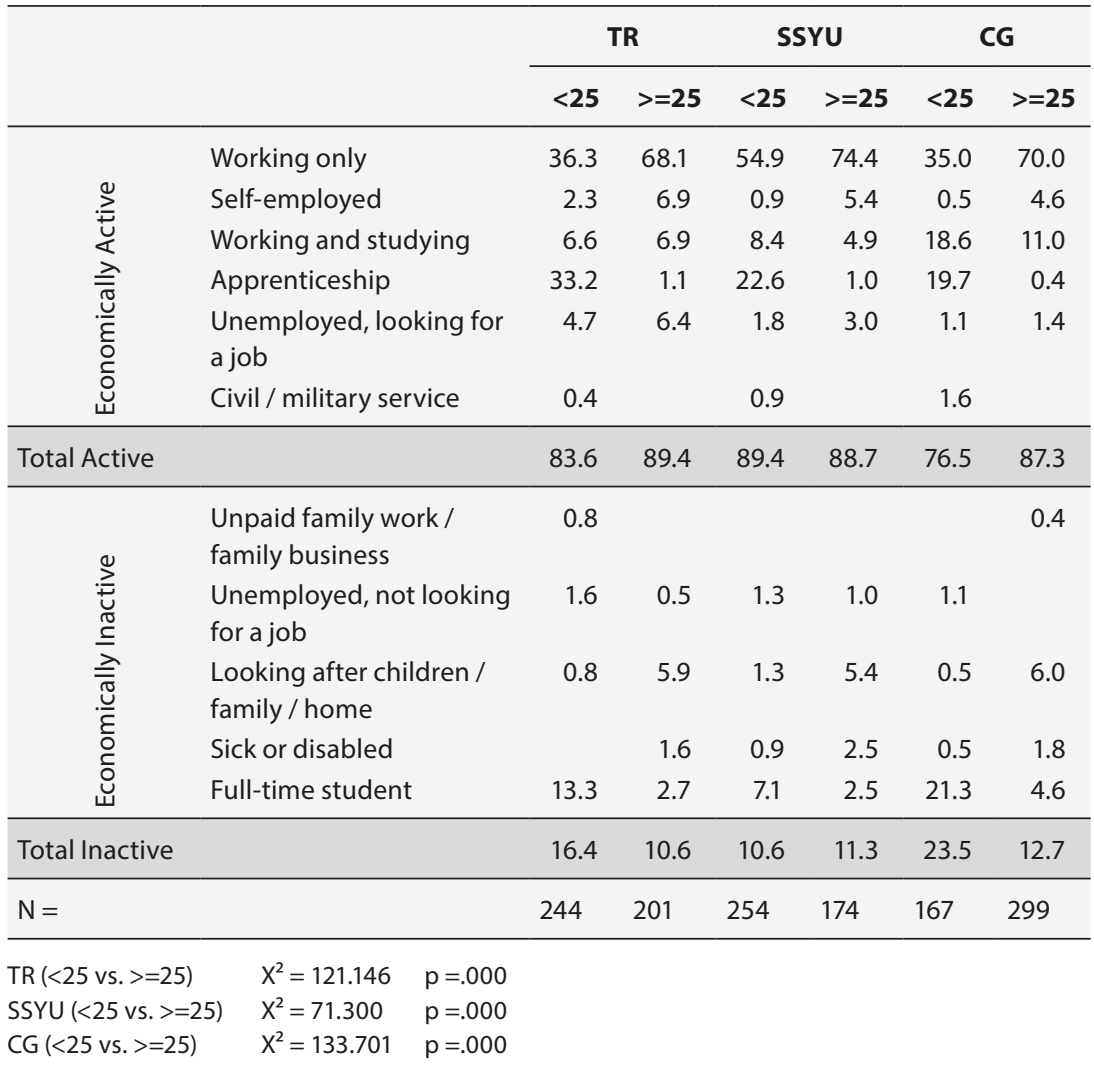

defined as the proportion of total employment made up of the self-employed. Individuals who operate a business or profession as the sole proprietor or partner, working alone or together with other paid wage earners, are here grouped under the label self-employed.

Second-generation Turkish respondents are more often involved in autonomous activities ( 5 per cent) than SSYU and comparison group respondents (below 4 per cent); a third own a business whereas two thirds are self-employed. Moreover, Turkish origin independent workers are less likely to be professionals and technicians in comparison to the Swiss-by-birth and are less often in craftsmen positions than second-generation SSYU respondents.

Self-employment may be seen either as a survival strategy for those who cannot find any other means of earning an income or as evidence of entrepreneurial spirit and a desire to be one's own boss. The self-employment rates shown in this section reflect these various motives. In Zurich and 
Table 5.7 Current work status, by origin group and agglomeration

\begin{tabular}{|c|c|c|c|c|c|c|c|}
\hline & & \multicolumn{2}{|c|}{ TR } & \multicolumn{2}{|c|}{ SSYU } & \multicolumn{2}{|c|}{ CG } \\
\hline & & $\mathbf{Z H}$ & BS & $\mathbf{Z H}$ & BS & ZH & BS \\
\hline \multirow{6}{*}{ 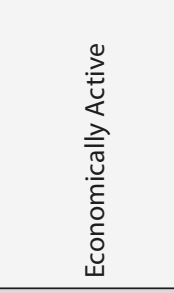 } & Working only & 54.7 & 46.3 & 65.1 & 63.3 & 56.7 & 55.8 \\
\hline & Self-employed & 3.5 & 4.1 & 4.2 & 1.1 & 3.0 & 3.4 \\
\hline & Working and studying & 7.0 & 7.0 & 6.7 & 6.4 & 16.9 & 11.7 \\
\hline & Apprenticeship & 15.4 & 22.7 & 11.8 & 13.3 & 7.5 & 8.7 \\
\hline & $\begin{array}{l}\text { Unemployed, looking for } \\
\text { a job }\end{array}$ & 8.0 & 3.3 & 2.5 & 2.7 & 1.0 & 1.5 \\
\hline & Civil / military service & & 0.4 & 0.8 & & & 1.1 \\
\hline Total Active & & 88.6 & 83.9 & 91.2 & 86.7 & 85.1 & 82.3 \\
\hline \multirow{5}{*}{ 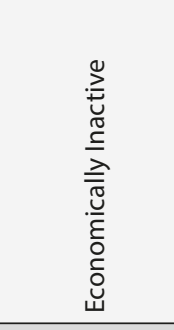 } & $\begin{array}{l}\text { Unpaid family work / } \\
\text { family business }\end{array}$ & & 0.8 & & & & 0.4 \\
\hline & $\begin{array}{l}\text { Unemployed, not looking } \\
\text { for a job }\end{array}$ & 1.0 & 1.2 & 1.3 & 1.6 & & 0.8 \\
\hline & $\begin{array}{l}\text { Looking after children / } \\
\text { family / home }\end{array}$ & 3.0 & 2.9 & 2.9 & 3.2 & 5.0 & 2.6 \\
\hline & Sick or disabled & & 1.2 & 1.7 & 1.6 & 1.0 & 1.5 \\
\hline & Full-time student & 7.5 & 9.9 & 2.9 & 6.9 & 9.0 & 12.5 \\
\hline Total Inactive & & 11.4 & 16.1 & 8.8 & 13.3 & 14.9 & 17.7 \\
\hline$N=$ & & 201 & 244 & 239 & 189 & 201 & 265 \\
\hline
\end{tabular}

CG (Zurich vs. Basel) $\quad X^{2}=24.648 \quad \mathrm{p}=.010$

All other differences are not statistically significant.

Basel, second-generation respondents of Turkish origin (5.1 per cent) especially men - are engaged in self-employment slightly more often than respondents of SSYU origin (3.5 per cent) and the comparison group (3.7 per cent).

Given the relatively high share of self-employed Turkish immigrant fathers, it is worth asking whether their children follow the same tradition. Recourse to self-employment is generally found in groups characterised by a combination of disadvantages and resources. Disadvantages may be due to membership in an ethnic group experiencing discrimination and a lack of educational credentials; resources include skills and access to networks that provide labour, capital, information, advice, imported goods and customers. In the classic model of integration, immigrants' children pursue professional work instead of self-employment. However, studies on the second generation show that this model may not apply to all groups (Gold et al. 2006). 
Among Turkish origin respondents only one in ten whose father was reported as self-employed is also self-employed; among SSYU respondents it is one in twenty. So the TIES data tend to confirm the classical model, i.e. the second generation moves out of self-employment into a waged position.

Let us summarise the findings so far by discussing labour force participation rates. The labour force participation of the second generation is high (86 and 89 per cent, respectively, for Turkish and SSYU origin youth), and higher than in the comparison group. However, the unemployment rate is a multiple of the rate observed in the comparison group, with second-generation Turkish respondents more vulnerable in this respect. Unemployment tends to be higher among men than women and among older respondents than younger ones. Turkish origin men in Zurich are confronted with a notably higher risk of unemployment than SSYU origin youth, who in turn face a higher risk of unemployment than the comparison group.

We further focus on the gender distribution of this variable because of its meaning in regard to both economic activity and understanding of gender roles.

Figure 5.1 Labour force participation by origin group and gender

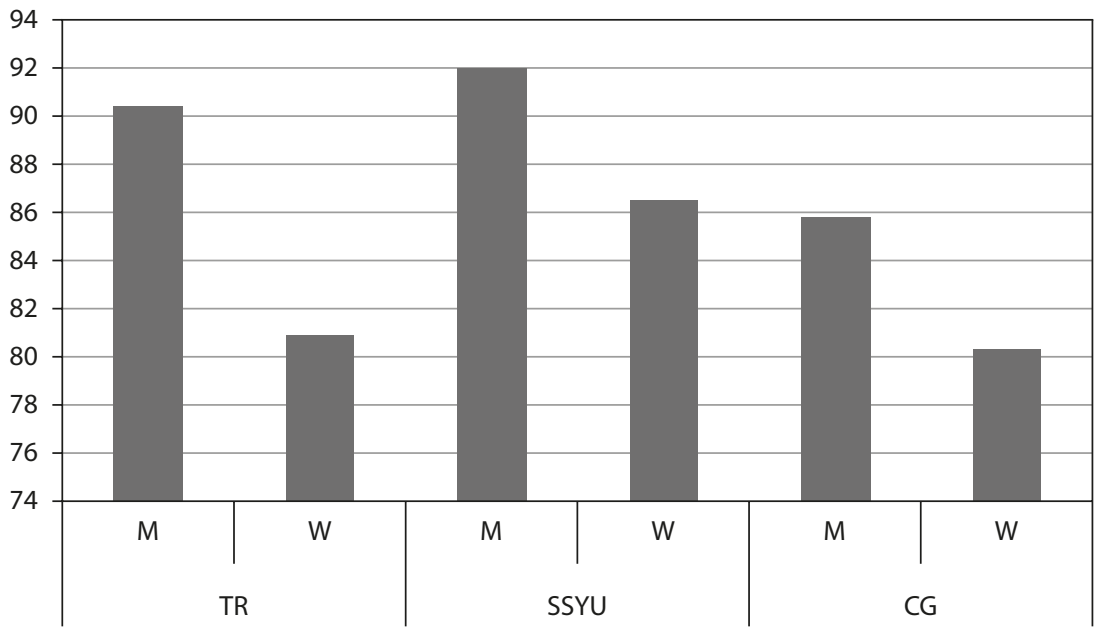

The figure makes clear that, in spite of a pronounced gender gap among Turkish origin respondents, the labour force participation rate of secondgeneration women relative to the comparison group is either similar - as in the case of Turkish origin women - or higher - as in the case of SSYU 
origin women. The employment attitudes of minority women are similar to women in the comparison group, since caretaking activities do not seem to affect their presence (or willingness to be present) in the labour market.

The delayed entry into employment of comparison group members is in sharp contrast to the earlier entry into adult life of children of immigrants. Age difference in labour force participation is only significant for the comparison group; the rate is lower for comparison group natives under 25 ( 75 per cent) compared to older native respondents ( 87 per cent). Those age differences are presumably related to qualification trajectories and the higher presence of the second generation in the labour market, due to the dual apprenticeship system. However, there are no overall signs of early, unqualified entry into the labour market, as observed among second-generation Italians in the seventies (Fibbi \& de Rham 1988; Eckmann et al 1994). The social norm of post-compulsory education is well anchored in this second generation.

The analysis of current labour market participation has so far shown convergence of activity rates between the second generation and the comparison group, although unemployment affects children of immigrants, especially those of Turkish origin, significantly more than the autochthonous population. The closer exploration of gender differences suggests that they persist in all origin groups. There is no indication of a lower participation rate among second-generation women in comparison to Swiss-by-birth that might point to a different understanding of gender roles; indeed, the lowest participation rate is observed among Swiss-by-birth mothers with children.

\subsubsection{Factors affecting labour force participation}

After studying current work status and labour force participation according to origin groups, gender, age and agglomerations, we analyse how labour force participation is related to both educational attainment and crucial life-course events, such as union formation and parenthood. We focus for this analysis only on those respondents who are out of education, representing some 60 per cent of the sample.

Taking into account only those young persons who are no longer enrolled in education, activity rates increase as expected with the achieved education level for all origin groups. In fact, the vast majority of tertiary education graduates are economically active, whereas 20-30 per cent of people with only compulsory school qualification are not on the job market. The impact of educational attainment on activity rate is highest for the comparison group (Table 5.8). 
Table 5.8 Labour force participation by highest achieved educational level (for those out of education), by origin group

\begin{tabular}{lcrrrrrc}
\hline & \multicolumn{3}{c}{ TR } & \multicolumn{3}{c}{ SSYU } & \multicolumn{3}{c}{ CG } \\
\cline { 2 - 7 } & $\%$ & $\mathbf{N}$ & $\%$ & $\mathbf{N}$ & $\%$ & $\mathbf{N}$ \\
\hline ISCED 2 & 75.0 & 42 & 70.0 & $(21)$ & 55.6 & $(9)$ \\
ISCED 3 & 95.8 & 170 & 92.4 & 206 & 87.4 & 157 \\
ISCED 5 & 96.6 & 30 & 92.3 & $(21)$ & 97.9 & 104 \\
\hline
\end{tabular}

TR (education levels) $\quad X^{2}=20.514 \quad p=.000$

SSYU (education levels) $\quad X^{2}=10.936 \quad p=.004$

CG (education levels) $\quad X^{2}=19.987 \quad p=.000$

Marriage or cohabitation are expected to influence the propensity to participate in the labour market (Wanner et al. 2005). Is the expected gender effect similar for all origin groups? Marriage or cohabitation tend to increase the labour force participation of men and women in all groups. Rates are similar for second-generation and comparison group women in a couple (Table 5.9).

Parenthood negatively affects activity rate for both fathers and mothers in all groups: the decrease is limited for men (except SSYU men) - but unexpected; it is pronounced for women. The sharpest decrease is observed among comparison group women (-45 per cent), notable among Turkish women (-30 per cent) and least marked among SSYU women. The contrast between comparison group and SSYU women is stark (Table 5.9).

Table 5.9 Labour force participation by marital status and parenthood, by origin group and gender

\begin{tabular}{|c|c|c|c|c|c|c|c|c|c|c|c|c|c|}
\hline & & \multicolumn{4}{|c|}{ TR } & \multicolumn{4}{|c|}{ SSYU } & \multicolumn{4}{|c|}{ CG } \\
\hline & & M & $\mathbf{N}$ & $\mathbf{W}$ & $\mathbf{N}$ & M & $\mathbf{N}$ & $\mathbf{W}$ & $\mathbf{N}$ & M & $\mathbf{N}$ & w & $\mathbf{N}$ \\
\hline \multicolumn{2}{|c|}{$\begin{array}{l}\text { Single (head of } \\
\text { household) }\end{array}$} & 94.1 & 33 & 82.1 & 30 & 90.0 & (28) & 89.1 & 45 & 90.0 & 63 & 87.7 & 68 \\
\hline \multirow[t]{2}{*}{ in Union } & $\begin{array}{l}\text { without } \\
\text { child }\end{array}$ & 96.2 & (26) & 96.4 & (29) & 97.6 & 35 & 96.2 & (26) & 93.3 & 62 & 98.1 & 54 \\
\hline & $\begin{array}{l}\text { with } \\
\text { child }\end{array}$ & 93.8 & 33 & 67.7 & 37 & 96.2 & (20) & 82.1 & 53 & 88.0 & 29 & 54.5 & 34 \\
\hline
\end{tabular}

$\begin{array}{llll}\text { TR (in union w/wo child vs. single) } & \text { Women } & X^{2}=8.074 & p=.018 \\ \text { CG (in union w/wo child vs. single) } & \text { Women } & X^{2}=29.976 & p=.000 \\ \text { Women with child } & \text { (SSYU-CG) } & X^{2}=7.829 & p=.005 \\ \text { Women single } & \text { n.s. } & & \end{array}$


These results diverge from the national statistics, which show a lower activity rate for foreign women with a child under seven, as compared to similar Swiss women (71.7 per cent vs. 57.6 per cent, respectively, for Swiss and foreign women with a child under seven; FOS, SLFS, http://www.bfs.admin.ch/ bfs/portal/fr/index/themen/o3/o2/blank/data/o3.html). However, national figures include all foreigners and not specifically children of immigrants. According to the TIES results (Table 5.9), women with a migrant background behave much like comparison group respondents; women of immigrant descent with children even work significantly more than Swiss mothers.

The labour market participation of respondents who have for now completed their education is clearly influenced by their level of school achievement; the higher the achievement, the higher the participation. Among children of immigrants, the participation of respondents with only compulsory education is markedly low. Marriage or cohabitation increases labour market participation whereas parenthood decreases it unexpectedly among both men and women. Comparison group women withdraw from work more often than second-generation migrant women when they have a child.

\subsection{Quality of labour market participation}

The quantitative analysis so far has revealed two major characteristics of the labour market participation of TIES respondents: higher activity rates and higher unemployment rates in the second generation than in the comparison group. We turn now to the quality of their participation by focusing on three dimensions: working conditions (stability, advancement, returns on credentials), socio-professional category and occupational prestige.

Modalities of labour market participation have notably changed in the last decade as working conditions have become more and more flexible. Non-standard forms of employment are thought to improve the employment opportunities of certain groups and have in fact accounted for a large part of recent job growth. However, non-standard employment can be highly problematic in terms of job quality in that it is often accompanied by lower job security and reduced access to both statutory and employer-provided social security benefits (Leschke \& Watt 2008). In many countries, younger generations have been particularly affected in the last decade by such flexible working conditions.

In Switzerland the issue has been expressed in terms of the relative importance of non-standard forms of employment (emplois atypiques) 
(Birchmeier 2002). Non-standard forms of employment are a consequence of the relaxing of the time frame for work. Examples include short-term assignments, temporary agency work, part-time employment and own-account self-employment, evening and night work, and work on call. Part-time jobs have increased markedly and account for 33 per cent of gainfully employed people (OFS 2009), as against 12 per cent in 1970 and 26.5 per cent in 1991 (Birchmeier 2002). Such evolution is directly associated with increased women's participation in working life and the expansion of the service sector.

We expect that children of immigrants would be especially affected by this increased flexibility of working conditions because of their comparatively lower educational and social capital.

\subsubsection{Working conditions}

We explore the quality of the labour market participation of TIES respondents whose main activity is work by looking at the relative importance of part-time jobs, fixed contracts (the reverse of short-term assignments), job advancement and income. When appropriate, distinctions by gender and naturalisation status are taken into account, along with age.

\section{Part-time work}

To examine part-time work, the analysis will be restricted to those respondents whose main activity is working, e.g., without considering those who work and study at the same time. Part-time is defined as an activity corresponding to less than $90 \%$ of a full-time job (42 hours per week); hence part-time work in Switzerland amounts to 38 hours per week or less.

About one TIES respondent in four has a part-time contract (24-28 per cent), a proportion significantly lower than the national average (33 per cent) (Table 5.10). Though origin group differences are negligible, part-time activity tends to be more frequent in Basel than in Zurich for all origin groups. As expected, part-time work is more characteristic of women's labour market participation than men's; more than a third of women, regardless of origin, are engaged on a part-time basis, compared with less than a fifth of men.

It is notable that the incidence of part-time work is more frequent among comparison group respondents than among immigrant origin youth. In fact, men make the difference: men in the comparison group are twice as likely to be in part-time work as SSYU origin men, in spite of the fact that their main activity is working. 
Table 5.10 Part-time work of those in paid employment, by origin group and gender

\begin{tabular}{lccccccccc}
\hline & \multicolumn{3}{c}{ TR } & \multicolumn{4}{c}{ SSYU } & \multicolumn{3}{c}{ CG } \\
\cline { 2 - 11 } & M & W & Tot & M & W & Tot & M & W & Tot \\
\hline Part-time work & 12.8 & 36.8 & 23.8 & 8.1 & 40.3 & 23.7 & 18.8 & 38.1 & 28.3 \\
N = & 134 & 110 & 244 & 142 & 138 & 280 & 144 & 139 & 283 \\
\hline
\end{tabular}

TR (Men vs. Women) $\quad X^{2}=18.955 \quad \mathrm{p}=.000$

SSYU (Men vs. Women) $\quad X^{2}=41.055 \quad p=.000$

CG (Men vs. Women) $\quad X^{2}=12.639 \quad \mathrm{p}=.000$

All other differences are not statistically significant.

Part-time work is often a way of accommodating family obligations and work life when women do not wish to quit the labour market at the birth of their children. Almost a third of single working women are in part-time work. When there is a child in the family, part- time occupation becomes the norm for the mother's activity: in fact, it reaches over 80 per cent in immigrant origin groups and is even higher (94 per cent) for the comparison group. We have already seen that when there is a child, female labour market participation drops sharply, especially for comparison group women (Table 9).

As far as part-time activity is concerned, second-generation women display similar behaviour to autochthonous women. If part-time activity is a sign of increased flexibility, it affects second-generation women as much as their autochthonous contemporaries.

\section{Fixed contracts}

The indicator of stability in the labour market is the proportion of workers with secure and long-term contracts over those gainfully employed. The analysis below looks only at respondents aged 25 and over in order to focus on those expected to have reached a more secure foothold in economic activity.

At least three out of four employees hold a fixed contract, regardless of origin group. Women tend to have fixed contracts more often than men, especially among migrant origin groups.

Fixed contracts seem to be more prevalent in Zurich than in Basel for all origin groups but particularly for second-generation Turkish respondents, for whom the proportion with a fixed contract is 85 per cent in Zurich versus 68 per cent in Basel. Thus, stability is the only dimension of working conditions where statistically significant agglomeration differences appear, but only for a specific segment of respondents. 


\section{Supervision}

Supervising other employees is a sign of greater responsibility in the workplace. Between a third and a half of respondents on a fixed contract and aged 25 or over supervise other employees, with no significant variation between origin groups or agglomerations.

However, gender differences are relevant: among SSYU and comparison group youth, men are twice as likely as women to reach such positions ( 56 per cent vs. 34 per cent for the former and 59 per cent vs. 27 per cent for the latter). In the Turkish origin group, however, access to responsibility is somewhat lower for both men and women, probably in line with their lower educational achievement (see Chapter 4, Table 4.19).

\section{Income}

Even if it is not always statistically significant, income distribution is an interesting indicator ranking origin groups in the labour market. We limit analysis to those who finished school and whose main activity is full-time employment (Table 5.11).

The modal monthly income category for second-generation Turkish respondents is lower $(4,000-4,799)$ than for SSYU and comparison group respondents $(4,800-6,399)$. The proportion of respondents in the highest income category is almost three times higher among the comparison group than Turkish descent respondents.

The gender cleavage is present in all groups; it is notable that only men are in the highest income category. This divide is especially pronounced among Turkish origin respondents; the proportion of women whose earnings are below the modal category $(4,000-4,799)$ is more than twice the proportion of men in similar conditions (44 vs. 18 per cent). On the other hand, SSYU respondents distinguish themselves with the lowest gap in earnings between men and women, lower than in the comparison group. Yet gender differences in income categories are significant only in the comparison group. This is surprising, as women have a distinctive position in the labour market, as we will see (see $\S 5 \cdot 2.2$ and $\S 5.2 .3$ ).

Second-generation respondents tend to achieve higher earnings in Zurich than in Basel; 50 per cent of Turkish respondents are in the three highest income categories in Zurich versus 26 per cent in Basel. This is not the case for the comparison group.

We have analysed various indicators of quality of working conditions (parttime activity, fixed contracts, career advancement and income) among TIES respondents, focusing on those whose main activity is working, in 
Table 5.11 Income category of those in paid employment working full-time, by origin group and gender

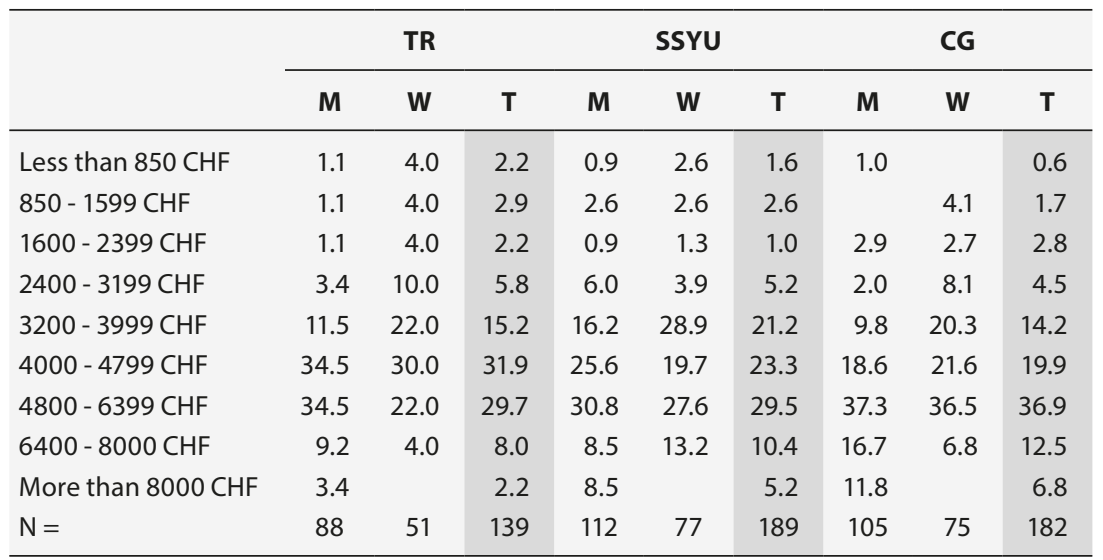

CG (Men vs. Women) $X^{2}=24.017 p=.002$

No difference among women or men according to origin group.

All other differences are not statistically significant.

the expectation that second-generation respondents might be confronted with appreciably lower standards of working conditions. However, this is not the case when we consider the sub-group of older second-generation respondents in full-time employment. In concluding this section, it appears that gender is more salient than migratory background in determining standards of working conditions.

\subsubsection{Occupational level}

We now look at achievement within particular labour market positions and analyse job levels using the well-established International Standard Codification of Occupations (ISCO-88). Since this classification may be unfamiliar to readers used to national classifications based on professions, it may be useful to give some examples of the professions found in our sample that are grouped under the ISCO-88 categories. Hence senior officials and managers include production and operation managers in the construction, wholesale and retail trade, restaurants, personnel managers, managers of small enterprises, and so on. Teachers, accountants, medical doctors, lawyers and computing professionals are to be found under professionals. Technicians include associated professionals in health (nursing, medical assistants), finance and sales. Clerks include secretaries, stock clerks, client information, receptionists, cashiers; service and sales workers include 
childcare-providers, cooks, hairdressers and salespersons. Craft workers include builders, roofers, plumbers, installers, machinery mechanics, auto mechanics, bakers, and so forth. Plant and machine operators include motor vehicle drivers, metal and mineral products machine operators, printingmachine operators, railway workers, crane and hoist operators, and so on. Finally, manufacturing labourers, building caretakers, messengers, porters, domestic helpers, cleaners and launderers are grouped under elementary occupations.

Table 5.12 gives an overview of occupational levels by origin group and shows significant differences in the three origin groups. While the share of technicians is similar across all groups, it represents the modal profile in the two second-generation groups, but is second in the comparison group behind professionals. It appears that second-generation youth have difficulties in reaching such positions. Sales occupations are significant for second-generation youth, but marginal for the comparison group. Clerks are the third category by importance for Turks and the comparison group, whereas SSYU youth show a distinct concentration in craftsmen's positions.

Given that the labour market is structured along gender lines it is worth considering the position of men and women separately; gender differences appear significant in each origin group. The structure of men's occupations presents a clear polarisation: a third of SSYU youth and a fifth of Turkish youth occupy craftsmen's positions whereas more than a fifth of comparison group men are active as professionals. More generally, blue collar workers represent almost half of SSYU men's occupations and a third of Turkish men's occupations, but only a fifth of the comparison group's. The second point of divergence is the clustering of second-generation men in sales jobs, whereas comparison group men are more numerous in clerical work. It is worth stressing the convergence of all origin groups in technical positions, where second-generation Turkish respondents are well represented.

The polarisation between second-generation and comparison group respondents is less pronounced among women, since blue collar occupations are marginal in all three groups. The category of technician - the most numerous - includes about a third of all women. The second commonality is clustering in clerical occupations, involving between a fifth and a sixth of all women. The gulf between immigrant origin and autochthonous youth appears in the notable importance of professional positions for comparison group women (higher than for their fellow country-men) and the relative concentration of second-generation women in the sales sector. 
Table 5.12 Occupational category of respondents whose main activity is work, by origin group and gender

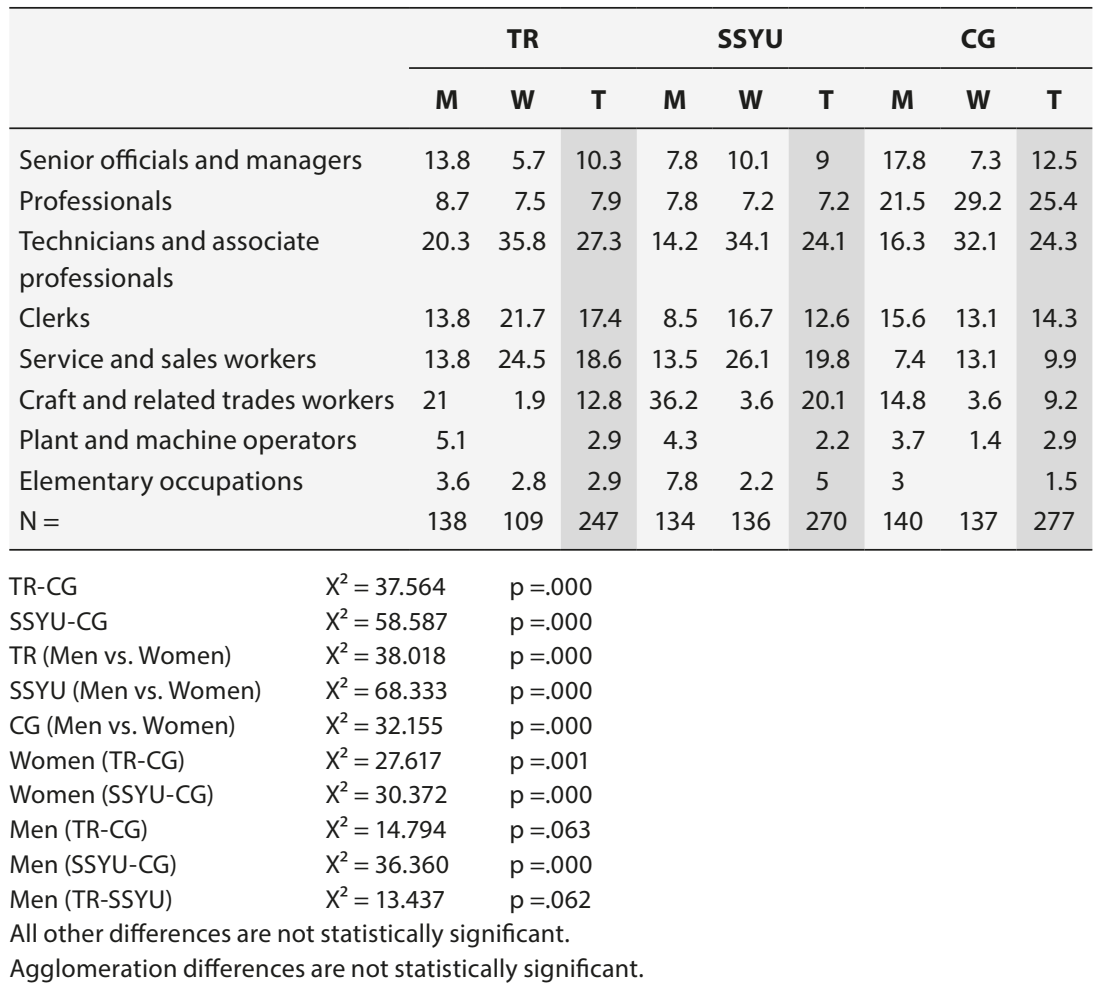

How do those findings compare with previous knowledge on the second generation in Switzerland? Classifications used in earlier studies vary so there can be no strict comparison. However, analysis of second-generation Italian and Spanish young adults also showed a clustering of men in blue collar positions; their share more closely resembles that for Turkish descent men than for SSYU descent men (Bolzman et al. 2003). Similarly, Spanish and Italian second-generation women are concentrated in clerical and sales jobs, as observed with second-generation Turkish and SSYU women.

In their analysis of Census 2000 for youth aged 15 to 29, Mey et al. (2005) contrast native-born second-generation (whatever their national origin) with foreign-born first-generation and Swiss by birth. They also note the second generation clustering around routine services such as sales and clerical work. However, skilled blue collar activities are just as frequent among second-generation respondents as among respondents who are Swiss by birth. This should be viewed with caution in our comparison, 
however, as it does not distinguish between immigration from neighbouring countries, with a high level of qualifications on average, and immigration flows from southern countries, with a low level of qualifications on average.

Previous findings have focused on the relative position of naturalised youth. On the basis of a survey, Bolzman et al. (2003) pointed at the higher school achievement of naturalised second-generation youth versus Swissborn youth of immigrant descent who did not acquire Swiss citizenship; however, occupational level was not analysed. Census data provide a more extensive account of labour market participation (Fibbi et al. 2005; Mey et al. 2005) for all origin groups. However, the proportion of second-generation Turkish and SSYU respondents who have naturalised increased sharply between 2000 and 2007-08, the period of the TIES survey, to include three out of four young people of immigrant descent. To test if naturalised youth perform better than non-naturalised in terms of occupational level, we look at the occupational category of second-generation respondents according to naturalisation status (Table 5.13).

Table 5.13 Occupational category of respondents whose main activity is work, by origin group and by naturalisation status

\begin{tabular}{|c|c|c|c|c|c|}
\hline & \multicolumn{2}{|c|}{ TR } & \multicolumn{2}{|c|}{ SSYU } & \multirow[t]{2}{*}{ CG } \\
\hline & Naturalised & $\begin{array}{l}\text { Non- } \\
\text { naturalised }\end{array}$ & Naturalised & $\begin{array}{c}\text { Non- } \\
\text { naturalised }\end{array}$ & \\
\hline $\begin{array}{l}\text { Senior officials and } \\
\text { managers }\end{array}$ & 10.6 & 11.1 & 8.3 & 9.6 & 12.5 \\
\hline Professionals & 9.6 & 1.9 & 8.8 & 2.7 & 25.4 \\
\hline $\begin{array}{l}\text { Technicians and associate } \\
\text { professionals }\end{array}$ & 30.9 & 14.8 & 28.9 & 11 & 24.3 \\
\hline Clerks & 16.5 & 18.5 & 15.7 & 4.1 & 14.3 \\
\hline Service and sales workers & 15.4 & 29.6 & 16.2 & 30.1 & 9.9 \\
\hline $\begin{array}{l}\text { Craft and related trades } \\
\text { workers }\end{array}$ & 12.2 & 14.8 & 15.2 & 34.2 & 9.2 \\
\hline $\begin{array}{l}\text { Plant and machine } \\
\text { operators }\end{array}$ & 2.7 & 3.7 & 2.5 & 1.4 & 2.9 \\
\hline Elementary occupations & 2.1 & 5.6 & 4.4 & 6.8 & 1.5 \\
\hline $\mathrm{N}=$ & 192 & 55 & 200 & 70 & 277 \\
\hline \multicolumn{2}{|c|}{ TR (Naturalised vs. Non-naturalised) } & $X^{2}=13.885$ & \multicolumn{2}{|l|}{$\mathrm{p}=.053$} & \\
\hline \multicolumn{2}{|c|}{ SSYU (Naturalised vs. Non-naturalised) } & \multirow{2}{*}{$x^{2}=31.578$} & \multicolumn{2}{|l|}{$p=.000$} & \\
\hline \multicolumn{2}{|c|}{ TR (Naturalised) vs. CG } & & \multicolumn{2}{|l|}{$\mathrm{p}=.003$} & \\
\hline \multicolumn{2}{|l|}{ SSYU (Naturalised) vs. CG } & $x^{2}=33.8$ & $\mathrm{p}=.000$ & & \\
\hline
\end{tabular}


Naturalised second-generation respondents compare favourably with non-naturalised second-generation respondents in the same origin group; they are markedly more numerous in professional positions, whereas nonnaturalised are more often in service and sales jobs, in craftsman positions or in elementary occupations.

Thanks to their higher performance, naturalised second-generation respondents reach levels equal to the comparison group, up to associate professional positions. Beyond this level, however, they seem to hit an invisible ceiling; the proportion of those who achieve professional positions is only a third of that of the comparison group. This effect may be due to family educational background and lower school performance.

So far, the occupational profile of second-generation respondents has been shown to be distinct in relation to the comparison group, especially for men, who are in blue collar positions which have been largely abandoned by the comparison group. Women's occupational profile is less marked by origin than men's. Naturalisation affects the vast majority of respondents of immigrant descent, but it remains socially selective; naturalised secondgeneration respondents achieve higher levels on the occupational ladder than those not naturalised, but they do not climb as high as the comparison group.

\subsubsection{Occupational prestige}

Prestige scales are often used to measure occupational status. They are continuous and involve evaluative judgements on the general desirability of occupations based on socio- economic status (SES) and education. In this analysis we use the International Socio-Economic Index of Occupational Status (ISEI), which measures the occupational attributes that convert a person's education into income. In constructing the measure, occupation is scaled so that it captures the indirect influence of education on income as much as possible. The ISEI job prestige score is based on the average level of education and earnings in an occupation and ranks worker occupations on a scale from 10 (low) to go (high) (Euwals et al. 2007).

The job prestige scores show a clear differentiation of the three origin groups, with the comparison group achieving the highest score, secondgeneration SSYU respondents the lowest and second-generation Turkish respondents in between (Table 5.14). Analysis of the prestige score by gender reveals that women have a higher prestige score in all three groups and that the difference between the comparison group and second-generation women is smaller than among men. Women in the two second-generation 
groups have similar job prestige scores. The global gulf between the two second-generation groups can be attributed to men's position in the job market, with SSYU men presenting the widest gap in relation to the comparison group.

Table 5.14 Current job prestige score (ISEI) of those in paid employment (average), by origin group, gender, age categories, agglomerations, highest achieved education level

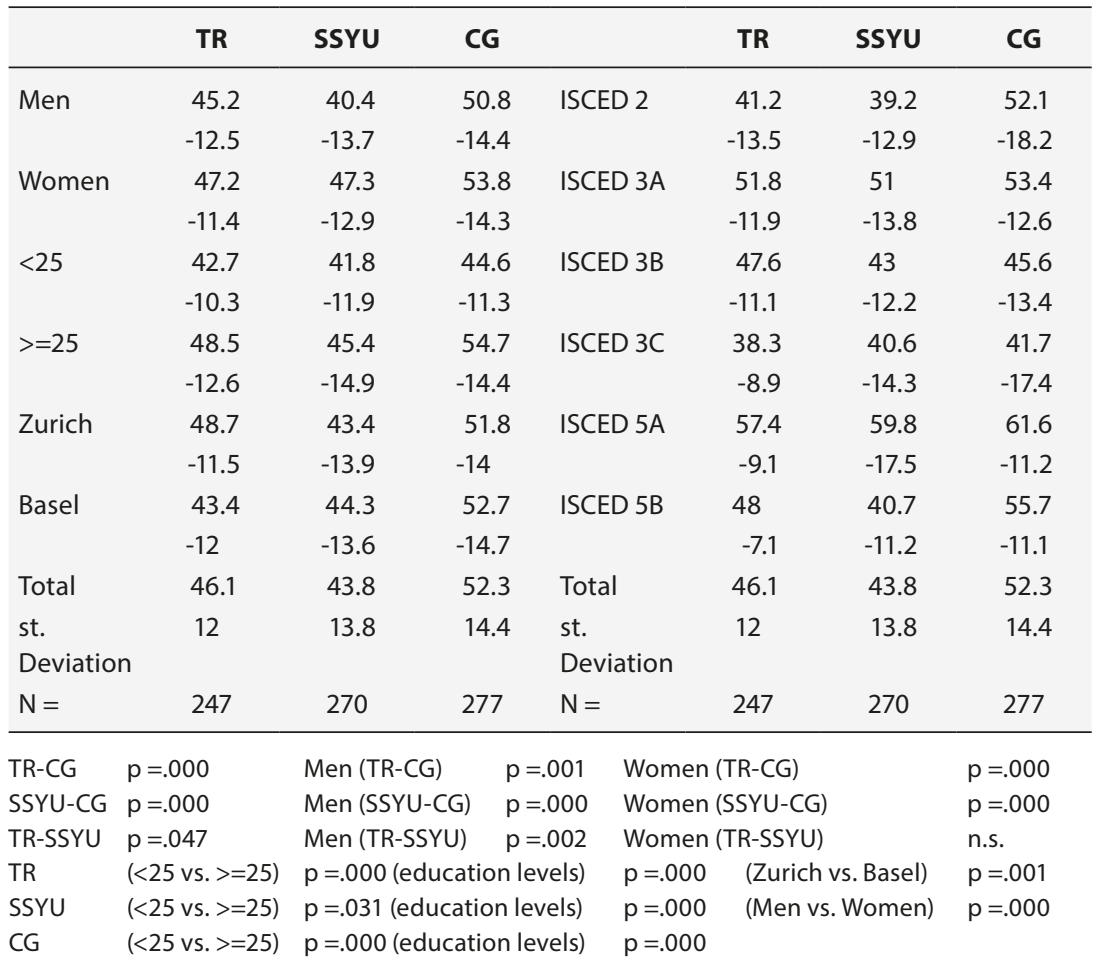

All other differences are not statistically significant.

By their construction, the ISEI prestige scores reflect the hierarchy of postcompulsory school achievement. Note the exception of vocational tertiary education, however, whose yields in terms of prestige are very different from one origin group to the other. The comparison group achieves relatively high prestige scores, significantly higher than either second-generation group, especially of SSYU descent. Analysis of prestige score by age indicates that the initial similarity found in the younger age group grows into significant cleavages after the age of 25 , when professional careers start to consolidate. This result is expected and yet notable. 
Average prestige scores do not differ significantly by gender although women in all origin groups tend to have higher scores than men; this does not seem to have an impact on income, which tends to be lower for women (Table 5.11). Finally, locality generally does not matter, though it does affect second-generation Turkish respondents, whose average prestige scores are lower in Basel than in Zurich.

We further analyse whether prestige varies according to descent for youth with similar educational attainment; this yields remarkable results. At the same level of school qualification the general rule is that the comparison group achieves the highest prestige score, followed by Turkish origin youth and finally second-generation SSYU respondents, with a few exceptions.

Job prestige varies most according to origin for youth having completed only compulsory school (ISCED 2). Comparison group respondents seem able to compensate for low school qualifications once on the job market, reaching a prestige level similar to that attained by ISCED $3 \mathrm{~A}$ achievers, whereas second-generation respondents tend to receive a return consistent with their low attainment (i.e. at most compulsory school). Striking differences in prestige according to origin are observed at the opposite pole of the educational hierarchy, in vocational tertiary education (ISCED 5 B). Again, the comparison group gains a much higher return in prestige than second-generation youth in general and SSYU descent youth in particular. Among second-generation Turkish youth, as many hold vocational tertiary qualifications as general tertiary education (6 per cent for both ISCED ${ }_{5} \mathrm{~B}$ and ISCED $5 \mathrm{~A}$ ); general tertiary education prevails over vocational tertiary education slightly among SSYU respondents (6 vs. 4 per cent) and markedly among comparison group respondents (27 vs. 10 per cent). Origin group differences are smallest for job prestige attained via general education at both ISCED 3 A and ISCED 5 A levels.

In all cases, it appears as though autochthonous respondents are able to effectively mobilise their social capital in order to achieve higher occupational positions, despite having similar educational credentials to second-generation youth. The impact of extra meritocratic inputs is especially striking for youth attending vocational tertiary education, who count among the high achievers in the second generation.

As we restricted analysis of working conditions to those respondents whose main activity is working, we find no confirmation of our hypothesis of major polarisation in working conditions between the Turkish and SSYU second generation and the Swiss-by-birth comparison group. This does 
not imply that the occupational profile of the second generation is the same as that of the comparison group; men of immigrant descent are either concentrated in blue collar positions, especially second-generation SSYU men, or in services and sales. Women's occupational profile is less marked by origin than men's. They are concentrated in white collar positions, especially second-generation women, whereas comparison group women more frequently reach senior positions.

Naturalised youth, the majority of the second-generation of Turkish and SSYU descent, represent a positive selection among children of immigrants in comparison to non-naturalised youth. In spite of their high achievement, however, they do not reach the same level as comparison group youth, as they cannot offset social background differences. Prestige scores largely reflect school achievement so that differences observed are legitimised by meritocratic criteria. However, social capital seems to be effectively mobilised by the comparison group when converting educational credentials into labour market positions. This is especially prominent among high achievers in vocational education.

\subsubsection{Evaluation of career and living conditions}

The description of participation and working conditions provides a snapshot of the relative position of second-generation respondents in the labour market. To give a comprehensive view of the situation through the eyes of respondents, we conclude this chapter by turning to their personal evaluation of their working trajectories.

Satisfaction with professional progress is used as a comparative assessment of the present labour market position in regard to expectations. Table 5.15 summarises the findings.

Table 5.15 Evaluation of career, by origin group and gender

\begin{tabular}{lcccccccccc}
\hline & \multicolumn{3}{c}{ TR } & \multicolumn{4}{c}{ SSYU } & \multicolumn{3}{c}{ CG } \\
\cline { 2 - 10 } & M & W & Total & M & W & Total & M & W & Total \\
\hline Worse than expected & 22.2 & 19.0 & 20.7 & 19.8 & 19.3 & 19.5 & 13.3 & 11.5 & 12.7 \\
As expected & 55.7 & 58.9 & 57.1 & 58.8 & 66.3 & 62.6 & 66.7 & 59.0 & 62.8 \\
Better than expected & 22.2 & 22.1 & 22.1 & 21.4 & 14.4 & 17.9 & 20.0 & 29.5 & 24.5 \\
N = & 193 & 164 & 357 & 187 & 183 & 370 & 198 & 184 & 382 \\
\hline
\end{tabular}

TR-CG $\quad X^{2}=8.646 \quad p=.013$

SSYU-CG $\quad X^{2}=9.357 \quad p=.009$

All other differences are not statistically significant. 
Altogether, one respondent in five among second-generation workers is disappointed with his or her situation; this is a significantly higher percentage than in the comparison group. In all origin groups, part-time occupations tend to be considered unsatisfactory more often than full-time activities. One respondent in five feels he did better than expected; comparison group respondents are most likely to surpass their expectations, followed by the second generation of Turkish origin, with SSYU origin youth following far behind. This finding recalls their remarkable success in the occupational prestige score in comparison to their level of education, observed in $\S 5$.2.3.

Personal evaluation of economic conditions is also examined. Though we discussed earnings in $\S 5.2 .1$, in order to understand the overall living conditions of our respondents we will consider sources of income other than employment and a general appraisal of personal economic situation. The indicators are subjective; for instance, we looked at the perception of economic condition whatever the source of funds, and objective, and the proportion of beneficiaries of social benefits. Table 5.16 reports the subjective evaluation of the overall financial situation of respondents.

Table 5.16 Appraisal of current financial situation, by origin group and gender

\begin{tabular}{|c|c|c|c|c|c|c|c|c|c|}
\hline & \multicolumn{3}{|c|}{ TR } & \multicolumn{3}{|c|}{ SSYU } & \multicolumn{3}{|c|}{ CG } \\
\hline & M & $\mathbf{W}$ & $\mathbf{T}$ & $\mathbf{M}$ & $\mathbf{w}$ & $\mathbf{T}$ & M & $\mathbf{w}$ & $\mathbf{T}$ \\
\hline With difficulties & 24.9 & 25.9 & 25.4 & 27.0 & 18.4 & 22.5 & 9.6 & 13.6 & 11.5 \\
\hline Without difficulties & 75.1 & 74.1 & 74.6 & 73.0 & 81.6 & 77.5 & 90.4 & 86.4 & 88.5 \\
\hline$N=$ & 229 & 220 & 449 & 214 & 217 & 431 & 240 & 228 & 468 \\
\hline TR-CG & \multicolumn{2}{|c|}{$X^{2}=29.380$} & $\mathrm{p}=.000$ & & & & & & \\
\hline SSYU-CG & \multicolumn{2}{|c|}{$X^{2}=19.311$} & $\mathrm{p}=.000$ & & & & & & \\
\hline SSYU (Men vs. Women) & \multicolumn{2}{|c|}{$X^{2}=4.495$} & $\mathrm{p}=.034$ & & & & & & \\
\hline
\end{tabular}

Among second-generation respondents, roughly a quarter encounter difficulties in making ends meet (25 per cent among Turkish origin respondents and 23 per cent among SSYU origin respondents), twice as many as the comparison group (12 per cent). Although this might be a temporary situation, partially linked to the younger age of second-generation respondents in relation to the comparison group, the gap is notable. Such a finding has to be related to the lower median income from employment observed among Turkish respondents ( $\$$ 5.2.1); in other words, Turkish respondents are more likely than others to be the working poor, defined as those with inadequate income to ensure sufficient support. 
Table 5.17 looks at social security beneficiaries (unemployment or disability allowances, student scholarship, social assistance or other) by origin group and gender. One respondent in five receives some form of social benefits; second-generation SSYU respondents are least likely to receive benefits while second-generation Turkish respondents are most likely. In all groups women tend to be more often entitled to social benefits. Among those who have not yet gained a foothold in the labour market, slightly more than a third of respondents are entitled to social benefits, whatever their origin group.

Table 5.17 Receipt of benefit, by origin group and gender

\begin{tabular}{lcccccccccc}
\hline & \multicolumn{3}{c}{ TR } & \multicolumn{4}{c}{ SSYU } & \multicolumn{3}{c}{ CG } \\
\cline { 2 - 10 } & M & W & Total & M & W & Total & M & W & Total \\
\hline $\begin{array}{l}\text { Receiving some } \\
\text { sort of benefit } \\
\text { N = }\end{array}$ & 22.7 & 25.9 & 24.3 & 16.8 & 20.7 & 18.8 & 20.0 & 21.9 & 20.9 \\
\hline
\end{tabular}

TR-SSYU $\quad X^{2}=3.905 \quad \mathrm{p}=.048$

No differences are statistically significant.

Immigrants from Turkey and SSYU are overrepresented as beneficiaries of welfare assistance. The share is 16.2 per cent for Turkish citizens and 7.4 per cent for SSYU citizens as against an average of 6.7 per cent for the whole foreign population (BFS 2009 in Burri Sharani et al. 2010; Haab et al. 2010). ${ }^{1}$ They are therefore stigmatised as a social burden on society. In the TIES data Turkish descent second-generation respondents appear to receive social benefits in a significantly higher proportion than their SSYU peers, but closer to the comparison group. The social benefits TIES respondents receive are listed in the table below (Table 5.18).

Half of the respondents who draw social benefits are entitled to financial aid for payment of premiums in the compulsory system of health insurance. The second most important source of social benefits are student scholarships. This has a distinct impact on Turkish students. By contrast, secondgeneration SSYU respondents benefit from unemployment allowances

1 In 2006, 16.2 per cent of Turkish nationals vs. 6.7 per cent for the whole foreign population received social assistance benefits (personal information from the SFSO, 14.11.08). This data on Turkish citizens is not strictly comparable to TIES results, which reflect second-generation respondents holding mostly Swiss citizenship. 
Table 5.18 Type of social benefits, by origin group

\begin{tabular}{llcc}
\hline & TR & SSYU & CG \\
\hline Health insurance premium & 50 & 46.3 & 59.2 \\
Student scholarship & 31.8 & 17.3 & 18.4 \\
Welfare benefit & 13.6 & 17.1 & 7.1 \\
Unemployment benefit & 10.1 & 18.3 & 8.2 \\
Disability benefit & 8.3 & 6.2 & 11.2 \\
Alimony & 5.5 & 7.3 & 15.3 \\
Other & 1.8 & 4.9 & 9.2 \\
N $=$ & 108 & 81 & 97 \\
\hline (Student scholarship) & TR- CG X ${ }^{2}=4.938 p=.026$ TR- SSYU X $X^{2}=5.167 \mathrm{p}=.023$ & \\
(Welfare) & SSYU-CG X $=4.272 \mathrm{p}=.039$ & & \\
(Unemployment) & SSYU-CG X ${ }^{2}=4.110 \mathrm{p}=.043$ & &
\end{tabular}

and welfare benefits significantly more often than comparison group respondents. We therefore conclude that there is no sign of consolidation of welfare dependency among second-generation respondents.

For the great majority of respondents, their labour market trajectory conforms to expectations. Dissatisfaction is reported by one second-generation respondent in five, a significantly higher percentage than in the comparison group; however, just as many respondents find their position better than expected.

Economic unease affects a high share of second-generation respondents, twice as many as in the comparison group. Given that this is reported by a notable proportion of working respondents, it indicates the presence of the working poor, especially among second-generation Turkish youth. In such conditions, it is understandable that they are the group with the highest share of people receiving social benefits, significantly higher than second-generation SSYU respondents.

\subsection{Barriers to effective labour market integration}

If conditions of participation in the labour market depend to a large extent on an individual's level of qualifications, they are also shaped by the conditions of reception of the various immigrant groups (Portes \& Böröcz 1989). The general economic situation also plays a major role in defining favourable or unfavourable conditions for labour market participation. The Swiss economy witnessed a steady increase of its GDP from 2003 into 2008, with signs of stagnation only in the last quarter of 2008; employment grew 
until October (SECO 2009). Conditions of reception encompass further integration policies, but also public opinion and attitudes developed by the local population toward specific immigrant groups.

Issues of public perception of the two origin groups under study will be dealt with extensively in Chapter 7; we limit our discussion here to indicators of labour market position that might be influenced by policy, formal or informal barriers to equality among groups and attitudes toward immigrant groups and their descendants. Those indicators are access to one's first job, access to public sector jobs, mismatch between education and occupation, and perceived discrimination.

\subsubsection{Access to first job}

When the TIES questionnaire was distributed, between 2007 and the first half of 2008, the Swiss economy was flourishing; in November 2008, when the economic downturn started affecting the Swiss economy, the unemployment rate was 2.7 per cent (SECO 2009). This accounts for the short time lag for respondents to find a job after finishing their education (Table 5.19).

Table 5.19 Average number of months between end of school and the first job* by origin group and gender

\begin{tabular}{lccc}
\hline & TR & SSYU & CG \\
\hline Men & 4.2 & 2.3 & 0.9 \\
(st. dev.) & 9.9 & 4.7 & 2.3 \\
Women & 2.1 & 1.8 & 2.7 \\
(st. dev.) & 4.9 & 5.4 & 7.6 \\
Total & 3.2 & 2 & 1.8 \\
st. deviation & 8 & 5 & 5.5 \\
N = & 74 & 60 & 87 \\
\hline
\end{tabular}

* Selecting those whose main activity is work

Men (TR-CG) $\quad \mathrm{p}=.030$

All other differences are not statistically significant.

It took less than two months for TIES comparison group respondents to find a job, as long as for SSYU youth, but for second-generation Turkish origin youth it took longer. Men tend to experience more difficulty in the job search among children of immigrants, whereas the opposite applies to the comparison group. 


\subsubsection{Access to the public sector}

Access to public sector jobs is an important indicator of inclusion of the second-generation in the labour market. In Switzerland, second-generation youth from previous migrant flows experienced significant difficulties in accessing those. Access to public sector employment was one of the major barriers encountered by second-generation Italian and Spanish youth; though more than a third of Swiss-by-birth were employed in the public sector, a fifth of non-naturalised second-generation youth and a quarter of naturalised children of immigrants managed to reach stable positions in the public sector (Bolzman et al. 2003). The issue of the public sector opening to immigrants and their children is also relevant outside Switzerland, as special measures have been taken in some countries in order to increase the access of children of immigrants to public sector employment (Commission des Communautés Européennes 2007).

We therefore analyse the situation for more recent immigrant groups and their children after almost a decade of federal integration policy which has triggered the implementation of local integration policies. To avoid bias deriving from formal reservation of jobs for national citizens, only naturalised children of immigrants are compared to Swiss-by-birth, even if not all public sector positions are formally restricted to Swiss nationals. Table 5.20 shows the percentage of naturalised youth of immigrant descent and the comparison group in public sector jobs.

Comparison group members are more often represented in governmental/civil organisations compared to naturalised children of immigrants; three out of ten in the comparison group work in these organisations compared to two out of ten naturalised Turkish and SSYU youth. While the presence of Swiss-by-birth in the public sector is slightly lower than that observed in the previous study on this topic (i.e. 40 per cent), Turkish and SSYU origin children are less well represented than Italians and Spaniards, since only a fifth manage to enter public employment, versus some 30 per cent for those previous second generation groups. In fact, the share of naturalised Turkish and SSYU second generation youth in civil service organisations is closer to that observed for non-naturalised Italians and Spaniards.

Women appear to find access to the civil service easier than men in all origin groups considered. The gender gap is especially wide between Turkish men and women; almost one in three women as against one in ten men of Turkish origin is employed in governmental or civil service organizations. Age does not seem to influence access to public sector jobs. Yet a higher 
Table 5.20 Access to public sector employment, by origin group* and gender

\begin{tabular}{lcccccccccc}
\hline & \multicolumn{3}{c}{ TR } & \multicolumn{4}{c}{ SSYU } & \multicolumn{3}{c}{ CG } \\
\cline { 2 - 10 } & M & W & Total & M & W & Total & M & W & Total \\
\hline $\begin{array}{l}\text { Governmental/ civil } \\
\text { service organisation }\end{array}$ & 10.9 & 28.9 & 20.2 & 16.5 & 23 & 20.3 & 31.6 & 32.6 & 31.9 \\
$\mathrm{~N}=$ & 129 & 136 & 265 & 129 & 149 & 278 & 198 & 184 & 382 \\
\hline
\end{tabular}

* Selecting citizens, naturalised of foreign origin and Swiss-by-birth

TR-CG $\quad \mathrm{X}^{2}=15.575 \quad \mathrm{p}=.000$

SSYU-CG $\quad X^{2}=23.529 \quad p=.000$

TR (Men vs. Women) $\quad X^{2}=15.568 \quad p=.000$

All other differences are not statistically significant.

percentage of respondents aged 25 and over in SSYU and comparison groups has access to the public sector compared to younger respondents.

An analysis of this indicator by level of qualification (Table 5.21) shows that for second-generation Turkish respondents and the comparison group, labour market participation in the public sector increases with level of education. The association is linear but not significant. In other words, equal educational credentials somewhat reduce origin group differences between these two groups; this is not, however, the case for second-generation SSYU respondents.

Table 5.21 Percentage who accessed public sector jobs, by origin group and highest achieved education levels*

\begin{tabular}{lcccccc}
\hline & \multicolumn{2}{c}{ TR } & \multicolumn{2}{c}{ SSYU } & \multicolumn{2}{c}{ CG } \\
\cline { 2 - 7 } & ISCED3 & ISCED5 & ISCED3 & ISCED5 & ISCED3 & ISCED5 \\
\hline $\begin{array}{l}\text { Governmental/ civil } \\
\text { service organisations }\end{array}$ & 19.2 & 26.1 & 18.2 & 16.7 & 23.3 & 35.5 \\
$\mathrm{~N}=$ & 122 & $(24)$ & 133 & $(15)$ & 132 & 102 \\
\hline
\end{tabular}

* Selecting citizens, naturalised of foreign origin and Swiss-by-birth as well as respondents out of education

Differences are not statistically significant.

Access to public sector employment is not statistically different in the two agglomerations, even if second-generation groups tend to find it easier in Basel than in Zurich - 21 versus 19 per cent for Turkish descent youth and 22 versus 18 per cent for SSYU origin youth. Conversely, a larger share of 
the comparison group in Zurich is employed in this sector (30 per cent in Basel vs. 35 per cent in Zurich).

Indeed, Basel has been at the forefront of the elaboration of local integration policy in Switzerland. In its programmatic document Integrationsleitbild 1997-2001 adopted in 1999, the government pledged in its capacity as an employer to guarantee a larger correspondence between civil servants and the local population; public administration and publicly funded organisations were to provide an example to the private sector (Ehret 1999). However, policy assessments do not mention this issue. In an evaluation document on the intercultural openness of the Basel administration, no reference is made to special recruitment strategies or diversity management (Doetsch et al. 2004). Recent data confirm a visible increase in foreigners in the Basel administration, possibly as a result of those policy statements (Statistiches Amt des Kantons Basel-Stadt 2010).

Public authorities play a major role as employers in the labour market, as they provide jobs for almost a third of comparison group respondents. Through equal intermediate educational credentials the second generation finds comparable access to this type of occupation, though this does not always seem to be the case when they reach higher levels of educational qualifications. Integration policy in Basel appears more sensitive to this issue than that in Zurich.

\subsubsection{Mismatch between education level and job requirements}

Another important aspect of labour market participation is the correspondence between achieved education level or skills and the requirements of the current job. Over-education is found when the attained level of education exceeds the required level of education to carry out a job. In an analysis of over-education based on Census 2000, Pecoraro finds that migrants are more strongly exposed to the risk of over-education than second-generation foreigners born in Switzerland; the risk of over-education is tripled for Africans, South Americans and nationals coming from non-European Community countries relative to members of the EU/EFTA and North Americans (2004).

In the TIES survey the only possible approach to this question was via respondents' self-assessment of congruence between skills and position, hence it is based on individual perceptions of the educational level required for a job. The analysis is restricted to respondents who have exclusive work activities, in order to filter out occasional work and students' activities (Table 5.22). 
Second-generation youth report higher levels of concern about over-education than the comparison group, though the difference is only significant for SSYU origin respondents: 26 per cent more often judge the requirements of their jobs as below their educational level than the comparison group, only 16 per cent of whom feel this way. Gender and agglomeration patterns are similar in all origin groups.

Age accounts for differences in evaluation of over-qualification. It is significantly higher among older second-generation SSYU respondents (29 per cent) compared to younger ones (23 per cent). By contrast, overeducation is more often reported by younger comparison group and Turkish respondents; a quarter of those under 25 and one out of ten aged 25 and over find their qualifications exceed the requirements of their current job. By and large, self-assessed over-education appears mainly to affect the transition from education to the labour market of Turkish origin youth and comparison group members, but seems a lasting condition for SSYU youth.

Table $\mathbf{5 . 2 2}$ Self-reported over-qualification, by origin group and age*

\begin{tabular}{lcccccccccc}
\hline & \multicolumn{3}{c}{ TR } & \multicolumn{4}{c}{ SSYU } & \multicolumn{3}{c}{ CG } \\
\cline { 2 - 10 } & $\mathbf{2 5}$ & $>\mathbf{= 2 5}$ & Total & $<\mathbf{2 5}$ & $>\mathbf{= 2 5}$ & Total & $<\mathbf{2 5}$ & $>\mathbf{2 5}$ & Total \\
\hline $\begin{array}{l}\text { Job is below the } \\
\text { education level } \\
\mathrm{N}=\end{array}$ & 25.3 & 21.4 & 22.9 & 23 & 29 & 26.2 & 26.6 & 14.2 & 17 \\
\hline
\end{tabular}

* Selecting only respondents working as main activity

SSYU-CG $\quad X^{2}=7.004 \quad p=.030$

SSYU ( $<25$ vs. $>=25) \quad X^{2}=6.009 \quad p=.050$

CG $(<25$ vs. $>=25) \quad X^{2}=12.600 \quad p=.002$

All other differences are not statistically significant.

We tested whether the level of educational attainment affects the frequency of perceived mismatch by respondents. Self-assessed over-education varies significantly according to educational level only in the comparison group and is higher for those who have a tertiary level of education. In the second generation the analysis of level of education does not reach a significant threshold, probably because of the limited number of respondents with tertiary education who are already economically active. However, it appears that lower school achievers report higher perceptions of over-education, expressing in this way their dissatisfaction with their labour market position.

The data does not support the hypothesis of over-education in secondgeneration respondents of Turkish and SSYU descent, hence of their 
perceived difficulties in achieving returns on their educational investment. However, some findings can be interpreted as giving evidence of disappointment in the evolution of their labour market position. This invites us to analyse perceptions of discrimination further.

\subsubsection{Perceived discrimination in the labour market}

In the literature concerning many Western European countries (Rydgren 2004; Silberman et al. 2007), strong evidence is presented for widespread ethnic discrimination in the labour market. In Switzerland, a study specifically targeted the issue of discrimination experienced by children of immigrants entering the labour market, focusing on Portuguese, Turkish and Albanian-speaking youth who had done all of their schooling in Switzerland (Fibbi et al 2003; Fibbi 2006). Following the ILO experimental methodology, the authors find a surprisingly high discrimination rate for the two groups of non EU-origin - 30 per cent for Turkish youth and 38 per cent for Albanian-speaking youth.

The TIES survey tests for the presence of discrimination on a subjective basis by asking respondents about both their opinion and their experience regarding ethnic discrimination in the process of looking for a job and in the workplace. As before, the analysis is limited to the experience of respondents exclusively in work. Individual opinion on personal and group discrimination in society will be discussed in Chapter 7 .

A third of second-generation respondents reported hostility due to origin while looking for a job and in the workplace; discrimination affects youth of Turkish and SSYU origin to the same extent (Table 5.23). Perceived hostility is higher in the process of job seeking (indeed, it is more difficult to detect) than in the workplace - four out of ten children of immigrants experienced hostility because of their ethnic origin while looking for a job and three out of ten in the workplace. An acute sense of discrimination affects some 5-7 per cent of second-generation respondents. SSYU youth report significantly more hostility in Zurich than in Basel while looking for a job (10 vs. 3 per cent, respectively).

According to a study carried out in eleven European cities, half of Muslims interviewed faced discrimination in the year before the survey, as against an average of 9 per cent for non-Muslims (Open Society Institute 2009). The study has no special focus on the second generation, but it raises the question of whether discrimination should be analysed along religious lines instead of national/ethnic lines. Questions on experience of discrimination were therefore tested by controlling both for descent 
Table 5.23 Personal experience of hostility because of origin while looking for a job and in the workplace, by origin group*

\begin{tabular}{lcccc}
\hline & \multicolumn{2}{c}{ TR } & \multicolumn{2}{c}{ SSYU } \\
\cline { 2 - 5 } & $\begin{array}{c}\text { While looking } \\
\text { for a job }\end{array}$ & $\begin{array}{c}\text { At the } \\
\text { workplace }\end{array}$ & $\begin{array}{c}\text { While looking } \\
\text { for a job }\end{array}$ & $\begin{array}{c}\text { At the } \\
\text { workplace }\end{array}$ \\
\hline Never & 62.5 & 67.1 & 62.7 & 70.4 \\
Sometimes & 32.1 & 28.8 & 30 & 26.8 \\
Often & 5.4 & 4.2 & 7.3 & 2.8 \\
$\mathrm{~N}=$ & 244 & & 280 & \\
\hline
\end{tabular}

* Selecting only respondents working as main activity

and the religious characteristics of respondents (Table 5.24). We find no evidence of perceived discrimination that might be related to the religious affiliation of respondents.

Table 5.24 Personal experience of hostility while looking for a job and at the workplace, by origin group and religion*

\begin{tabular}{lcccccccccccc}
\hline & \multicolumn{3}{c}{ TR } & \multicolumn{10}{c}{ SSYU } \\
\hline & $\begin{array}{c}\text { While looking } \\
\text { for a job }\end{array}$ & $\begin{array}{c}\text { At the } \\
\text { workplace }\end{array}$ & \multicolumn{2}{c}{$\begin{array}{c}\text { While looking for a } \\
\text { job }\end{array}$} & At the workplace \\
& $\begin{array}{l}\text { Non- } \\
\text { reli- } \\
\text { gious }\end{array}$ & $\begin{array}{c}\text { Mus- } \\
\text { lim }\end{array}$ & $\begin{array}{c}\text { Non- } \\
\text { reli- } \\
\text { gious }\end{array}$ & $\begin{array}{c}\text { Mus- } \\
\text { lim }\end{array}$ & $\begin{array}{c}\text { Non- } \\
\text { reli- } \\
\text { gious }\end{array}$ & $\begin{array}{c}\text { Chris- } \\
\text { tian }\end{array}$ & $\begin{array}{c}\text { Mus- } \\
\text { lim }\end{array}$ & $\begin{array}{c}\text { Non- } \\
\text { reli- } \\
\text { gious }\end{array}$ & $\begin{array}{c}\text { Chris- } \\
\text { tian }\end{array}$ & $\begin{array}{c}\text { Mus- } \\
\text { lim }\end{array}$ \\
\hline Never & 57.7 & 66.4 & 63.1 & 70.4 & 66.1 & 60.8 & 67.7 & 70.1 & 71.0 & 74.2 \\
Some- & 36.9 & 28.0 & 31.5 & 26.4 & 29.1 & 30.4 & 22.6 & 27.6 & 25.8 & 19.4 \\
times & & & & & & & & & & \\
Often & 5.4 & 5.6 & 5.4 & 3.2 & 4.7 & 8.8 & 9.7 & 2.4 & 3.2 & 6.5 \\
$\mathrm{~N}=$ & 111 & 130 & 111 & 130 & 124 & 120 & 33 & 124 & 120 & 33 \\
\hline
\end{tabular}

* Selecting only respondents working as main activity No difference is statistically significant.

To put the findings on discrimination into perspective, we compared them with the result of an earlier study on second-generation youth in Switzerland; the comparison cannot be strict since in the previous study respondents were not questioned on the frequency of hostile experiences (Bolzman et al. 2003). The proportion of children of Italian and Spanish immigrants reporting experiences of discrimination reached 40 per cent in general but only 5 per cent related these unpleasant incidents to their 
work situation: 75 per cent of respondents reported that fellow youth were the most frequent source of discrimination.

Table 5.25 Persons manifesting hostility because of origin in the workplace, by origin group

\begin{tabular}{lcc}
\hline & TR & SSYU \\
\hline Co-workers or colleagues & 53.5 & 44.3 \\
Foremen or supervisors & 19.5 & 26.6 \\
Boss or director & 33.3 & 38.0 \\
Clients & 32.2 & 26.6 \\
Others & 5.8 & 11.4 \\
$\mathrm{~N}=$ & 88 & 75 \\
\hline
\end{tabular}

No difference is statistically significant.

Table 5.25 details the profile of the people who provoked TIES respondents' feelings of discrimination. Half of second-generation respondents were concerned by the unfriendly behaviour of their colleagues; roughly a third felt aggression from clients. However, a significant proportion felt targeted by people in a position of power, whether supervisors or bosses - half of Turkish respondents and two thirds of SSYU respondents reported such experiences of hostility.

Overall, TIES respondents originating from non EU-countries perceive themselves as being exposed to hostility to a notably greater extent than second-generation youth from EU countries, in spite of the fact that the survey took place during an economic boom. This finding echoes the study objectively measuring discrimination against Turkish and Albanianspeaking youth entering the labour market (Fibbi et al. 2003).

Second-generation youth of Turkish and SSYU descent have a somewhat harder time than Swiss-by-birth youth in accessing the labour market and enviable job positions, but we do not find indications of major discrepancies in their structural integration that can not be traced back to educational credentials. Nevertheless, over a quarter perceive diffuse hostility in the labour market that hampers their feeling of acceptance in Swiss society.

\section{$5 \cdot 4$ Conclusions}

The labour market position of the second generation is clearly framed by two poles: an undeniable improvement in comparison to their parents' labour 
market participation and the persistence of a significant difference in terms of unemployment rate compared to autochthonous contemporaries.

Second-generation and comparison group respondents have similar labour force participation behaviour. This rate among second-generation Turkish and SSYU youth is not only comparable but indeed higher than that observed in the comparison group, thanks to the high share of children of immigrants in the dual apprenticeship track, which entails a working contract. Gender differences in activity persist - the rate is lower for women than for men. However, this finding is not due to an ethnic understanding of gender roles, as the activity rate of second-generation Turkish women is identical to that observed among comparison group women, with SSYU women showing the strongest participation rate. Motherhood reduces the labour force participation rate, but the lowest figure is to be found among Swiss-by-birth mothers with children. In spite of those similarities, the second generation is significantly more affected by unemployment than the comparison group.

Today's labour market is characterised by the increasing importance of flexibility in labour force use. However, the second generation are no more affected by these more flexible and somewhat precarious conditions than the comparison group. Flexible employment conditions run more along gender than origin lines.

So far we have identified similarities between second-generation and comparison group respondents. However, a more detailed account reveals a stark contrast between children of immigrants and the autochthonous population in terms of occupational category which is influenced by educational background. Differences in both origin and gender are crucial in mapping the labour market position of youth.

Second-generation men are concentrated in skilled blue collar positions particularly SSYU origin men - and lower service occupations - especially Turkish origin men. The latter appear more successful than SSYU men in reaching technical positions. Comparison group men cluster around professional positions. Similarities are stronger in the case of women, who are mostly present in white collar positions, in spite of the highest prevalence of professional occupations among comparison group women. Prestige scores largely reflect this differentiated picture; the comparison group achieves the highest score, second-generation SSYU respondents the lowest and second-generation Turkish respondents occupy an intermediate position. This is mainly due to men's visible specificity in the job market whereas prestige scores for women are generally similar across origin groups. 
Despite different occupational categories and prestige, second-generation Turkish and SSYU respondents generally display similar feelings of mismatch between educational achievement and occupation, discrimination in the labour market and appreciation of their professional career. It is therefore surprising that children of Turkish immigrants appear more economically vulnerable than the SSYU second generation.

Discrimination in the labour market is an issue for a third of secondgeneration respondents and a real problem for some 5 to 7 per cent of them. Especially worrying is the significant proportion who feel threatened by people in positions of power in their workplace.

Naturalised youth represent a positive selection among the second generation, but despite higher achievement by naturalised respondents compared to these non-naturalised and greater similarities between naturalised second-generation and comparison group respondents, profound differences persist, an effect likely due to lower family educational capital and somewhat lower school performance among second-generation respondents. When holding intermediate educational credentials, the second generation finds comparable access to public sector occupations; when reaching higher levels of educational qualification, this is not always the case. Integration policy in Basel appears more sensitive to this issue than in Zurich. This is one good point for Basel, as otherwise youth, especially second-generation youth, seem to face less favourable conditions than in Zurich given that in Basel labour force participation tends to be lower, part-time jobs more frequent and occupational prestige lower.

\section{References}

Birchmeier, Urs (2002), 'Les aspects économiques des formes d'emploi atypiques sur le marché suisse du travail', Vie économique (4): 8-13.

Bolzman, Claudio, Rosita Fibbi \& Marie Vial (2003), 'Secondas - Secondos': Le processus d'intégration des jeunes issus de la migration espagnole et italienne en Suisse. Zurich: Seismo.

Burri Scharani, Barbara, Denise Efionayi-Mäder, Stephan Hammer, Marco Pecoraro, Bernhard Soland, Astrit Tsaka \& Chantal Wyssmüller (2010), Die Kosovarische Diaspora in der Schweiz. Bern: Bundesamt für Migration.

Commission des Communautés Européennes (2007), 'Troisième rapport annuel sur la migration et l'intégration', COM(2007) 512 final. Bruxelles: Commission des Communautés Européennes.

Doetsch, Nadine, Rahel Heeg, Sandra Balsiger, Leticia Figueroa, Natalie Joerin, Anettina Prévost, Mandana Roozpeikar \& Britta Scharping (2004), Empirische Vorstudie zur interkulturellen Problem- und Bedarfsanalyse in der Basler Verwaltung: Kundenorientierung und interkulturelle Sensibilisierung in der Verwaltung des Kantons Basel-Stadt. Basel: baseconsult. 
Eckmann-Saillant, Monique, Claudio Bolzman \& Gérard de Rham (1994),Jeunes sans qualification: Trajectoires, situations, stratégies. Genève: Les Editions IES.

Ehret, Rebekka \& Regierungsrat des Kantons Basel-Stadt (1999), Leitbild und Handlungskonzept des Regierungsrates zur Integrationspolitik des Kantons Basel-Stadt. Basel: Polizei- und Militärdepartement des Kantons Basel-Stadt.

Euwals, Rob, Jaco Dagevos, Merove Gijsberts \& Hans Roodenburg (2007), 'Immigration, integration and the labour market: Turkish immigrants in Germany and the Netherlands', IZA Discussion Paper No. 2677. http://www.iza.org/en/webcontent/publications/papers. Accessed.

Fibbi, Rosita \& Gérard de Rham (1988), 'Switzerland: The position of second generation immigrants on the labour market', in Wilpert Czarina (ed.), Entering the working world:Following the descendants of Europe's immigrant labour force, 24-55. Aldershot: Gower.

Fibbi, Rosita, Bülent Kaya \& Etienne Piguet (2003), Nomen est omen: Quand s'appeler Pierre, Afrim ou Mehmet fait la différence. Berne: Programme national de recherche Formation et emploi.

Fibbi, Rosita \& Marco Pecoraro (2003), 'Well argued proposal. Switzerland: Zurich and Basle, BMU 2nd Generation Project'. Neuchâtel: Swiss Forum for Migration and Population Studies.

Fibbi, Rosita, Mathias Lerch \& Philippe Wanner (2006), 'Unemployment and discrimination against youth of immigrant origin in Switzerland: When the name makes the difference', Journal of International Migration and Integration 7 (3): 351-366.

FSO (2009), Key findings of the Swiss labour force survey. Neuchâtel: Swiss Federal Statistical Office.

Gold, Steven J., Ivan Light \& M. Francis Johnston (2006), 'The second generation and selfemployment'. www.migrationinformation.org. Accessed 1 October 2008.

Haab, Katharina, Claudio Bolzman, Andrea Kugler \& Özcan Yılmaz (2010), Die Türkische Diaspora in der Schweiz. Bern: Bundesamt für Migration.

Kasinitz, Philip, John Mollenkopf \& Mary Waters (2008), The second generation advantage: The children of immigrants inherit the city. Cambridge: Harvard University Press.

Leschke, Janine \& Andrew Watt (2008), 'Job quality in Europe', European Trade Union Institute for Research, Education and Health and Safety (ETUI-REHS) WP 2008.07: 42.

Mey, Eva, Miriam Rorato \& Peter Voll (2005), 'Die soziale Stellung der zweiten Generation. Analysen zur schulischen und beruflichen Integration der zweiten Ausländergeneration', in OFS (ed.) L'intégration des populations issues de l'immigration en Suisse: personnes naturalisées et deuxième génération. 61-152 Neuchâtel: Office fédéral de la statistique.

OFS (2009), Vie active et rémunération du travail. Neuchâtel: Office fédéral de statistique.

Open Society Institute (2010). 'Muslims in Europe: A Report on 11 EU Cities.'

Pecoraro, Marco (2004), Highly skilled migrants in Switzerland, 1-20. Neuchâtel: Swiss Forum for Migration and Population Studies.

Portes, Alejandro \& Josef Böröcz (1989), 'Contemporary immigration: Theoretical perspectives on its determinants and modes of incorporation', International Migration Review 23(3): 606-630.

Rydgren, Jens (2004), 'Mechanisms of exclusion: Ethnic discrimination in the Swedish labour market', Journal of Ethnic and Migration Studies 30(4): 697-716.

SECO (2009), 'Tendances conjoncturelles, hiver 2008-o9'. Berne: SECO.

Silberman, Roxane, Richard Alba \& Irène Fournier (2007), 'Segmented assimilation in France? Discrimination in the labour market against the second generation', Ethnic and Racial Studies 30(1): $1-27$.

Statistisches Amt des Kantons Basel-Stadt (2010), 'Auswertung der kantonalen Beschäftigten nach Nationalität und Kaderstufe', Basel-Stadt, Statistisches Amt.

Suro, Roberto (1998), Strangers among us: How Latino immigration is transforming America. New York: Alfred A. Knopf. 
Tilly, Charles \& Chris Tilly (1994), 'Capitalist work and labour markets', in N.J. Smelser, \& Richard Swedberg (eds), The Handbook of economic sociology. Princeton: Princeton University Press. Wanner, Philippe, Marco Pecoraro \& Rosita Fibbi (2005), 'Femmes étrangères et marché du travail', in Werner Haug \& Philippe Wanner (eds), Migrants et marché du travail en Suisse, 17-38. Neuchâtel: Office fédéral de statistique, Forum suisse pour l'étude des migrations et de la population.

Zhou, Min (1997), 'Segmented assimilation: Issues, controversies, and recent research on the new second generation', International Migration Review 31(4): 975-1008. 


\section{$6 \quad$ Identity}

While previous chapters addressed questions of structural integration of the second generation, the present one deals with the socio-cultural dimension of integration and focuses on how second-generation respondents construct personal identity by selecting among and arranging available identification references. As a consequence of their parents' migratory history, children of immigrants can, and are sometimes pressured to, form attachments to multiple sources of identification emerging from their parents' nations, cultures and religions and from the cultures of the country where they were born and grew up (among others see Gordon 1964; Basch et al. 1994; Vertovec 1999).

Identity is most frequently theorised as socially constructed and not as a singular, unalterable identity that one is born with (Anderson 1983; Hobsbawm \& Ranger 1983). Rather, both immigrants and natives may have multiple identities, e.g., one can simultaneously be attached to more than just one source of identification (Clifford 1994; Gilroy 1993). Identities are also fluid and change over time, and reflect context by changing in response to particular life situations (Gupta \& Ferguson 1997; Brubaker \& Cooper 200o). While valid for many in the ever-more globalized world, such theories are especially pertinent to migrants and their children.

Despite theories of multiple, flexible and contextual identities based on abundant empirical evidence, they are still too often conceptualized as being firmly rooted in cultures, which are in turn rooted in a particular physical and historical space and the people living there (Çağlar 1997). Migrants transgress this concept when they move from country to country, keeping fragments of their country of origin cultures and encountering new cultures, refracting them through their own experiences of movement and thus forming new hybrid identities (Bhabha 1994).

To take into account these theoretical ideas and the lived realities of our respondents, the TIES survey contained numerous questions regarding possible multi-level (from local to supranational) identifications and allowed respondents to check as many as they wished, independently from each other. Such an approach is distinct from the classical binary opposition of country of origin versus country of residence, which has dominated the literature on children of migrants since the seminal work of Irvin Child (1943). In order to quantitatively capture evidence of the multifaceted nature of identity, the survey was designed to allow for the possibility of expressing identification not only in broadly political but also religious terms, as well 
as identifications arising from daily life. All this taken together enabled respondents to overcome the demands for a singular and coherent identity that essentialised claims of belonging often entail.

Nevertheless, the data obtained through surveys should be interpreted cautiously when analysing identity processes among the second generation in European cities. Survey data by its nature tends to present an overly static picture of society - in this case, a snapshot of identity construction processes at the time the respondent answered the questionnaire. Surveys cannot readily reflect the highly fluid and context dependent nature of identities as they are expressed in urban environments and are hardly adequate to capture what Michel Foucault (1988) has called the 'technologies of the self' - the active, fluid and imperfect selection and performance of various identities that are available to individuals as a consequence of existing social relations and discourses of power (see also Bauman 1996; Hannerz 1996).

The concept of identity encompasses two complementary dimensions. The first is the sociological / anthropological concept of collectively established identifications (such as Croat, manager, mother, anarchist, Zürcher, European and many others), which are an outcome of the social classifying and structuring processes through which we attempt to understand and control ever more complex social relations within modern societies (Anderson 1983; Brubaker \& Cooper 2000; Pieterse 2007). The second concept was developed within psychology (Jung 1939; Tajfel 1974; Turner 1987) and deals with the process of individuation, or establishment of a unique and coherent self. Similar to Foucault's ideas on technologies of the self, individuation is theorised as a process of individual differentiation through conscious or unconscious selection among many collectively available identifications and their subsequent creative manipulation. Thus, individuation - along with highly selective memory processes - enables one to establish a unique life biography that one calls the self (Sciolla 2000).

Both dimensions are firmly grounded in the existing structural arrangements and distributions of power, defined as the opportunity, existing within a social relationship, to carry out one's own will even against resistance and regardless of the basis on which this opportunity rests (Weber 1962). Which collective identifications are created and celebrated and which are consigned to oblivion is, therefore, a question of distribution of power to define socially acceptable discourses of belonging and right; these identifications are moulded through state institutions, modes of production, media, judiciary and other means of social control (Gramsci 1971; Foucault 1965; Pieterse 2007). Processes of individuation are also confined 
by existing relations of power in society. While performing one's identity one is never completely free to choose among the myriad existing possibilities of identification, but one is confined by one's own history and existing social relations to a limited range of possibilities that can compose one's self (Foucault 1988). Therefore, processes of individuation are often riddled with conflict as individuals continually attempt to overcome the structurally imposed limits on what they see as their freedom of self realisation.

Although seemingly whole and unchangeable, identifications revealed by the TIES survey are not stable ontological identities but should be seen as fragmented into possible 'cultural repertoires' (Hannerz 1996) that respondents perform depending on personal interests, wider structural arrangements of power and available public discourses. Identification with a given collectively constructed identity (such as Swiss, Yugoslav, Serb, Muslim or Basler) must therefore be seen as a sign of both personal affinity with a given identification (or better yet, some of its parts) and as a strategy elaborated in consideration of the wider arrangements of power within a given society (Camilleri et al. 1997). Recent theoretical emphasis on so-called reactive identities - identifications taken up as a result of social marginalisation and lack of other possibilities for identification (such as public discourse which excludes immigrants and their children from identifying with the national culture or demonises their religions and ways oflife) - show the importance of wider social arrangements for the processes of personal identity construction (see Portes \& Zhou 1993; Stepick \& Stepick 2002; Pieterse 2007).

In the TIES study, identity is defined as a multi-faceted indicator of feelings towards and construction of belonging to a number of collective references, ranging from neighbourhoods and countries to ethnic and religious groups. In this chapter we will first review respondents' identifications and analyse if, and to what extent, respondents combine various often presumed conflicting identifications. We will also address the issue of language use, which provides one way of performing identity in daily life. Identifications - as collectively established sets of appropriate cultural codes and behaviours (repertoires) - are always communicated through language, which therefore often functions as a possible way of expressing belonging to a given group. We will focus on mastery of Swiss-German and country of origin languages as well as on reported actual usage of these languages in conversations with family, friends, and partners. This chapter also addresses religion as another important axis of personal identification, focussing on respondents' religious education during childhood and their current religious identification as well as their religious practices. This will 
enable us to highlight intergenerational changes in religious belonging between respondents and their parents. Finally, we will address respondents' opinions about the role of religion in modern society (notably in public life and in multicultural environments) and conclude the chapter by offering some thoughts about the significance of presented data.

\subsection{Multiple levels of identity}

In this subsection, we will concentrate on respondents' personal attachments to various collectively established identifications and attempt to give an overview of their complex identity constructions. The TIES survey included several questions about feelings of belonging to various possible local, national, and supranational reference frames for identification. We will analyse how these multi-level identification reference frames interact to form the particular constellations of personal identifications observed among TIES survey respondents.

Our first aim is to outline the most salient identifications, focusing particularly on residence and parents' country ethnic and national identifications, and examining their mutual relationships. For second-generation respondents, the resulting narratives of personal belonging will be analysed in parallel with their naturalisation practices in order to account for the role of institutions in the process of personal individuation. We will also test the relative importance of various identificational frames, from the frequent - and highly problematic - national one to personally experienced local city and neighbourhood ones.

\section{Parents' countries of origin}

In the country of residence immigrants and their children are often categorised or defined by their national origin, a fact which often exerts a commanding influence over their lives. Therefore national categories are unavoidable in the field of identificational research. We will start this section by presenting ethno-national characteristics of the parents of our respondents. In the two cases under scrutiny however, this is not an easy task. The group defined by one or both of their parents emigrating from Turkey needs to be further distinguished by ethnic and linguistic categories into Turkish or Kurdish groups. Respondents classified together as children of people coming from successor States of Socialist Federal Republic of Yugoslavia (SSYU) must be further divided into at least the existing seven nation-states in order to account properly for ethno-national identifications. 
As a result, we first assess the factual membership (based on country of parent's origin for SSYU respondents and the language their parents grew up with for respondents of Turkish descent) and only later distinguish the current personal ethno-national claims of our respondents.

Most SSYU parents of TIES respondents came from Serbia (25 per cent), Bosnia (22 per cent) and Croatia (18 per cent), followed by substantial numbers from Kosovo (15 per cent) and Macedonia (9 per cent); the number of parents coming from the two smallest republics of former Yugoslavia, Slovenia and Montenegro, is negligible (see Chapter 3). Among the Turkish group, parents of about 16 per cent of the respondents $(\mathrm{N}=70)$ grew up speaking Kurdish, but about 20 per cent $(\mathrm{N}=94)$ of Turkish respondents identify as Kurdish (Table 6.3). This example shows the difficulties encountered when trying to assess the factual origin of respondents.

While only about 3 per cent of mothers in both groups were born in Switzerland, about 8 per cent grew up in Switzerland from as early as the age of four. As expected, given the uneven gender distribution of the early flows of guest workers, and sampling based on the name recognition method (onomastic method), percentages of fathers brought up in Switzerland are low: 5 per cent and 4 per cent for Turkish and SSYU groups respectively. Only about 1 per cent of fathers in both groups were actually born in Switzerland.

\subsubsection{Present identifications of respondents}

To give an overview of present identification of our respondents, Table 6.1 compares the three origin groups on the strength of their local (city, neighbourhood), national (both residence country and parents' country) and supranational identifications. Among all groups the strongest feelings of belonging were reserved for city and neighbourhood - the main arenas of lived experience.

More than half of SSYU descent respondents feel strongly Swiss, while they feel more attachment to local and supranational (city ${ }^{1}$ and Europe) entities than the comparison group. Turkish descent respondents also have strong local attachments, similar to respondents of SSYU descent, but they feel Swiss significantly less strongly than the SSYU origin group while showing a much stronger attachment towards the country of their parents' origin. However, they feel European to nearly the same extent as the comparison group.

1 The very important issue of city and neighbourhood attachment will be discussed in more detail in the subsection on local attachment. 
Table 6.1 Strong feeling of belonging to various references by group

\begin{tabular}{lccc}
\hline & TR & SSYU & CG \\
\hline Neighbourhood & 70.3 & 69.3 & 64.3 \\
City/Canton: Zurich/ Basel & 60.1 & 63.5 & 57.5 \\
Switzerland & 47.1 & 54.8 & 61.7 \\
Parents' country & 58.8 & 38.6 & -- \\
Europe & 48.8 & 57.2 & 51.7 \\
N $=$ & 449 & 431 & 468 \\
\hline
\end{tabular}

TR-SSYU

$\begin{array}{lll}\text { Switzerland } & X^{2}=8.022 & \mathrm{p}=.046 \\ \text { Europe } & \mathrm{X}^{2}=7.309 & \mathrm{p}=.063 \\ \text { Parent's country } & \mathrm{X}^{2}=17.256 & \mathrm{p}=.000 \\ \text { TR-CG } & & \\ \text { Switzerland } & \mathrm{X}^{2}=43.992 & \mathrm{p}=.000 \\ \text { Europe } & \mathrm{X}^{2}=10.918 & \mathrm{p}=.012 \\ \text { SSYU-CG } & & \\ \text { Switzerland } & \mathrm{X}^{2}=28.732 & \mathrm{p}=.000 \\ \text { Europe } & \mathrm{X}^{2}=8.632 & \mathrm{p}=.035\end{array}$

How strongly do immigrant origin youth identify with the countries of their parents and with Switzerland? Respondents of Turkish and SSYU descent differ sharply in this respect. Among the former, the proportion of those who identify firmly with their parents' country is higher than the proportion of people strongly identifying with Switzerland (59 and 47 percent respectively); the gap is even more pronounced for the Kurdish second generation, where only 32 per cent report a great attachment to Switzerland (not shown in the table).

By contrast, among respondents of all national groups of SSYU descent, identification with Switzerland is higher than identification with their parents' countries of birth. This is especially striking for children of Macedonians, Kosovars and Bosnians, who exhibit the lowest levels of identification with countries of their parents' origin. With Bosnians this is most likely a consequence of the tense socio-political conditions in the country split by a recent war and successive sharp ethno-religious divisions among Serbs, Croats and Muslims. The fact that about 10 per cent of Bosnian origin respondents stated that they identify strongly as Bosniak ${ }^{2}$ is evidence

2 Bosniak is an identification designating Bosnians of Muslim faith, re-established as a result of the war and ethnic divisions in Bosnia. This combination of national and religious category enjoys an official recognition as it was used in the Dayton agreements and the present Bosnian constitution, recognising Bosniaks as one of its constituent ethnic groups. 
of a crystallisation of these religious divisions within the national Bosnian identity. On the other hand, despite the fact that Yugoslavia does not exist anymore as a state, about 14 per cent (one in every seven young persons of SSYU descent) still choose to define their in relation to that (regional supranational) reference.

With regard to ethnic identifications, respondents in the Turkish group mostly identify as Turkish, while some also define themselves in relation to one of the many ethnic groups that compose present day Turkey. Among the 20 per cent of Turkish origin respondents identifying themselves as Kurdish, two out of three reported strong attachment to that ethnic group. A total of about to per cent of Turkish origin respondents identify with other minority groups present in Turkey (for example, Armenian, Greek, Chechen, Circassian or Suryan), with no single group reaching more than 3 per cent. As the only numerically significant minority presence among Turks in Switzerland, the Kurdish minority is singled out in the following analysis.

Table 6.2 Attachment to Switzerland by respondents reporting strong feelings of belonging to parents' country of origin

\begin{tabular}{lccc}
\hline Country of origin & $\begin{array}{c}\text { A: Respondents } \\
\text { reporting strong } \\
\text { feelings for country } \\
\text { of origin (N) }\end{array}$ & $\begin{array}{c}\text { B: Respondents } \\
\text { reporting strong } \\
\text { feelings for CH and } \\
\text { country of origin (N) }\end{array}$ & $\begin{array}{c}\text { C: Strong feelings } \\
\text { for both countries } \\
\text { (B/A in per cent) }\end{array}$ \\
\hline Turkey & 266 & 129 & 48.3 \\
Kurdish* & 51 & 16 & 31.4 \\
Kosovo & 23 & 14 & 59.1 \\
Bosnia & 26 & 13 & 51.9 \\
Croatia & 51 & 29 & 57.7 \\
Macedonia & 14 & 9 & 64.3 \\
Serbia & 57 & 25 & 43.9 \\
\hline
\end{tabular}

* 94 Turkish origin respondents identify themselves as Kurdish.

In order to assess the exclusivity of feelings of belonging, we consider only those respondents who declared being strongly attached to their parents' country of origin and observe if this feeling is associated with an equal attachment to Switzerland (Table 6.2). Strong bilateral identifications are indeed quite frequent: more than half of the respondents who identified strongly with the country of origin of their parents also identified strongly with their country of residence. Youth of Macedonian and Kosovar descent have the highest percentage of such double positive identifications and the 
Kurdish second generation the lowest. Thus, data seem to corroborate the weakness of exclusive identifications as well as the hypothesis of multiple belongings presented at the beginning of this chapter.

Double identifications are not restricted to descendants of international migrants. The intense politicisation of the Kurdish conflict in Turkey may suggest that identification as Kurdish is incompatible with identification as Turkish; however, this is not the perception of these respondents. Among the 94 people saying they feel some degree of belonging to the Kurdish ethnic group, one fourth combines strong feelings for both identifications and some 60 per cent articulate strong and moderate feelings to those references (Table 6.3).

Table 6.3 Self-identification as Kurdish vs. Turkish, among Turkish origin respondents / Feeling of being Kurdish (row) by feeling of being Turkish*

\begin{tabular}{lccccc}
\hline Kurdish/Turkish & Strong & $\begin{array}{c}\text { Neither strong } \\
\text { nor weak }\end{array}$ & Weak & $\begin{array}{c}\text { Not ap- } \\
\text { plicable }\end{array}$ & Total N \\
\hline Strong & 25 & 12 & 13 & 5 & 50 \\
Neither strong nor weak & 6 & 14 & 5 & 0 & 25 \\
Weak & 10 & 5 & 5 & 0 & 19 \\
$\mathrm{~N}=$ & 38 & 29 & 22 & 5 & 94 \\
\hline
\end{tabular}

* Percentages are calculated out of the total $(\mathrm{N}=94)$

$X^{2}=10.960 \quad p=.090$

No gender differences were observed in terms of second-generation respondents' identification with their parents' country of origin. On the contrary, attachment to Switzerland is significantly stronger among women than among men for both Turkish and SSYU descent groups, independent of age group; such a gender difference has been observed by Mahler and Pessar (2006) in their discussion of the importance of gender in migration studies. In fact, SSYU women show an even stronger bond to Switzerland than women of the comparison group; the difference is statistically significant for women aged 25 and above. As will be seen in Chapter 7 , women also experience less discrimination than men. However, the obverse side of these results is that among 18 to 24 year olds, about 20 per cent of Turkish and about 15 per cent of SSYU descent men have a weak identification with Switzerland. Importantly, for both Turkish and SSYU men this percentage decreases significantly as they grow older. 
Table 6.4 Feeling of belonging in Switzerland by group and gender

\begin{tabular}{lrrrrrrrrrrr}
\hline & \multicolumn{3}{c}{ TR } & \multicolumn{4}{c}{ SSYU } & \multicolumn{3}{c}{ CG } \\
\cline { 2 - 11 } & Men & Women & Total & Men & Women & Total & Men & Women & Total \\
\hline Strong feelings & 42.4 & 52.3 & 47.2 & 46.0 & 64.1 & 55.1 & 60.7 & 62.7 & 61.5 \\
Neither strong & 38.3 & 34.1 & 36.1 & 39.1 & 28.1 & 33.6 & 35.0 & 35.5 & 35.3 \\
nor weak & & & & & & & & & \\
Weak feelings & 16.2 & 11.4 & 13.8 & 10.7 & 4.6 & 7.6 & 4.2 & 1.8 & 1.4 \\
Not applicable & 3.5 & 2.3 & 2.9 & 4.2 & 3.2 & 3.7 & 0.4 & 0 & 0.2 \\
N = & 229 & 220 & 449 & 214 & 217 & 431 & 240 & 228 & 468 \\
\hline SSYU (Men vs. Women) & $X^{2}=15.733$ & $\mathrm{p}=.001$ & & & & & \\
TR-CG & $\mathrm{X}^{2}=53.006$ & $\mathrm{p}=.000$ & & & & & \\
SSYU-CG & $\mathrm{X}^{2}=26.750$ & $\mathrm{p}=.000$ & & & & & \\
TR-SSUY & $\mathrm{X}^{2}=12.035$ & $\mathrm{p}=.007$ & & & & &
\end{tabular}

The analysis of respondents' feeling of belonging shows that strong identification with Switzerland concerns half of the immigrant-origin youth. (Table 6.4). Identification with one's parents' country of origin is for the majority of respondents not in conflict with the development of an attachment to Switzerland: they often occur simultaneously. Moreover, this identification is often articulated in unproblematic relation to strong local and supranational attachment. While there are no significant differences in their attachment to their parents' countries of origin, second-generation women tend to identify with Switzerland more than second-generation men. In terms of age differences, older second-generation respondents seem to identify more strongly with Switzerland than younger ones. In the next section, we will examine naturalisation and its impact on narratives of attachment.

\subsubsection{Naturalisation}

In Switzerland, naturalisation of native-born children of immigrants does not rely on the principle of jus soli and, hence, they have no automatic access to Swiss citizenship. Though the legal requirements are more easily met by children of immigrants who grew up in the country, their naturalisation remains a socially selective process (Achermann \& Gass 2003; Fibbi et al. 2007). Double nationality has been permitted in case of naturalisation since 1992.

In spite of this strict naturalisation policy, children of the two immigrant groups under scrutiny here show quite high naturalisation rates (see chapter 2 demography): three fourths of second-generation respondents 
hold Swiss citizenship (73 per cent among Turkish origin and 75 per cent among SSYU origin youth) and most others (some 20 per cent overall) plan to apply in the near future; only 4 per cent of the sample have not considered naturalisation. This conduct is in sharp contrast with the naturalisation behaviour of second-generation youth of previous immigration flows to Switzerland assessed on the basis of the Census 2000: those naturalised represented 28 per cent of the native-born Italian second generation, 32 per cent of the Turkish and 56 per cent of the Croatian second generation (Fibbi et al. 2005).

Legislation both in Switzerland and respondents' 'home' countries acknowledges dual nationality. According to the assumption of multiple belonging, it might be expected that all naturalised youth hold two passports. Indeed, the majority of naturalised respondents make use of this opportunity and maintain previous citizenships and therefore legal rights of memberships in both nations. Some, however, do not possess the citizenship of their parent's country, with significant differences between the Turkish and SSYU origin groups (14 vs. 29 per cent). The connection between nationality and inheritance of property rights may explain why most Turkish origin respondents keep their parents' nationality. No significant differences are to be observed in the behaviour of older and younger respondents in this group. On the contrary, one in three naturalised respondents of SSYU descent has only Swiss citizenship, which might be a consequence of the socio-political tensions in most of the successor states of Yugoslavia and the resulting practical difficulties in keeping the previous passport.

Women consistently display a stronger attachment to Switzerland than men: they identify more with Switzerland, they naturalise more and more often hold only a Swiss passport. This is especially the case for SSYU women.

Do naturalised youth develop a stronger feeling of belonging to Switzerland than those who do not hold a Swiss passport but have similarly lived in this country all their lives? In both origin groups, there is a high association between naturalisation and firm attachment to Switzerland (Table 6.5), probably because of the intertwined and reinforcing nature of the two forms of belonging (feeling of attachment and citizenship).

In regard to naturalisation practices, second-generation youth, and especially women, show a stark tendency to apply for and obtain the citizenship of the country where they were born, while at the same time maintaining the citizenship of their parents' countries. Thus, the vast majority of our respondents manage to combine their personal multiple identifications with the countries of their parents' birth and the country they were born in with legal rights of belonging to two different nation-states. 
Table 6.5 Feeling of belonging in Switzerland by naturalisation status and origin group

\begin{tabular}{lcccc}
\hline & \multicolumn{2}{c}{ TR } & \multicolumn{2}{c}{ SSYU } \\
\cline { 2 - 5 } & Naturalised & Non-naturalised & Naturalised & $\begin{array}{c}\text { Non- } \\
\text { naturalised }\end{array}$ \\
\hline Strong feelings & 49.4 & 40.8 & 59.6 & 41.3 \\
Moderate feelings & 40.7 & 24.0 & 34.3 & 31.2 \\
Weak feelings & 9.6 & 25.6 & 5.2 & 14.7 \\
Not applicable & 0.3 & 9.6 & 0.9 & 12.8 \\
N = & 326 & 123 & 325 & 106 \\
\hline
\end{tabular}

TR (Naturalised vs. Non-naturalised) $\quad X^{2}=51.838 \quad p=.000$

SSYU (Naturalised vs. Non-naturalised) $\quad X^{2}=44.218 \quad p=.000$

\subsubsection{Local attachments to city and neighbourhood}

As noted before, while most respondents reported simultaneous attachments to multiple identification sources at different levels of geopolitical organisation (local, national, supranational), there are certain important trends that need to be addressed. All respondents, especially second-generation respondents, report stronger feelings of identification at the lower end of the locality scale. The strongest identification is reserved for city and neighbourhood - where one lives, associates with others, loves, integrates, works and brings up the next generation of children.

Patterns of local identification nevertheless show slight dissimilarities - statistically insignificant - in attachment towards the two cities of our sample. If only city inhabitants are taken into consideration, city level identification is more or less similar for the second-generation youth of SSYU descent, while the Turkish descent group finds it easier to identify with Zurich. This is peculiar, since second-generation Turkish respondents indicated more closely knit social networks in Basel than in Zurich (see Chapter 7).

Overall, second-generation respondents tend to display a tighter local anchorage than comparison group members. Social characteristics of the neighbourhood affect degree of attachment, which is generally stronger for middle and upper-class neighbourhoods, whatever the origin group. However, youth of Turkish descent, who live in working class neighbourhoods significantly more often than the comparison group, identify significantly more with their close urban environment than the comparison group. The 
comparison group shows significantly more attachment towards neighbourhoods populated predominantly by co-ethnics, whereas this is not the case for SSYU descent respondents, who report higher levels of attachment to neighbourhoods that are mixed or predominantly populated by other groups. Turkish origin respondents enjoy a predominantly co-ethnic environment but are comfortable in mixed neighbourhoods (Table 6.6).

Table 6.6 Feeling of attachment to neighbourhood by ethnic composition of neighbourhood and group

\begin{tabular}{|c|c|c|c|c|c|}
\hline & & Strong & $\begin{array}{l}\text { Neither } \\
\text { strong nor } \\
\text { weak }\end{array}$ & Wear & $\mathbf{N}=$ \\
\hline \multirow[t]{5}{*}{ TR } & Predominantly co-ethnics & 79.2 & 6.3 & 14.6 & 46 \\
\hline & Mixed & 71.8 & 19.2 & 9.0 & 75 \\
\hline & $\begin{array}{l}\text { Predominantly other } \\
\text { groups }\end{array}$ & 69.3 & 16.8 & 13.9 & 309 \\
\hline & Do not know & 66.7 & 16.7 & 16.7 & 19 \\
\hline & $N=$ & 320 & 72 & 57 & 449 \\
\hline \multirow[t]{5}{*}{ SSYU } & Predominantly co-ethnics & 56.8 & 21.6 & 21.6 & 40 \\
\hline & Mixed & 73.9 & 18.8 & 7.2 & 72 \\
\hline & $\begin{array}{l}\text { Predominantly other } \\
\text { groups }\end{array}$ & 69.2 & 18.2 & 12.6 & 286 \\
\hline & Do not know & 76.5 & 11.8 & 11.8 & 33 \\
\hline & $N=$ & 298 & 78 & 55 & 431 \\
\hline \multirow[t]{5}{*}{ CG } & Predominantly co-ethnics & 73.7 & 17.0 & 9.4 & 224 \\
\hline & Mixed & 57.8 & 24.7 & 17.5 & 155 \\
\hline & $\begin{array}{l}\text { Predominantly other } \\
\text { groups }\end{array}$ & 46.7 & 28.0 & 25.3 & 75 \\
\hline & Do not know & 81.3 & 0.0 & 18.8 & 14 \\
\hline & $N=$ & 301 & 97 & 70 & 468 \\
\hline
\end{tabular}

CG $\quad X^{2}=27.256 \quad p=.000$

In conclusion, second-generation youth display a strong attachment to their urban and immediate environment, similar to or higher than the comparison group. Regardless of origin group, but especially for secondgeneration respondents, the more local and concrete the identification reference (notably at neighbourhood level), the stronger the identification. At the same time, both Turkish and especially SSYU descent respondents seem to identify readily with an ethnically mixed environment, whereas the comparison group identifies more with neighbourhoods predominantly populated by co-ethnics. 


\subsection{Language mastery and use}

One way to analyse to what extent youth of immigrant descent are performing (ethnic) identifications available to them is by examining their knowledge and use of their parents' and local languages.

\subsubsection{Mastery of local language}

The overwhelming majority of second-generation respondents grew up exposed to Swiss-German. As expected, most of them grew up bilingual, but about to per cent of SSYU origin and 8 per cent of Turkish origin respondents reported growing up only with Swiss-German, while 9 per cent of SSYU and 7 per cent of Turkish origin respondents reported growing up only with their parents' languages. While almost all (99 per cent) of the comparison group respondents reported growing up with Swiss-German, some 10 per cent also reported growing bilingually with French or Italian, a feature understandable in multilingual Switzerland.

Both second-generation groups present a fairly high self-reported mastery (combined speaking, reading, and writing) of German, with youth of SSYU origin showing more confidence than Turkish origin respondents. In both groups, women reported a significantly better command of SwissGerman. Those results are consistent with the better school performance of second-generation women and the higher average school performance of second-generation SSYU respondents as compared to Turkish origin respondents (see Chapter 4).

In Basel, Turkish descent respondents declare a lower command of the local language than in Zurich, possibly related to the slightly higher concentration of Turks in the Rhine city.

\subsubsection{Mastery of parental language}

Half of second-generation respondents report mastery of their parents' language, entailing speaking, reading and writing (Table 6.7). Oral proficiency is systematically higher, probably due to the prevalence of informal learning of parental language among second-generation respondents without adequate support of formalised curricula.

Active practice of parental language continues in the private sphere, despite the linguistic integration of the second generation of Turkish and SSYU descent. No significant differences were observed between genders and age groups. Youth in Zurich report better knowledge of their parents' languages. 
Even if the highest proportion of competent parental language speakers is taken into account, the figures for language retention appear relatively low. This is highlighted when compared with a previous study on the second generation of Italian and Spanish descent. Like TIES respondents, they were between 18 and 35 years old, but the proportion of adult speakers of the parental language with parents sharing the same first language is close to 95 per cent (Bolzman et al. 2003). More recently, qualitative research was conducted on heritage language transmission to the third generation of Italian and Spanish descent; a significant number is able to speak the heritage language in a sample where half the respondents were born to parents not sharing the same first language (Fibbi \& Wyssmüller 2009). Another study dealt with the 16-to-18-year-old Portuguese and Serb-Croatian-speaking second generation in Geneva and Zurich; the share of children of immigrants with a good command of their parents' language was 70 per cent among Portuguese and 62 per cent among Serb-Croatian second generation (Fibbi et al.2007). These figures may not be strictly comparable as they are from studies where the discussion of language issues was prominent and detailed. Nevertheless, they all point to a relatively low retention of parental languages among the TIES respondents.

Table 6.7 Mastery of languages of childhood exposure

\begin{tabular}{lccc}
\hline & $\begin{array}{c}\text { Grew up with } \\
\text { language }\end{array}$ & $\begin{array}{c}\text { Overall mastery of } \\
\text { language now }\end{array}$ & Spoken proficiency \\
\cline { 2 - 4 } & $\mathbf{N}=$ & \% good & \% good \\
\hline TURKEY & & & \\
Kurdish & 44 & 15.6 & 25.0 \\
Turkish & 407 & 57.0 & 65.4 \\
\hline Total Turkey & 451 & & \\
SSYU & & & \\
Albanian & 78 & 47.2 & 58.4 \\
Bosnian & 41 & 30.0 & 52.0 \\
Serbo-Croatian & 105 & 46.4 & 72.7 \\
Croatian & 98 & 56.7 & 64.2 \\
Serbian & 90 & 56.5 & 61.1 \\
Macedonian & 19 & 55.6 & \\
\hline Total SSYU & 435 & & \\
\hline
\end{tabular}

* The total $\mathrm{N}$ and percentages add up to more than $100 \%$ because respondents could choose more than one answer. 
The figures found in the TIES survey are more in tune with Fishman's theory of language maintenance and language shift (1964;1999), predicting heritage language loss by the third generation, than those observed among older immigrant flows to Switzerland. It may be that the stigmatisation in Swiss society of those more recent immigrant groups and hence of their languages and the international status of the languages concerned (considered extra-European and of only regional interest) along with their very weak institutionalisation in school curricula, accounts for the lower effective maintenance of heritage language across generations.

\subsubsection{Language use}

Since identifications and their expression are contextually based, secondgeneration respondents negotiate their use of Swiss-German and their parents' languages according to situational requirements (Table 6.8). Thus, while they mostly speak Swiss-German in public and with friends, at home they alternate between their parents' languages when speaking with their parents and predominantly using Swiss-German with their siblings.

Almost one out of five second-generation respondents speaks mostly the local language with parents. SSYU youth use Swiss-German slightly more often with their mothers than Turkish youth. With siblings however, three out of four second-generation respondents (Turkish slightly more) prefer to use the local language.

Census 2000 data showed a quite high integration of German as the local language into the family repertoire of Swiss citizens with a non-national language background: 59 per cent for Serbo-Croatian speakers, $5^{8}$ per cent for Turkish speakers and 54 per cent for Albanian speakers (Lüdi \& Werlen 2005). The indicator in the TIES questionnaire is more stringent than in the Census, since it asks for predominance of local language in the family environment, whereas the Census asserted the mere use of local language in the family context.

More than half of the respondents reported speaking mostly SwissGerman with their partner; this is significantly lower than the use of local language with friends who rank highest in the frequency of Swiss-German use. The reason lies in the fact that about 70 per cent of Turkish and 60 per cent of SSYU respondents have a partner whose descent can be traced back to the respondents' parent's country of origin (see Chapter 8).

In both second-generation groups, young women speak Swiss-German significantly more often with their parents and siblings. Also, younger 
Table 6.8 Percentage of respondents speaking mainly Swiss-German with family and friends

\begin{tabular}{lcc}
\hline & TR & SSYU \\
\hline With mother & 17.2 & 23.7 \\
With father & 18.7 & 18.5 \\
With partner & 52.3 & 57.5 \\
With siblings & 75.3 & 68.9 \\
With friends & 86.8 & 89.5 \\
$\mathrm{~N}=$ & 449 & 431 \\
\hline
\end{tabular}

TR / SSYU:

Siblings $\quad X^{2}=10.479 \quad p=.015 \quad$ Friends $\quad X^{2}=6.939 \quad p=.031$

Mother $\quad X^{2}=6.879 \quad p=.076 \quad$ Partner $\quad X^{2}=13.880 \quad p=.003$

respondents, aged 18-24, speak more Swiss-German with their parents (significant for Turkish, but not for SSYU respondents).

In conclusion, second-generation respondents report having a good knowledge of the local language, as well as its significant use within their family. Moreover, half of them master their parents' language and successfully manage to switch language codes as needed. This illustrates that maintenance of parental language and hence bilingualism is not a threat to knowledge of local language.

\subsection{Religion}

In recent decades, religion has been a focus of immigration and integration research in Europe. Reasons for this renewed emphasis can be found in the religious background of the new immigrants as well as public awareness of the long-term settlement of immigrants changing the religious landscape in receiving countries (Cadge \& Howard Ecklund 2007). Today's migrants frequently have religious backgrounds (e.g., Muslim, Hindu) quite different from those traditional to the countries they are migrating to; moreover, they often come from countries where political and religious spheres tend to be strongly intertwined. This has created a concern - sharpened by post- $9 / 11$ events and combining Islam, immigration and national security - about the effects that new immigrant religions might have on social cohesion and political structures in countries of immigration. Nevertheless, immigrants' settlement is now widely considered a long-term phenomenon, entailing not only durable redefinition of the religious landscape of the countries of 
immigration but also the need for accommodation of those new religions (Bader 2007; Baumann \& Stolz 2007).

This subsection deals with religion (or its lack) as a possible axis of identification for people of immigrant descent. Since religious convictions are often passed down through families, we will first focus on respondents' religious upbringing and later discuss evidence on religious retention by comparing the three groups and four major religions or religious denominations (Catholic, Protestant, Muslim and Orthodox). After giving an overview of the present day religious belonging of our respondents, the subsection discusses their religiosity, that is, the level of conformity to religious prescriptions; it also deals with the importance of religion in respondents' lives along with their attitudes towards religion and its role in multicultural environments.

To conclude this subsection, we will return to the question of the combination of various identifications, so relevant throughout this chapter on identity constructions. We will discuss how successfully our respondents are in combining their religious identification with national identification with the country of residence.

\subsubsection{Religious upbringing in the family}

In order to give an overview of the religious background of TIES respondents, Table 6.9 presents percentages of youth brought up religiously for all three origin groups and various religious denominations. Since city differences are prominent in this respect, data is presented separately for each of the selected cities.

Families in all three origin groups display a significantly less religious upbringing in Basel than in Zurich. Comparison group respondents reported significantly less religious rearing than children of immigrant origin, while Turkish youth consistently reported more religious education than SSYU respondents. As for religious denominations, in Basel more Turkish origin respondents were raised in the Alevi tradition whereas Muslims are less represented among SSYU respondents than in Zurich. Among the comparison group, respondents with a Protestant background outnumber Catholics in Basel, while the opposite is the case in Zurich.

An association between the level of education of the parents and religious socialisation could be identified only in the SSYU group, where the better educated parents were less inclined to bring their children up religiously $(\mathrm{p}=.007)$. Religious socialisation in families does not vary according to gender. 
Table 6.9 Religious upbringing by origin group, religious denomination and agglomeration

\begin{tabular}{lrrrrrr}
\hline & \multicolumn{2}{c}{ TR } & \multicolumn{2}{c}{ SSYU } & \multicolumn{2}{c}{ CG } \\
\cline { 2 - 7 } & Zurich & Basel & Zurich & Basel & Zurich & Basel \\
\hline $\mathrm{N}$ (total) = & \multicolumn{1}{c}{202} & 247 & 239 & 192 & 202 & 266 \\
Religiously raised (\%) & 83.5 & 66.0 & 79.1 & 62.0 & 70.3 & 61.7 \\
$\mathrm{~N}$ (religiously raised) $=$ & 168 & 162 & 195 & 122 & 143 & 163 \\
\hline Raised as (\%): & & & & & & \\
Catholic & 1.7 & 1.2 & 32.1 & 39.5 & 47.6 & 40.9 \\
Protestant & 2.3 & 0.6 & 1.1 & 1.7 & 45.5 & 48.2 \\
Orthodox & 0.6 & 0.6 & 29.9 & 33.6 & 0.0 & 0.0 \\
Other Christian & 0.0 & 0.0 & 0.0 & 0.0 & 2.8 & 6.1 \\
Sunni & 63.4 & 59.1 & 20.3 & 8.4 & 0.0 & 0.6 \\
Shia & 2.3 & 5.5 & 0.5 & 0.8 & 0.0 & 0.0 \\
Alevi & 11.6 & 28.0 & 0.0 & 2.5 & 0.0 & 0.6 \\
Other Muslim & 16.9 & 3.7 & 15.5 & 11.8 & 0.0 & 0.0 \\
$\quad$ Jewish & 0.0 & 0.0 & 0.0 & 0.0 & 1.4 & 1.2 \\
$\quad$ Other & 1.2 & 1.2 & 0.5 & 1.7 & 2.8 & 2.4 \\
\hline
\end{tabular}

Zurich / Basel:

$\begin{array}{lll}\text { TR } & X^{2}=17.864 & p=.000 \\ \text { SSYU } & X^{2}=15,264 & p=.000 \\ \text { CG } & X^{2}=3.789 & p=.032\end{array}$

By contrast, age appears an important variable affecting religious socialisation, though the pattern differs according to origin group. In the comparison group, older respondents reported a more religious upbringing, so that religious socialisation amongst them appears just as frequent as among the younger group of Turkish and SSYU respondents (Table 6.10). The variation in parental religious transmission is limited and non-significant for Turkish origin youth but very sharp for the SSYU group, where younger respondents experienced more pronounced religious socialisation than older ones. Younger SSYU respondents may have been influenced by the ethno-religious tensions in their parents' countries of origin, which amplified the impact of religion on their lives and influenced their socialisation.

As adults, younger respondents of immigrant descent tend to uphold their religious membership more than older ones, in contrast with the comparison group, where older respondents are significantly more likely to be religious. It is worth noting that despite the younger cohort of SSYU respondents' exposure to a significantly more religious upbringing than 
Table 6.10 Religious upbringing by age and origin group

\begin{tabular}{lccc}
\hline & $<\mathbf{2 5}$ & $>=\mathbf{2 5}$ & Total \\
\hline TR (upbringing) & 74.7 & 72.9 & 74.0 \\
TR (now) & 61.0 & 51.2 & 57.4 \\
$\mathrm{~N}=$ & 248 & 201 & 449 \\
SSYU (upbringing) & 78.3 & 62.9 & 71.6 \\
SSYU (now) & 60.4 & 52.4 & 56.9 \\
$\mathrm{~N}=$ & 256 & 175 & 431 \\
CG (upbringing) & 52.3 & 74.5 & 64.2 \\
CG (now) & 23.3 & 39.3 & 32.7 \\
$\mathrm{~N}=$ & 168 & 300 & 468 \\
\hline
\end{tabular}

Above / Below 25:

$\begin{array}{lll}\text { TR (now) } & \mathrm{X}^{2}=4.106 & \mathrm{p}=.027 \\ \text { SSYU (upbringing) } & \mathrm{X}^{2}=12.268 & \mathrm{p}=.000 \\ \text { SSYU (now) } & \mathrm{X}^{2}=2.750 & \mathrm{p}=.059 \\ \text { CG (upbringing) } & \mathrm{X}^{2}=24.726 & \mathrm{p}=.000 \\ \text { CG (now) } & \mathrm{X}^{2}=13.123 & \mathrm{p}=.000\end{array}$

the older cohort, present claims of religious belonging among younger and older SSYU respondents are less polarised.

\subsubsection{Retention of religious affiliation}

Religious affiliation is not only a matter of transmission but also a matter of choice. To what extent do those who were brought up religiously retain this affiliation today? To what extent do those who did not have a religious education autonomously choose to embrace a religion?

Religious retention varies significantly between the comparison group and second generation (Table 6.11). More than half of the comparison group respondents that reported being raised religiously declare that they are non-religious today. A similar trend is also apparent with second-generation respondents, where less than 30 per cent did not remain religious. Among other factors, this could be explained by the increased importance of religion in parents' countries (religiously-based conflicts in SSYU and conflict over the secular constitution of the Turkish republic) and the secularisation process in Switzerland (Bovay \& Broquet 2004). Despite the significant differences in religious upbringing between Zurich and Basel, discussed above, there are no significant differences between the two cities in terms of religious retention.

It is worth analysing differences in religious retention for different religions and religious denominations (Table 6.12). The inter-generational 
Table 6.11 Present religious affiliation according to religious family upbringing by origin group

\begin{tabular}{llccc}
\hline & & Religious today & $\begin{array}{c}\text { Not religious } \\
\text { today }\end{array}$ & N = \\
\hline TR & Upbringing & 53.8 & 19.7 & 330 \\
& No upbringing & 3.2 & 23.3 & 119 \\
& Percent of TR sample & 57.0 & 43.0 & 449 \\
\multirow{2}{*}{ SSYU } & Upbringing & 52.3 & 21.3 & 317 \\
& No upbringing & 5.6 & 20.8 & 114 \\
& Percent of SSYU sample & 57.9 & 42.1 & 431 \\
CG & Upbringing & 29.9 & 35.4 & 306 \\
& No upbringing & 2.8 & 31.8 & 162 \\
& Percent of CG sample & 32.7 & 67.3 & 468 \\
\hline
\end{tabular}

pattern of diminishing religious affiliation observed among all religious groups is especially strong for the Christian denominations. It is also more prominent in the comparison group. Thus, the lowest level of religious retention is reported by comparison group Protestants: only about 40 per cent of people educated religiously claim to be religious now. Furthermore, if Catholic intergenerational retention is analysed according to country of origin of respondents, leading to a distinction between comparison group Catholics and SSYU Catholics, less than half of comparison group Catholics still adhere to the religion they were brought up with, whereas more than 80 per cent of SSYU Catholic respondents remain faithful to their parents' religion.

This percentage is similar to that for respondents belonging to SSYU Orthodox and Turkish Sunni denominations, while SSYU Sunni and Turkish Alevi report lower religious retention. This indicates that religion plays a more essential role in the lives of children of Turkish and SSYU descent than it does for comparison group respondents. Another interesting comparison concerns the Muslim Sunni denomination: Turkish background Sunnis remain to a large extent faithful to their parents' religion, while SSYU descent Sunnis more often experience distancing from their parents' religions as they grow up. However, the percentage of religious retention among Turkish Sunnis is strictly comparable to that of SSYU Catholics and SSYU Orthodox.

To what extent have those who were not religiously socialised developed a sense of religious affiliation independently of family transmission? In the U.S., religion has often been theorised as one possible identification source for immigrant groups whose parents' ethno-national identifications have 
Table 6.12 Religious retention among youth by national-religious origin groups

\begin{tabular}{lcc}
\hline & Religious upbringing & Still religious \\
\cline { 2 - 3 } & $\mathbf{N}=$ & (\%) \\
\hline CG Protestant & 143 & 41.0 \\
CG Catholic & 137 & 47.1 \\
SSYU Catholic & 108 & 81.3 \\
SSYU Orthodox & 96 & 80.2 \\
SSYU Muslims & 56 & 56.3 \\
TR Sunni & 201 & 79.6 \\
TR Alevi & 67 & 62.1 \\
\hline
\end{tabular}

been looked down upon in their country of residence (Zhou 1997; Stepick \& Stepick 2002; Foner \& Alba 2008).

Young people who were not religiously brought up but became religious later in their lives represent only between 3 per cent (comparison group and Turkish origin group) and 6 per cent (SSYU second generation) when the whole sample is taken into consideration. Among the second generation of Turkish and SSYU descent there is instead persistent religious affiliation rooted in a strong adherence to their parents' religions.

\subsubsection{Current religious affiliation and practice}

There is a notable difference in current religious affiliation between the comparison group and youth of immigrant descent (Table 6.13). The percentage of respondents stating that they belong to a religion is twice as high among second-generation respondents as the comparison group. As expected, most of the Turkish background Muslim respondents are Sunni, with a substantial minority declaring themselves Alevi (two out of three living in Basel) or some other Muslim denomination. Most people of SSYU descent are Catholic or Orthodox Christians, while about 21 per cent practise Islam (mostly Sunni). Within the comparison group, Catholics are just as numerous as Protestants among the religious youth today, in spite of the fact that Basel and Zurich are in two traditionally Protestant regions. Despite significant differences between the two cities in terms of second-generation respondents' religious upbringing (Table 6.9), the reported present religious affiliations are quite similar.

The TIES questionnaire explores various ways in which religious membership influences respondents' behaviours and asks how far religious 
Table 6.13 Present religious affiliation by group and agglomeration

\begin{tabular}{lcccccc}
\hline & \multicolumn{2}{c}{ TR } & \multicolumn{2}{c}{ SSYU } & \multicolumn{2}{c}{ CG } \\
\cline { 2 - 7 } & Zurich & Basel & Zurich & Basel & Zurich & Basel \\
\hline $\mathrm{N}$ (Total) = & 202 & 247 & 239 & 192 & 202 & 266 \\
Religious (\%) & 60.2 & 55.1 & 59.1 & 54.4 & 33.2 & 32.3 \\
$\mathrm{~N}$ (Religious) $=$ & 125 & 134 & 141 & 108 & 68 & 86 \\
\hline Religion /Denomination (\%) & & & & & & \\
Catholic & 0.0 & 0.0 & 36.0 & 37.1 & 37.3 & 40.7 \\
Protestant & 0.8 & 1.5 & 0.0 & 1.0 & 41.8 & 44.2 \\
Orthodox & 0.8 & 0.7 & 33.8 & 46.7 & 0.0 & 0.0 \\
Other Christian & 0.0 & 0.0 & 0.0 & 0.0 & 3.0 & 8.1 \\
Sunni & 65.3 & 65.9 & 17.3 & 3.8 & 0.0 & 0.0 \\
Shia & 1.6 & 3.7 & 0.7 & 1.9 & 0.0 & 0.0 \\
Alevi & 12.9 & 25.2 & 0.0 & 1.9 & 0.0 & 0.0 \\
Other Muslim & 16.9 & 3.0 & 11.5 & 3.8 & 0.0 & 0.0 \\
Jewish & 0.0 & 0.0 & 0.0 & 0.0 & 3.0 & 1.2 \\
Other & 1.6 & 0.0 & 0.7 & 3.8 & 14.9 & 5.8 \\
\hline
\end{tabular}

* Differences between the cities are not significant for any of the above groups.

Religious now:

TR-CG $\quad X^{2}=56.792 \quad p=.000$

SSYU-CG $\quad X^{2}=53.079 \quad p=.000$

affiliation is translated into practices shared by the religious community. To examine this question, an additive religiosity index was established by combining questions on fasting during Ramadan, eating halal food, frequency of prayer and visiting the mosque for Muslim respondents, and respecting the period of fasting, frequency of prayer, and visiting the church or synagogue for all other respondents identifying themselves as religious. Such an index is intended to test respondents' compliance with behavioural prescriptions of their respective religions. It is, however, a very rough measure of religiosity, since prescriptions such as praying, visiting places of worship and fasting carry a different importance in the different religions and groups of people under consideration. This is, for instance, a crucial difference between Sunni and Alevi respondents as well as between Catholics and Protestants.

The share of youth reporting high compliance with religious prescriptions is quite low; at most a third of respondents who define themselves as religious reported high compliance with prescriptive behaviour. Turkish and SSYU Sunni and SSYU Catholics report a similar percentage, while other groups report significantly lower religious compliance. As expected, given 
their relaxed attitude towards praying, visiting the mosque and fasting, the lowest religiosity was recorded for Turkish Alevi respondents; none of these 52 respondents would fit into the high compliance category of the religiosity index.

Table 6.14 High compliance with religious prescriptions according to origin group among those who claim to be religious

\begin{tabular}{lcc}
\hline & High Compliance (\%) & N (total) $=$ \\
\hline CG Protestant & 8.8 & 65 \\
CG Catholic & 6.0 & 62 \\
SSYU Catholic & 35.9 & 89 \\
SSYU Orthodox & 13.5 & 95 \\
SSYU Sunni & 31.0 & 33 \\
TR Sunni & 33.7 & 169 \\
TR Alevi & 0.0 & 50 \\
\hline
\end{tabular}

As with religious belonging, there is a stark contrast between Catholics in different groups and their compliance with religious rules: only 6 per cent of comparison group Catholics reported high compliance with religious rules, as against nearly 36 per cent of SSYU Catholics. In fact, SSYU Catholics report higher religiosity than any Muslim group, bringing into question the assumption that Muslims in Europe are more influenced by their religious precepts than other immigrant groups.

\subsubsection{Importance of religion in personal and public life}

The influence of a religion over its followers reaches beyond their performance of prescribed religious practices - it shapes people's innermost opinions and attitudes. This issue will be addressed by considering the role religion plays in the private life of our respondents as well as the role they believe it should play in the wider national sphere. Table 6.15 summarises responses to questions dealing with the first issue. Two items in the questionnaire are singled out: 'The fact that I am religious is something I think about often', expressing an intimate, reflexive attitude toward religion, and, 'If somebody says something against my religion I feel personally hurt', expressing personal identification with religion and hence a request for recognition and consideration of this identity trait.

Muslim respondents (with the possible exception of Turkish Alevis) generally tend to report that religion has a stronger influence over their 
personal and social lives than other religious groups. This could be explained by the persistence of a highly charged debate about the role of Islam in Western democracies and its effects on national security and processes of immigrant integration (Allievi 2005).

We should again point out the difference between the comparison group and SSYU Catholics - the latter report significantly higher importance of religion over their personal and social lives than comparison group respondents.

Table 6.15 Percentage of respondents reporting strong role of religion in their personal life and strong demand for religious recognition by ethnoreligious group

\begin{tabular}{lccc}
\hline & $\begin{array}{c}\text { Religion in } \\
\text { personal life* }\end{array}$ & $\begin{array}{c}\text { Identification with } \\
\text { religion** }\end{array}$ & N (total) $=$ \\
\hline CG Protestant & 27.7 & 29.2 & 65 \\
CG Catholic & 16.9 & 13.6 & 62 \\
SSYU Catholic & 40.9 & 39.8 & 89 \\
SSYU Orthodox & 33.7 & 29.2 & 95 \\
SSYU Sunni & 71.4 & 65.5 & 33 \\
TR Sunni & 66.5 & 62.4 & 169 \\
TR Alevi & 50.0 & 50.0 & 50 \\
\hline
\end{tabular}

* Survey statement: The fact that I am religious is something I think about often.

** Survey statement: If somebody says something against my religion I feel personally hurt.

The arrival of a large number of mostly Muslim immigrants in Europe has stimulated a heated debate about the role of religion in Western societies (Kaltenbach \& Tribalat 2002; Scheffer 2003; Modood 2003; Joppke 2009). The emblematic issue of the veiling of Muslim women in public spaces touches upon three main themes involved in these debates: the division of public and private spheres, the issue of religious accommodation, and the representation of religious viewpoints and practices in politics. In this debate, Islam's presumed 'inherent' traits, organised around its perceived anti-modern tendencies such as moral authoritarianism, oppressive gender relations and lack of clear division between the church and the state (Buijs \& Rath 2003), often function as the opposite pole to the established image of enlightened and secular European society (Allievi 2005).

TIES respondents' attitudes towards the role of religion in societies are reflected in Table 6.16, which summarises answers concerning these three themes; the overwhelming majority believe that religion should 
be a private matter, with the notable exception of the comparison group Protestants. Slightly more than one respondent in six favours representation of religion in the political arena - contrary to public perception and fear of politicised Islam, it is comparison group Catholics who most favour such representation, followed by SSYU Sunnis and comparison group Protestants.

A large percentage of respondents agree that multi-religious coexistence is a benefit for their cities and only about to per cent openly oppose it. About 13 per cent of comparison group respondents doubt the value of religious pluralism for the well-being of their cities, the largest group who feel this. While Turkish origin respondents have a significantly more positive outlook on the question, respondents of SSYU descent share the reservations of the comparison group. Their scepticism about multi-religious coexistence may be influenced by the experience of conflict on a religious basis in their parents' country.

Looking at differences between various religious denominations in terms of attitudes towards this question, Muslim groups report the most tolerant stance, while SSYU Catholics along with comparison group Protestants disagree with the statement the most. It is also worth mentioning that about 12 per cent of non-religious respondents also expressed their doubts about the value of religious pluralism.

Table 6.16 Role of religion in modern societies

\begin{tabular}{|c|c|c|c|c|}
\hline & $\begin{array}{c}\text { 1: 'Religion } \\
\text { should be a } \\
\text { private matter' }\end{array}$ & $\begin{array}{l}\text { 2: 'Religion } \\
\text { should be } \\
\text { represented in } \\
\text { politics' }\end{array}$ & $\begin{array}{l}\text { 3: 'Religious } \\
\text { pluralism is good } \\
\text { for city' }\end{array}$ & Total \\
\hline TR & 91.4 & 17.8 & 58.3 & 449 \\
\hline SSYU & 89.7 & 16.2 & 44.3 & 431 \\
\hline CG & 86.8 & 18.4 & 45.5 & 468 \\
\hline CG Protestant & 76.9 & 21.5 & 36.4 & 65 \\
\hline CG Catholic & 86.4 & 30.5 & 49.2 & 62 \\
\hline SSYU Catholic & 87.5 & 15.9 & 36.0 & 89 \\
\hline SSYU Orthodox & 86.5 & 15.6 & 46.9 & 95 \\
\hline SSYU Sunni & 86.2 & 24.1 & 62.1 & 33 \\
\hline TR Sunni & 93.0 & 20.6 & 65.9 & 169 \\
\hline TR Alevi & 90.0 & 22.0 & 70.0 & 50 \\
\hline Non religious & 91.3 & 13.3 & 46.3 & 686 \\
\hline \multicolumn{5}{|c|}{ Religious pluralism is good for city: } \\
\hline TR-SSYU $\quad X^{2}=4$ & $847 \quad \mathrm{p}=.089$ TR-SSYU & $X^{2}=17.73$ & $p=.000$ & \\
\hline TR-CG & $754 \quad \mathrm{p}=.056 \quad$ TR-CG & $X^{2}=18.14$ & $\mathrm{p}=.000$ & \\
\hline
\end{tabular}


With regard to the highly politicised topic of Muslim women wearing headscarves, only a very small percentage of second-generation respondents advocate this prescription of Islamic tradition, while about 60 per cent in each of the three groups disagree with it (Table 6.17); Turkish respondents are most in favour, while youth of SSYU descent object the most. However, given that Turkey is the only group with a more or less homogeneously Muslim population, one would expect a much larger difference between the Turkish group and the other two groups. This tendency might be explained by the very secular nature of the Turkish Republic, which, until very recently, banned headscarves from public spaces.

Table 6.17 'Muslim women should wear headscarves', by age and origin group

\begin{tabular}{llrrc}
\hline & & $<\mathbf{2 5}$ & $>\mathbf{= 2 5}$ & Total \\
\hline TR & Agree & 11.5 & 5.4 & 9.3 \\
& $\mathrm{~N}=$ & 248 & 201 & 449 \\
\multirow{2}{*}{ SSYU } & Agree & 7.1 & 0.5 & 4.2 \\
& $\mathrm{~N}=$ & 256 & 175 & 431 \\
\multirow{2}{*}{ CG } & Agree & 5.7 & 5.8 & 5.8 \\
& $\mathrm{~N}=$ & 168 & 300 & 468 \\
\hline
\end{tabular}

TR $\quad X^{2}=5.554 \quad p=.062$

SSYU $\quad X^{2}=11.275 \quad p=.004$

TR-SSYU $\quad X^{2}=8.179 \quad \mathrm{p}=.017$

The only significant gender difference was recorded for the comparison group, where women disagree with this statement significantly more than men. Paralleling their stronger religious identification, younger cohorts of Turkish and SSYU background respondents agree more strongly with the statement than older ones.

Table 6.18 'Muslim women should wear headscarves' - Muslims only

\begin{tabular}{lccccc}
\hline & Sunni & Shia & Alevi & Other & Total \\
\hline Agree & 16.1 & 40.0 & 3.8 & 6.5 & 13.4 \\
Neither agree nor & 42.2 & 20.0 & 17.3 & 37.0 & 36.5 \\
disagree & & & & & \\
Disagree & 41.7 & 40.0 & 78.8 & 56.5 & 50.2 \\
$\mathrm{~N}=$ & 202 & 10 & 52 & 50 & 314 \\
\hline
\end{tabular}


In order to account for the internal heterogeneity in the views of Muslim respondents, differences between the Sunni, Shia, and Alevi denominations on the question of headscarves were further explored (Table 6.18). Shia - who represent a limited minority in the TIES sample - are much more in favour of headscarves than Sunnis or Alevis. It should nevertheless be pointed out that more than two Sunnis in five oppose the idea that Muslim women should wear headscarves, and altogether half of all Muslims in the Swiss TIES sample disagreed with that statement, while a third is reserved on this issue. Surprisingly, the differences between the sexes are not significant for any of the religious denominations.

\subsubsection{Feeling of belonging in Switzerland according to religious identification}

To conclude this chapter, we return to the question of combining various identifications, so relevant throughout this chapter on identity constructions. We discuss how TIES respondents combine religious affiliation with identification with country of residence, often regarded as incompatible, especially for people with a Muslim background.

Comparison-group Protestants identify most with Switzerland; second to them are SSYU Muslims, whose feelings are similar to comparison-group Catholics. There is nevertheless a general tendency for second-generation religious people to have more moderate feelings towards Switzerland than religious people from the comparison group (Table 6.19). This result points to the complicated entanglement of ethnic and religious attachment and its effects on developing a feeling of belonging to Switzerland.

Comparing religious respondents with non-religious respondents, we note that comparison group non-religious people tended to report weaker feelings of belonging to Switzerland. Among second-generation respondents (with the possible exception of SSYU Sunni), however, it was religious respondents who reported lower levels of attachment to their country of residence. None of these differences are statistically significant.

\subsubsection{Weak feeling of belonging to Switzerland}

If we focus on respondents that reported weak feelings towards Switzerland, we also note some interesting patterns. Three quarters of SSYU descent respondents who reported weak feelings of belonging live in Zurich. While this difference is not significant for Turkish descent respondents, 
Table 6.19 Feeling of belonging in Switzerland, by religious group

\begin{tabular}{|c|c|c|c|c|c|c|}
\hline & & $\begin{array}{l}\text { Strong } \\
\text { feelings }\end{array}$ & $\begin{array}{l}\text { Neither } \\
\text { strong nor } \\
\text { weak }\end{array}$ & $\begin{array}{c}\text { Weak } \\
\text { feelings }\end{array}$ & $\begin{array}{c}\text { Not } \\
\text { applicable }\end{array}$ & $\mathbf{N}=$ \\
\hline \multicolumn{2}{|l|}{ CG Protestant } & 72.3 & 27.7 & 0.0 & 0.0 & 65 \\
\hline \multicolumn{2}{|l|}{ CG Catholic } & 61.7 & 33.3 & 5.0 & 0.0 & 62 \\
\hline \multicolumn{2}{|c|}{ CG Non-religious } & 60.4 & 35.8 & 3.5 & 0.3 & 314 \\
\hline \multicolumn{2}{|l|}{ SSYU Catholic } & 51.7 & 34.8 & 11.2 & 2.2 & 89 \\
\hline \multicolumn{2}{|l|}{ SSYU Orthodox } & 50.0 & 38.5 & 5.2 & 6.3 & 95 \\
\hline \multicolumn{2}{|l|}{ SSYU Muslims } & 60.6 & 31.2 & 6.6 & 1.6 & 56 \\
\hline \multicolumn{2}{|c|}{ SSYU Non-religious } & 57.3 & 30.8 & 7.6 & 4.3 & 182 \\
\hline \multicolumn{2}{|l|}{ TR: Sunni } & 42.9 & 39.9 & 13.7 & 3.6 & 169 \\
\hline \multicolumn{2}{|l|}{ TR: Alevi } & 34.0 & 44.0 & 16.0 & 6.0 & 50 \\
\hline \multicolumn{2}{|c|}{ TR Non-religious } & 52.1 & 32.8 & 13.5 & 1.6 & 190 \\
\hline \multicolumn{4}{|l|}{ Non-religious: } & \multicolumn{2}{|l|}{ Catholic: } & \\
\hline TR-CG & $X^{2}=20.709$ & $p=.000$ & SSYU-CG & $X^{2}=3.610$ & $p=.307$ & \\
\hline SSYU-CG & $X^{2}=15.002$ & $\mathrm{p}=.002$ & Sunni Muslim: & & & \\
\hline TR-SSYU & $X^{2}=6.220$ & $\mathrm{p}=.101$ & TR-SSYU & $X^{2}=3.853$ & $3 \quad p=.278$ & \\
\hline
\end{tabular}

the comparison group shows a reverse trend, with a disproportionate percentage of people who live in Basel reporting weak attachment to Switzerland. As reported in Table 6.4, in terms of gender we see that with all three groups, men report weak feelings towards Switzerland significantly more often than women. This trend is especially significant among second-generation male respondents. In terms of age we again confirm the idea that second-generation respondents' weak feelings of belonging tend to dissipate as they grow older. However, in the comparison group this trend is reversed and we find that most people with weak feelings towards Switzerland in the group of respondents are older than 25 years. We also note the effect of naturalisation. While in the whole sample of second-generation respondents almost three quarters have Swiss citizenship, among those who report weak feelings towards Switzerland we see only half have naturalised - this is a significant difference that clearly points towards a positive relationship between naturalisation and feelings of belonging.

In terms of education, we note interesting differences between respondents from different origin groups. Thus, among Turkish descent respondents, those reporting weak feelings towards Switzerland tend to be less educated than the rest of their group. Neither SSYU descent respondents nor comparison group respondents show significant educational differences between those with weak feelings towards Switzerland and others. 
Table 6.20 Respondents who reported weak feelings towards Switzerland by origin group and city / gender / naturalisation / age:

\begin{tabular}{|c|c|c|c|c|c|c|c|c|c|c|}
\hline & & \multicolumn{2}{|c|}{ City } & \multicolumn{2}{|c|}{ Gender } & \multicolumn{2}{|c|}{ Naturalised } & \multicolumn{2}{|c|}{ Age } & \multirow[t]{2}{*}{$\mathbf{N}=$} \\
\hline & & Zurich & Basel & Men & Women & Yes & No & $<25$ & $25+$ & \\
\hline \multirow[t]{2}{*}{ TR } & Weak feelings & 46.0 & 54.0 & 59.7 & 40.3 & 49.2 & 50.8 & 68.3 & 31.7 & 63 \\
\hline & $\begin{array}{l}\% \text { of whole TR } \\
\text { group }\end{array}$ & 45.0 & 55.0 & 51.0 & 49.0 & 72.2 & 27.8 & 63.3 & 36.5 & 449 \\
\hline \multirow[t]{2}{*}{ SSYU } & Weak feelings & 75.8 & 24.2 & 69.7 & 30.3 & 51.5 & 48.5 & 65.6 & 34.4 & 34 \\
\hline & $\begin{array}{l}\% \text { of whole } \\
\text { SSYU group }\end{array}$ & 55.6 & 44.4 & 49.8 & 50.2 & 75.0 & 25.0 & 56.4 & 43.6 & 431 \\
\hline \multirow[t]{2}{*}{ CG } & Weak feelings & 28.6 & 71.4 & 71.4 & 28.6 & n.a & n.a & 35.7 & 64.3 & 14 \\
\hline & $\begin{array}{l}\% \text { of whole } \\
\text { CG group }\end{array}$ & 43.2 & 56.8 & 51.3 & 48.7 & n.a & n.a & 41.2 & 58.8 & 468 \\
\hline
\end{tabular}

\begin{tabular}{llllrl} 
Gender: & & \multicolumn{5}{c}{$\begin{array}{r}\text { Naturalisation: } \\
\text { TR }\end{array}$} & $X^{2}=2.166$ & $p=.091$ & TR & $X^{2}=19.220$ & $p=.000$ \\
SSYU & $X^{2}=5.676$ & $p=.013$ & SSYU & $X^{2}=10.510$ & $p=.002$ \\
City: SSYU & $X^{2}=5.906$ & $p=.011$ & & &
\end{tabular}

Table 6.21 Respondents who reported weak feelings towards Switzerland by origin group and education level

\begin{tabular}{llcccccr}
\hline & & $\begin{array}{c}\text { ISCED 2 } \\
\text { completed }\end{array}$ & $\begin{array}{rlcccc}\text { ISCED 3-4 } \\
\text { ongoing }\end{array}$ & $\begin{array}{c}\text { ISCED 3 } \\
\text { Completed }\end{array}$ & $\begin{array}{c}\text { ISCED 5 } \\
\text { ongoing }\end{array}$ & $\begin{array}{c}\text { ISCED 5 } \\
\text { completed }\end{array}$ & N = \\
\hline TR & $\begin{array}{l}\text { Weak feelings } \\
\text { \% of whole TR }\end{array}$ & 24.2 & 32.3 & 37.1 & 4.8 & 1.6 & 61 \\
& 10.1 & 33.9 & 41.8 & 6.9 & 7.2 & 343 \\
& $\begin{array}{l}\text { group } \\
\text { SSYU }\end{array}$ & & & & & & \\
& $\begin{array}{l}\text { Weak feelings } \\
\text { \% of whole }\end{array}$ & 3.1 & 31.3 & 50.0 & 9.4 & 6.3 & 32 \\
& $\begin{array}{l}\text { SSYU group } \\
\text { GC }\end{array}$ & & 25.0 & 54.5 & 7.3 & 6.8 & 385 \\
& $\begin{array}{l}\text { Weak feelings } \\
\text { \% of whole }\end{array}$ & 0.0 & 7.7 & 53.8 & 7.7 & 30.8 & 13 \\
& CG group & 2.3 & 23.7 & 36.6 & 16.2 & 22.2 & 431 \\
\hline
\end{tabular}

*Not including respondents who are still completing ISCED 2 level of education.

TR $\quad X^{2}=18.107 \quad p=.001$

Overall, the three SSYU religious groups and, to a lesser extent, Turkish Sunni and Alevi, manage to combine affiliation with a religion not considered native to Switzerland and identification with the country. Thus we can conclude that religious identity and national belonging are not seen as conflicting identifications by the large majority of religious people in our survey. 


\subsection{Conclusions}

The three fields we selected for this report (ethno-national identifications, language and religion) can all be interpreted as different ways in which children of immigrants position themselves in relation to both their parents' cultures and ways of life and those of their place of birth. The TIES survey data strongly support the hypothesis that most construct their own identity narratives by combining various (sometimes even discursively conflicting) sources of identification. Among second-generation respondents, simultaneous bilateral identifications with Switzerland and parents' countries of origin are frequent and not seen as mutually exclusive. Second-generation youth in this TIES survey often hold Swiss citizenship, while at the same time maintaining the citizenship of their parents' countries. In a similar vein, data show the linguistic integration of the second generation of Turkish and SSYU descent while keeping some parental languages proficiency. These examples demonstrate how second-generation respondents manage to balance various sources of identification out of the repertoire available to them as a result of their parents' migration histories.

In terms of religious belonging, respondents of SSYU and Turkish descent retained religious affiliation much more than comparison group respondents; this accounts for the difference in current religious belonging between the second generation and comparison groups. Nevertheless, the data show no evidence of a 'religious revival' among the second generation. It is important to note that a very large majority of respondents agree that multi-religious coexistence is a benefit for their cities.

Both SSYU and Turkish descent youth manage to combine identifications with Switzerland and with religions neither accommodated for in Switzerland nor considered native. This illustrates the multiplicity and simultaneous coexistence of various identifications that second generation youth are able to access in the process of their individuation. Thus the data on secondgeneration identification support general propositions of identity theory, emphasising the various frames of reference negotiated daily by children of immigrants, on which they rely to build a sense of belonging and identity.

Religious identification might act as a point of distinction by subsuming immigrants' children's experience of otherness in the society in which they live without necessarily questioning their allegiance to this society. Given that religion does not seem to be used for making demands (see positions on the role of religion in society), its function in the lives of the second generation might be connected to retention of difference by means that the host society is supposed to tolerate, given its professed policy of religious pluralism. 
The most telling argument in favour of the construction 'from below' of identities among children of immigrants is the fact that the strongest feelings of belonging were reserved for city and neighbourhood - the places of lived experience in relation to which respondents have developed real feelings of belonging through a process of dwelling in and accommodating to the immediate physical and social surroundings. Thanks to this local attachment, these feelings are significantly associated with identifications with the nation state. Naturalisation behaviour and the comparatively low retention rate of parental languages, along with the clearly stated attachment to the local environment and firm decision to remain there, point to a preference to building lives in Switzerland.

\section{References}

Achermann, Christin \& Stefanie Gass (2003), Staatsbürgerschaft und soziale Schliessung. Eine rechtsethnologische Sicht auf die Einbürgerungspraxis der Stadt Basel. Zürich: Seismo.

Allievi, Stefano (2005), 'How the immigrant has become Muslim: Public debates on Islam in Europe', Revue européenne des migrations internationales 21(2): 135-163.

Anderson, Benedict (1983), Imagined communities: Reflections on the origin and spread of nationalism. London: Verso.

Bader, Veit (2007), Secularism or democracy? Associational governance of religious diversity. Amsterdam: Amsterdam University Press.

Basch, Linda, Nina Glick Schiller \& Cristina Szanton Blanc (eds) (1994), Nations unbound: Transnational projects, postcolonial predicaments, and deterritorialized nation-states. New York: Gordon and Breach Publishers.

Baumann, Gerd (1996), Contesting culture: Discourses of identity in multi-ethnic London. Cambridge: Cambridge University Press.

Baumann, Martin \& Jörg Stolz (2007), Eine Schweiz - viele Religionen: Risiken und Chancen des Zusammenlebens. Bielefeld: Transcript Verlag.

Bhabha, Homi K. (1994), The location of culture. New York: Routledge.

Bolzman, Claudio, Rosita Fibbi \& Marie Vial (2003), 'Secondas - Secondos': Le processus d'intégration des jeunes issus de la migration espagnole et italienne en Suisse. Zurich: Seismo.

Bovay, Claude \& Raphaël Broquet (2004), Le paysage religieux en Suisse. Neuchâtel: Office fédéral de la statistique.

Brubaker, Roger \& Frederick Cooper (2000), 'Beyond “identity", Theory and Society 29(1): 1-47.

Buijs, Frank J. \& Jan Rath (2003), 'Muslims in Europe: The state of research', 1-48, IMISCOE Working Papers <http:/www.imiscoe.org/workingpaper/documents/muslims_in_europe>. Accessed 1 October 2008.

Cadge, Wendy \& Elaine Howard Ecklund (2007), 'Immigration and religion', Annual Review of Sociology 33: 359-379.

Çağlar, Ayse (1997), 'Hyphenated identities and the limits of culture', in Tariq Modood \& Pnina J. Werbner (eds), Debating cultural hybridity, multi-cultural identities and the politics of anti-racism, 169-185. London: Zed Books. 
Camilleri, Carmel, Joseph Kasterszteien, Edmond M. Lipiansky, Hanna Malewska-Peyre, Isabel Taboada-Leonetti \& Ana Vasquez (1997), Stratégies Identitaires. Paris: Presses Universitaires de France.

Child, Irving L. (1943), Italian or American: The second generation in conflict. Oxford: Oxford University Press.

Clifford, James (1994), 'Diasporas', Cultural Anthropology, 9(3): 302-338.

Fibbi, Rosita, Mathias Lerch \& Philippe Wanner (2005), 'Processus de naturalisation et caractéristiques socio-économiques des jeunes issus de la migration', in Werner Haug \& Marie Cécile Monin (eds), L'intégration des populations issues de l'immigration en Suisse: Personnes naturalisés et deuxième génération. Neuchâtel: Office fédéral de statistique.

Fibbi, Rosita, Mathias Lerch \& Philippe Wanner (2007), 'Naturalisation and socio-economic characteristics of youth of immigrant descent in Switzerland', Journal ofEthnic and Migration Studies 33(7): 1121-1144.

Fibbi, Rosita \& Chantal Wyssmüller (2009), 'Langue héritée et identité des petits-enfants de migrants', SAGW Bulletin.

Fishman, Joshua Aaron (1964), 'Language maintenance and language shift as a field of inquiry. A definition of the field and suggestions for its further development', Linguistics 9: 32-70.

Fishman, Joshua Aaron (1999), Handbook of language and ethnic identity. Oxford: Oxford University Press.

Foner, Nancy \& Richard Alba (2008), 'Immigrant religion in the U.S. and Western Europe: Bridge or barrier to inclusion?', International Migration Review, 42(2): 360-392.

Foucault, Michel (1965), Madness and civilization. New York: Pantheon.

Foucault, Michel (1988), 'Technologies of the self', in L. H. Martin, H. Gutman \& P. H. Hutton (eds), Technologies of the self. 16-49, Amherst: University of Massachusetts Press.

Gilroy, Paul (1993), The blackAtlantic: Modernity and double consciousness. Cambridge: Harvard University Press.

Gordon, Milton M. (1964), Assimilation in American life. New York: Oxford University Press.

Gramsci, Antonio (1971), Selections from the prison notebooks. London: Lawrence \& Wishart.

Gupta, Akhil \& James Ferguson (1992), 'Beyond "culture”: Space, identity, and the politics of difference', Cultural Anthropology 7(1): 6-23.

Hannerz, Ulf (1996), Transnational connections: Culture, people, places. New York: Routledge.

Hobsbawm, Eric J. \& Terrence O. Ranger (1983), The invention of tradition. London: Cambridge University Press.

Joppke, Christian (2009), Veil: Mirror of identity. Cambridge, Polity Press.

Jung, Carl Gustav (1939), The integration of the personality. New York: Farrar \& Rinehar.

Kaltenbach, Jeanne-Helene and Michele Tribalat (2002), La république el l'Islam, entre crainte et aveuglement. Paris: Gallimard.

Lüdi, Georges \& Iwar Werlen (2005), Le paysage linguistique en Suisse. Neuchâtel: Office fédéral de la statistique.

Mahler, Sarah J. \& Patricia R. Pessar (2006), ‘Gender matters: Ethnographers bring gender from the periphery toward the core of migration studies', International Migration Review 40(1): $27-63$.

Modood, Tariq (2003), 'Muslims and the politics of difference', Political Quarterly 74: 100-115.

Pieterse, Jan Nederveen (2007), Ethnicities and global multiculture: Pants for an octopus. Boulder: Rowman \& Littlefield.

Portes, Alejandro \& Min Zhou (1993), 'The new second generation: Segmented assimilation and its variants', The Annals of the American Academy of Political and Social Science 530: 74-96. 
Scheffer, Paul (2003), 'The land of arrival', in René Cuperus, Karl Dufek \& Johannes Kandel (eds), The Challenge of Diversity: European Social Democracy. Facing Migration, Integration, and Multiculturalism, 23-3o. Munich: Studien Verlag.

Sciolla, Loredana (2000), 'Riconoscimento e teoria dell'identità', in D. Della Porta, M. Greco and A. Szakolczai (eds), Identità, riconoscimento, scambio. Saggi in onore di Alessandro Pizzorno, 5-29. Rome: Latzera.

Stepick, Alex \& Carol Dutton Stepick (2002), 'Becoming American, constructing ethnicity: Immigrant youth and civic engagement', Applied Developmental Science 6(4): 246-257.

Tajfel, Henri (1974), 'Social identity and intergroup behaviour', Social Science Information 14: 101-118.

Turner, John C. (1987), Rediscovering the social group: A self-categorization theory. Oxford: Basil Blackwell.

Vertovec, Steven (1999), 'Conceiving and researching transnationalism', Ethnic and Racial Studies $22(2): 445-462$.

Weber, Max (1962), Basic concepts in sociology. New York: Citadel Press.

Zhou, Min (1997), 'Segmented assimilation: Issues, controversies, and recent research on the new second generation', International Migration Review 31(4): 975-1008. 



\section{$7 \quad$ Social relations}

Children of immigrants develop a wide range of social relations with other individuals and social institutions in the cities and neighbourhoods where they grow up. This chapter gives an overview of some of the social relations that descendants of Turkish and SSYU immigrants and respondents from the comparison group were brought up into and maintain up to the present day. Since we are primarily interested in the ethnic ${ }^{1}$ makeup of various social relations among the TIES survey respondents, it is best to distinguish between primary group relations, developed within small groups whose members share close, personal and enduring bonds, and secondary group social relations, which are less personal and do not involve sustained intensive contact among individuals.

In his seminal multidimensional analysis of assimilation, Gordon (1964) also makes use of this distinction by placing a strong emphasis on what he calls structural assimilation; ${ }^{2}$ that is, large scale entrance into cliques, clubs, and institutions of host society, on primary group level' (Gordon 1964: 169, emphasis added). Gordon's structural assimilation is thus a form of primary social relations with established groups and institutions of the receiving society which contributes to the development of other primary social ties between immigrants and natives; over time, this leads to intermarriage and near total assimilation of descendants into the receiving society. If structural assimilation does not occur due to prejudice, discrimination or other barriers to inclusion, acculturation alone will not suffice for assimilation to take place, as indicated by Gordon's discussion of African Americans. In such conditions (which Gordon calls structural pluralism, as opposed to cultural pluralism), different ethnic groups are inserted into - or, after the initial experience of exclusion, themselves develop - parallel economic, social, and sometimes even legal and educational institutions that enable their survival in society. This process diminishes contact across ethnic and often class lines, preventing formation of multi-ethnic primary social relations which are important for the progressive cultural negotiations necessary in a multi-cultural society.

1 In the TIES study, as in Tribalat (1995), ethnic origin is defined by parents' place of birth.

2 It may be useful to underscore that this chapter refers to the notion of structural assimilation in Gordon's terms; elsewhere in the report the term structural refers to the socio-economic integration of immigrants and specifically the second generation. 
Gordon brought acculturation and structural assimilation into creative tension within a single framework and thus opened up a way to theorise the impact of social structures on the processes of assimilation. As he wrote, 'There is a distinct tendency to confine consideration of cultural pluralism to the issue of cultural differences in behaviour and to slight or ignore pertinent issues of social structure and their relationship to communal group life' (Gordon 1964: 16). His theories were elaborated by many social scientists, notably by Portes and Zhou (1993), who took the idea of structural pluralism as a starting point for their segmented assimilation theory. It proposed that immigrants coming into the US are inserted into a segmented labour market where - depending on their human capital, modes of reception by the host country and economic conditions - some risk downward assimilation and a life of low paying and low status jobs, while others might assimilate into a dominant middle class or reach social mobility within established ethnic networks. This theory stimulated debate in both the US and Europe and is currently being re-tested by children of migrants to Europe, whose experiences of growing up differ from their US peers (Mollenkopf 2000; Crul 2000; Crul 2003; Kasinitz et al. 2004; Hochschild \& Mollenkopf 2008).

In order to examine what kind of immediate, personal social relations our respondents are engaged in, this chapter begins with an overview of their primary group relationships, focusing on respondents' family relations, friendships and dating patterns. We will examine different types of social relations within respondents' families (parents, siblings, relatives) in order to discuss possible links with respondents' structural integration. More importantly, by analysing friendship and relationship patterns, we will search for evidence of inter-ethnic mixing between the established population and second-generation respondents, as well as between different ethnic groups in the immigrant population.

Neighbourhood and social institutions such as schools constitute a grey area between primary and secondary group social relations. Strictly speaking, neither schools nor neighbourhoods are spaces intended for close, unmediated personal relations; nevertheless many primary group relations (e.g., friendships, intimate relationships) are formed as a result of interactions established within these spaces. They therefore play a very important role in immigrant integration and their ethnic composition. The second section of this chapter deals with social relations established in schools, neighbourhoods, through associations and through political participation. It also considers the role of these institutions in stimulating or preventing inter-ethnic contact and structural integration. 
In order to improve our understanding of processes of structural assimilation of children of immigrants into the receiving society, we also have to address issues of prejudice and discrimination. Although somewhat overshadowed in subsequent studies on integration, Gordon (1964) included lack of prejudice and discrimination in the seven dimensions of his theory of assimilation; Portes (1989) and Reitz (1998) discuss the 'warmth of the welcome' as a key feature of incorporation dynamics. In the last two decades this perspective has acquired more and more importance in European studies as well (Bataille 1997; Simon 2000; Simon 2008).

While low levels of human capital among immigrants and their children create obstacles to structural assimilation, it is their exclusion from social networks and the institutions of the receiving society that lies at the heart of the current integration problem in European societies. Therefore, we will discuss experiences of discrimination and hostility based on ethnic, racial or religious grounds. Children of immigrants experience some prejudice and discrimination, while at the same time displaying a degree of prejudice towards other groups which make up the host society, crucially affecting patterns of both secondary and primary social relations.

The last section of this chapter is devoted to transnational social relations established by immigrants and their children, linking their country of residence with that of their parents' birth. While it is widely accepted that immigrants themselves often may live transnational lives, the same does not necessarily apply to their children. We will therefore examine frequency of visits to parents' countries of birth, the number of remittances sent, use of ethnic TV programming and the possibility of return migration in order to evaluate how connected children of immigrants are to their 'countries of origin'.

\subsection{Primary group relations}

The presentation of TIES respondents' primary group relations examines their basic structure and the extent of ethnic mixing. In their most intimate relations, people generally wish to associate with people of similar ethnicity, class, age, occupation, religion and other social categories (McPherson et al. 2001). We would, however, expect this to decrease in more impersonal secondary group relations. Despite our focus on the ethnic composition of our respondents' social relations, these are highly affected by educational and economic status. Therefore we will control for these two factors where necessary in the following analysis. 


\subsubsection{Family}

The first social contacts a person establishes are with immediate and extended family. Since more detailed analysis of parents' demography and socio-economic position can be found in Chapter 3 , we will focus here only on respondents' family structure, relations and the type of extended family contacts they maintain.

Respondents' family composition is a fundamental issue, as intact families provide more resources - economic and emotional - to their children than single-parent families (Pyke 2004). This insight from general sociological theory has prompted some American integration scholars (Portes 2000) to emphasise the significantly higher percentage of two-parent families among people with immigrant backgrounds as a possible asset that secondgeneration children can use to attain a better educational and occupational position. Second-generation children of both Turkish and SSYU background grew up in intact families significantly more often (87 and 83 per cent, respectively) than comparison group respondents ( 72 per cent).

Another important variable in predicting the development of the second generation's social relations and integration patterns is the amount of intergenerational conflict within the nuclear family. Some authors (Zhou \& Bankston 1994; Stepick \& Stepick 2003) claim that, as a result of their advanced acculturation to the country of birth, some children of immigrants are likely to experience more conflict with their parents over values, allegiances and expectations than comparison group families. This conflict can lead to a rejection of parents' cultures and identities, which further limits the transmission of social and economic capital within the family. However, when discussing reasons to leave the parental home (see Chapter 2, Table 2.9), the degree of intergenerational tension was similar across groups and affected male respondents more often than female ones. Similar evidence against the theory of the predominance of conflict-torn immigrant families is to be found in several studies (Bolzman et al. 2003; Boos-Nünning \& Karakasoglu 2004; Fibbi \& Lerch 2007).

Table 7.1 shows that levels of conflict are quite low for all three groups, with the possible exception of issues like relationships and going out, where conflict seems to be more prevalent among second-generation respondents. In terms of gender, the issue of relationships is the only topic where young women in all three groups reported significantly more conflict with their parents than young men. While this also applies to the issue of domestic work among the second-generation respondents, the difference between men and women is not significant for the comparison group. Domestic work 
is also the only area where there are systematic differences in the level of conflict with the father and mother; in all three groups the level of conflict is much lower with the father.

Table 7.1 Reasons for conflict with parents

\begin{tabular}{lcccccc}
\hline & \multicolumn{2}{c}{ TR } & \multicolumn{2}{c}{ SSYU } & \multicolumn{2}{c}{ CG } \\
\cline { 2 - 7 } & Father & Mother & Father & Mother & Father & Mother \\
\hline School & 6.5 & 6.4 & 9.9 & 7.0 & 7.0 & 7.2 \\
Friends & 7.6 & 6.4 & 5.4 & 6.2 & 4.5 & 5.0 \\
Relationships & 8.5 & 8.1 & 5.7 & 6.4 & 3.8 & 3.6 \\
Leisure & 6.5 & 7.3 & 8.4 & 5.9 & 5.8 & 4.8 \\
Going out & 11.0 & 12.0 & 13.8 & 11.8 & 8.3 & 9.8 \\
Domestic work & 4.6 & 12.6 & 5.7 & 10.1 & 5.3 & 14.1 \\
Money & 5.4 & 6.4 & 8.1 & 5.9 & 5.8 & 5.0 \\
Religion & 2.0 & 2.2 & 1.8 & 1.7 & 1.3 & 1.2 \\
Politics & 0.8 & 0.6 & 4.5 & 0.6 & 2.5 & 1.0 \\
$\mathrm{~N}=$ & 349 & 353 & 334 & 356 & 399 & 418 \\
\hline
\end{tabular}

TR-CG (mother) $\quad \mathrm{X}^{2}=28.580 \quad \mathrm{p}=.039$

The number of siblings is another crucial dimension of family structure. It is controversial whether siblings represent an asset or a liability. Some theorists argue that having more siblings creates a situation of increased competition for the already limited social and economic capital that parents have to offer (Blake 1989), while others (Stepick \& Stepick 2003; Crul \& de Valk 2008) emphasise the importance of older siblings for the education and well-being of younger brothers or sisters. They argue that by being more acculturated to the country of residence, older siblings may take upon themselves a supportive role for their younger siblings, supplementing immigrant parents' insufficient knowledge of the local educational system and way of life. Our data do not show any significant difference in educational outcomes between second-generation respondents with older siblings and those with younger siblings, thus we cannot confirm any of these hypotheses. Nevertheless, when examining the role of older siblings in helping with school work, we note that both second-generation groups reported significantly more involvement from their siblings than the comparison group. Thus, while between 45 (SSYU) and 55 (Turkish) per cent of second-generation respondents with older siblings reported that they gave important help with school work, only 25 per cent of comparison group respondents with older siblings claimed the same. 
Respondents of Turkish descent have the largest families (average number of siblings 2.1), followed by SSYU-descent children (1.8) and comparison group respondents (1.5) (Table 7.2). More educated parents have fewer children in all three groups, but it is only with the comparison group that this is significant. This might be a result of the fact that only comparison group parents exhibit a complete distribution over education levels, while parents of second-generation (especially Turkish) respondents can mostly be found in lower education levels.

Table 7.2 Number of siblings

\begin{tabular}{|c|c|c|c|}
\hline & TR & SSYU & CG \\
\hline None & 2.4 & 6.3 & 10.9 \\
\hline One to three & 86.3 & 85.5 & 84.4 \\
\hline More than three & 11.2 & 8,2 & 4.7 \\
\hline $\mathrm{N}=$ & 449 & 431 & 468 \\
\hline TR-SSYU $\quad X^{2}=9.858$ & $\mathrm{p}=.007$ & & \\
\hline TR-CG $\quad X^{2}=37.134$ & $p=.000$ & & \\
\hline SSYU-CG $\quad X^{2}=9.676$ & $p=.008$ & & \\
\hline
\end{tabular}

The family environment of TIES respondents also includes a considerable number of members of the wider family circle residing in Switzerland: four out of five respondents reported having a relative living in the same city while almost two out of three second-generation respondents have relatives living in other Swiss cities. It is worth noting that this is a similar figure to that reported by the comparison group. SSYU respondents in particular reported that they were in contact with these relatives significantly more frequently than comparison group respondents; while a quarter of secondgeneration respondents reported seeing their relatives often, only about 15 per cent of comparison group respondents reported the same frequency of contact.

We have seen so far that second-generation respondents are more likely than the comparison group to have grown up in intact families, have more siblings, and have closer ties to relatives living in their cities and in the country. We have noted some significant but not stark differences in the level of intergenerational conflict between the two groups. Children of Turkish and SSYU origin migrants do not show marked signs of dissonant acculturation (Portes \& Rumbaut 2001) - in fact, they seem to exhibit relatively stable intergenerational relations and wide-reaching family networks. 


\subsubsection{Friendships and dating}

One of the most common indicators of inter-ethnic mixing among the different groups composing society is the number and intensity of social relations across ethnic lines. To examine this issue, we focus our attention on the composition of close friendship circles for the groups under consideration. In order to avoid a static view of the issue, we present current and secondary school age friendships in same tables; we thus highlight possible changes in the number and frequency of inter-ethnic contacts between the two periods. The hypothesis is that the selection of close friends changes as school selection moves forward, influencing respondents' immediate social environment.

Between a third and half of the children of immigrants have many Swiss among their close friends, somewhat more in Basel than in Zurich. The number of majority-minority friendships does not change significantly between secondary school and the present time (Table 7.3). Nevertheless, when looking at the differences between age cohorts, we note that in both cities younger comparison group respondents reported having significantly more friends of Turkish or SSYU origin than older ones. In terms of gender, we found no significant differences. However, women of SSYU origin tend to have more Swiss friends than men, both in secondary school and at present.

Table 7.3 Past and present Swiss friends among Turkish and SSYU origin respondents

\begin{tabular}{llcccc}
\hline & & \multicolumn{2}{c}{ TR } & \multicolumn{2}{c}{ SSYU } \\
\cline { 2 - 6 } & & $\begin{array}{c}\text { In secondary } \\
\text { school }\end{array}$ & Present time & $\begin{array}{c}\text { In secondary } \\
\text { school }\end{array}$ & Present time \\
\hline Zurich & Few & 28.2 & 20.8 & 23.0 & 19.1 \\
& Some & 35.4 & 36.2 & 37.0 & 43.3 \\
& Many & 36.4 & 43.0 & 40.0 & 37.4 \\
& N $=$ & 206 & 206 & 235 & 235 \\
Basel & Few & 20.6 & 15.4 & 22.4 & 17.7 \\
& Some & 32.3 & 36.0 & 31.8 & 30.7 \\
& Many & 47.2 & 48.6 & 45.8 & 51.6 \\
& N $=$ & 248 & 248 & 191 & 191 \\
\hline
\end{tabular}

Another way of approaching the question of ethnic mixing is to investigate to what extent respondents' best friends' ethnic background changed between their teen years and the present (Table 7.4). In all three groups 
respondents mentioned having a best friend from another ethnic group much more often in secondary school than at present. While the percentage of people reporting having a best friend of a different ethnic group decreases during the same period, the percentage of people reporting having a best friend of the same ethnicity increases between secondary school and the present. ${ }^{3}$ This is a consistent trend among both second-generation groups in both cities and with the comparison group in Zurich. While Turkish respondents more often report having best friends of the same ethnic group in Basel, SSYU and comparison group respondents seem to have more coethnics as best friends in Zurich. As far as gender differences are concerned, SSYU women report having significantly more Swiss best friends and significantly fewer SSYU best friends. The difference is not at all significant for the Turkish group.

Table 7.4 Ethnic background of the best friend in lower secondary and now, by origin group and agglomeration

\begin{tabular}{lcccccc}
\hline & \multicolumn{2}{c}{ TR } & \multicolumn{2}{c}{ SSYU } & \multicolumn{2}{c}{ CG } \\
\cline { 2 - 7 } & $\begin{array}{l}\text { In second- } \\
\text { ary school }\end{array}$ & $\begin{array}{c}\text { Present } \\
\text { time }\end{array}$ & $\begin{array}{c}\text { In second- } \\
\text { ary school }\end{array}$ & $\begin{array}{c}\text { Present } \\
\text { time }\end{array}$ & $\begin{array}{c}\text { In second- } \\
\text { ary school }\end{array}$ & $\begin{array}{c}\text { Present } \\
\text { time }\end{array}$ \\
\hline ZURICH & & & & & & \\
Swiss & 35.7 & 32.5 & 33.6 & 33.6 & 81.1 & 91.6 \\
Turkish & 20.3 & 39.3 & 3.8 & 2.1 & 1.0 & 0.5 \\
SSYU & 15.5 & 10.7 & 34.5 & 49.4 & 3.0 & 2.5 \\
Other & 28.5 & 17.5 & 28.1 & 14.9 & 14.9 & 5.4 \\
N $=$ & 206 & 206 & 235 & 235 & 202 & 202 \\
BASEL & & & & & & \\
Swiss & 37.1 & 28.3 & 52.4 & 48.4 & 80.1 & 80.1 \\
Turkish & 37.9 & 53.4 & 6.3 & 3.6 & 1.0 & 2.6 \\
SSYU & 10.1 & 4.9 & 22.0 & 35.9 & 3.0 & 2.2 \\
Other & 14.9 & 13.4 & 19.4 & 12.0 & 14.9 & 15.0 \\
N = & 248 & 248 & 191 & 191 & 266 & 266 \\
\hline
\end{tabular}

Secondary / Present

TR $X^{2}=290.454 \quad p=.000 ; \quad$ SSY $X^{2}=193.626 p=.000 ; \quad$ CG X $X^{2}=284.124 \quad p=.000$

Let us now consider the ethnic background of boyfriends and girlfriends of the TIES survey respondents in order to see to what extent dating or intimate relationships of descendants of Turkish and SSYU immigrants

3 Given that this pattern persists with respondents' three closest friends, we decided to omit tables for second and third best friend for the sake of expediency. 
and the comparison group are ethnically mixed at a stage in life when such relations do not yet entail common cohabitation.

In both immigrant origin groups, ethnic homogeneous couples are the exception and not the rule at this stage in life (Table 7.5), an observation in contrast with the predominant ethnic proximity of cohabitating partners (see Chapter 8). Whereas gender differences are not significant for SSYU origin respondents, in the Turkish descent group, men reported having Swiss girlfriends much more often than women, who tend to have Turkish origin boyfriends. By contrast, women in the comparison group tend to have intimate friendships across ethnic lines significantly more often than men. Similar out-group dating behaviour was also observed by Yancey (2002), who found that more than half of African, Hispanic and Asian-American adults have dated someone from a different racial group.

Table 7.5 Ethnic background of boyfriend / girlfriend

\begin{tabular}{lcccccccccc}
\hline $\begin{array}{c}\text { Boy/girl- } \\
\text { friend's } \\
\text { back- } \\
\text { ground }\end{array}$ & Men & $\begin{array}{c}\text { Wom- } \\
\text { en }\end{array}$ & Total & Men & $\begin{array}{c}\text { Wom- } \\
\text { en }\end{array}$ & Total & Men & $\begin{array}{c}\text { Wom- } \\
\text { en }\end{array}$ & Total \\
\hline Swiss & 59.8 & 36.0 & 48.1 & 46.7 & 46.7 & 46.7 & 89.5 & 75.2 & 82.1 \\
Turkish & 32.6 & 48.3 & 40.3 & 1.1 & 5.3 & 3.0 & 0.0 & 5.4 & 3.1 \\
SSYU & 2.2 & 1.1 & 1.7 & 47.8 & 37.3 & 43.1 & 1.0 & 1.1 & 1 \\
Other & 5.4 & 14.6 & 9.9 & 4.3 & 10.7 & 7.2 & 9.4 & 18.3 & 13.8 \\
N $=$ & 91 & 82 & 173 & 100 & 79 & 179 & 93 & 92 & 185 \\
\hline
\end{tabular}

$\begin{array}{lll}\text { TR-SSYU } & X^{2}=126.542 & \mathrm{p}=.000 \\ \text { TR-CG } & \mathrm{X}^{2}=81.013 & \mathrm{p}=.000 \\ \text { SSYU-CG } & \mathrm{X}^{2}=96.400 & \mathrm{p}=.000 \\ \text { Gender: } & & \\ \text { TR } & \mathrm{X}^{2}=12.238 & \mathrm{p}=.007 \\ \text { CG } & \mathrm{X}^{2}=9.057 & \mathrm{p}=.029\end{array}$

Exogamy is predominant in both cohabiting and non-cohabiting nonmarried couples. The highest percentage of exogamous couples is observed among cohabiting couples. Endogamy largely prevails in married couples. Among Turkish second-generation respondents, the partner has a different origin in 60 per cent of non-cohabiting couples and in 72 per cent of cohabiting couples, but only in 15 per cent of married couples. Among SSYU second-generation respondents, the partner has a different origin in 57 per cent of non-cohabiting couples and in 82 per cent of cohabiting couples, but only in 23 per cent of married couples (see Chapter 8). 
In her survey, 'Mobilité géographique et insertion sociale', Tribalat (1995) also finds a noteworthy drop in exogamous couples when comparing non-cohabiting with married couples among Algerian origin respondents; exogamous couples are reduced to half when it comes to married couples. In our study, however, the difference is much more pronounced, since partners with a different origin are close to four times less frequent in married couples than in non-cohabiting couples. The difference between dating and cohabiting relations shows that ethnically diverse social relations are more frequent in more informal relations.

We can further explore the issue of diversity in the social networks by asking whether respondents participate in public events attended by a significant number of minority members. Does such diversity also vary according to age?

In the Turkish origin group, a majority of respondents attend such events. While age is only significant in Zurich, agglomeration makes a big difference: Turkish respondents attend such events significantly more often in Basel than in Zurich (Table 7.6). This is yet another finding that corroborates the image of a strong Turkish community in the Rhine city. In fact, younger comparison group respondents also attend events with many SSYU and/or Turkish people more often in Basel than in Zurich. Also in the SSYU origin group, a majority of respondents attend such events.

There is a distinct age difference in both agglomerations: younger respondents attend more events with co-ethnics than older ones, apparently in contrast with the fact that their friendships are more mixed during secondary school. While there are no significant city differences for the older cohort of comparison group respondents, younger ones reported going to such events significantly more often in Basel than in Zurich.

This sub-section shows that both second-generation and comparison group respondents report having significantly more inter-ethnic friendships in secondary school than they do at present. A similar pattern can be detected for intimate relationships; all three groups report lower ethnic homogeneity in non-cohabitating couples than in cohabitations and the highest levels of ethnic homogeneity in marriage. The highly ethnically mixed early schooling environment does not seem to last into adulthood, when people engage in less intimate inter-ethnic relationships. Diversity in public space, however, seems less sensitive to evolution with age. Thus, as TIES respondents grow up, their intimate relationships become more ethnically homogeneous, but they engage in less intensive forms of social relationships where ethnicity is not seen as a barrier. 
Table 7.6 Attendance at events with a significant proportion of Turkish and SSYU origin people

\begin{tabular}{cccccccc}
\hline & & \multicolumn{2}{c}{ TR } & \multicolumn{2}{c}{ SSYU } & \multicolumn{2}{c}{ CG } \\
\cline { 3 - 8 } & & $<\mathbf{2 5}$ & $>\mathbf{2 5}$ & $\mathbf{2 5}$ & $>\mathbf{2 5}$ & $<\mathbf{2 5}$ & $>=\mathbf{2 5}$ \\
\hline \multirow{2}{*}{ Zurich } & Yes & 59.6 & 47.2 & 67.5 & 55.2 & 24.0 & 35.0 \\
& $\mathrm{~N}=$ & 101 & 67 & 130 & 81 & 56 & 135 \\
\multirow{3}{*}{ Basel } & Yes & 71.9 & 73.6 & 67.9 & 49.2 & 53.8 & 35.8 \\
& $\mathrm{~N}=$ & 126 & 64 & 95 & 53 & 108 & 131 \\
\hline
\end{tabular}

TR-CG $\quad X^{2}=52.229 \quad \mathrm{p}=.000$

SSYU-CG $\quad X^{2}=42.311 \quad p=.000$

Age groups:

TR $\quad X^{2}=2.698 \quad p=.064$

SSYU $\quad X^{2}=7.836 \quad p=.004$

\subsection{Secondary group relations}

It is not easy to distinguish between primary and secondary group relations. Though individuals can establish multiple intimate relations in their neighbourhoods, at school, at work or in associations, as a context, these are places of structured social interactions that should be considered as qualitatively different from interactions occurring among friends and family. Moreover, as stated in the introduction to this chapter, it is in schools, work places, neighbourhoods and political organisations that the important process of structural assimilation - in Gordon's meaning - takes place, which might in due course change the primary social relations of populations under consideration. Thus, we shall now inspect these contexts for secondary social relations and examine how they contribute to the process of ethnic mixing in Swiss cities.

\subsubsection{Neighbourhood composition}

The ethnic composition of the neighbourhoods where respondents live (Table 7.7) is diverse; most second-generation respondents in Basel and Zurich do not live in ethnically homogeneous sections of towns, but in predominantly mixed or Swiss populated neighbourhoods and are thus in daily contact with people outside of their ethnic group. This is also the case for the comparison group, where more than $5^{\circ}$ per cent of respondents reported living in mixed neighbourhoods. This feature is explained by both the low level of ethnic segregation in Swiss cities (Huissoud 2003; 
Wimmer 2003) and by the diversified composition of immigrant flows into Switzerland.

Table 7.7 Ethnic composition of the neighbourhood by group

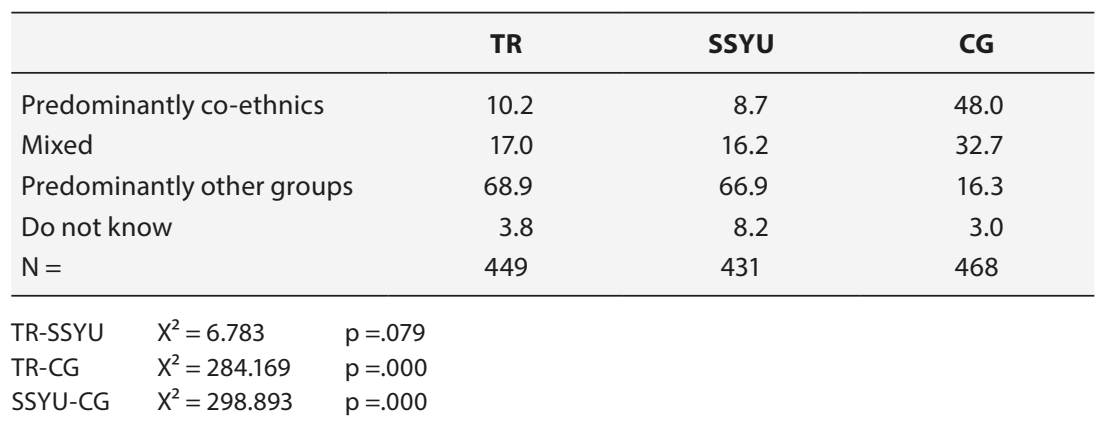

There is no significant difference between the three groups in their judgment on the type of relations in their neighbourhoods (Table 7.8). Since children of Turkish and SSYU migrants live mostly in mixed neighbourhoods and alongside more established communities, it is not a surprise that all three groups strongly agree with the statement that people know each other in their neighbourhoods and that almost 70 per cent of respondents report familiarity with their immediate neighbours. However, while the responses of the three groups are similar when looking at respondents living in predominantly co-ethnic areas (though SSYU origin youth seem less at ease in such an environment) and those in neighbourhoods populated predominantly by other ethnic groups, it is curious that comparison group respondents report a stronger feeling of social isolation in ethnically mixed neighbourhoods than that reported by children of immigrants.

The ethnically mixed neighbourhoods our respondents live in are not fraught with anonymity; such neighbourhoods offer opportunities for contacts across ethnic groups that might provide incentives for more ethnically mixed primary group social relations in the future.

\subsubsection{School environment}

As a social institution, school is assigned the sometimes contradictory double task of socialisation and selection. It familiarises the newcomer, native or foreigner, with the knowledge, ways and customs of their society, and at the same time provides legitimate distribution of individuals in the society's stratified social systems. The possible social segregation of 
Table 7.8 'People know each other in this neighbourhood', by type of neighbourhood and group

\begin{tabular}{llccc}
\hline & & TR & SSYU & CG \\
\hline Predominantly co-ethnics & Agree & 60.4 & 54.1 & 60.3 \\
& Neither agree nor disagree & 22.9 & 18.9 & 28.1 \\
& Disagree & 16.7 & 27.0 & 11.6 \\
& $\mathrm{~N}=$ & 47 & 39 & 224 \\
\hline \multirow{2}{*}{ Mixed } & Agree & 64.1 & 64.7 & 40.6 \\
& Neither agree nor disagree & 24.4 & 20.6 & 28.4 \\
& Disagree & 11.5 & 14.7 & 31.0 \\
& N $=$ & 77 & 70 & 155 \\
\hline Predominantly other & Agree & 51.5 & 54.9 & 48.6 \\
& Neither agree nor disagree & 26.9 & 24.5 & 25.7 \\
& Disagree & 21.7 & 20.6 & 25.7 \\
\hline & $\mathrm{N}=$ & 311 & 284 & 75 \\
\hline
\end{tabular}

second-generation youth should thus be seen as a consequence of this double task, along with its countervailing effects, and not only as the result of spatial positioning of groups in the urban context. What is the degree of educational segregation for second-generation respondents? Are they streamed into tracks with highly segregated ethnic compositions or do they attend fairly mixed school environments?

Almost 40 per cent of second-generation respondents interviewed attended primary schools with a large, above-city-average share of immigrant children (over 30 per cent) (Table 7.9). Since the general rule is that pupils attend schools in the immediate vicinity of their home, this result can be interpreted as a consequence of unequal spatial distribution in the urban fabric.

Since selection is institutionalised at the end of primary school in the Zurich and Basel school systems, the degree of social and ethnic mixing diminishes with the transition to lower secondary schools. As a result of educational streaming into various tracks, the second generation appears increasingly isolated in predominantly immigrant school environments as they continue their education.

At lower secondary level, children of immigrants are clearly overrepresented in vocational and mixed tracks. Moreover, no matter which track they were streamed into, second-generation respondents reported attending schools with a higher percentage of immigrant children than that reported by comparison group respondents. Thus, we can conclude that second-generation children are affected by a process of academic streaming 
Table 7.9 Percentage of immigrant children at primary and lower secondary school by group

\begin{tabular}{|c|c|c|c|c|c|c|}
\hline & \multicolumn{2}{|c|}{ TR } & \multicolumn{2}{|c|}{ SSYU } & \multicolumn{2}{|c|}{ CG } \\
\hline & Primary & Secondary & Primary & Secondary & Primary & Secondary \\
\hline Up to $30 \%$ & 60.7 & 50.6 & 60.8 & 49.8 & 80.8 & 82.8 \\
\hline $30-70 \%$ & 26.3 & 30.3 & 26.9 & 33.0 & 14.0 & 12.3 \\
\hline Above $70 \%$ & 12.9 & 19.2 & 12.3 & 17.2 & 5.2 & 5.0 \\
\hline$N=$ & 444 & 444 & 418 & 423 & 463 & 463 \\
\hline
\end{tabular}

which brings them into increasing contact with other second-generation groups and immigrants as their schooling progresses.

Table 7.10 Concentration of children of immigrants in lower secondary school levels by tracks and origin group

\begin{tabular}{|c|c|c|c|c|c|c|}
\hline TRACK & \multicolumn{3}{|c|}{$\%$ of children of immigrants } & TR & SSYU & CG \\
\hline \multirow[t]{4}{*}{ Vocational } & \multicolumn{3}{|c|}{ Up to $30 \%$} & 34.8 & 36.7 & 53.8 \\
\hline & \multicolumn{3}{|l|}{$30-70 \%$} & 37.7 & 40.1 & 28.8 \\
\hline & \multicolumn{3}{|c|}{ Above $70 \%$} & 27.5 & 23.2 & 17.5 \\
\hline & \multicolumn{3}{|l|}{$N=$} & 241 & 215 & 79 \\
\hline \multirow[t]{4}{*}{ Mixed } & \multicolumn{3}{|c|}{ Up to $30 \%$} & 67.6 & 52.2 & 80.8 \\
\hline & \multicolumn{3}{|l|}{$30-70 \%$} & 22.2 & 33.7 & 16.0 \\
\hline & \multicolumn{3}{|c|}{ Above $70 \%$} & 10.2 & 14.1 & 3.3 \\
\hline & \multicolumn{3}{|l|}{$\mathrm{N}=$} & 110 & 92 & 127 \\
\hline \multirow[t]{4}{*}{ Academic } & \multicolumn{3}{|c|}{ Up to $30 \%$} & 81.3 & 84.2 & 96.4 \\
\hline & \multicolumn{3}{|l|}{$30-70 \%$} & 15.6 & 15.8 & 2.7 \\
\hline & \multicolumn{3}{|c|}{ Above $70 \%$} & 3.1 & 0.0 & 0.9 \\
\hline & \multicolumn{3}{|l|}{$\mathrm{N}=$} & 30 & 38 & 105 \\
\hline \multicolumn{7}{|l|}{ Vocational: } \\
\hline TR-CG & $X^{2}=9.207$ & $p=.010$ & SSYU-CG & $X^{2}=8.820$ & $p=.012$ & \\
\hline SSYU-CG & $X^{2}=6.914$ & $p=.032$ & TR-CG & $X^{2}=8.905$ & $\mathrm{p}=.012$ & \\
\hline \multicolumn{6}{|l|}{ Mixed: } & \\
\hline TR-CG & $X^{2}=6.933$ & $p=.010$ & & & & \\
\hline SSYU-CG & $X^{2}=21.468$ & $p=.000$ & & & & \\
\hline
\end{tabular}

Despite differences in type and ethnic composition of the lower secondary schools attended, three out of four respondents reported good relations with their teachers and fellow students. The only exceptions to this rule 
are SSYU respondents who attended the academic track and comparison group respondents who attended the vocational track. In both cases about 10 per cent complained about their relationship with teachers.

In conclusion, we can state that by opening public schooling to all children, schools are still the primary place where young children encounter diversity and difference that characterise their generations. This diversity seems to be accepted by the respondents. However, schools also work as meritocratic selection systems. As a result of their parents' limited human capital, prejudice, or both, second-generation children are disproportionately streamed into less demanding educational tracks. This has serious consequences for the extent of social contact across ethnic lines, which for both comparison group and second-generation respondents diminishes as their schooling progresses. In addition, the type of secondary education has a strong influence on the amount of inter-ethnic contact that secondgeneration groups establish; respondents in academic tracks in secondary school reported having significantly more Swiss friends.

\subsubsection{Formal social networks}

Other important secondary social relations are established through voluntary activity and participation in organised social life via groups such as sport clubs, religious, cultural and professional organisations and other interest groups. In Basel and Zurich many of these organisations have a very diverse constituency and offer opportunities for social contact outside the narrow confines of a particular ethnic background, class or neighbourhood. As Gordon points out, joining the receiving society's associations and organisations is an important part of the integration process because it enables close contact with other social groups and provides opportunities for development of primary social relations across ethnic and social lines.

About 50 per cent of second-generation respondents report some kind of structured involvement in the public sphere. While this is not low, they are significantly less engaged than comparison group respondents, who report 70 per cent involvement (Table 7.11). These figures are nevertheless markedly higher than those observed among second- generation youth of similar age of Italian and Spanish origin and their contemporaries (40 and 47 per cent, respectively) in Geneva and Basel (Bolzman et al. 2003).

This difference between the second generation and the comparison group is especially striking when it comes to involvement in political parties, professional associations, environmental movements and artistic or cultural organisations. Turkish descent respondents report significantly 
higher involvement with women's groups, whereas SSYU respondents show significantly lower participation in religious organisations and human rights or peace movements. Generally, women are less involved in organised social life than men; this tendency applies to both second-generation youth and the comparison group, but among the latter the difference is not statistically significant.

Table 7.11 Participation in associations* by group

\begin{tabular}{|c|c|c|c|c|c|}
\hline & \multicolumn{2}{|c|}{ TR } & \multicolumn{2}{|c|}{ SSYU } & \multirow{2}{*}{$\begin{array}{c}\text { CG } \\
\text { Participation }\end{array}$} \\
\hline & Participation & $\begin{array}{l}\text { Ethnically } \\
\text { oriented** }\end{array}$ & Participation & $\begin{array}{l}\text { Ethnically } \\
\text { oriented** }\end{array}$ & \\
\hline Sport club & 33.3 & 14.6 & 35.8 & 22.7 & 37.4 \\
\hline Student union & 5.3 & 12.5 & 3.1 & 35.7 & 6.2 \\
\hline $\begin{array}{l}\text { Religious } \\
\text { organisations }\end{array}$ & 8.8 & 87.2 & 4.0 & 76.5 & 7.7 \\
\hline Political parties & 2.0 & 44.4 & 1.9 & 42.9 & 5.1 \\
\hline $\begin{array}{l}\text { Art, music, } \\
\text { cultural }\end{array}$ & 12.4 & 17.9 & 11.7 & 20.0 & 27.8 \\
\hline Trade unions & 2.0 & 0.0 & 1.4 & 0.0 & 1.1 \\
\hline Women's groups & 3.3 & 80.0 & 1.4 & 40.0 & 1.5 \\
\hline Local community & 2.9 & 15.4 & 1.6 & 0.0 & 2.6 \\
\hline $\begin{array}{l}\text { Third world } \\
\text { development }\end{array}$ & 2.0 & 11.1 & 1.2 & 20.0 & 2.8 \\
\hline Environment & 2.0 & 0.0 & 1.6 & 0.0 & 7.7 \\
\hline $\begin{array}{l}\text { Human rights, } \\
\text { peace movement }\end{array}$ & 2.9 & 25.0 & 0.7 & 33.3 & 2.8 \\
\hline $\begin{array}{l}\text { Professional } \\
\text { associations }\end{array}$ & 2.9 & 0.0 & 4.4 & 11.1 & 6.6 \\
\hline $\begin{array}{l}\text { Parents' } \\
\text { organisations }\end{array}$ & 1.8 & 25.0 & 0.5 & 0.0 & 1.7 \\
\hline $\begin{array}{l}\text { NO } \\
\text { PARTICIPATION }\end{array}$ & 46.8 & n.a. & 49.4 & n.a. & 31.2 \\
\hline Other & 2.9 & 46.2 & 3.8 & 18.8 & 7.3 \\
\hline$N=$ & 449 & & 431 & & 468 \\
\hline
\end{tabular}

* Given that respondents could positively answer multiple questions the total of percentages is more than 100.

** Percentage of ethnically oriented associations calculated for an $\mathrm{N}$ of those participating in associations.

TR-CG $\quad X^{2}=23.583 \quad \mathrm{p}=.000$

SSYU-CG $\quad X^{2}=30.906 \quad p=.000$

Only a handful of respondents reported being involved in associations with a direct focus on the country of their parents or the origin group. 
Interestingly, Turkish and SSYU descendants are involved in different types of associations with an ethnic orientation. Among the former, high scores relate to religious and women's defence associations as well as human rights movements and parents' associations. Among the latter, participation in groups with an ethnic orientation tends to be lower and primarily concerns sports clubs and cultural or artistic associations. Ethnic orientation seems aimed at catering for community needs in Swiss society among Turkish respondents, while it seems more geared toward individual needs among SSYU respondents.

\subsubsection{Civic participation via voting}

The last form of secondary social relations discussed in this subsection is participation in the voting process. This is of central importance in Swiss democracy, as citizens go to the polls on average four times a year, not only to elect their representatives but also to vote on initiatives and referendums.

Slightly more than a third of second-generation respondents reported voting in the last elections. However, if only those with Swiss citizenship are considered, half of the eligible voters among the second generation (50 per cent and 47 per cent among descendants of Turkish and SSYU immigrants, respectively) did vote, a high figure which stands comparison with the 63 per cent of the comparison group respondents. Moreover, if we control for the present education of the respondent, we see that the difference between the second generation and comparison group ceases to be significant (with the exception of those with upper secondary level education, where comparison group respondents still vote significantly more often than their second-generation peers). The majority of children of immigrants holding voting rights in Basel exercised them ( 56 per cent) while in Zurich only a minority took part in the political life (43 per cent among second-generation Turkish youth and 38 per cent among SSYU origin youth).

Women are more likely than men to hold Swiss citizenship (see Chapter 2.6.1) and hence are entitled to vote; however, we discovered no significant gender differences in frequency of voting or voting patterns.

In conclusion, TIES respondents live in ethnically mixed neighbourhoods and attended schools which, in spite of early tracking, still enabled contact between majority population and youth of Turkish and SSYU descent. The 
second generation reported lower yet comparable levels of social and civic participation to those of comparison group respondents.

In the next section we will discuss some of the more important social consequences of increased inter-ethnic contact, particularly discrimination and attitudes toward multicultural coexistence, in order to examine their effect on the structural assimilation of youth of Turkish and SSYU descent in Zurich and Basel.

\subsection{Inter-ethnic relations}

TIES survey respondents were sampled in ethnically diverse and densely populated urban areas, where they come into frequent contact with both the established Swiss population and numerous immigrant groups that compose the ethnic fabric of Zurich and Basel. Given that most Swiss children attend state schools where different ethnic groups have considerable contact with one another, it is the younger generations of Swiss residents - including the age cohorts sampled for the TIES survey - that most often engage in social relations across ethnic and cultural lines.

Inter-group contact provides opportunities for bonding as well as for increased friction (De Rudder 1984). The issue of ethnicity-based hostility and discrimination (with consequences for identity formation and structural integration) is prominent in literature on the second generation, both in the US (Portes \& Zhou 1993; Portes \& Rumbaut 2001; Kasinitz et al. 2004; Stepick \& Stepick 2009) and in Europe (Tribalat 1995; Crul \& Vermeulen 2003; Simon 2003; Aparicio 2007). This is in sharp contrast to the situation in Switzerland, where the issue was raised only in recent years (Fibbi et al. 2003; Wessendorf 2007) and is now slowly making its way into mainstream literature on migration, if not yet onto the political agenda.

As Gordon points out in Assimilation in American life (1964), structural assimilation (which he considered to be the keystone of the process of assimilation) will proceed at a slower pace if the 'attitude receptional' (absence of prejudice) and 'behaviour receptional' (absence of discrimination) dimensions of assimilation are not attained. In similar fashion, other social scientists (Sibley 1995; Zolberg \& Long 1999) have argued that persistent patterns of prejudice and discrimination against particular ethnic or religious groups often ossify into an ethno-religious hierarchy, which is closely related to the observed differences in the degree of structural integration of various ethnic groups composing the society under consideration. 
This also points to the need to account for the power differentials between various groups. While all groups face prejudice (as one way in which social worlds are organised), we need to ask who is in a position to discursively define and enforce the content of these prejudices. If we define discrimination as

... distinction, exclusion, restriction or preference based on race, colour, descent or national or ethnic origin (and we might add sexual orientation, class, and religion), which has the purpose or effect of nullifying or impairing the recognition, enjoyment or exercise, on an equal footing, of human rights and fundamental freedoms in the political, economic, social, cultural or any other field of public life, ${ }^{4}$

it becomes clear that one can only discriminate if one has the power to do so. Nevertheless, as we shall see below, it is also possible to display prejudice and hostility towards groups perceived to be higher up in the ethno-religious hierarchy in a given society.

Most Swiss studies focus more on objective measures of discrimination (Fibbi 2006) and less on the perceptions of the phenomenon among the people affected (e.g. for Switzerland see Juhasz \& Mey 2003). For obvious methodological reasons, discussion of hostility and discrimination in the TIES survey is grounded in the subjective perception of the respondent. This approach is, of course, largely influenced by way the respondent lived, experienced and interpreted a treatment as being unfair; in certain cases, discrimination may have been overlooked, whereas in others it may be mentioned even if other reasons led to the unfavourable outcome. Let us underscore, however, that when subjective perceptions can be compared to objective measures of discrimination, victimisation measures tended to underestimate the phenomenon of discrimination (Bovenkerk 1992). Individual perception is not firm proof of unfair treatment but it is nevertheless highly relevant. It sheds light on the way reality is interpreted by social actors under the influence of both individual - life experience, resources, social position - and social factors like public discourse on immigrants' integration dynamic and discrimination in society.

In this subsection, we will address these issues first by examining TIES survey respondents' experiences of hostility and discrimination based on their socio-cultural background. We will then compare the frequency, type, and ethnic character of these incidents to get a clearer picture of prejudice 
and hostility experienced by youth of Turkish and SSYU descent. We will address our respondents' perceptions of ethno-religious hierarchy and the relative positions of various groups within this hierarchy. To conclude the subsection, we will connect these perceptions with consequent attitudes that respondents hold on issues of multicultural coexistence, such as the right to public expression of cultural specificities, evaluation of multi-ethnic coexistence, and the role of government in the process.

\subsubsection{Hostility and discrimination}

Experiences of hostility interpreted by the respondents as based on their background are presented in Table 7.12. Around $5^{\circ}$ per cent of secondgeneration respondents, especially those of Turkish descent, reported experiencing hostility in their lives. This is higher than the 40 per cent reported by second-generation Italian and Spanish youth in a survey (Bolzman et al. 2003). About 10 per cent of Turkish respondents and 5 per cent of SSYU descent respondents reported experiencing hostility frequently in their lives. In contrast to the 2003 study, younger and older respondents reported similar experiences of hostility; in other words, the situation did not improve over time.

The most striking pattern observed in Table 7.12 is the gendered perception of hostility; men see themselves as systematically more exposed to hostility than women. Therefore when discussing perceptions of ethnic hostility in this subsection we will deal with group comparisons for men and women separately.

The difference in reported experience of hostility between the two second-generation groups is statistically significant, with descendants of Turkish immigrants reporting significantly higher levels in both cities. This is especially the case in Basel and for Turkish origin women.

The question about personal experience of hostility was framed very broadly and included both ethnic origin and social background. We can therefore analyse the different explanations given by our respondents as to possible reasons for such hostility. Turkish descendants cite ethnic origin, religion, class and even skin colour as the main reasons, while SSYU descendants more frequently mention ethnic origin and class (Table 7.13). It appears that Turkish origin youth have a more ethnicised perception of their group than SSYU origin youth.

Given the gendered dimension of hostility noted above, contexts where it is experienced may also differ according to gender. In fact, men report that they are much more likely to experience hostility from the police and when 
Table 7.12 Hostility due to ethnic and social background

\begin{tabular}{|c|c|c|c|c|c|c|}
\hline & & \multicolumn{3}{|c|}{ TR } & \multicolumn{2}{|c|}{ SSYU } \\
\hline & & Men & & Women & Men & Women \\
\hline \multirow[t]{4}{*}{ Zurich } & Never & 48.5 & & 57.3 & 36.8 & 45.9 \\
\hline & Occasionally & 40.8 & & 37.9 & 56.8 & 48.6 \\
\hline & Frequently & 10.7 & & 4.9 & 6.4 & 5.4 \\
\hline & $N=$ & 100 & & 102 & 128 & 111 \\
\hline \multirow[t]{4}{*}{ Basel } & Never & 35.1 & & 44 & 45.9 & 55.1 \\
\hline & Occasionally & 55 & & 45.7 & 49.4 & 38.3 \\
\hline & Frequently & 9.9 & & 10.3 & 4.7 & 6.5 \\
\hline & $N=$ & 129 & & 118 & 86 & 106 \\
\hline $\begin{array}{l}\text { TR-SS } \\
\text { TR }\end{array}$ & $\begin{array}{ll}\text { Zurich) } & X^{2}=12.363 \\
\text { cities) } & X^{2}=7.862\end{array}$ & $\begin{array}{l}p=.002 \\
p=.020\end{array}$ & asel) & $X^{2}=6.693$ & $\mathrm{p}=.035$ & \\
\hline
\end{tabular}

Table 7.13 Perceived reasons for personal experiences of hostility

\begin{tabular}{llr}
\hline & TR & SSYU \\
\hline Ethnic origin or culture & 61.1 & 70.6 \\
Language or accent & 18.8 & 22.5 \\
Skin colour & 13.8 & 3.9 \\
Religion & 36.0 & 13.4 \\
Social class & 27.6 & 33.2 \\
Other & 10.5 & 15.6 \\
$\mathrm{~N}=$ & 239 & 232 \\
\hline
\end{tabular}

*Given multiple answers possibility, the total of percentages is higher than 100.

$\begin{array}{lllll}\text { (Ethnic) } \quad X^{2}=5.385 & p=.059 & \text { (Skin) } \quad X^{2}=16.013 & p=.000\end{array}$

(Religion) $\quad X^{2}=33.259 \quad \mathrm{p}=.000 \quad$ (Other) $X^{2}=15.389 \quad \mathrm{p}=.000$

they go out in the evenings (Table 7.14). Turkish origin men are not only especially affected, but they are also more often confronted with hostility in school and in relation to the police; SSYU origin men face hostility mainly when going out and in school. Feeling less exposed to hostility than men, women of both Turkish and SSYU origin cite school as the context of most frequent enmity.

It is worth emphasising that school is frequently mentioned as a context where ethnicity-based hostility occurs. Examining sources of hostility in school, both second-generation groups report quite high levels of hostility from teachers (about a third of all second-generation respondents reported experiencing this form of discrimination) and other staff at the school. Teachers and staff, like the police, are representatives of public authority 
in a position of power over the 'victim' and thus possibly in the condition of discriminating. This differs from the hostility of peers, who may create a generally unfriendly atmosphere, as was commonly experienced by youth from previous migration flows (Bolzman et al. 2003).

Hostility poses particular difficulties when it is related to work. Both men and women mention feeling unwelcome when entering the labour market, but SSYU origin men are clearly the most affected. Once in the workplace, however, they seem to be able to negotiate greater acceptance.

Table 7.14 Contexts of ethnicity-based experience of hostility

\begin{tabular}{lcccc}
\hline & \multicolumn{2}{c}{ TR } & \multicolumn{2}{c}{ SSYU } \\
\cline { 2 - 5 } & Men & Women & Men & Women \\
\hline Neighbourhood & 5.1 & 3.7 & 0.0 & 6.5 \\
Cafes, discos & 4.7 & 1.4 & 6.7 & 3.2 \\
Police & 8.5 & 2.6 & 3.3 & 1.4 \\
School & 8.5 & 4.7 & 5.3 & 3.7 \\
$\mathrm{~N}^{*}=$ & 138 & 108 & 124 & 108 \\
\hline Looking for work & 5.2 & 5.6 & 8.2 & 5.6 \\
At workplace & 3.6 & 4.0 & 3.3 & 1.7 \\
$\mathrm{~N}^{* *}=$ & 197 & 165 & 183 & 182 \\
\hline
\end{tabular}

* Calculated based on those that reported experiencing hostility in their lives.

**Calculated based on those that reported already having a job.

TR-SSYU (Police) $\quad X^{2}=5.290 \quad \mathrm{p}=.071$

Gender:

SSYU (Neighbourhood) $X^{2}=8.335 \quad \mathrm{p}=.015$

SSYU (Police) $X^{2}=6.221 \quad \mathrm{p}=.045$

TR (Cafe) $\quad X^{2}=6.106 \quad \mathrm{p}=.047$

TR (Police) $\quad \mathrm{X}^{2}=5.862 \quad \mathrm{p}=.053$

In a multi-ethnic environment, hostility based on socio-cultural background is not a singular process: it concerns majority-minority relations as well as relations between different minority groups. Table 7.15 examines the reported origin of the offenders. For both immigrant origin groups, offenders are mainly identified as members of the majority group (over 75 per cent), but relations with other immigrant groups also appear to be strained. As a result of composition effect, or more contact with Swiss people, this phenomenon is quite possibly underestimated in the survey results.

Friction internal to the origin group reach a relatively high level among SSYU descendants, a fact that can be explained by the composite character 
of this group and the impact that violent ethnic conflicts in the countries of origin have had on people from the former Yugoslavia residing abroad. Similar friction - although less pronounced - characterises the Turkish origin group, notably in Basel. In fact all three groups reported significantly higher levels of hostility from Turkish people in Basel compared to Zurich. Such results are a useful reminder that the perception of immigrants as monolithic, firmly bounded communities - common in the majority group - is indeed misleading.

Table 7.15 Reported origin of the offender

\begin{tabular}{lcccc}
\hline & \multicolumn{2}{c}{ TR } & \multicolumn{2}{c}{ SSYU } \\
\cline { 2 - 5 } & Zurich & Basel & Zurich & Basel \\
\hline Swiss & 80.7 & 77.5 & 86.4 & 73.8 \\
Turkish & 3.6 & 13.3 & 11.1 & 16.0 \\
SSYU & 15.7 & 15.0 & 29.9 & 27.2 \\
Other & 38.6 & 31.7 & 29.7 & 46.3 \\
N $=$ & 83 & 103 & 117 & 78 \\
\hline
\end{tabular}

* Given multiple answers possibility, the total of percentages is higher than 100.

TR-SSYU (SSYU) $\quad \mathrm{X}^{2}=9.846 \quad \mathrm{p}=.001$

Zurich / Basel:

TR (Turkish) $\mathrm{X}^{2}=5.463 \quad \mathrm{p}=.015$

SSYU (Swiss) $\quad X^{2}=5.053 \quad \mathrm{p}=.020$

(Other) $\quad X^{2}=5.670 \quad p=.013$

To grasp the general feeling between immigrant groups and their descendants and the comparison group, respondents were asked to evaluate the quality of relations between majority and minority groups (Table 7.16); the results suggest tension. Majority-minority links with people of Balkan origin appear to be under particular stress: a third of comparison group respondents rated their relations with SSYU group members as unfriendly, twice as many as reported by SSYU origin respondents. Relations between the majority and the Turkish origin group seem better: a sixth of comparison group respondents characterise relations as distant, one and a half times more than minority group members. Thus, while these minorities tend to evaluate relations with the majority more positively than the majority does, the general trend of strained relations between Swiss and the SSYU populations remains visible among all respondents.

Members of all groups have a pessimistic outlook on the evolution of intergroup relations over time. About a third of comparison group and SSYU respondents (with comparison group respondents being more pessimistic) 
Table 7.16 Evaluation of relations between majority and minority groups

\begin{tabular}{|c|c|c|c|c|}
\hline & TR-CH & CG-TR & SSYU-CH & CG-SSYU \\
\hline Unfriendly & 9.7 & 17.1 & 15.5 & 32.9 \\
\hline Indifferent & 24.4 & 38.7 & 33.0 & 40.4 \\
\hline Friendly & 65.9 & 44.2 & 51.5 & 26.7 \\
\hline $\mathrm{N}=$ Comparison group respondents & & 468 & & 468 \\
\hline $\mathrm{N}=$ Turkish origin respondents & 449 & & & \\
\hline $\mathrm{N}=\mathrm{SSYU}$ origin respondents & & & 431 & \\
\hline $\begin{array}{lll}\text { TR/CH } & X^{2}=43.826 & p=.000 \\
\text { TR-SSYU/CH } & X^{2}=18.824 & p=.000\end{array}$ & $\mathrm{SSYU} / \mathrm{CH}$ & $X^{2}=68.631$ & $p=.000$ & \\
\hline
\end{tabular}

expressed the opinion that relations between the two groups became less friendly in recent years, while a fifth of Turkish and comparison group respondents share this opinion about Turkish-Swiss relations. Our data corresponds to other reports (Mikić 2003; Wessendorf 2007) noting progressively tenser relations between SSYU migrants and the native population in Switzerland since the 1990s, coinciding with the new immigration policy and the inflow of asylum seekers from the Balkan region.

Finally, Table 7.17 presents our respondents' perceptions of the social hierarchy or the 'pecking order' - that is, how they judge the relative position of their own group with respect to other groups in Swiss society, in terms of prestige and absence of unfair treatment, sketching in this way ethnoreligious hierarchies. While dark-skinned minorities are unanimously considered to be the most discriminated against, Muslims and SSYU origin migrants are not far behind.

This is not surprising, as the data reflect the general opinion in Switzerland, which is quite unfavourable towards people from the SSYU region. It is interesting to see that Turkish people, while often Muslim, are considered (by all three groups) much less discriminated against than Muslims. This might be related to their experiences with the secular Turkish state or, more probably, the recent sharpening of the public debate around the 'difficult' integration of Muslims in the European context. In fact, Turkish respondents see Turks as being significantly less discriminated against than SSYU origin people - a perception shared by the comparison group.

The last opinion poll on attitudes towards immigrants from various countries living in Switzerland dates back to 2002. At that time, some 700 Swiss citizens were asked whether they regarded various groups as enriching or problematic for Switzerland, the focus being immigrant origin and not generational succession. Despite these caveats, this study is a useful 
comparator, since perception of groups compounds generations in a single encompassing ensemble and makes visible a hierarchy among immigrant groups in the autochthonous perception that was dominant as the TIES respondents were growing up. The groups under study in the TIES survey were viewed as least enriching and most problematic in the 2002 poll; people from Turkey were considered very problematic by 15 per cent of Swiss citizens interviewed, while people from Serbia and Bosnia were rated as such by 25 per cent and people from Albania by 34 per cent (Raymann 2003). Five years later the answers of the comparison group in the TIES survey reflect an even more sombre perception of Turkish and SSYU origin immigrants.

Table 7.17 Perception of group discrimination by group and agglomeration

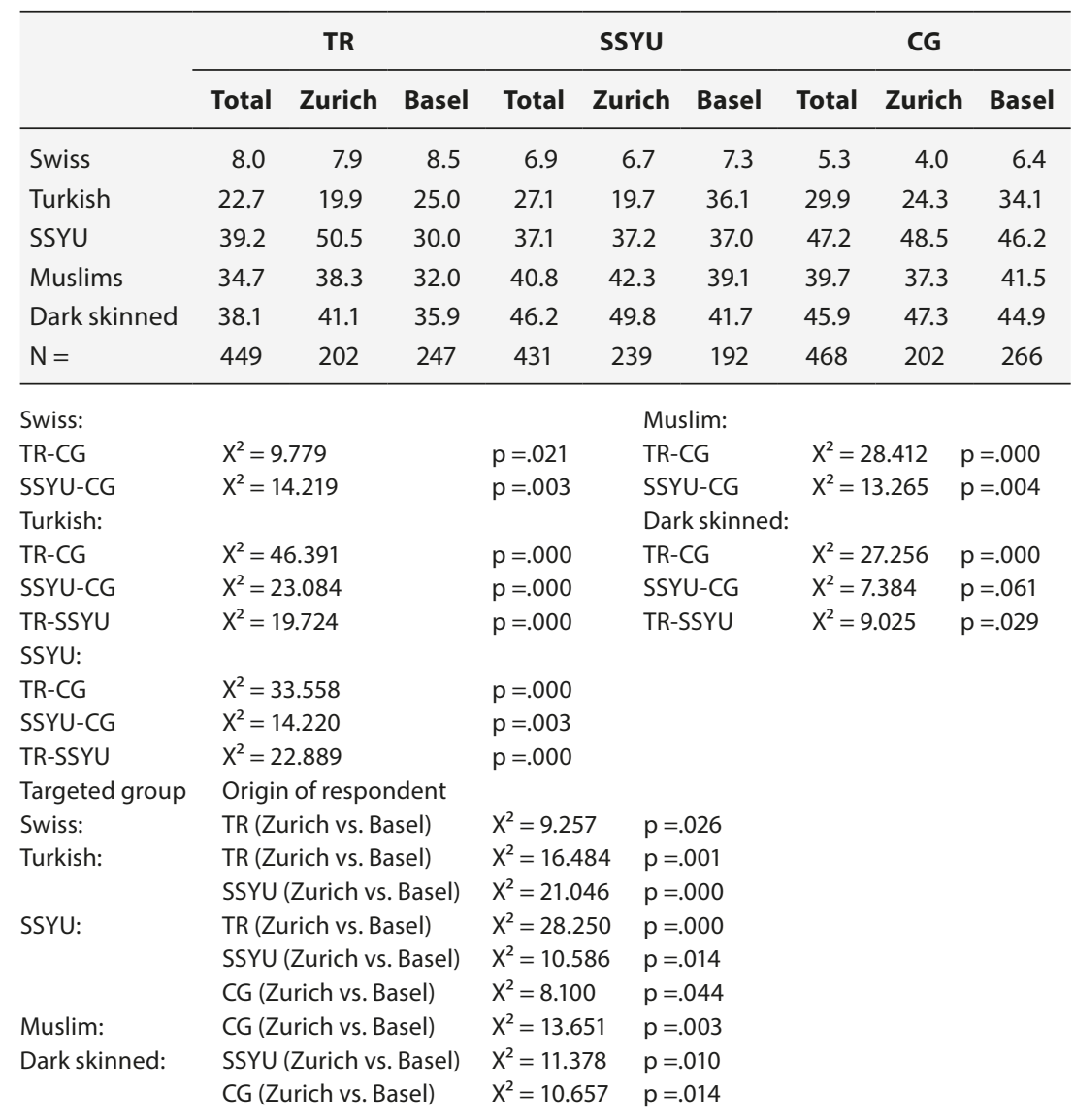

The perception of immigrant groups varies significantly according to the agglomeration in which they live. In the opinion of respondents from all 
origin groups, Turks are clearly more often a target of hostility in Basel than in Zurich. By contrast, SSYU immigrants are more targeted in Zurich than in Basel, though the gap within agglomerations is not as wide as for Turks; this is also the case for Muslims and dark skinned people, at least in the eyes of second-generation respondents.

It is worth underscoring the discrepant perception of personal and group discrimination in the two immigrant origin groups. SSYU immigrant descendants display the typical pattern of stronger perception of group-related discrimination than personal discrimination, as already assessed in the literature (Dion \& Kawakami 1996; Taylor et al. 1990). Second-generation Turkish respondents display the reverse pattern, however, with a stronger perception of personal discrimination than for the group. This is a surprising pattern, given that the literature suggests the absence of a discrepancy between personal and group perceived discrimination.

How can this be explained? To answer this question it is useful to refer to the discursive construction of perception of discrimination. Such a perception is influenced by public debate. In the last two decades the SSYU origin population has occupied centre stage - they have been accused of lower compliance with local rules than other immigrant groups because of involvement in drug dealing, low labour market participation rates, over-proportional recourse to social security and violent behaviour (Burri Sharani et al. 2010; Wyssmüller 2005). In this study it may be that the difference in the relative size of the groups accounts for the less threatening perception of immigrants from Turkey, who represent only a fourth of the SSYU origin population.

A third argument may explain the overshadowing of 'Turks' in the Swiss public debate. National membership has long been the main criterion for defining immigrant groups on a political agenda largely determined by the xenophobic characterisation of foreigners since the sixties (Mahnig et al. 2005). However, since the development of the new admission policy and the federal integration policy in the nineties, national categorisations for immigrants have been replaced by more encompassing ones, notably European vs. third-country-nationals. In this context, religious affiliations have gained importance (Allievi 2005): 'Turks' have been problematised mainly as Muslims, whose values are said to be incompatible with dominant Western values. The large popular vote against the building of new minarets in November 2009, echoing somewhat the Kulturkampf that split the country in the late $19^{\text {th }}$ century, is emblematic in this respect. 
When negative stereotyping now affects the Turkish origin group, it is probably more due to the discourse on religiously defined group membership, as Muslims are assumed to be a homogeneous religious community representing a threat to Switzerland as a European country, rather than a group whose boundaries are defined by nationality (Haab et al. 2010). This is reflected in the TIES survey, as Muslims are perceived as more discriminated against both by second-generation Turkish respondents and the comparison group.

This produces a paradoxical discrepancy between personal experience and perceived position in the pecking order, whereby second-generation Turkish respondents feel collectively less rejected than they really are on a personal basis and second-generation SSYU respondents are entangled in a collective negative image unsubstantiated in daily individual experience.

What are the consequences of this chasm? According to relative deprivation theory, the configuration observed in the TIES survey among Turkish respondents - where personal position is deemed more unsatisfactory than the group's position in society - should yield more stress symptoms. On the contrary, the configuration observed in the TIES survey among SSYU respondents, where the group's position in society is more unsatisfactory than the personal position, is associated with protest reactions (Dion \& Kawakami 1996). In the same vein, in the case of the second generation, the literature points at the link between lack of positive recognition and reinforcement of group identity or even re-ethnicisation (Heitmeyer et al. 1997; Nauck \& Settles 2001) as a strategy to regain a positive social identity lost by failed efforts to reach sufficient social, cultural and economic resources. The goal is to valorise in-group specific capital as opposed to the capital of an opposing dominant group (Skrobanek 2010). While the TIES survey results show a clear negative association between discrimination and personal feeling of belonging, the 'reactive identity' hypothesis could not be confirmed; none of the associations between the experience of hostility (or conviction that one's group is often discriminated against) and the feeling of belonging to parents' country of origin turned out to be statistically significant.

We tested the relationship between education and perception of the risk of being discriminated against; better educated second-generation respondents perceive more hostility and discrimination. This trend is obvious for both second-generation groups, but statistically significant for descendants of Turkish immigrants. This is also the case for the perception of group discrimination: among all three origin groups, better educated 
respondents reported higher levels of group discrimination against Turkish and SSYU people.

\subsubsection{Attitudes towards multi-ethnic coexistence}

What is the perception of Swiss urban multi-ethnic and stratified society in the eyes of TIES respondents? In this subsection, we will deal with our respondents' evaluations of living in a multicultural society, the issue of public and private display of cultural norms and habits, and the role of the government in the process of immigrant accommodation. Table 7.18 shows that despite high levels of reported experiences of discrimination and hostility, a majority of respondents see living with people of different origin as enriching to their own culture and only a small minority finds it threatening. ${ }^{5}$ Half of respondents in all groups find multi-ethnic coexistence enriching; however, about one person in six in the comparison group finds it threatening - a figure significantly higher than among second-generation respondents.

Younger comparison group members, especially men, constitute a large share of those with doubts about or indifference to the value of multicultural coexistence. However, among the older comparison group respondents there seems to be a trend towards a more pacific perception of the effects of cultural difference on one's own group. Second-generation respondents in Zurich tend to take a more positive view of inter-ethnic coexistence than in Basel, while city differences among majority respondents are negligible.

Table 7.18 Living with people of different origins

\begin{tabular}{|c|c|c|c|c|c|c|}
\hline & \multicolumn{2}{|c|}{ TR } & \multicolumn{2}{|c|}{ SSYU } & \multicolumn{2}{|c|}{ CG } \\
\hline & $<25$ & $>=25$ & $<25$ & $>=25$ & $<25$ & $>=25$ \\
\hline Threatening & 7.3 & 9.0 & 4.1 & 9.1 & 16.1 & 12.3 \\
\hline Makes no difference & 37.6 & 25.9 & 42.3 & 37.1 & 42.5 & 30.1 \\
\hline Enriching & 55.1 & 65.1 & 53.5 & 53.8 & 41.5 & 57.6 \\
\hline $\mathrm{N}=$ & 248 & 201 & 256 & 175 & 168 & 300 \\
\hline
\end{tabular}

Age groups:

$\begin{array}{lll}\text { TR } & X^{2}=6.524 & p=.038 \\ \text { SSYU } & X^{2}=4.852 & p=.088 \\ \text { CG } & X^{2}=11.943 & p=.003\end{array}$

5 The question was framed in the following way: 'Would you say that living together with people of different origins in Basel / Zurich is threatening or enriching for your own culture?' 
How should this multi-ethnic coexistence be managed? Should cultural specificities be restricted to the private sphere or do they have a place in the public arena? In the TIES survey, questions dealing with this issue are formulated as describing a situation but may imply a normative position. ${ }^{6}$ TIES respondents' opinions on individual rights to live in accordance with one's cultural norms vary depending on whether the question deals with the issue in private or public spaces. While about three quarters of all groups agree that everybody is free to live in accordance with their cultural norms in the private sphere, significantly fewer respondents ( 40 to 50 per cent) agree about that right in public spaces.

In both respects, respondents of Turkish descent take a more liberal stand and are the only group where more than $5^{\circ}$ per cent of respondents agreed with the right to openly display and practise one's cultural habits in public. SSYU respondents are more restrictive, as is the comparison group. While there are no significant differences by city and age group, comparison group women are much more liberal in their view on the right to live according to one's own cultural norms than comparison group men are. The gender difference is otherwise not significant in relation to the issue of public spaces.

Table 7.19 Right to live according to one's own cultural norms, by origin group

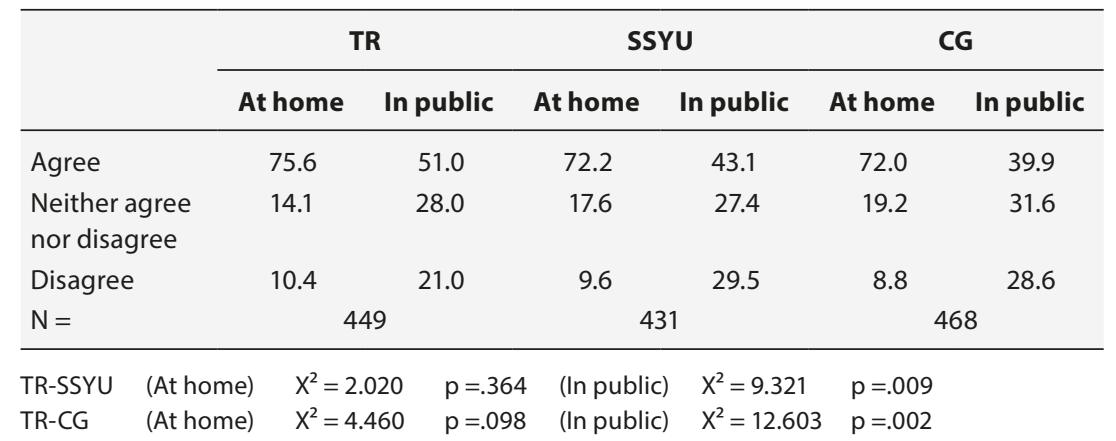

These prevailing opinions on a limited place for cultural specificities in the public sphere refer to a regulating role for public authorities. Indeed, the majority of respondents plead for a more active role on the part of government in improving the position of immigrants and their families

6 The two questions dealing with this issue were framed in the following way: 'At home / in public people of immigrant origin have the right to live as much as possible in accordance with the cultural customs and norms of their parents' country or region of origin.' 
in Swiss society. Table 7.20 presents opinions about the role of the government in the process of immigrant integration, distinguishing by gender. Second-generation Turkish youth are more inclined than those of SSYU descent and the comparison group to put forward claims in this respect. In all groups, but especially among the comparison group, women favour greater involvement from the government.

Table 7.20 Government should be more involved in promoting immigrants' wellbeing by group and gender

\begin{tabular}{lcccccc}
\hline & \multicolumn{2}{c}{ TR } & \multicolumn{2}{c}{ SSYU } & \multicolumn{2}{c}{ CG } \\
\cline { 2 - 7 } & Men & Women & Men & Women & Men & Women \\
\hline Agree & 63.4 & 65.5 & 50.2 & 54.4 & 46.7 & 59.6 \\
$\begin{array}{l}\text { Neither agree nor } \\
\text { disagree }\end{array}$ & 25.1 & 24.5 & 30.6 & 28.6 & 25.0 & 21.5 \\
$\begin{array}{l}\text { Disagree } \\
\mathrm{N}=\end{array}$ & 11.5 & 10.0 & 19.1 & 17.1 & 28.3 & 18.9 \\
\hline
\end{tabular}

$\begin{array}{lll}\text { TR-SSYU } & X^{2}=15.936 & \mathrm{p}=.000 \\ \text { TR-CG } & X^{2}=27.616 & \mathrm{p}=.000 \\ \text { SSYU-CG } & X^{2}=6.440 & \mathrm{p}=.040 \\ \text { CG (gender) } & X^{2}=8.761 & \mathrm{p}=.013\end{array}$

In this subsection we noted that while Turkish respondents reported experiencing more ethnically based hostility than SSYU respondents, they nevertheless seem aware of the better position of Turkish people in a discursive hierarchy of ethnic discrimination in Switzerland. This might be the reason why they are also more prone to expressing demands for cultural freedom in public spaces and for government involvement in promoting immigrants' wellbeing than SSYU respondents who, in regard to these topics, have very similar opinions to those held by the comparison group.

\subsection{Transnationalism}

In a critique of methodological nationalism (Glick Schiller \& Wimmer 2002) since the beginning of the 1990s, literature on transnationalism has focused on social fields where migrants establish links - real and/or imagined - between the country where they live and the one where they come from (Glick Schiller et al. 1992; Portes 1997). It is claimed that immigrants maintain relations and develop life projects transcending nation-state boundaries as 
the technological and communicational advances of the recent post-Cold War wave of globalisation enable them to maintain various social relations across vast distances in nearly real time. In migration studies, this approach is a sort of third way between two perspectives: individual action being framed as determined by macro-social constraints (Portes 1999) or as the outcome of migrants' agency (Kivisto 2001). For first-generation migrants transnationalism has even been portrayed as an alternative to the assimilation option, as well as to the option of return. The question is open as to what extent this can also be an option for the second generation.

Whilst the theoretical literature on transnationalism is quite developed, the empirical assessments are limited, especially in continental Europe, where this issue may appear less topical (Fibbi \& D'Amato 2008). This is even more the case for the issue of second-generation involvement in transnational activities. The classical assimilation literature has emphasised that transnational links decline over generations; recent studies both in Germany and Switzerland show a weakening of ethnic bonds among Turks over generations (Nauck et al. 1997; Wimmer 2004). Taking up this issue, we test the degree of engagement of children of immigrants in transnational activities on the basis of the following indicators: visits to parents' country of origin, remittances, media consumption and 'return' plans.

Between 3 and 5 per cent of second-generation respondents reported going back to their parents' country of birth for more than three months when they were school-age. As young adults, some 95 per cent of each respondent group had travelled to their parents' country of origin at least once in the last five years, while about half of them had been there frequently (once a year or more) - most of them on holiday or for family visits. In both origin groups, younger people go to their parents' country of origin more often than older respondents, possibly accompanying their parents on their trips back home (Table 7.21). Curiously, among second-generation Turkish respondents, visits to the parental country of origin are less frequent in Basel than in Zurich.

Another important question related to migrant transnational activities is the number of remittances that second-generation respondents send to their respective countries of origin. Remitting money to someone residing in the country of origin demonstrates immigrants' lasting attachment to their ancestral land and family. In our sample, about 20 per cent of secondgeneration respondents have remitted money to Turkey or SSYU in the last five years. While more than 70 per cent remitted less than 1,6oo CHF (about 1,000 euros) per year, there are a few cases of considerable investments in the country of origin. In both groups, men and older respondents reported 
Table 7.21 Visits to the parent's country of origin, in the last 5 years, by origin, age group and agglomeration

\begin{tabular}{|c|c|c|c|c|c|}
\hline & & \multicolumn{2}{|c|}{ TR } & \multicolumn{2}{|c|}{ SSYU } \\
\hline & & $<25$ & $>=25$ & $<25$ & $>=25$ \\
\hline \multirow[t]{4}{*}{ Zurich } & Seldom & 14.9 & 21.9 & 16.7 & 28.3 \\
\hline & Occasionally & 27.2 & 19.2 & 15.0 & 15.2 \\
\hline & Frequently & 57.9 & 58.9 & 68.3 & 56.6 \\
\hline & $N=$ & 103 & 81 & 130 & 92 \\
\hline \multirow[t]{4}{*}{ Basel } & Seldom & 37.1 & 28.8 & 18.3 & 31.1 \\
\hline & Occasionally & 23.9 & 24.7 & 26.0 & 12.2 \\
\hline & Frequently & 39.0 & 46.6 & 55.8 & 56.8 \\
\hline & $N=$ & 133 & 98 & 110 & 69 \\
\hline $\begin{array}{l}\text { SSYU } \\
\text { TR }\end{array}$ & ups) $\quad \begin{array}{l}X^{2}=8.069 \\
X^{2}=16.920\end{array}$ & $\begin{array}{l}p=.018 \\
p=.000\end{array}$ & & & \\
\hline
\end{tabular}

sending remittances significantly more often. Both the share and amount of money remitted seem quite high, especially if it is borne in mind that respondents are aged 18 to 35 and therefore in the early years of economic independence. Moreover they reported a considerable share of their family living in the same city or at least in Switzerland.

Links to parents' country of origin may also pass through media consumption. What type of media is most used by second-generation youth? They watch significantly more TV than the comparison group who, in turn, use the Internet significantly more often. In both second-generation groups, younger respondents use the Internet significantly more than the older respondents (95 per cent vs. 90 per cent for Turkish descent respondents and 96 per cent vs. 89 per cent for SSYU descent respondents).

Which programmes are generally watched? Turkish origin respondents report a relatively high level of ethnic media consumption (Table 7.22); about 30 per cent reported watching as many German as Turkish programmes, while about 11 per cent reported watching mostly origin language stations. These percentages are significantly lower for the SSYU group, whose consumption of German language media is similar to that of the comparison group. Moreover, younger SSYU origin respondents report watching significantly more German programmes than older respondents, whereas this is not the case for Turkish origin youth.

So far, the findings on frequency of travel to parents' country of origin, media language use and remittances reflect a transnational orientation among second-generation respondents. However, this does not necessarily 
Table 7.22 Media consumption: TV channels watched by origin groups

\begin{tabular}{lccc}
\hline & TR & SSYU & CG \\
\hline Mostly German & 55.4 & 82.2 & 84.2 \\
As much German as parental language & 28.7 & 10.3 & 13.2 \\
Mostly parental language & 10.7 & 1.5 & 2.6 \\
As much German as other & 4.6 & 46 & 0.0 \\
Mostly other & 0.7 & 1.5 & 0.0 \\
N $=$ & 432 & 415 & 415 \\
\hline
\end{tabular}

$\begin{array}{lll}\text { TR-SSYU } & X^{2}=88.730 & \mathrm{p}=.000 \\ \text { TR-CG } & X^{2}=92.705 & \mathrm{p}=.000 \\ \text { SSYU-CG } & X^{2}=28.490 & \mathrm{p}=.000\end{array}$

entail plans to live in the country of their parents for any length of time. SSYU and Turkish descent respondents may envisage this option, but only between 3 and 5 per cent expressed plans in this direction (Table 7.23).

In both groups, women showed significantly less interest in such 'return' migration, while among SSYU descent respondents, the younger cohort expressed greater willingness. Given that this age cohort was interviewed at a stage in their lives when they are looking for an adult place in society, their willingness to relocate is likely to diminish as they grow up. There are no significant differences between agglomerations in respect of this issue.

In conclusion, we argue that the lives of a significant minority of secondgeneration respondents span borders. This means that while they will not 'return' to their parents' countries, they will continue to connect their country of residence with their parents' countries of birth, using modern transport and communication technologies to maintain social relations in both places. Their transnational activities may be less developed than their parents' - an issue often tackled in the literature that we cannot assess on the basis of our survey. However the relevance of such activities among TIES children of immigrants clearly goes beyond the 10 per cent threshold found by Rumbaut in the CILS survey (2002), which pushes the author to dismiss the hypothesis of transnationalism among youth of immigrant descent. In this respect, the European experience may differ somewhat from the American one.

\subsection{Conclusions}

In this chapter we examined various social relations of TIES survey respondents in order to discuss the extent of structural integration (as defined 
Table 7.23 Plans to go and live for at least a year in the parents' country of origin, by origin and age groups and agglomerations

\begin{tabular}{llcccc}
\hline & & \multicolumn{2}{c}{ TR } & \multicolumn{2}{c}{ SSYU } \\
\cline { 3 - 6 } & & $<\mathbf{2 5}$ & $>\mathbf{= 2 5}$ & $<\mathbf{2 5}$ & $>\mathbf{= 2 5}$ \\
\hline \multirow{2}{*}{ Zurich } & Certainly not & 45.8 & 62.5 & 55.5 & 72.6 \\
& Possibly & 35.0 & 21.6 & 22.7 & 10.4 \\
& Likely & 7.5 & 8.0 & 9.4 & 6.6 \\
& Certainly & 4.2 & 2.3 & 2.3 & 4.7 \\
& Do not know & 7.5 & 5.7 & 10.2 & 5.7 \\
& N $=$ & 98 & 90 & 125 & 94 \\
Basel & Certainly not & 64.7 & 60.3 & 70.3 & 79.0 \\
& Possibly & 18.8 & 30.8 & 16.2 & 4.9 \\
& Likely & 4.1 & 2.6 & 4.5 & 7.4 \\
& Certainly & 5.9 & 1.3 & 1.8 & 3.7 \\
& Do not know & 6.5 & 5.1 & 7.2 & 4.9 \\
& N $=$ & 133 & 99 & 107 & 73 \\
\hline TR / SSYU (Zurich) $\quad X^{2}=9.915$ & $\mathrm{p}=.042$ & & & \\
TR / SSYU (Basel) $\quad X^{2}=12.762$ & $\mathrm{p}=.013$ & & & \\
SSYU (age) in ZH $\quad \mathrm{X}^{2}=10.765$ & $\mathrm{p}=.029$ & & &
\end{tabular}

by Gordon) of children of Turkish and SSYU immigrants and inter-ethnic mixing with the majority population in Zurich and Basel.

Second-generation TIES respondents most often lived in two-parent families with a low level of intergenerational conflict in ethnically mixed neighbourhoods and attended schools which, in spite of problems created by early streaming into different educational tracks, still enabled contact between majority population and children of Turkish and SSYU immigrants. They also show high levels of social and civic participation, while a small minority reported being involved in associations that have a direct focus on the country of their parents' birth.

The relatively high diversity of social contacts on the level of secondary group relations (school, neighbourhoods, associations, etc.) is not mirrored in more intimate relations, where most people retain a higher degree of homophily, or desire to associate with people similar to them in terms of ethnicity, class, age, occupation, religion and other social categories. Both second-generation and comparison group respondents report having significantly more inter-ethnic friendships in secondary school than as adults. A similar pattern can be detected for intimate relationships; all three groups report less ethnic homogeneity in non-cohabitating couples than in cohabitations and the highest levels of ethnic homogeneity in marriage. 
Thus, as TIES respondents grow up, their intimate relationships become more ethnically homogeneous, but they frequently engage in less intensive forms of social relationships where ethnicity is not seen as a barrier.

While both second-generation groups mention high levels of hostility and discrimination, we also noted an important discrepancy between personal and group discrimination in the two immigrant origin groups. SSYU immigrant descendants display the typical pattern of stronger perception of group-related discrimination than personal discrimination, while second-generation Turkish respondents display the reverse pattern of stronger perception of personal discrimination than of their group as a whole. Nevertheless, Turkish origin respondents are clearly more prone to expressing demands for free cultural expression in public spaces and for government involvement in promoting immigrants' wellbeing than SSYU origin respondents, who hold similar views to the comparison group.

Lastly, a minority of thise second-generation groups engage in transnational activities, yet to a greater extent than second generations in the US. Nevertheless, only a few respondents entertains the idea of a 'return migration' to the country of their parents' origin. It is very clear that both groups under consideration consider themselves at home in Switzerland, where they have established a wide variety of social relations which they intend to maintain in the future.

\section{References}

Allievi, Stefano (2005), 'How the immigrant has become Muslim: Public debates on Islam in Europe', Revue européenne des migrations internationales 21(2): 135-163.

Aparicio, Rosa (2007), 'The Integration of the Second and 1.5 Generations of Moroccan, Dominican and Peruvian Origin in Madrid and Barcelona', Journal of Ethnic and Migration Studies 33(7): 1169-1193.

Bataille, Philippe (1997), Le racisme au travail. Paris: Editions la découverte.

Blake, Judith (1989), Family size and achievement. Berkeley: University of California Press.

Bolzman, Claudio, Rosita Fibbi \& Marie Vial (2003), 'Secondas - Secondos': Le processus d'intégration des jeunes issus de la migration espagnole et italienne en Suisse. Zurich: Seismo.

Boos-Nünning, Ursula \& Yasemin Karakasoglu (2004), Viele Welten Leben. Lebenslagen von Mädchen und jungen Frauen mit griechischem, italienischem, jugoslawischem, türkischem und Aussiedlerhintergrund. Berlin: Bundesministerium für Familien, Senioren, Frauen und Jugend.

Bovenkerk, Frank (1992), A manual for international comparative research on discrimination on the grounds of 'race' and ethnic origin. Geneva: ILO.

Burri Scharani, Barbara, Denise Efionayi-Mäder, Stephan Hammer, Marco Pecoraro, Bernhard Soland, Astrit Tsaka \& Chantal Wyssmüller (2010), Die Kosovarische Diaspora in der Schweiz. Bern: Bundesamt für Migration. 
Crul, Maurice (2000), 'Breaking the circle of disadvantage. Social mobility of second generation Moroccans and Turks in the Netherlands', in Hans Vermeulen \& Joel Perlman (eds), Immigrants, schooling and social mobility. Does culture make a difference? London: McMillan.

Crul, Maurice \& Helga de Valk (2008), 'Education', in Maurice Crul \& Lisbeth Heering (eds), The position of the Turkish and Moroccan second generation in Amsterdam and Rotterdam. Amsterdam: Amsterdam University Press.

Crul, Maurice \& Hans Vermeulen (2003), 'The second generation in Europe', International Migration Review 37(4): 965-986.

De Rudder, Véronique (1984), 'La cohabitation pluri-ethnique', Espaces et Sociétés 45.

Dion, Kenneth L. \& Kerry Kawakami (1996), 'Ethnicity and perceived discrimination in Toronto: Another look at the personal/group discrimination discrepancy', Canadian Journal of Behavioural Science 28(3): 203-213.

Fibbi, Rosita, Bülent Kaya \& Etienne Piguet (2003), Le passeport ou le diplôme? Etude des discriminations à l'embauche des jeunes issus de la migration. Neuchâtel: Forum suisse pour l'étude des migrations et de la population.

Fibbi, Rosita (2006), 'Discrimination dans l'accès à l'emploi des jeunes d'origine immigrée en Suisse', Formation-emploi 94: 45-58.

Fibbi, Rosita \& Mathias Lerch (2007), Transition à la vie adulte des jeunes issus de la migration: Dynamique intergénérationnelle et outcomes sociaux. Neuchâtel: Swiss Forum for Migration and Population Studies.

Fibbi, Rosita \& Gianni D’Amato (2008), 'Transnationalisme des migrants en Europe: Une preuve par les faits', Revue européenne des migrations internationales 24(2): 7-22.

Glick Schiller, Nina, Linda Basch \& Cristina Szanton Blanc (1992), 'Transnationalism: A new analytic framework for understanding migration', Annals of the New York Academy of Science $645(1-24)$.

Glick Schiller, Nina \& Andreas Wimmer (2002), 'Methodological nationalism and beyond: Nation-state building, migration and the social sciences', Global Networks 2(4): 301-334.

Gordon, Milton M. (1964), Assimilation in American Life. The role of race, religion and national origins. New York: Oxford University Press.

Haab, Katharina, Claudio Bolzman, Andrea Kugler \& Özcan Yılmaz (2010), Die Türkische Diaspora in der Schweiz. Bern: Bundesamt für Migration.

Heitmeyer, Wilhelm, Joachim Müller \& Helmut Schröder (1997), Verlockender Fundamentalismus: Türkische Jugendlichen in Deutschland. Frankfurt: Suhrkamp.

Hochschild, Jennifer \& John Mollenkopf (eds)(2008), Bringing outsiders in. Transatlantic perspectives on immigrant political incorporation. Ithaca: Cornell University Press; New York: Russell Sage.

Huissoud, Thérèse, Suzanne Stofer, Antonio Cunha \& Martin Schuler (2003), 'Structures et tendances de la différenciation dans les espaces urbains en Suisse', in Hans Rudolph Wicker, Rosita Fibbi \& Werner Haug (eds), Les migrations et la Suisse, 175-198. Zurich: Seismo.

Juhasz, Anne \& Eva Mey (2003), "'Desintegration” oder "gelungene Integration" der zweiten Ausländer-generation?' Revue suisse de sociologie 29(1): 115-139.

Kasinitz, Philip, John Mollenkopf \& Mary Waters (eds) (2004). Becoming New Yorkers. New York: Russell Sage.

Kivisto, Peter (2001), 'Theorising transnational immigration: a critical review of current efforts', Ethnic and Racial Studies 24(4):549-577.

Mahnig, Hans, Sandro Cattacin, Mauro Cerutti, Yves Flückiger, Matteo Gianni, Marco Giugni, Jean-Marie Le-Goff, Martin Niederberger, Lorena Parini, Florence Passy \& Etienne Piguet (2005), Histoire de la politique de migration, d'asile et d'intégration en Suisse depuis 1948. Zurich: Seismo. 
McPherson, Miller, Lynn Smith-Lovin \& James M. Cook (2001), 'Birds of a feather: Homophily in social networks', Annual review of sociology 27(1): 415-444.

Mikic, Dejan \& Erika Sommer (2003), 'Als Serbe warst du plötzlich nichts mehr wert': Serben und Serbinnen in der Schweiz. Zurich: Orell Füssli.

Mollenkopf, John (2000), 'Assimilating immigrants in Amsterdam: A perspective from New York', The Netherlands Journal of Social Sciences 26(2): 126-145.

Nauck, Bernhard, Annette Kohlmann \& Heike Diefenbach (1997), 'Familiäre Netzwerke, intergenerative Transmission und Assimilationsprozesse bei türkischen Migrantenfamilien', Kölner Zeitschrift für Soziologie und Sozialpsychologie 49(3): 477-499.

Nauck, Bernhard \& Barbara H. Settles (2001), 'Immigrant and ethnic minority families: An introduction', Journal of Comparative Family Studies 32(4): 461-463.

Portes, Alejandro (1997), 'Globalization from below: The rise of transnational communities', in Don Kalb, Marco van der Land, Richard Staring, Bart van Steenbergen \& Nico Wilderding (eds), The ends of globalization. Bringing society back in, 253-271. Lanham: Rowman \& Littlefield.

Portes, Alejandro (1999), 'Conclusion: Towards a new world - the origin and effects of transnational activities', Ethnic and Racial Studies 22(2): 463-477.

Portes, Alejandro (2000), 'The two meanings of social capital', Sociological Forum 15(1): 1-12.

Portes, Alejandro \& Josef Böröcz (1989), 'Contemporary immigration: Theoretical perspectives on its determinants and modes of incorporation', International Migration Review 23(3): 6o6-63o.

Portes, Alejandro \& Rubén Rumbaut (eds)(2001), Legacies: The story of the mmigrant second generation. Los Angeles \& New York: University of California Press.

Portes, Alejandro \& Min Zhou (1993), 'The new second generation: Segmented assimilation and its variants', The Annals of the American Academy of Political and Social Science 530: 74-96.

Pyke, Karen (2004), 'Immigrant families in the US', in Jacqueline Scott, Judith Treas \& Martin Richards (eds), The Blackwell Companion to the Sociology of Family, 253-269. Oxford: Blackwell.

Raymann, Ursula (2003), Meinungen und Einstellungen gegenüber Ausländerinnen and Ausländern in der Schweiz. Zürich.

Reitz, Jeffrey (1998), Warmth of the welcome. The social causes of economic success for immigrants in different nations and cities. Boulder: Westview Press.

Rumbaut, Rubén G. (2002), 'Severed or sustained attachments? Language, identity and imagined communities in the post-immigrant generation', in Peggy Levitt \& Mary Waters (eds), The changing face of home, 43-95. New York: Russell Sage.

Sibley, David (1995), Geographies of exclusion. London: Routledge.

Simon, Patrick (2000), Les discriminations ethniques dans la sociétéfrançaise. Paris: Institut des hautes études de la sécurité intérieure.

Simon, Patrick (2003), 'France and the unknown second generation: Preliminary results on social mobility', International Migration Review 37(4): 1091-1119.

Simon, Patrick (2008), “'Race”, ethnie et statistiques en France', Revue française de Sociologie 49(1): 153-168.

Skrobanek, Jan (2009), 'Perceived discrimination, ethnic identity and the (re-) ethnicisation of youth with a Turkish ethnic background in Germany', Journal of Ethnic and Migration Studies 35(4): 535-554.

Stepick, Alex \& Carol Stepick-Dutton (2003), 'Becoming American: Immigration, identity, intergenerational relations, and academic orientation', in Nancy Foner (ed.), American arrivals: Anthropology engages the new immigration, 129-162. Santa Fe: School of American Research Press.

Stepick, Alex \& Carol Dutton Stepick (2009), 'Diverse contexts of reception and feelings of belonging', Forum: Qualitative Social Research, 10(3). 
Taylor, Donald.M. Stephen C. Wright, Fathali M. Moghaddam \& Richard N. Lalonde (1990), 'The personal/group discrepancy: Perceiving my group, but not myself, to be a target of discrimination', Personality and Social Psychology Bulletin 16(2): 254-262.

Tribalat, Michèle (1995), Faire France. Une enquête sur les immigrés et leurs enfants. Paris: La Découverte/Essai.

Wessendorf, Susanne (2007), 'Sushi-eating secondos and casual Latins. Political movements and the emergence of Latino counter-culture among second generation Italians in Switzerland', Journal of Intercultural Studies 28(3): 345-360.

Wimmer, Andreas (2003), 'Etablierte Ausländer und einheimische Aussenseiter', in Hans Rudolph Wicker, Rosita Fibbi and Werner Haug (eds), Migration und die Schweiz. Zurich:Seismo.

Wimmer, Andreas (2004), 'Does ethnicity matter? Everyday group formation in three Swiss immigrant neighborhoods', Ethnic and Racial Studies 27(1): 1-36.

Wyssmüller, Chantal (2005), 'Menschen “aus dem Balkan” in Schweizer Printmedien'. Philosophisch-Naturwissenschaftliche Fakultät. Bern, Universität Bern. Liz.: 140.

Yancey, George (2002), 'Who dates interracially? An examination of the characteristics of those who have dated interracially', Journal of Comparative Family Studies 33(2): 179-190.

Zhou, Min \& Carl L. Bankston III (1994), 'Social capital and the adaptation of the second generation: The case of Vietnamese youth in New Orleans', International Migration Review 28(4): 821-845.

Zolberg, Aristide \& Litt Woon Long (1999), 'Why Islam is like Spanish: Cultural incorporation in Europe and the United States', Politics and Society 27: 5-38. 


\section{Union and family formation of the second generation}

Union formation and marriage are not only important steps in the transition to adulthood, but also social institutions aiming at establishing alliances and ensuring group reproduction. It is therefore an established field of research in migration studies as an indicator of cultural change and possible convergence between groups of immigrant origin and the autochthonous population. Partner choice, specifically intermarriage, has been the traditional focus of migration research in this field as it signals a lessening of 'social distance' between a minority group and the majority (Alba \& Nee 2003; Song 2009). The partner choice of youth with a migrant background reflects opportunities within society (determined by group size, sex ratio, composition of friendship circles, spatial segregation and social distance) and the influence of third parties, whether through socialisation or control of behaviour by sanction.

However, the topic of union formation is broader than intermarriage, as it touches upon differentiation of gender roles, sequencing life trajectories and living arrangements, as well as intergenerational relations. This broader perspective guides our preliminary exploration of the TIES survey.

This chapter deals with three main topics: the experience of union formation, analysis of partner choice behaviour with respect to ethnic, religious and social homogamy and finally, family life in terms of living arrangements and parenthood.

\subsection{Union formation experience}

In this subsection we first analyse whether respondents are in a couple and if this union is marriage or cohabitation; we then discuss the conditions surrounding this union in terms of timing and relative influence of the family.

\subsubsection{Types of current relation}

The first topic that will be addressed concerns the type of current relations the respondents have established: are they single or do they live with a spouse or unmarried partner? In order to have a general idea about union 
formation, percent age distributions are given according to origin groups, gender and agglomerations in the tables below. Three states are examined here: singlehood, cohabitation and marriage. We seek an answer to questions like: what is the union formation behaviour of children of immigrants and the comparison group? Is it different among origin groups? Is it different for men and women?

Table 8.1 Type of current relation, by origin group, gender and agglomeration

\begin{tabular}{|c|c|c|c|c|c|c|c|c|c|}
\hline & \multicolumn{3}{|c|}{ TR } & \multicolumn{3}{|c|}{ SSYU } & \multicolumn{3}{|c|}{ CG } \\
\hline & M & w & Total & M & w & Total & M & w & Total \\
\hline $\begin{array}{l}\text { Single, both in } \\
\text { own and in paren- } \\
\text { tal households }\end{array}$ & 74.7 & 73.3 & 74.2 & 68.4 & 60.8 & 64.6 & 64.6 & 62.6 & 63.5 \\
\hline $\begin{array}{l}\text { Cohabiting with } \\
\text { partner }\end{array}$ & 4.8 & 3.2 & 4.0 & 11.2 & 7.4 & 9.3 & 18.3 & 15.9 & 17.3 \\
\hline Married & 20.5 & 23.5 & 21.8 & 20.5 & 31.8 & 26.2 & 17.1 & 21.6 & 19.2 \\
\hline $\mathrm{N}=$ & 229 & 220 & 449 & 214 & 217 & 431 & 240 & 228 & 468 \\
\hline TR-CG & $x^{2}=$ & 11.957 & $\mathrm{p}=.000$ & & & & & & \\
\hline SSYU-CG & $x^{2}=$ & 5.631 & $p=.000$ & & & & & & \\
\hline TR-SSYU & $x^{2}=$ & 3.853 & $\mathrm{p}=.001$ & & & & & & \\
\hline SSYU (Men vs. Women) & $x^{2}=$ & .928 & $\mathrm{p}=.019$ & & & & & & \\
\hline
\end{tabular}

Due to the relative youth of our sample, a large majority of TIES respondents are single, particularly in the Turkish origin group. Some 25 to 35 per cent of respondents in all origin groups live in a union (marriage and cohabitation, see Table 8.1). Between 20 and 25 per cent of respondents across origin groups are married. The main group difference emerges in terms of cohabitation: it is very rare among second-generation Turkish respondents, more common among respondents from the Successor States of Yugoslavia (SSYU) and as frequent as marriage in the comparison group.

Men and women have similar behaviours in all groups, but the SSYU group is distinguished by the fact that men are more likely to be single or cohabiting, whereas significantly more SSYU women are married.

Age appears to influence the pattern of union formation. Among under 25 only 10 per cent of respondents are already cohabiting, regardless of origin group. In this age category marriage appears to be more frequent in immigrant origin groups than in the comparison group.

Age structures of respondents in the various origin groups are quite different, with a high concentration of children of immigrants, especially 
Turkish youth, in the younger age category. In order to account for this age effect, analyses of marriage/cohabitation will only be carried out on the answers of respondents aged 25 and older.

Table 8.2 Type of union, by origin group and age category

\begin{tabular}{|c|c|c|c|c|c|c|c|c|}
\hline & & \multicolumn{2}{|r|}{ TR } & & \multicolumn{2}{|c|}{ SSYU } & \multicolumn{2}{|c|}{ CG } \\
\hline & & $<25$ & $>=25$ & & $<25$ & $>=25$ & $<25$ & $>=25$ \\
\hline \multicolumn{2}{|c|}{$\begin{array}{l}\text { Single, both in own and } \\
\text { in parental households }\end{array}$} & 90.4 & 51.3 & & 88.9 & 38.2 & 91.8 & 45.1 \\
\hline \multicolumn{2}{|l|}{$\begin{array}{l}\text { Cohabiting with } \\
\text { partner }\end{array}$} & 1.5 & 7.4 & & 2.7 & 16.2 & 5.4 & 25.0 \\
\hline \multicolumn{2}{|l|}{ Married } & 8.0 & 41.3 & & 8.4 & 45.6 & 2.7 & 29.9 \\
\hline \multicolumn{2}{|l|}{$\mathrm{N}=$} & 248 & 201 & & 256 & 175 & 168 & 300 \\
\hline $\operatorname{TR}(<25$ vs. $>=25)$ & $X^{2}=$ & 7.105 & $\mathrm{p}=.000$ & & & & & \\
\hline SSYU (<25 vs. >=25) & $X^{2}=$ & 20.385 & $\mathrm{p}=.000$ & & & & & \\
\hline CG (<25 vs. $>=25)$ & $X^{2}=$ & 06.190 & $\mathrm{p}=.000$ & & & & & \\
\hline TR-CG $(<25)$ & $X^{2}=$ & 0.492 & $\mathrm{p}=.005$ & $(>=25)$ & & 24.712 & $\mathrm{p}=.000$ & \\
\hline SSYU-CG $(<25)$ & $X^{2}=$ & & $\mathrm{p}=.021$ & $(>=25)$ & & 3.632 & $\mathrm{p}=.001$ & \\
\hline TR-SSYU $(<25)$ & n.s. & & & $(>=25)$ & & 0.502 & $\mathrm{p}=.005$ & \\
\hline
\end{tabular}

Half of the respondents aged 25 and over (Table 8.2) are currently in a union (around 50 per cent of Turkish youth and the comparison group and 6o per cent of second-generation SSYU respondents). For children of immigrants, marriage is the main type of union, while marriage and cohabitation are almost equally frequent in the comparison group. Hence union formation behaviour differs significantly by origin.

It is worthwhile to further query to what extent these 'ethnic' differences are related to educational attainment. We analyse whether level of educational attainment influences union formation behaviour and then investigate the connection between education and ethnic origin.

Studying different female cohorts in the Netherlands, Manting (1996) states that the probability of marriage is much lower for highly educated women: ' $[\mathrm{H}]$ igher level of education hampers entry into marriage, but it stimulates entry into cohabitation.' In our case, however, the relationship between level of education and probability of marriage is not statistically significant, although it points in the same direction; due to the small sample size, we cannot conclude that degree of cohabitation varies according to education in immigrant groups, though it appears to do so in the comparison group.

It was further tested whether educational attainment had a similar impact on union formation for men and women in the various origin groups. 
However, the results do not reveal a clear association between educational attainment and type of union either for men or women. Cohabitation increases with education level for comparison group men, but differences by education level are not statistically significant for these men.

So far we have focused on the current type of union and living arrangement by asking whether origin group, gender and respondents' education level determine behaviour. For children of immigrants, marriage is the most common form of union, while cohabitation appears more unusual; marriage and cohabitation are almost equally preferred by the comparison group.

We will now concentrate on marriage, the primary type of union for the second generation. We will compare indicators for married respondents with those in cohabitation when possible.

\subsubsection{Age at first marriage}

Age at first marriage is a well-accepted socio-demographic indicator which sheds light on the culture of marriage. It is used as a proxy determinant of fertility, especially for countries like Turkey where almost all births occur within marriage (Hancığlu 1997). First marriage is still an important life-cycle transition for many young people, especially in traditional communities; understanding its timing is therefore crucial. In the last few decades, marriage age was significantly postponed in Switzerland as in other European countries, but according to the 2000 Census, differences are expected between Swiss and foreign communities, among whom ages at first marriage are strongly correlated to imported norms (Wanner et al. 2005). Therefore we will investigate the frequency of marriages concluded before the age of 25 (early marriages) and the age at first marriage: does the timing of marriage differ by origin group, gender and agglomeration?

Table 8.3 Percentage of respondents married before age 25, by origin group, gender and agglomeration (selecting 25 and over)

\begin{tabular}{lccclccc}
\hline & TR & SSYU & CG & & TR & SSYU & CG \\
\hline Men & 71.8 & 51.3 & 10.8 & Zurich & 58.1 & 66.1 & 24.3 \\
Women & 74.4 & 75.5 & 25.6 & Basel & 82.6 & 63.9 & 14.3 \\
Total & 73.1 & 65.2 & 19 & Total & 73.1 & 65.2 & 19 \\
\hline $\mathrm{N}=$ & 86 & 77 & 87 & $\mathrm{~N}=$ & 86 & 77 & 87 \\
\hline TR-CG & & & $\mathrm{X}^{2}=50.131$ & $\mathrm{p}=.000$ & & & \\
SSYU-CG & & & $\mathrm{X}^{2}=43.843$ & $\mathrm{p}=.000$ & & & \\
SSYU & (Men vs. Women) & $\mathrm{X}^{2}=11.925$ & $\mathrm{p}=.008$ & & &
\end{tabular}


For respondents in the older age category, early marriage (i.e. before age 25) affects at least two thirds of youth with a migrant background as against two out of ten comparison group members (Table 8.3).

Early marriage behaviour also varies significantly with gender. A significantly higher percentage of women of SSYU origin married before age 25 (Table 3) than men. By contrast, among youth of Turkish origin, early marriage is surprisingly just as frequent for men as for women. Among comparison group members, marriage is frequently delayed by both men and women.

Table 8.4 Mean age at first marriage, by origin group and gender (of those who have never married or lived with another before current spouse, age 25 and over)

\begin{tabular}{lrrrlrrr}
\hline & TR & SSYU & CG & & TR & SSYU & CG \\
\hline Men & 23 & 24.6 & 28.5 & Zurich & 22.9 & 23.4 & 27.7 \\
Women & 22.3 & 22.1 & 26.9 & Basel & 22.5 & 22.8 & 27.6 \\
Total & 22.6 & 23.1 & 27.7 & Total & 22.6 & 23.1 & 27.7 \\
St. dev. & 2.9 & 3.6 & 3.6 & & 2.9 & 3.6 & 3.6 \\
\hline $\mathrm{N}=$ & 83 & 73 & 79 & $\mathrm{~N}=$ & 83 & 73 & 79 \\
\hline
\end{tabular}

$\begin{array}{lcc}\text { TR-CG } & \text { mean age at first marriage } & \mathrm{p}=.000 \\ \text { SSYU-CG } & \text { mean age at first marriage } & \mathrm{p}=.000 \\ \text { SSYU (Men vs. Women) } & \text { mean age at first marriage } & \mathrm{p}=.001 \\ \text { CG (Men vs. Women) } & \text { mean age at first marriage } & \mathrm{p}=.059 \\ \text { Other mean differences are not statistically significant. } & \end{array}$

Accordingly, mean age at first marriage of men is systematically higher (22.5 years) than women's mean age (Table 4) in SSYU and comparison groups, whereas among Turks, 73 per cent of both men and women appear to be married in the lower age category, on average at the age of 22.6. Altogether, the mean age at first marriage is much lower in migrant origin groups than in the comparison group (around 23 years vs. 27.7 years).

Which factors could account for differences in timing of marriage? Studying the transition of high school students to adulthood in the US, Marini (1978) finds that educational attainment is the most important factor influencing timing of marriage; the impact is stronger for women than men. Likewise, analysing how resources affect the probability of marriage among young men and women in the US, Goldscheider and Waite (1986) observe that education influences primarily the timing of marriage by postponing it until after schooling is completed. In our exploration of factors influencing 
timing of marriage of the second generation, we analyse the impact not only of respondent's education, in line with the authors cited above, but also of the partner's nationality.

According to TIES results, partner's nationality does not influence the proportion of early marriages. However, it does influence the timing of marriage for youth of Turkish origin: those with a Swiss partner of Turkish origin tend to marry significantly earlier (22.3 years on average) than those married to a spouse of Swiss origin (22.8 years) or other nationality (26.5 years). Likewise, education level affects the timing of marriage for the Turkish second generation: age at marriage increases from 21.6 years to 26.4 years as achieved education level moves from compulsory school to tertiary education (Table 8.5). Neither the proportion of early marriages nor the timing of marriage significantly changes with education for SSYU youth and the comparison group. The limited number of observations prevents gender analysis.

Table 8.5 Percentage of respondents married before age 25 according to highest achieved education level, by origin group (selecting 25 and over)

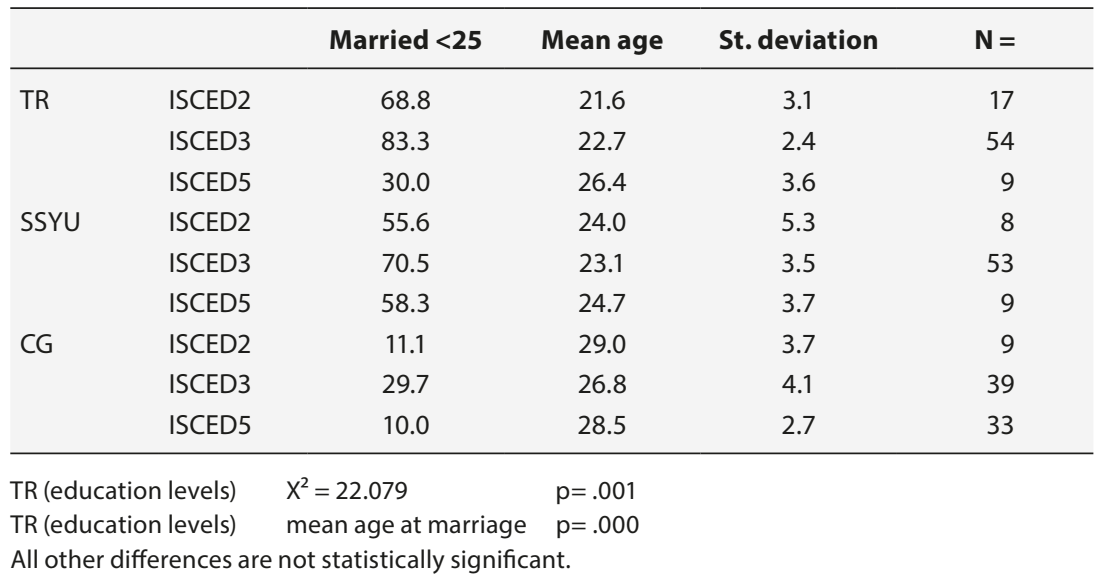

It is interesting to note variations in age at entering a union according to type of living arrangement. Two distinct patterns emerge: among secondgeneration men and women, age at cohabitation is higher than at first marriage. Among comparison group youth, on the contrary, age at cohabitation is lower than age at marriage. We may hypothesise that the reason behind it lies in the different implications of cohabitation for immigrant origin youth and comparison group: the former enter a type of union which is not common in their social group and may encounter resistance from 
family and others. They may enter this type of union at an older age as a conscious or unconscious strategy to 'wait out' parental objections to this type of living arrangement (Kasinitz et al. 2008). For comparison group youth, on the contrary, this living arrangement is largely socially accepted and appears more as a form of premarital cohabitation. Overall, mean age at cohabitation is similar across origin groups.

Table 8.6 Mean age at first marriage and mean age at cohabitation, by origin group and gender (selecting 25 and over)

\begin{tabular}{|c|c|c|c|c|c|c|c|c|c|}
\hline & \multicolumn{3}{|c|}{ TR } & \multicolumn{3}{|c|}{ SSYU } & \multicolumn{3}{|c|}{ CG } \\
\hline & Men & Women & Total & Men & Women & Total & Men & Women & Total \\
\hline $\begin{array}{l}\text { Mean age at } \\
\text { first marriage }\end{array}$ & 23.0 & 22.3 & 22.6 & 24.6 & 22.1 & 23.1 & 28.5 & 26.9 & 27.7 \\
\hline $\begin{array}{l}\text { Standard } \\
\text { deviation }\end{array}$ & 3.1 & 2.8 & 2.9 & 3.2 & 3.5 & 3.6 & 3.4 & 3.6 & 3.6 \\
\hline $\mathrm{N}=$ & 39 & 44 & 83 & 28 & 45 & 73 & 38 & 41 & 79 \\
\hline $\begin{array}{l}\text { Mean age at } \\
\text { cohabitation }\end{array}$ & 24.9 & 25.9 & 25.4 & 27.7 & 25.3 & 26.7 & 26.9 & 25.9 & 26.5 \\
\hline $\begin{array}{l}\text { Standard } \\
\text { deviation }\end{array}$ & 3.1 & 5.9 & 4.5 & 3.9 & 4 & 4.1 & 3.8 & 3.3 & 3.6 \\
\hline$N=$ & 8 & 9 & 17 & 15 & 14 & 29 & 42 & 34 & 76 \\
\hline $\begin{array}{ll}\text { TR-CG } & \\
\text { SSYU-CG } \\
\text { SSYU (Men v }\end{array}$ & s. Wom & $\begin{array}{r}\text { mea } \\
\text { mea } \\
\text { en) } \quad \text { mea }\end{array}$ & $\begin{array}{l}n \text { age at } \\
n \text { age at }\end{array}$ & $\begin{array}{l}\text { irst ma } \\
\text { irst ma } \\
\text { irst ma }\end{array}$ & $\begin{array}{l}\text { iage } \\
\text { iage } \\
\text { iage }\end{array}$ & $\begin{array}{l}=.000 \\
=.000 \\
=.001\end{array}$ & & & \\
\hline
\end{tabular}

So far, the TIES survey has documented that the percentage of early marriages, before age 25 , is significantly higher among the second generation than in the comparison group; accordingly, age at first marriage is lower. The gender age gap at first marriage is higher for the comparison group and SSYU couples but very limited for Turkish origin respondents (Table 8.6).

We have so far studied types of living arrangement with a partner and timing of marriage; let us now approach the question of the conditions which govern spouses' encounters.

\subsubsection{Marriage market and family influence}

Families have nearly always played a decisive role in the marriage projects of their children, even more so when those unions involved family interests and capital (Bourdieu 1980). Even if in modern societies this influence has 
progressively waned, partner choice is still framed by social, economic and religious determinants. It is heuristically useful to compare collectivist and individualist societies: in the former, in-group needs and interests are valued and relatedness within the family and the community are emphasised; in the latter, priority is given to personal desires over social obligation and individuals are viewed as separate from family and community (Kağıtç̧ıaşı 1997). While in collectivist societies unions are conceived as deeply rooted in the fabric of family social relations, in individualistic societies partner choice tends to be conceived as the outcome of individual choice, suggesting a decrease in family influence.

What is the importance of family influence in the marriage choices of second-generation youth born, socialised and living in Switzerland? Does it contrast with the marriage choices of the comparison group? One way of addressing this issue is to examine the role of the family in shaping occasions of encounter and framing the marriage market for their children. We refer to the marriage market in its double meaning: on the one hand, it is - like any other market - the place where the various forms of capital of the social actors are negotiated, exchanged and made profitable for the individual and the group (Desrosières 1978) and on the other hand, in its more restrictive sense, it 'consists of all potential marriage partners at any point in time' (Hirshman \& Matras 1971).

The TIES survey addressed this issue by asking respondents to describe the circumstances of the first meeting with their future spouse. The majority of respondents, whatever their background, found their partner on social occasions where they were active on an individual basis, although this share varies from 54 per cent among second-generation Turkish respondents to 75 per cent among SSYU origin youth and reaches 87 per cent for the comparison group. Accordingly, the role of family is quite different among origin groups: Turkish youth more often met their partner through family (41 per cent) than SSYU youth (19 per cent) whereas family influence is very limited for the comparison group (4 per cent) (Table 8.7). Parents never introduced SSYU second-generation respondents to their partners whereas this was the case for 3 per cent of Turkish origin respondents. Meeting during holidays in the parents' home country also appears to be a feature characterising the Turkish origin group: one fifth as against one out of ten SSYU youth. These findings confirm Straßburger's (2004) view that 'old transnational ties with the country of origin based on kinship are increasingly complemented by "new" transnational ties of friendships that start during summer vacations or on similar occasions.' 
Table 8.7 Circumstances of first meeting with the partner/spouse, by origin group, age and gender (married and unmarried couples)

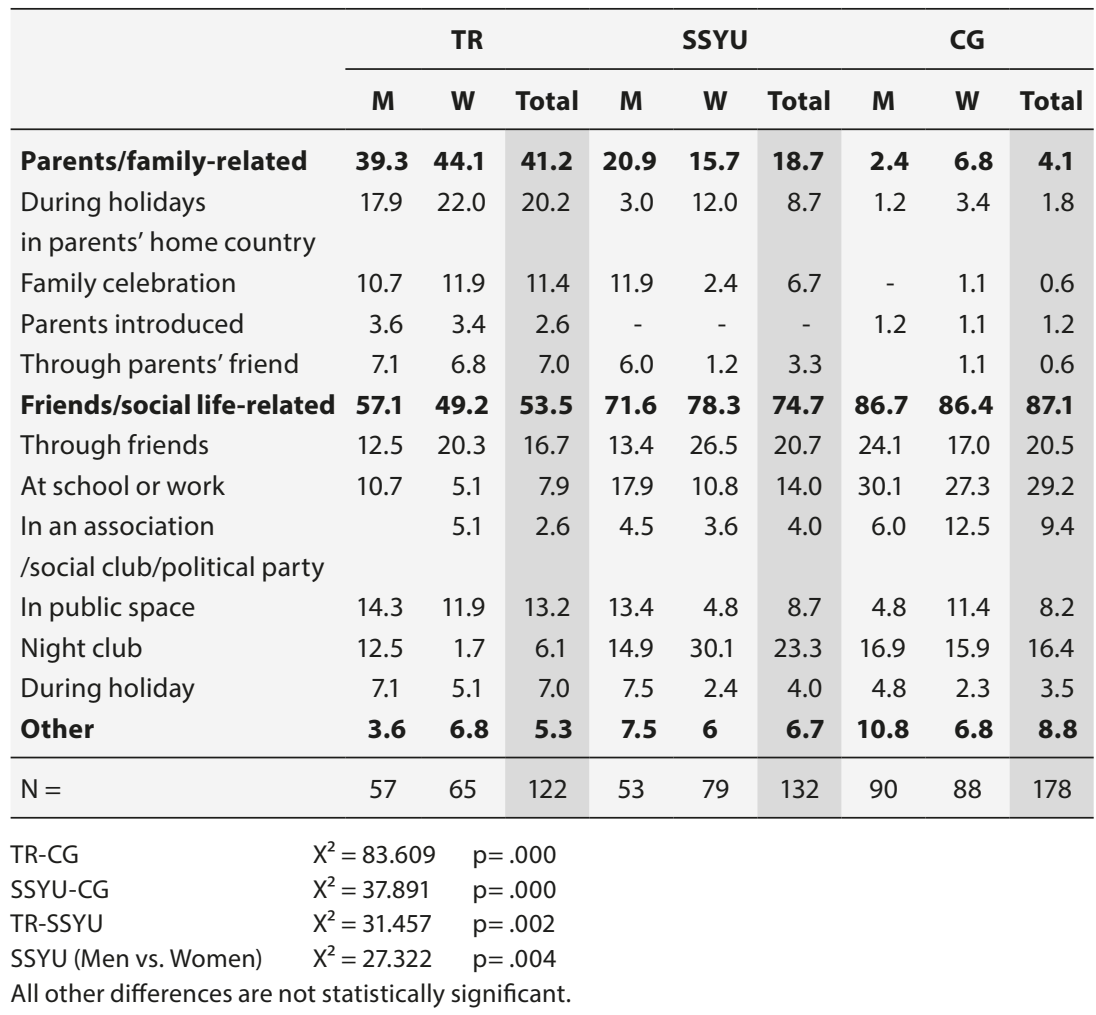

The family role in framing encounters affects men and women of Turkish origin to a similar extent. SSYU men, however, rely significantly more than women on family networks: a majority of women found their partners through social life related events ( 78 per cent) and especially through friends and in night clubs (57 per cent). More than 9o per cent of comparison group men and women met their partners on social occasions and through their friends. There are no statistically significant differences in the way encounters take place between the two agglomerations, whatever the background of the respondents.

Family influence on union formation can go beyond the framing of encounters and take the form of advice and pressure on the marriage or dating behaviour of young people. How strongly or frequently do families take a stand on the marriage or dating choices of their children? Table 8.8 portrays family pressure as perceived by the respondents both in the sense of supporting or opposing the proposed partner selection. 
Table 8.8 Families encouraged/opposed to marriage, by origin group and gender (married couples)

\begin{tabular}{lcccccc}
\hline & \multicolumn{3}{c}{ TR } & \multicolumn{3}{c}{ SSYU } \\
\cline { 2 - 7 } & M & W & Total & M & W & Total \\
\hline Encouraged & 2.3 & 6.1 & 4.3 & 0.0 & 4.3 & 2.7 \\
Discouraged & 4.5 & 12.5 & 9.7 & 0.0 & 16.4 & 10.0 \\
Total & 6.8 & 18.6 & 14.0 & 0.0 & 20.7 & 12.7 \\
$\mathrm{~N}=$ & 45 & 54 & 99 & 34 & 63 & 97 \\
\hline
\end{tabular}

SSYU (Men vs. Women) families opposed $X^{2}=7.844 \quad p=.005$

All other differences are not statistically significant.

Whereas comparison group respondents report no interference from family in this respect, second-generation youth are confronted with some pressure. This almost exclusively affects women (19 per cent and 21 per cent respectively for Turkish and SSYU origin women), in supporting or discouraging union. It would be a mistake to make family influence on marriage primarily a religious matter: if all Turkish origin women have a Muslim background, only two of the SSYU women who experienced family pressure share the same Muslim background. This means that interpretations of family influence must rely more on a traditional understanding of parents' relations with children than on mere religious background. Let us underscore that those women who were discouraged are now married to the spouse that was initially opposed by the family; thus the daughter's choice triggered a negotiation within the family.

It is true, however, that the marriage behaviour of women is under stricter collective control among Muslims, since women's religious out-marriage is in principle disapproved of; moreover, there is a traditional preference for consanguineous marriages. Koç (2008) reports that

especially in Muslim populations throughout the North of Africa, Middle East, South and Central Asia, a significant proportion of marriages takes place between close biological relatives. Turkey, as a Muslim society, is not an exception. Despite marked urbanisation and modernisation, demographic surveys consistently show that the prevalence of consanguineous marriages in Turkey remains high, with a decreasing trend from 27 to 22 per cent (of all marriages) during the last four decades. Traditionally in Turkey, most consanguineous unions are first cousin unions. Where a potential first cousin partner is not available and/or not suitable, unions with a second or more distant cousin become preferential (TDHS-2003) 
Courbage and Todd (2007) point out that the marriage endogamy rule - entailing preference to a parallel patrilineal spouse - in Muslim Arab countries applies in roughly 25 to 40 per cent of marriages. This preference, however, is not a Koranic prescription; as such it does not find universal application in Muslim countries. In particular it is not practised in countries like Bosnia, Albania and Kosovo, at the periphery of the Muslim world.

To what extent is the marriage market effectively restricted to consanguineous partners for second-generation youth? Does this restriction differ by gender, age category or agglomeration? According to TIES results, only the Turkish second generation is involved in consanguineous marriages (Table 8.9), a prevalence lower than that in Turkey (15 per cent vs. 22 per cent). Surprisingly, consanguineous marriages are more frequent among younger than older respondents. However, the former are involved in unions with 'other relatives' while for those in older age category, consanguineous unions are almost exclusively with cousins.

Table 8.9 Kinship with the partner, by origin group, gender, age and agglomerations (living with a spouse or a partner)

\begin{tabular}{|c|c|c|c|c|c|c|c|}
\hline & \multicolumn{7}{|c|}{ TR } \\
\hline & Total & M & w & $<25$ & $>=25$ & Zurich & Basel \\
\hline No kinship & 85.1 & 84.4 & 85.7 & 78.9 & 86.7 & 85.0 & 85.5 \\
\hline Cousins & 10.6 & 11.1 & 10.2 & 5.3 & 12.0 & 7.5 & 12.7 \\
\hline Other relatives & 4.3 & 4.4 & 4.1 & 15.8 & 1.3 & 7.5 & 1.8 \\
\hline$N=$ & 102 & 46 & 56 & 19 & 83 & 38 & 64 \\
\hline
\end{tabular}

TR (<25 vs. $>=25) \quad X^{2}=8.198 \quad \mathrm{p}=.017$

All other differences are not statistically significant.

Does it make a difference whether the partner is a cousin or only another relative? As a matter of fact, the latter can be interpreted as less traditional to a certain extent. This is a conclusion that can be drawn from the factors suggested by Koç (2008) for explaining the steady decline of first cousin marriages from one marriage cohort to the next and the increase in second cousin unions in Turkey. He enumerates factors such as the increase in the educational level of women, the nuclearisation of the family system, rural to urban mobility, improved family socio-economic status, an increase in women's labour force participation in formal sectors, lower fertility rates resulting in fewer cousins available for marriage, as well as an increased awareness of the effects of consanguineous unions on child health in cases 
where there is an inherited recessive disease in the family. Consanguineous marriages are as frequent in Zurich as in Basel, with a statistically nonsignificant preference for cousins as partners in Basel.

Our analysis of union formation showed that children of immigrants display distinctive family behaviours in various respects. They enter marriage more often and earlier than the comparison group; conversely, cohabitation of unmarried partners is rare, whereas marriage and cohabitation are found with almost equal frequency in the comparison group. Family influences the decisions of children of immigrants in this area, generally in the indirect form of framing encounter occasions; one woman in five, however, is exposed to direct interference in her choice, in both Turkish and SSYU second generation groups. Consanguineous marriages are found only among Turkish origin respondents and are more frequent in the younger age group.

\subsection{Partner choice}

Generally, educational and social homogamy tend to prevail in partner choice (Girard 1964): therefore the spouse is often chosen out of a socially similar milieu, thus avoiding spousal mismatch (mésalliances) and insuring stability to the couple. Strategies to achieve this goal may sometimes entail selecting a spouse residing far away (Saraceno \& Naldini 2001); in other words, homogamy is not synonymous with endogamy - the obligation to marry in the same community. Homogamy can be regarded not only as a social norm but as the consequence of the fact that sociability is socially framed (Bozon \& Héran 2006).

In the sociology of migration, the issue of partner choice has been traditionally reframed as a question of endogamy vs. exogamy, leaving the distinctive social parameter of homogamy somewhat out of focus. In his seminal work, Gordon puts what he calls 'structural assimilation' (largescale entrance into cliques, clubs and institutions of the host society on primary group level) at the centre of the assimilation process, as it signals lessening of social distance; he consequently attributes a key role to 'amalgamation', or 'marital assimilation' (Gordon 1964). In this view, intermarriage is the litmus test of integration (Alba \& Nee 2003).

Kalmijn (1998) highlights the tendency to choose a partner who is socially or culturally similar. There are several aspects of social/cultural similarity to homogamy. We will investigate here nationality, ethnicity (since 
the definition of groups in the TIES sample is based on descent and not on actual nationality), religion and education as possible characteristics that the second generation looks for in a partner. This may result in mixed marriages/unions or homogamy/endogamy. Intermarriage is considered to be an indicator for the degree of social and cultural distance between immigrant and indigenous groups. 'The extent to which different groups attend the same schools, live in the same neighbourhood, work in the same places, go to the same clubs, bars or worship together strongly influences the propensity to intermarry' (Kalmijn 1998).

We will analyse both endogamy and homogamy and investigate three aspects of partner choice: ethnic, religious endogamy and social homogamy in both marriage and cohabitation. We will focus our analysis on marriage, however, because of the legal implications therein, namely the right entrenched in marriage to allow acquisition of a residence permit and consequent marriage migration.

\subsubsection{Ethnic endogamy}

The theme of ethnic endogamy vs. exogamy is vast. The issue of a spouse's nationality gains prominence where migration is conceptualised on a national versus non-national basis. Within this framework the notion of 'mixed' unions or intermarriage becomes important. Our analysis also considers family background, i.e., ethnicity, defined as descent from foreign parents born abroad (Tribalat 1995).

Analysis of endogamous marriages includes an investigation of the conditions of socialisation of the spouse; we look at the length of the acculturation process of the spouse in terms of generational successions and examine the relative importance of marriage migration among firstgeneration spouses.

\subsubsection{Ethnic endogamy: Nationality and ethnicity of spouse}

The first question studied is the pattern of ethnic endogamy at marriage: is it similar for the two origin groups? Does it differ for men and women? We define endogamy on the basis of nationality and ethnic origin.

The 2000 Swiss Census shows great variability according to national origin of spouse, but there appears to be a prevalence of endogamous marriages according to an in-depth study of the 2000 Census in relation to nationality of partners of Swiss-born foreign men. Exogamous marriages account for less than 40 per cent when they involve a Swiss partner and 14 per cent with spouses of other nationalities; endogamous marriages account for 
less than $5^{\circ}$ per cent. Exogamous marriages are especially frequent in older immigration groups (Italians 43 per cent; Spaniards 38 per cent). Among more recent flows - Portugal, Turkey or the former Yugoslavia - some 9o per cent of marriages are endogamous (Wanner et al. 2005).

Table 8.10 Nationalities of spouse of married respondents, by origin group and gender (married couples)

\begin{tabular}{lrrrrrrrrr}
\hline & \multicolumn{3}{c}{ TR } & \multicolumn{3}{c}{ SSYU } & \multicolumn{3}{c}{ CG } \\
\cline { 2 - 9 } & M & W & Total & M & W & Total & M & W & Total \\
\hline Swiss & 6.5 & 3.9 & 5.2 & 11.4 & 23.1 & 18.8 & 67.5 & 85.7 & 77.8 \\
Turkish & 54.3 & 72.5 & 63.9 & & & & & & \\
Turkish/Swiss & 26.1 & 17.6 & 21.6 & & & & & & \\
SSYU & & & & 52.3 & 46.4 & 49.1 & 2.5 & & 1.1 \\
SSYU/Swiss & & & & 27.3 & 29.0 & 27.7 & & & \\
Other & 13 & 5.9 & 9.3 & 9.1 & 1.4 & 4.5 & 30 & 14.3 & 21.1 \\
\hline N = & 47 & 57 & 104 & 35 & 64 & 99 & 45 & 50 & 95 \\
\hline
\end{tabular}

TR-CG $\quad X^{2}=144.074 \quad p=.000$

SSYU-CG $\quad X^{2}=116.973 \quad p=.000$

TR-SSYU $\quad X^{2}=180.161 \quad p=.000$

All other differences are not statistically significant.

Nationality background of spouses of TIES survey respondents is reported in Table 8.10. As in the Census, for the groups under scrutiny ethnic endogamy is the dominant pattern in the spouse selection of TIES respondents, although the proportion of same-background couples is lower than in the Census. At least three quarters of respondents in all origin groups have partners of the same ethnic background, but this trend is more pronounced among Turkish youth (86 per cent) than second-generation SSYU respondents (77 per cent) and the comparison group ( 78 per cent). The proportion of endogamy in the comparison group is, however, difficult to compare with the groups under study, as the probability of marrying a Swiss partner when living in Switzerland is higher than the probability of marrying a Turkish one, for instance.

Women's tendency to marry a same-origin spouse is higher than men for second-generation Turkish respondents and the comparison group, yet the gender difference is not statistically significant. Endogamy observed among second-generation women of Turkish origin in Zurich and Basel is in line with the finding of the Family History Survey in France; Hamel and Milewski (2007) report 80 per cent of Turkish origin women are married to Turkish migrants. 
However, women's lower tendency to marry out of the ethnic group is not a general rule (Song 2009). The behaviour of SSYU women in the Swiss TIES survey reflects diversified gender patterns according to nationality - their spouses tend to be chosen from outside the origin group more often than SSYU men's spouses. This finding is consistent with the previous one on lower family influence on SSYU respondents' partner choice. Moreover, the exogamous spouses of SSYU women are almost always Swiss, whereas the exogamous spouses of SSYU men are roughly $5^{\circ}$ per cent Swiss, with others from a variety of different countries.

The literature suggests that less institutionalised unions tend to be more mixed (Schoen 1993; Tribalat 1995). Exogamous unions would therefore be expected to be more frequent in cohabitation - where marriage migration plays no role - than in marriage.

Table 8.11 Nationalities of partners in cohabitation and in all types of unions, by origin group

\begin{tabular}{lcccccc}
\hline & \multicolumn{3}{c}{ COHABITATION } & \multicolumn{3}{c}{ ALL TYPES OF UNIONS } \\
\cline { 2 - 7 } & TR & SSYU & CG & TR & SSYU & CG \\
\hline Swiss & 50.0 & 63.2 & 81.5 & 12.2 & 29.5 & 80.0 \\
Turkish & 11.1 & & & 55.3 & & \\
Turkish/Swiss & 16.7 & & 1.2 & 20.2 & & 0.6 \\
SSYU & & 13.2 & 1.2 & & 40.3 & 0.6 \\
SSYU/Swiss & & 5.3 & & & 22.1 & \\
Other & 22.2 & 18.4 & 16.0 & 12.3 & 8.1 & 18.8 \\
\hline $\mathrm{N}=$ & 19 & 33 & 83 & 123 & 132 & 178 \\
\hline
\end{tabular}

TR-CG (Cohabitation)

$X^{2}=28.453$

$\mathrm{p}=.000$

SSYU-CG (Cohabitation)

TR-SSYU (Cohabitation)

TR-CG (All unions)

$X^{2}=14.309$

$\mathrm{p}=.014$

$X^{2}=17.214$

$\mathrm{p}=.009$

$X^{2}=187.313$

$\mathrm{p}=.000$

SSYU-CG (All unions)

$X^{2}=146.437$

$\mathrm{p}=.000$

TR-SSYU (All unions)

$X^{2}=194.575$

$\mathrm{p}=.000$

The results largely confirm the expectation of diminishing endogamy by diminishing institutionalisation of the relationship. This may be explained by the likelihood that cohabitees are less traditional than those marrying young. Two out of ten married second-generation youth are in a mixed union, while seven/eight out of ten young people with a migrant background cohabit (Table 8.10 and Table 8.11). Gender, age category or agglomeration do not account for differences in partners' nationality in marriage; the sample size is too small for a detailed investigation of these aspects among cohabiting respondents. 
Taking into account both marriage and cohabitation, the findings show prevailing endogamy in both origin groups. However, exogamous couples are found to a large extent among SSYU origin youth ( 38 per cent) and, to a lesser degree, among Turkish origin youth (25 per cent). We will discuss later (see $\$$ 8.2.1.3) the issue of crossing of religious boundaries in intermarriage, where a group's religious background is different from the dominant one in the receiving society.

\subsubsection{Socialisation of endogamous spouse: First, second and 1.5 generation} Generally, studies of intermarriage focus on nationality and/or ethnicity (or race) but fail to look carefully at the life experience of partners. The complementary scenario of endogamous unions can involve quite different situations in terms of socialisation. TIES data allows introducing this distinction and therefore explore not only origin but also spouses' socialisation. Three cases can be distinguished: a) partners share similar second-generation experience (as they are both Swissborn); b) partners share similar origin but not socialisation: one is Swissborn and the other is foreign born but has been partially socialised in Switzerland; c) partners share similar origin but not socialisation: one is Swissborn and the other is foreign born and has not been socialised in Switzerland before marriage (in this case it is generally spoken of as marriage migration).

To what extent do endogamous couples share not only origin but also a similar experience of a long-standing socialisation in Switzerland, having grown up in the social and cultural environment of the immigration country? In fact, partners holding double nationality are to a large extent born in Switzerland or they have been educated in Switzerland. Among Turkish origin youth, this is the case in one fifth of unions, in both marriage (17 per cent) and cohabitation (22 per cent). For SSYU youth, this proportion is much higher among those married ( 28 per cent) than among those in cohabitation (5 per cent) (Table 8.10 and Table 8.11).

To what extent do endogamous couples have different life experiences, where a second-generation youth associates with a first-generation migrant? To investigate the relative significance of first-generation spouses in endogamous unions, we will take into account in which country partners gained their highest educational achievement (Table 8.12).

A majority of marriages (55-57 per cent) of TIES second-generation respondents involve a first-generation Turkish or SSYU migrant who achieved his/her highest level of education in the country of origin. This pattern does not differ for men and women. For the majority of spouses of comparison group respondents, the country of education is Switzerland. 
Table 8.12 Spouse's country of achieved highest level of education, by origin group and gender of spouse (selecting only married couples)

\begin{tabular}{|c|c|c|c|c|c|c|c|c|c|}
\hline & \multicolumn{3}{|c|}{ TR } & \multicolumn{3}{|c|}{ SSYU } & \multicolumn{3}{|c|}{ CG } \\
\hline & M & w & Total & M & w & Total & M & w & Total \\
\hline Switzerland & 32.7 & 30.4 & 31.6 & 38.2 & 42.9 & 40.2 & 90.0 & 73.2 & 82.4 \\
\hline Turkey & 59.6 & 54.3 & 57.1 & & & & & & \\
\hline Bosnia & & & & 10.3 & 7.1 & 8.9 & & & \\
\hline Croatia & & & & 7.4 & 16.7 & 11.6 & & 2.4 & 1.1 \\
\hline Serbia & & & & 19.1 & 7.1 & 14.3 & 2.0 & & 1.1 \\
\hline $\begin{array}{l}\text { Kosovo/ } \\
\text { Macedonia }\end{array}$ & & & & 20.6 & 21.4 & 20.5 & & & \\
\hline Other & 7.7 & 15.2 & 11.2 & 4.4 & 4.8 & 4.5 & 8.0 & 24.4 & 15.4 \\
\hline $\mathrm{N}=$ & 57 & 48 & 105 & 64 & 35 & 99 & 50 & 46 & 96 \\
\hline
\end{tabular}

TR-CG $\quad X^{2}=76.470 \quad \mathrm{p}=.000$

SSYU-CG $\quad X^{2}=66.827 \quad \mathrm{p}=.000$

TR-SSYU $\quad X^{2}=122.440 \quad \mathrm{p}=.000$

All other differences are not statistically significant.

Does this pattern also apply to cohabiting respondents? We saw that cohabitation is less conventional than marriage as far as partner origin goes: is this also true for socialisation? The vast majority of partners of TIES respondents in cohabitation (around 80 per cent) achieved their highest education level in Switzerland. In the case of cohabitation, the most frequent case - out of the few observed - corresponds to foreign-born youth socialised in Switzerland, or the 1.5 generation, according to Rumbaut's taxonomy (2002).

Country of education delivers a general picture of partners' migratory status sufficient to distinguish between the second and first generation. First-generation migrants may have come to Switzerland for marriage or other purposes. We will now investigate timing of migration in order to examine whether spouses arrived in Switzerland because of marriage, that is, whether they are marriage migrants.

\subsubsection{Socialisation of endogamous spouse: Marriage migration}

There is strong evidence in literature that the second generation, especially of Turkish origin, in many Western European countries often choose a partner who not only shares the same origin but also comes directly from their country of origin, so that marriage induces migration. Among alternative partner choices, newcomer partners attract the attention of social scientists because of the specific features of their inclusion in the 
host society. Moreover, attention has increased as a result of restrictive immigration policies in countries where marriage is the only way to obtain legal entry. As Timmerman (2008) observes,

For marriages in migrant communities much more is at stake than just love or the ambition to establish a harmonious household; it is often about the possibility of entering the promised land, about economic and social benefits for the family of the one who is marrying and moving to Europe, about reviving the bonds with region of origin, about loyalties and debts between families who wish to improve their socio-economic position and about young people that are dissatisfied with their current situation in the society.

The phenomenon of newcomer spouses has long been studied in various immigration countries (Kofman 1999; Lievens 1999; Çelikaksoy et al. 2006; Timmermann 2006; Ballard 2008), especially those which have adopted a specific, dissuasive legislation for this type of family reunification.

The topic has not attracted as much attention in Switzerland, however. A preliminary analysis of the 2000 Census data regarding marriage migration from Turkey to Switzerland reveals its high prevalence in the second generation (Topgül \& Wanner 2008). Choosing a newcomer spouse was found to be the most common among second-generation men (39 per cent) and women ( 38 per cent). According to the Swiss Central Aliens Register, subsequent immigration of the spouse constitutes the reason for migration of almost half the immigrants from Turkey in 2002-2004.

Multivariate analysis of Swiss Census data points out the different impact of education on newcomer partner choice for second-generation men and women; a negative correlation between education and marriage migration is observed only for men. Factors which could be considered indicators of inclusion in the host society (naturalisation and confidence in one of the Swiss languages) are found to decrease the likelihood of women having a newcomer spouse (Topgül \& Wanner 2009).

Among TIES respondents who entered an endogamous marriage, is there a tendency to choose a spouse coming directly from the country of origin? In order to investigate marriage migration, newcomer spouses are defined as Turkish/SSYU citizens who arrived in the year of marriage or the following year. Migratory status of the partner is grouped into five categories: Swiss, other nationality, Turkish/SSYU and Swiss, Turkish/SSYU, newcomer Turkish/SSYU. Analysis by gender, age category and agglomeration is affected by the low number of observations. 
One third of marriages involve marriage migrants; the prevalence is significantly higher for youth of Turkish origin (37 per cent) than SSYU youth (29 per cent) (Table 8.13). Marriage migration accounts for less than 50 per cent of endogamous marriages in both origin groups. Gender differences in the migration status of spouses are not statistically significant; however, marriage migration is more frequent among SSYU men than women. The proportion of endogamous couples is higher among younger SSYU youth under 25 compared to those aged 25 and over, but age does not have a significant impact on the migration status of the spouses.

The marriage market for SSYU origin youth appears quite similar in the two agglomerations under study, but Turkish origin youth exhibit distinctive features. The marriage market in Zurich is characterised by more stability than in Basel: the proportion of spouses holding dual nationality (hence both partners belong to the second generation) is three times higher than couples with non-newcomer Turkish spouses. The Turkish second generation in Basel, on the contrary, relies more heavily on country of origin social resources for partner choice in marriage.

Table 8.13 Migratory status of the spouse, by origin group, gender, age and agglomerations (only married couples)

\begin{tabular}{lccccccc}
\hline & Total & M & W & $<\mathbf{2 5}$ & $>\mathbf{= 2 5}$ & ZH & BS \\
\hline & \multicolumn{7}{c}{ TR spouse } \\
Swiss & 5.2 & 6.5 & 3.9 & & 6.5 & 2.3 & 7.3 \\
Other & 9.3 & 13.0 & 5.9 & 10.0 & 9.1 & 13.6 & 7.3 \\
Swiss-Turkish & 17.5 & 23.9 & 13.7 & 10.0 & 19.5 & 29.5 & 9.1 \\
Turkish (not-newcomer) & 30.9 & 21.7 & 37.3 & 45.0 & 27.3 & 13.6 & 43.6 \\
Turkish (newcomer) & 37.1 & 34.8 & 39.2 & 35.0 & 37.7 & 40.9 & 32.7 \\
\hline N= & 104 & 47 & 57 & 19 & 85 & 41 & 63 \\
\hline & & \multicolumn{1}{c}{ SSYU } & spouse & & & & \\
Swiss & 18.9 & 12.0 & 24.0 & 5.0 & 22.0 & 18.0 & 21.0 \\
Other & 4.5 & 9.0 & 2.0 & 5.0 & 4.0 & 3.0 & 7.0 \\
Swiss-SSYU & 25.2 & 23.0 & 27.0 & 21.0 & 26.0 & 24.0 & 28.0 \\
SSYU (not-newcomer) & 22.5 & 21.0 & 24.0 & 32.0 & 21.0 & 25.0 & 19.0 \\
SSYU (newcomer) & 28.8 & 35.0 & 25.0 & 37.0 & 27.0 & 31.0 & 26.0 \\
\hline N = & 99 & 35 & 64 & 21 & 78 & 60 & 39 \\
\hline
\end{tabular}

TR-SSYU $\quad X^{2}=13.487 \quad p=.009$

TR (Zurich vs. Basel) $\quad X^{2}=15.525 \quad p=.004$

All other differences are not statistically significant. 
We have seen so far that endogamy is the main feature of marriages in the Turkish and SSYU second generation. The following figure summarises our results on the background of spouses, singling out the dimensions of nationality and familiarity with life in Switzerland (Figure 8.1). Using the criterion of nationality, five marriages in six are endogamous among Turkish origin respondents and three in four among SSYU origin respondents. One marriage in three involves a newcomer partner for Turkish respondents whereas this is the case for one marriage in four for SSYU partners.

Figure 8.1 Exogamy, endogamy and marriage migration of partner in unions by origin group

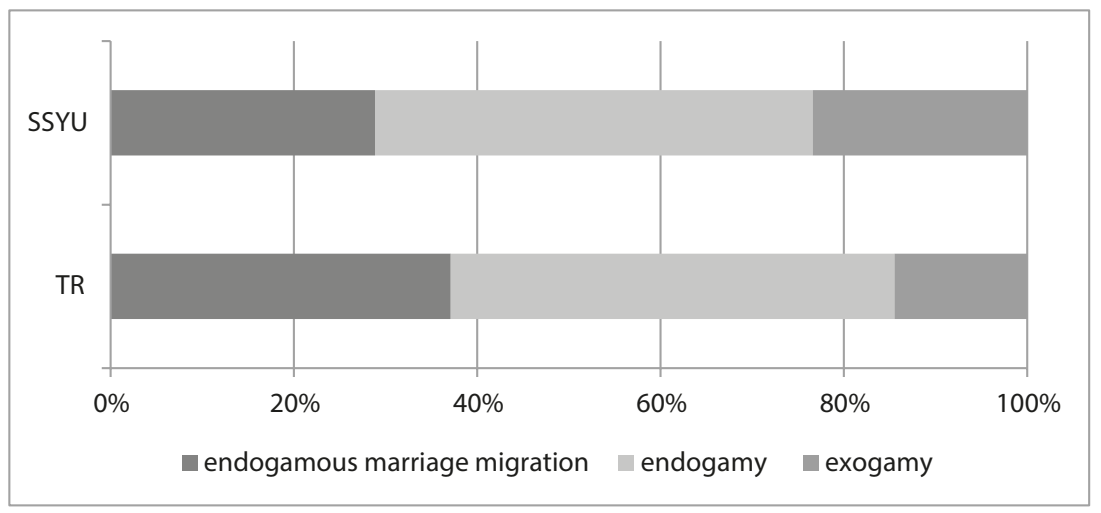

One marriage in three among Turkish respondents and one marriage in two among SSYU respondents involve a partner highly acculturated to local society (Swiss, other foreign partner or dual nationals). Among cohabitants - representing between 15 and 25 per cent of unions - the share of highly acculturated partners reaches more than go per cent.

\subsubsection{Religious endogamy}

Kalmijn (1998) notes that, '[r]eligion is a core element of culture, since it is associated with cultural values, beliefs and practices'. It is assumed that though assimilation may blur cultural, national and ethnic boundaries, this might be less the case for religion. In the theoretical strand of assimilation studies concerning the second generation in the US after the Second World War, it was observed that marriage across national boundaries was taking place within population pools contained inside religious boundaries (Reeves 
Kennedy 1944; Reeves Kennedy 1952). In the sixties in France, religious homogamy was the rule (Girard 1964).

Working today on intermarriage among first generation immigrants in the Netherlands, Van Tubergen and Maas (2007) found that religion plays an important role in ethnic endogamy both on the individual and contextual level. Immigrants affiliated to a religion differing from mainstream society are more likely to marry co-ethnics, as this leads to fewer opportunities to meet natives of a similar religion. Moreover, studying the Swiss Census 2000, Topgül \& Wanner (2009) show that the Muslim Turkish second generation in Switzerland are much more involved in endogamous marriages than their non-Muslim peers.

How important are religious boundaries for the second generation? This question is especially important in the current European context where the proportion of youth with no religious affiliation is quite high. In the Swiss context, 67 per cent of the comparison group and 43 per cent of the second generation report a lack of religious affiliation (see Chapter 6). Almost all respondents of Turkish origin who report being religious are Muslim (primarily Sunni and Alevi), while the comparison group are Christian (Catholic or Protestant). The majority of religious SSYU respondents are Christian (mainly Orthodox and Catholic); 23 per cent are Muslim.

What is the impact of a partner's religion in the partner choice of respondents? Is partner choice of the religious second generation and comparison group in line with their religious affiliation? Among Turkish origin youth, 56 per cent of couples bring together Muslim partners, while 24 per cent have a Muslim partner and a non-religious one, 12 per cent have two non-religious partners and 2 per cent have a Muslim and a Christian partner. Among SSYU respondents, homogeneous Christian-Christian couples dominate (40 per cent), along with homogeneous Muslim-Muslim couples (15 per cent) and homogeneous non-religious couples (14 per cent). Religious (Muslim or Christian) and non-religious pairings make up 23 per cent of couples. Among comparison group respondents, couples with two Christian partners (39 per cent) are just as numerous as couples with a Christian partner and a non-religious one. In some 20 per cent of couples both partners are non-religious (Table 8.14).

TIES results confirm high religious endogamy at marriage. Turkish Muslim respondents marry a Muslim partner in the majority of cases. In all other configurations, religiously endogamous couples are in the minority: one in six couples for SSYU Muslim respondents have a partner of the same 
Table 8.14 Religion of both spouses, by origin group and gender (selecting married couples - columns 1-3 and selecting cohabiting couples - columns 4-6)

\begin{tabular}{|c|c|c|c|c|c|c|}
\hline \multirow[b]{2}{*}{$\begin{array}{l}\text { Religion of the respondent } \\
\text { Religion of the spouse / partner }\end{array}$} & \multicolumn{3}{|c|}{ Marriage } & \multicolumn{3}{|c|}{ Cohabitation } \\
\hline & TR & SSYU & CG & TR & SSYU & CG \\
\hline \multicolumn{7}{|l|}{ Christian } \\
\hline Christian & & 39.8 & 38.9 & 5.3 & 20.0 & 18.5 \\
\hline Muslim & & 0.9 & & & & \\
\hline Not religious & & 2.7 & 4.4 & & 15.0 & 4.9 \\
\hline Other & & 1.8 & 2.2 & & & 1.2 \\
\hline \multicolumn{7}{|l|}{ Muslim } \\
\hline Muslim & 55.6 & 15.0 & & 10.5 & & \\
\hline Christian & 2.0 & & & 21.1 & & \\
\hline Not religious & 4.0 & & & 5.3 & 2.0 & \\
\hline \multicolumn{7}{|l|}{ Jew } \\
\hline Jew & & & 1.1 & & & \\
\hline \multicolumn{7}{|l|}{ Other religion } \\
\hline Christian & & & 1.1 & & 5.0 & 1.2 \\
\hline Other & & 1.8 & & & & \\
\hline \multicolumn{7}{|l|}{ No religious affiliation } \\
\hline No religious affiliation & 12.1 & 14.2 & 20.0 & 21.1 & 32.0 & 29.6 \\
\hline Christian & 1.0 & 11.5 & 30.0 & 21.1 & 20.0 & 39.5 \\
\hline Muslim & 24.2 & 11.5 & & 15.8 & 2.0 & 2.5 \\
\hline Other & 1.0 & 0.9 & 2.2 & & 5.0 & 2.5 \\
\hline$N=$ & 106 & 100 & 96 & 19 & 35 & 83 \\
\hline $\begin{array}{lll}\text { TR-CG } & \text { (marriage) } & X^{2}=153.596 \\
\text { SSYU-CG } & \text { (marriage) } & X^{2}=39.647 \\
\text { TR-SSYU } & \text { (marriage) } & X^{2}=92.663\end{array}$ & $\begin{array}{l}\mathrm{p}=.000 \\
\mathrm{p}=.000 \\
\mathrm{p}=.000\end{array}$ & $\begin{array}{l}\text { (cohak } \\
\text { (cohak } \\
\text { (cohak }\end{array}$ & $\begin{array}{l}\text { ation) } \\
\text { ation) } \\
\text { ation) }\end{array}$ & $\begin{array}{l}X^{2}=40.730 \\
\text { n.s. } \\
X^{2}=23.656\end{array}$ & $\mathrm{p}=.000$ & \\
\hline
\end{tabular}

religion (15 per cent), and only one in two couples for SSYU and comparison group Christians.

Respondents who marry out of their religious group do not engage in a relationship with someone of a different religion, but more often choose a non-religious partner. The relative importance of non-religious respondents reduces the proportion of homogeneous couples; 'mixed' couples at the religious level remain an exception. Non-religious people account for the blurred outline of religious population pools and make religious border crossing an easier step now than it may have been in the American postWorld War II context of Reeves Kennedy. 
Women and men do not display different patterns. Interestingly, 'mixed' religious couples seem more frequent in cohabitation than marriage (Table 8.14), but the limited number of observations of this type of union does not allow for further analysis.

We have found so far that religious endogamy affects more than half of second-generation couples of both Turkish and SSYU descent: 55 per cent of couples share the same religion while some 13 per cent share the same non-religious attitude. A third of marriages bring together partners with different religious beliefs (either non-religious or different religions). Though second-generation Turkish and SSYU respondents have brought new religions into the Swiss marriage market, religious boundaries are not stronger than national ones.

\subsubsection{Social and educational homogamy}

The tendency of modern couples to escape social control does not mean that social determinism does not exist: social structures influence union formation and homogamy tends to prevail in partner choice so that spouses share a similar milieu. Educational attainment is one way of testing homogamy.

In the literature, homogamy is sometimes considered the unintended byproduct of individual preferences for socio-economic and cultural resources in a partner as well as social segmentation of sociability. 'This argument has often been made for educational homogamy, because education is not only strongly related to income and status, but also to taste, values and lifestyles' (Kalmijn 1998). Burgess \& Wallin (1943) argue that 'persons having relatively similar education are more likely to have a similar cultural outlook, the same universe of discourse, common interests, etc., and, accordingly, to have the basis for initiating and maintaining an enduring relationship' (Girard 1964; Bozon \& Héran 2006).

What is the role of educational resemblance in the spouse choice of the second generation and comparison group? What is the pattern of partners' educational level by origin group and gender? We analyse this in Table 8.15 which shows the highest educational level achieved by partners in all type of unions.

Partners of second-generation Turkish respondents have the lowest level of educational attainment: 24 per cent have at most completed compulsory school. This proportion is lower for SSYU partners (12 per cent) and much lower for comparison group partners (2 per cent). In all origin groups, at least half the partners achieved post-compulsory education, with the highest proportion among SSYU partners (65 per cent). A quarter of the partners 
Table 8.15 Highest achieved education level of partner, by origin group and gender of partner (all unions)

\begin{tabular}{lrrrrrrrrr}
\hline & \multicolumn{3}{c}{ TR } & \multicolumn{3}{c}{ SSYU } & \multicolumn{3}{c}{ CG } \\
\cline { 2 - 10 } & M & W & T & M & W & T & M & W & T \\
\hline ISCED 0/1 & 7.8 & 10.4 & 9.1 & & & & & & \\
ISCED 2 & 17.6 & 12.5 & 15.2 & 16.0 & 7.0 & 11.9 & 3.8 & 1.5 & 2.1 \\
ISCED 3 & 43.1 & 56.3 & 49.5 & 61.0 & 70.0 & 65.2 & 57.7 & 60.0 & 59.2 \\
ISCED 5 & 31.4 & 20.8 & 26.3 & 23.0 & 23.0 & 23.0 & 38.5 & 38.5 & 38.7 \\
\hline N = & 58 & 49 & 107 & 69 & 49 & 118 & 79 & 69 & 148 \\
\hline
\end{tabular}

TR-CG $\quad X^{2}=29.872 \quad \mathrm{p}=.000$

SSYU-CG $\quad X^{2}=15.518 \quad \mathrm{p}=.000$

TR-SSYU $\quad X^{2}=15.399 \quad \mathrm{p}=.002$

Gender differences are not statistically significant.

of second-generation respondents are university graduates whereas comparison group partners are more likely to have earned a university degree. Educational achievement does not differ by gender of partner (Table 8.15). Turkish and SSYU partners with low qualifications are more numerous than respondents, but this is also the case for the highly qualified. Partners of comparison group respondents tend to be better qualified than respondents.

Given the achieved education level of the partners, what is the proportion of couples with the same educational level by origin group and gender? For more than two thirds of SSYU and comparison group couples, education levels of partners are the same. Turkish couples have the lowest level of educational homogamy (43 per cent). This finding does not seem consistent with the well-established variability of homogamy depending on structural position, where homogamy is stronger in working-class milieus, weaker among the middle class (Girard 1964; Gokalp 1978) and stronger again in the upper middle class (Bozon 1991). Reduced numbers of observations as well as the fact that some respondents are still in education may account for this finding.

Gender does not account for differences in couples' educational level, despite the fact that women with a lower educational achievement level than their partner (hypergamy) tend to be more numerous than men. However, male respondents seem to have the same level of education as their partners more often than women across origin groups. This contrasts with the traditional trend of less educated women marrying more educated men.

In this subsection on partner choice we found that national endogamy characterises marriages in the Turkish and SSYU second generation, 
Table 8.16 Couples' education level by origin group and gender of respondent (all unions)

\begin{tabular}{lcccccccccc}
\hline & \multicolumn{3}{c}{ TR } & \multicolumn{3}{c}{ SSYU } & \multicolumn{3}{c}{ CG } \\
\cline { 2 - 10 } & M & W & Total & M & W & Total & M & W & Total \\
\hline Same level of education & 48.8 & 37.0 & 43.2 & 71.7 & 62.9 & 67.2 & 72.0 & 67.2 & 69.8 \\
$\begin{array}{l}\text { Respondent higher than } \\
\text { partner }\end{array}$ & 20.9 & 26.1 & 22.7 & 11.3 & 12.9 & 11.5 & 6.0 & 6.0 & 5.2 \\
Respondent lower than partner & 30.2 & 37.0 & 34.1 & 17.0 & 24.3 & 21.3 & 22.0 & 26.9 & 25.0 \\
\hline $\mathrm{N}=$ & 44 & 52 & 96 & 44 & 64 & 108 & 51 & 68 & 119 \\
\hline
\end{tabular}

TR-CG $\quad X^{2}=19.620 \quad \mathrm{p}=.000$

TR-SSYU $\quad X^{2}=12.295 \quad \mathrm{p}=.002$

All other differences are not statistically significant.

reflected in one marriage in four. Moreover, a majority of marriages of TIES second-generation respondents (55 per cent) involve a Turkish or SSYU first-generation migrant who achieved his or her highest level of education in the country of origin, but in only roughly a third of marriages does union trigger immigration of the spouse. Religious endogamy affects more than half of second-generation couples of both Turkish and SSYU descent: 55 per cent of couples share the same religion and some 13 per cent share the same non-religious attitude. We can therefore conclude that religious boundaries are not stronger than national ones.

Let us underline the strong unexpected parallel between the Turkish and SSYU second generation in spite of their respective diverse national, ethnic and religious compositions. Only when looking at social homogamy is there a distinction, with SSYU descent youth experiencing a higher degree of homogamy than second-generation Turkish youth.

\subsection{Family life}

The last section of this chapter will tackle issues of family life, in particular gender roles and decisions on who is to participate in the labour market, be responsible for domestic chores and take care of the children.

\subsubsection{Labour force arrangements in the couple}

At least three quarters of partners (married or cohabitating) in all origin groups are economically active; the activity rate of partners of 
second-generation Turkish respondents is the lowest ( 76 per cent as against 92-93 per cent for SSYU youth and the comparison group). Labour force participation differs for male and female partners for all origin groups, but the sharpest gender difference is among partners of second-generation Turkish respondents (91 per cent of men versus 60 per cent of women).

Partners of Turkish youth and the comparison group are significantly more often economically active in Zurich than Basel. By contrast, the activity rate of partners of SSYU youth is significantly higher in Basel.

What is the pattern of labour force participation of couples by origin groups? Couples with both partners economically active represent the majority in all origin groups: both partners are active in two thirds of unions of Turkish youth and 80-85 per cent of unions of SSYU youth and the comparison group. In a third of unions, either the Turkish respondent or his/her partner is inactive; this is much less frequent among SSYU youth and the comparison group (Table 8.17).

Gender analysis reveals that couples where an economically active respondent lives with an inactive partner are more common among secondgeneration men of Turkish origin. This pattern is found in 39 per cent of all unions whereas they involve 12-14 per cent of unions in other origin groups; the presence of children in Turkish origin families may explain this result. In couples with a second-generation Turkish woman, however, the configuration where both partners are economically active is more frequent and closer to that observed in the comparison group; the rather traditional configuration of an active male partner and an inactive woman is found in 16 per cent of such couples, a frequency close to that observed in the comparison group (19 per cent).

In SSYU couples, the configuration where both partners are active is most frequent. In this respect SSYU descent youth have the most egalitarian arrangements, followed by the comparison group and finally by the Turkish second generation, who display a more traditional labour force arrangement, with a higher frequency of inactive women.

\subsubsection{Parenthood}

We saw in Chapter 2 that the average household size for respondents living on their own is higher for second-generation respondents $(2.5$ members for Turkish youth, 2.6 members for SSYU youth) than for the comparison group (2.1 members): young people with a migrant background are more likely to have children. 
Table 8.17 Couples' labour force participation, by origin group and gender

\begin{tabular}{|c|c|c|c|c|c|c|c|}
\hline \multirow[b]{3}{*}{ Partner } & & \multicolumn{6}{|c|}{ Male respondents } \\
\hline & & \multicolumn{2}{|c|}{ TR } & \multicolumn{2}{|c|}{ SSYU } & \multicolumn{2}{|c|}{ CG } \\
\hline & & active & inactive & active & inactive & active & inactive \\
\hline \multirow[t]{2}{*}{ TR } & active & 57.9 & 1.8 & & & & \\
\hline & inactive & 38.6 & 1.8 & & & & \\
\hline \multirow[t]{2}{*}{ SSYU } & active & & & 83.1 & 1.5 & & \\
\hline & inactive & & & 13.8 & 1.5 & & \\
\hline \multirow[t]{2}{*}{ CG } & active & & & & & 81.5 & 4.9 \\
\hline & inactive & & & & & 12.3 & 1.2 \\
\hline \multirow[t]{3}{*}{$N=$} & & 58 & & 52 & & 88 & \\
\hline & & \multicolumn{6}{|c|}{ Female respondents } \\
\hline & & \multicolumn{2}{|c|}{ TR } & \multicolumn{2}{|c|}{ SSYU } & \multicolumn{2}{|c|}{ CG } \\
\hline Partner & & active & inactive & active & inactive & active & inactive \\
\hline \multirow[t]{2}{*}{ TR } & active & 75.4 & 15.8 & & & & \\
\hline & inactive & 7.0 & 1.8 & & & & \\
\hline \multirow[t]{2}{*}{ SSYU } & active & & & 86.6 & 11.0 & & \\
\hline & inactive & & & 1.2 & 1.2 & & \\
\hline \multirow[t]{2}{*}{ CG } & active & & & & & 80.2 & 18.6 \\
\hline & inactive & & & & & 1.2 & 0 \\
\hline $\mathrm{N}=$ & & 65 & & 77 & & 87 & \\
\hline
\end{tabular}

A third of Turkish descent women and half of SSYU origin women are mothers versus 29 per cent of comparison group women. The majority (83 per cent) of married SSYU woman in this age category have at least one child (on average 1.8 children). By contrast, there is a larger dissociation between marriage and parenthood for women of Turkish origin. This contrasts with the findings of Tavan (2005), who observes early fertility after marriage for the Turkish population in France, whereas in the general French population, over the course of generations couples are living longer without children. According to TIES results, around two thirds (69 per cent) of married Turkish women have on average one child (1.2 children), while 63 per cent of the comparison group have an average of 1.23 children.

In summary, it is worth underscoring that parenthood tends to reduce the labour force participation of mothers: comparison group women experience 
the sharpest drop in activity rate (-44 per cent), followed by Turkish descent women (-30 per cent) and finally SSYU origin women (-15 per cent).

\subsubsection{Gender roles}

Gender roles are the sets of behaviours commonly exhibited by women and men and the normative expectations that are associated with such behaviours. They are learnt in the family and in school, among other places, but are subject to change in the context of new socialisations and personal experiences.

The TIES questionnaire approaches the issue of the understanding of gender roles by asking respondents to say to what extent they agree with statements on family arrangements and social life, such as: 'Women should not work outside the house when there are small children in the family', or 'It is against nature when women in leading positions are given authority over men', or 'Study and higher education are less important for women than for me'. To give a synthetic picture of gender role attitudes an additive scale and an average score were computed: the lower the score, the more traditional the understanding of gender roles. Analysis reveals a stable pattern of attitudes mainly influenced by both origin and gender (Table 8.18).

Second-generation respondents have significantly more traditional views than the comparison group; moreover, men's attitudes are markedly more traditional than women's across origin groups. The cleavage between immigrant origin youth and the comparison group is more pronounced among men than women, whereas among women each origin group differs on this point. The gap between men's and women's opinions is widest among SSYU descent respondents, followed by comparison group respondents, whereas among Turkish descent youth some convergence appears.

Though, as expected, location does not influence comparison group opinions, this is not the case for the second generation. Means tend to be significantly lower in Zurich than in Basel, both among the Turkish and SSYU second generation. We also found that labour market participation does not affect attitudes about gender roles.

Testing whether personal status affected the normative attitudes associated with gender roles, we observed that neither marital nor parental status had an impact. We took further into consideration the ethnic background of the partner (Table 8.19), on the basis that co-ethnic couples might distinguish themselves from mixed couples in respect to gender role attitudes, demonstrating a form of group closure, a much discussed issue in public debate. This is definitely not the case. Moreover, couples uniting 
Table 8.18 Gender role attitudes (means and standard deviation), by origin group and gender

\begin{tabular}{|c|c|c|c|c|c|}
\hline & & TR & \multicolumn{2}{|c|}{ SSYU } & CG \\
\hline \multirow[t]{2}{*}{ Men } & & 3.7 & \multicolumn{2}{|c|}{3.6} & 4.0 \\
\hline & & 0.7 & \multicolumn{2}{|c|}{0.7} & 0.7 \\
\hline \multicolumn{2}{|l|}{$\mathrm{N}=$} & 229 & \multicolumn{2}{|c|}{214} & 240 \\
\hline \multirow{2}{*}{\multicolumn{2}{|c|}{ Women }} & 3.9 & \multicolumn{2}{|c|}{4.1} & 4.3 \\
\hline & & 0.7 & \multicolumn{2}{|c|}{0.7} & 0.6 \\
\hline \multicolumn{2}{|l|}{$\mathrm{N}=$} & 220 & \multicolumn{2}{|c|}{217} & 228 \\
\hline \multirow{2}{*}{\multicolumn{2}{|c|}{ Zurich }} & 3.6 & \multicolumn{2}{|c|}{3.8} & 4.1 \\
\hline & & 0.7 & \multicolumn{2}{|c|}{0.7} & 0.7 \\
\hline \multicolumn{2}{|l|}{$\mathrm{N}=$} & 202 & \multicolumn{2}{|c|}{239} & 202 \\
\hline \multirow{2}{*}{\multicolumn{2}{|c|}{ Basel }} & 3.9 & \multicolumn{2}{|c|}{4.0} & 4.1 \\
\hline & & 0.7 & \multicolumn{2}{|c|}{0.8} & 0.7 \\
\hline \multicolumn{2}{|l|}{$N=$} & 247 & \multicolumn{2}{|c|}{192} & 266 \\
\hline \multirow{2}{*}{\multicolumn{2}{|c|}{$\begin{array}{l}\text { Total } \\
\text { st. deviation }\end{array}$}} & 3.8 & \multicolumn{2}{|c|}{3.9} & 4.1 \\
\hline & & 0.7 & \multicolumn{2}{|c|}{0.7} & 0.7 \\
\hline \multicolumn{2}{|l|}{$\mathrm{N}=$} & 449 & \multicolumn{2}{|c|}{431} & 468 \\
\hline TR-CG & $\mathrm{p}=.000$ & Women (TR-CG) & $\mathrm{p}=.000$ & Men (TR-CG) & $\mathrm{p}=.000$ \\
\hline SSYU-CG & $\mathrm{p}=.000$ & Women (SSYU-CG) & $\mathrm{p}=.002$ & Men (SSYU-CG) & $\mathrm{p}=.000$ \\
\hline TR-SSYU & n.s. & Women (TR-SSYU) & $\mathrm{p}=.012$ & & \\
\hline TR (M vs. W) & $\mathrm{p}=.000$ & (Zurich vs. Basel) & $\mathrm{p}=.000$ & & \\
\hline SSYU (M vs. W) & $\mathrm{p}=.000$ & (Zurich vs. Basel) & $\mathrm{p}=.001$ & & \\
\hline CG (M vs. W) & $\mathrm{p}=.000$ & & & & \\
\hline
\end{tabular}

a second-generation and a newcomer spouse, a combination supposedly associated with markedly traditional gender roles, have quite high - i.e., non-traditional - scores in respect of gender role attitudes.

We finally tested whether the present religious affiliation of TIES respondents affects the attitudes towards the behaviours exhibited by men and women (Table 8.20); we observe no variation within the Turkish second generation in this respect. By contrast, religious identity has an impact on gender role in the two other groups: among SSYU origin respondents, Muslims take the most traditional stand out of all ethno-religious groups in contrast with Christians and non-religious respondents, whereas in the comparison group the cleavage lies between religious and non-religious youth.

The few spotlights cast on family life of TIES respondents show that second-generation respondents, especially men, share distinctive, more traditional opinions on gender roles than the comparison group. This is only partially reflected in labour force participation within couples. Economic 
Table 8.19 Gender role attitudes (means and standard deviation), by origin group and background of spouse

\begin{tabular}{lcc}
\hline & TR & SSYU \\
\hline Swiss & 3.4 & 4.0 \\
& -1.1 & -0.7 \\
Other & 3.7 & 4.0 \\
& -0.7 & -0.7 \\
Swiss \& Turkish/SSYU & 3.7 & 3.6 \\
& -0.5 & -0.6 \\
Turkish/SSYU & 3.7 & 3.8 \\
(not-newcomer) & & \\
& -0.7 & -0.7 \\
Turkish/SSYU (newcomer) & 3.9 & 3.9 \\
& -0.7 & -0.7 \\
Total married & 3.8 & 3.8 \\
& -0.7 & -0.7 \\
$\mathrm{~N}$ (married)= & 104 & 99 \\
\hline
\end{tabular}

Partner choice differences are not statistically significant.

Table 8.20 Gender role attitudes (means and standard deviation), by origin group and religion

\begin{tabular}{lccc}
\hline & TR & SSYU & CG \\
\hline No religious affiliation & 3.8 & 3.9 & 4.2 \\
$\mathrm{~N}=$ & 0.7 & 0.8 & 0.7 \\
Christian & 190 & 182 & 314 \\
& 3.2 & 3.9 & 4.0 \\
$\mathrm{~N}=$ & 0.9 & 0.7 & 0.7 \\
Muslim & 4 & 185 & 137 \\
$\mathrm{~N}=$ & 3.8 & 3.5 & \\
Total & 0.7 & 0.6 & \\
st. deviation & 253 & 61 & $\mathbf{4 . 1}$ \\
$\mathrm{N}=$ & $\mathbf{3 . 8}$ & 3.9 & 0.7 \\
\hline
\end{tabular}

TR (religion) n.s.

SSYU (religion) $\quad \mathrm{p}=.001$

CG (religion) $\quad \mathrm{p}=.017$

activity tends to be lower in couples with a Turkish male respondent, but the proportion of couples with the configuration where the female respondent 
is inactive and the partner active is similar to comparison group women. Consistent with earlier marriages, parenthood is more frequent at a younger age in second-generation couples.

Attitudes on gender roles appear deeply rooted: neither participation in the labour market nor marital status nor choice of partner influence those dispositions. Religious affiliation affects attitudes in this respect; however, this influence is modulated by ethnic origin.

\subsection{Conclusions}

Children of immigrants display distinctive family behaviours in various respects. They are more likely to enter into marriage than the comparison group; conversely, cohabitation is rarer, whereas marriage and cohabitation are almost equally frequent in the comparison group. They also marry earlier, often in their early twenties. Partner's nationality does not influence mean age at first marriage while the impact of education is evident for Turkish youth but not SSYU youth or the comparison group.

Immigrant families influence respondents' decisions in this field, especially in the Turkish origin group. This generally takes the indirect form of arranging encounter opportunities; however, one woman in five is exposed to direct interference in partner choice, in both Turkish and SSYU second-generation groups. Only the Turkish second generation enters into consanguineous marriages, which are more frequent among younger than older respondents.

Where marriage is concerned, ethnic endogamy is the dominant pattern in spouse selection among TIES respondents. Mixed unions are more frequent among respondents in cohabitation. Around half of unions involve first-generation migrants, who achieved their highest education in the country of origin but only in roughly a third of those marriages does union trigger immigration of the spouse. Newcomer spouses are more frequent in the Turkish second generation than among youth of SSYU descent. Religious endogamy affects more than a half of second-generation couples of both Turkish and SSYU descent, but religious boundaries appear less strong than national ones. The parallels between the Turkish and SSYU second generation in partner choice contrast with their distinctive pattern in social homogamy: SSYU descent youth experience a higher degree of homogamy than the Turkish second generation. Finally, our analysis shows that secondgeneration respondents, especially men, generally have more traditional 


\section{opinions on gender roles than the comparison group. This is only partially reflected in labour force participation within couples.}

\section{References}

Alba, Richard \& Victor Nee (2003), Remaking the American mainstream: Assimilation and contemporary immigration. Cambridge: Harvard University Press.

Ballard, Roger (2008), 'Inside and outside: Contrasting perspectives on the dynamics of kinship and marriage in contemporary South Asian transnational networks', in Ralph Grillo (ed.), Immigrant families in multicultural Europe: Debating cultural difference. Amsterdam: Amsterdam University Press.

Bourdieu, Pierre (1980), Le sens pratique. Paris: Éditions de Minuit.

Bozon, Michel (1991), 'Le choix du conjoint', in François De Singly (ed.), La famille: L'état des savoirs, 22-33. Paris: La Découverte.

Bozon, Michel \& François Héran (2006), La formation du couple. Paris: La Découverte.

Burgess, Ernest W. \& Pall Wallin (1943), 'Homogamy in Social Characteristics', American Journal of Sociology 49(2): 109-124.

Çelikaksoy, Aycan, Helena Nielsen \& Mette Verner (2006), 'Marriage migration: Just another case of positive assortative matching?', Review of Economics of the Household 4(3): 253-275.

Courbage, Youssef \& Emmanuel Todd (2007), Le rendez-vous des civilisations. Paris: Le Seuil.

Desrosières, Alain (1978), 'Marché matrimonial et structure des classes sociales', Actes de la recherche en sciences sociales 20(20-21): 97-107.

Girard, Alain (1964), Le choix du conjoint. Paris: PUF, INED.

Gokalp, Catherine (1978), 'Le réseau familial', Population 33(6): 1077-1094.

Goldscheider, Frances Kobrin \& Linda J. Waite (1986), 'Sex differences in the entry into marriage', American Journal of Sociology 92(1): 91-109.

Gordon, Milton M. (1964), Assimilation in American life: The role of race, religion and national origins. New York: Oxford University Press.

Hamel, Christelle \& Nadja Milewski (2007), 'Is it all about the family? On transnational union formation of descendants of Turkish immigrants in France', Second workshop of the EAPS Working Group on the anthropological demography of Europe. Paris, 13.2.2007.

Hancıoğlu, Attila (1997), 'Fertility trends in Turkey: 1978-1993', in Hacettepe University Institute of Population Studies/Macro International Inc. (ed.), Fertility trends, women's status, and reproductive expectations in Turkey: Results offurther analysis of the 1993 Turkish Demographic and Health Survey, 1-78. Calverton: HUIPS and MI.

Hirschman, Charles \& Judah Matras (1971), 'A new look at the marriage market and nuptiality rates, 1915-1958', Demography 8(4): 549-569.

Kağıtçıbaşı, Çiğdem (1997), 'Individualism and collectivism', in John W. Berry, Marshall H. Segall \& Çiğdem Kağıtçıbaşı (eds), Handbook of cross-cultural psychology. Boston: Allyn \& Bacon.

Kalmijn, Matthijs (1998), 'Intermarriage and homogamy: Causes, patterns, trends', Annual Review of Sociology 24: 395-421.

Kasinitz, Philip, John Mollenkopf \& Mary Waters (2008), The second generation advantage: The children of immigrants inherit the city. Cambridge: Harvard University Press.

Koç, İsmet (2008), 'Prevalence and sociodemographic correlates of consanguineous marriages in Turkey', Journal of Biosocial Science 40(1): 137-148. 
Kofman, Eleonore (1999), 'Female "Birds of Passage" a decade later: Gender and immigration in the European Union', International Migration Review 33(2): 269-299.

Lievens, John (1999), 'Family-forming migration from Turkey and Morocco to Belgium: The demand for marriage partners from the countries of origin', International Migration Review 33(3): 717-744.

Manting, Dorien (1996), 'The changing meaning of cohabitation and marriage', European Sociological Review 12(1): 53-65.

Marini, Margaret Mooney (1978), 'The transition to adulthood: Sex differences in educational attainment and age at marriage', American Sociological Review 43(4):483-507.

Reeves Kennedy, Mary-Jo (1944), 'Single or triple melting pot? Intermarriage trends in New Haven 1870-1940', American Journal of Sociology 49: 331-339.

Rumbaut, Rubén G. (2002), 'Severed or sustained attachments? Language, identity and imagined communities in the post-immigrant generation', in Peggy Levitt \& Mary Waters (eds), The changing face of home, 43-95. New York: Russell Sage.

Saraceno, Chiara \& Manuela Naldini (2001), Sociologia della famiglia. Bologna: il Mulino.

Schoen, Robert \& Robin M. Weinick (1993), 'Partner choice in marriage and cohabitation', Journal of Marriage and Family, 55: 408-414.

Song, Miri (2009), 'Is intermarriage a good indicator of integration?', Journal of Ethnic and Migration Studies 35(2): 331-348.

Straßburger, Gaby (2004), 'Transnational ties of the second generation: Marriages of Turks in Germany', in Thomas Faist \& Eyüp Özveren (eds), Transnational social spaces: Agents, networks and institutions, 211-232. Aldershot: Ashgate.

Tavan, Chloé (2005), 'Les calendriers de constitution de la famille: Quelles différences entre les immigrés et l'ensemble de la population?' in Cécile Lefèvre \& Alexandra Filhon (eds), Histoire des familles, histoires familiales. Les résultats de l'enquête famille de 1999, 443-460. Paris: INED Cahiers de l'INED 156.

TDHS-2003 (2003), 'Turkey Demographic and Health Survey.' Hacettepe University, Institute of Population Studies, Ankara.

Timmerman, Christiane (2006), 'Gender dynamics in the context of Turkish marriage migration: The case of Belgium', Turkish Studies 7(1): 125-143.

Timmerman, Christiane (2008), 'Marriage in a culture of migration: Emirdag marrying into Flanders', European Review 16(04): 585-594.

Topgül, Ceren \& Philippe Wanner (2008), 'Perpetuation of international migration from Turkey to Switzerland in the form of marriage migration: Describing the incidence', paper presented at the European Population Conference, Barcelona, 10 July 2008.

Topgül, Ceren \& Philippe Wanner (2009), 'Marriage migration from Turkey to Switzerland: Exploring the causes for women and men', Twenty-ninth International Population Conference of the International Union of Scientific Study of Population, IUSSP, Marrakech, 1 October 2009.

Tribalat, Michèle (1995), Faire France. Une enquête sur les immigrés et leurs enfants. Paris: La Découverte/Essai.

Van Tubergen, Frank \& Ineke Maas (2007), 'Ethnic intermarriage among immigrants in the Netherlands: An analysis of population data,' Social Science Research 36(3): 1065-1086.

Wanner, Philippe, Mathias Lerch \& Rosita Fibbi (2005), Familles et migrations. Le rôle de la famille sur les flux migratoires. Neuchâtel: Office fédéral de la statistique. 



\section{Assessing the social position of the new second generation}

The Swiss TIES study deals with the new second generation, children of immigrants from Turkey and the SSYU who arrived in Switzerland mainly during the eighties, and portrays their trajectories. These trajectories are the product of a number of factors ranging from youth engagement, personal and familial resources as well as economic and social opportunities offered by the immigration society in childhood, adolescence and young adulthood. Assessing the socio-economic integration of the Turkish and SSYU second generation raises a feeling of cautious optimism, as positive elements are balanced by reasons for concern.

Youth of the new second generation improved their qualifications compared to their parents by taking advantage of the educational opportunities offered by the country where they were born. Census data demonstrate that they perform better than foreign-born immigrants of similar origin. TIES results show that the vast majority reach post-compulsory educational certification, mostly VET qualifications, indicators which point to convergence between children of immigrants and the autochthonous population. Yet the share of youth holding at most compulsory education is still considerable. Men are especially at risk: one Turkish respondent in five who has left school enters the labour market with compulsory schooling only, twice as many as SSYU men and five times as many as autochthonous men.

In a society where education is available for free, parents are not faced with the challenge of choosing in which of their children to invest scant resources for education. In this context, parents appear to be as concerned about and supportive of their daughters' schooling as of their sons'. Findings show that in Switzerland it is uncommon for second-generation women of Turkish and SSYU descent to retreat from school before completing their education, a phenomenon observed elsewhere in Europe (Crul et al. 2012). However, no support is found for the competing hypothesis of secondgeneration women achieving higher levels of education than their fellow countrymen. Overall, however, second-generation women manage better than men to avoid dead-ends such as lack of post-compulsory education or meagre post-compulsory qualifications.

Gender differences are visible, yet they do not affect second-generation youth more than the autochthonous population. Although lower than their male counterparts', second-generation women's labour market participation 
is either similar to or higher than that for autochthonous women. The family life model in which mothers withdraw from the labour market when children arrive is more present among comparison group women than among the second generation of both Turkish and SSYU descent.

However, the labour market situation is a domain of concern. The unemployment rate for the Turkish second generation is double that for the comparison group, even though women are not more affected than men. A large share of economically active second-generation respondents face a difficult financial situation and rate their labour market trajectory worse than expected; about a third felt targeted by hostility while looking for a job or at the workplace, frequently by people in a position of power over them.

Our discussion of the findings will be developed along the three axes of comparisons presented in the introduction: how do the two secondgeneration groups compare with each other? To what extent does the agglomeration context shape distinct trajectories for the two groups? How does this 'new' second generation compare with the 'old' second generation whose integration path in Swiss society is sufficiently recent to function as an implicit benchmark? The discussion will lead to a tentative assessment of the process of integration engaging both immigrant groups and immigration society and will be built on the concept of boundary-making, developed by Zolberg (1999) Alba (2005) and Wimmer (2008).

The TIES study on 18-to-35-year-old Swiss-born youth of Turkish and SSYU descent captured a special fraction of the new second generation, the very first native-born cohorts, resulting from labour migrations that took place more than 30 years ago. It allows an assessment of their economic and social integration for the first time.

\subsubsection{Socio-economic participation}

Census 2000 data showed that the educational qualifications of Swiss-born Turkish and SSYU youth are improving in comparison to foreign-born Turkish and SSYU youth (Fibbi et al. 2011). Such a result confirms that the Swissborn groups are on a convergent path toward local standards in education. Since these results are not easily visible in official statistics - which do not distinguish by place of birth/length of stay, but only by nationality (Fibbi et al. 2007; Salentin 2003) - the false conclusion is often drawn that gaps are not narrowing over time.

The outcomes differ, however, between the two second-generation groups. Due to the low educational capital of the parents, second-generation Turkish respondents have the most unfavourable starting conditions for 
school and labour market attainment. They run the highest risk of leaving school early and attaining limited vocational qualifications. However, this group displays the largest internal polarisation in school outcomes, as the percentage of youth at risk is roughly comparable to the percentage of those in higher education. In the labour market, the Turkish second generation is channelled into relatively less skilled service occupations and appears more exposed to unemployment.

Thanks to their parents' intermediate level of education, the SSYU second generation enjoys more favourable starting conditions for school and labour market attainment. This is reflected by their higher likelihood of attaining post-compulsory qualifications or higher-qualifying VET certificates, and thereby greater possibilities of securing a stronger foothold in the labour market, with comparatively lower levels of unemployment. SSYU origin youth tread the traditional working-class path of status consolidation through access to VET qualifications, a path enjoying great social recognition and highly commended in Switzerland. All in all, differences in outcomes among the two second-generation groups under study appear largely determined by the notable gap in educational capital of the first generation.

Both groups show signs of acculturation to local norms in education, by compliance with the social norm of post-compulsory education and equal parental valorisation of sons' and daughters' school achievement. They also apparently benefit from various ad hoc structures providing a safety net to ensure support during the transition from compulsory school to the labour market. Another domain where convergence appears is labour market participation: the gap between men and women is twice as big in the Turkish second generation as compared to the SSYU second generation and in the comparison group, yet the labour force participation of Turkish women is identical with that of comparison group women. Moreover, withdrawal from the labour market in maternity is less pronounced among second-generation mothers than among comparison group mothers. In this respect, the SSYU second generation is characterised by similarities in the school and professional trajectories between men and women, much more prominent than among the comparison group.

Altogether, children of immigrants display higher labour market participation than autochthonous youth, because of their early involvement in the labour market through the VET system and the higher enrolment rate of autochthonous youth in tertiary education. Position in the labour market is clearly divided along origin lines, notably in the case of men, less so for women. Unemployment is also undoubtedly differentiated along the same lines, mirroring educational attainment. 
Gaps in school and labour market participation between immigrant and autochthonous origin groups are definitely there, yet they cannot be imputed to failed acculturation of the former to socio-cultural norms toward school and socio-economic integration. The position of men in all groups is more polarised than women's: at one end of the spectrum they are most likely to lack any post-compulsory education while at the other, they are more numerous than women in tertiary education.

\subsubsection{Socio-cultural features}

This new second generation is actively looking for inclusion in the country where they were born and live, as shown by high attachment to city and neighbourhood, mastery of local language, mixed friendship and naturalisation behaviour. Yet their bilingualism, bilateral identifications and citizenships show that double references are not lived as mutually exclusive. This is not a feature peculiar to the Turkish and SSYU second generation, but it deserves to be underscored in their case, as public discourse repeatedly challenges the possibility of such combinations and questions their legitimacy.

Many attitudes and behaviours witness this claim: strong local identification, taste for diversity both at ethnic and religious level, no 'return myth', inclination to relinquish previous nationality (especially among children of SSYU descent), high rates of naturalisation already in the family of birth and especially among young adults, active political participation both through associations and voting. Participation in the public sphere may not reach the same intensity as the one observed among comparison group youth, differences in social background accounting for those gaps; nevertheless, they appear a quite assertive second generation.

Marked differences appear, however, in the private sphere of family relations. Age and motives for leaving parental household, formation of unions, influence of the family on marriage decision, and most of all choice of spouse distinguish Turkish and SSYU second-generation groups from the comparison group. Endogamy and marriage migration are the outstanding features of partner choice for this second generation. In the case of marriage, ethnic endogamy is the dominant pattern in the spouse selection of TIES respondents. Among the Turkish second generation, 86 per cent of marriages are endogamous, 37 per cent prompting the immigration of the spouse. Among the SSYU second generation the trend is similar, although the percentages are lower: 78 per cent of marriages are endogamous, with 29 per cent concerning an immigrating spouse. In the former group, women 
marry out less than men; while in the latter women marry out more than men. As interethnic cohabitation is more frequent than interethnic marriage, mixed marriage rates underestimate the inter-ethnic contact. Taking into consideration all types of unions, ethnic non-homogeneous couples represent 25 per cent of couples involving a Turkish second-generation partner and 38 per cent of couples involving a SSYU second-generation partner.

Data on high endogamy are interpreted as a signal of ethnic closure on the side of the migrants. Yet, if mixed marriages are a measure of social distance, then endogamy may be interpreted as a consequence of social closure both on the side of the migrants and of the majority.

Religious endogamy affects more than half of second-generation married couples of both Turkish and SSYU descent. Religious boundaries appear more blurred than national ones, because of the considerable share (above 40 per cent) of respondents who declare being not religious. Religious exogamous marriages of TIES respondents can be distinguished between a strict (between a Muslim and a Christian spouse) and an enlarged (between spouses of any different religious affiliation) notion; strict exogamy is seen with 3 per cent of married Turkish respondents and 1 per cent of SSYU married respondents, while enlarged exogamy is reflected in $3^{2}$ per cent of Turkish respondents' marriages and 31 per cent of their SSYU peers.

To understand intermarriage rates, it is useful to consider that in many cases intermarriage for the Turkish and SSYU second generation entails not only the crossing of a linguistic and national boundary, but also of culturalreligious boundaries. In this respect, recalling the historical experience of Jews in the United States may put things into perspective: intermarriage between Jews and Gentiles reached only 11 per cent in 1965, that is, after more than 6o years of Jewish settlement in the US (Alba and Nee 2003). The Turkish and SSYU populations have been living in Switzerland for some 30 years.

\subsection{Second generation integration: Communities, contexts and outcomes}

The two groups of the new second generation share a number of contextual conditions surrounding their immigration, such as the same institutional frame for non-EU nationals as well as the economic situation and historical timing of their immigration; these common conditions make the comparison between the groups legitimate. Yet these groups are distinct in their geographical, linguistic, educational and religious backgrounds and live 
in singular relation to their respective countries of origin. Moreover, they differ in their relative size, in the settlement regions, and faced a somewhat different reception environment in Switzerland.

We will therefore discuss outcomes of the second generation by paying attention to the local contextual frame, namely the cities and their larger agglomerations. Such a research design, which is the cornerstone of the TIES project, serves to distance the research from methodological nationalism as well as explore and exploit intra-national contextual variability. The findings show that the ways the second generation negotiates its way into a new society differ according to the local context. The analyses systematically raise this issue and here we draw the big picture around two clusters of factors distinguishing the two agglomerations: type of immigrant settlement and the outcomes of second-generation groups.

\subsubsection{Ethnic settlements}

In sketching the characteristics of the community environment available at the local level for the second generation in the two contexts, a contrasting picture helps to identify specifics for each group and place of settlement. The Turkish 'community' in Zurich and Basel is in fact not the same community.

\section{Turkish immigration}

Turkish immigration started earlier in Zurich than in Basel. Turkish parents of TIES respondents appear better qualified, with a higher proportion of mothers and fathers holding upper secondary and tertiary qualifications. As a corollary, the Turkish second generation in Zurich may have easier access to post-compulsory education and in all be more successful in acquiring Swiss citizenship while retaining a better command of their parents' language. They are also comparatively more ready to identify with the city, a feeling that might well go along with the fact that they perceive themselves to be less frequently targeted by discrimination.

Turkish immigration started later in Basel, though Basel currently has a higher percentage of people of Turkish origin in the resident population. The qualifications the parents brought along with them are somewhat lower. Given the lower cultural capital of their parents, the Turkish second generation in Basel is more exposed to the risk of lacking post-compulsory education. The ethnic background of the group generally subsumed under the homogenising term 'Turkish community' is more diverse, including more Kurdish (and Kurdish-Turkish) speakers and more Alevi. Altogether, religions practice appears less pronounced in Basel than in Zurich, for all origin groups. 
The Turkish second generation reported more closely knit social networks in Basel than in Zurich; they rely more on country of origin social resources for marriage and marriages between cousins appear more frequent. Turkish descent respondents declare a worse command of the local language than those in Zurich, a fact that might be related to the relatively higher concentration of Turks in the Rhine city, as well as their lower school qualifications. Identification with the city appears slightly less pronounced in Basel, where the Turkish second generation more often experiences diffuse hostility. Nevertheless, they are the ones who most decisively reject the prospect of living in their parents' country of origin and actively participate in local political life.

\section{SSYU immigration}

The 'communities' originating via immigration from the Socialist Federal Republic of Yugoslavia also show very distinctive traits in the two agglomerations under study.

Zurich today has a higher share of SSYU immigrants and their descendants than Basel, although immigration from those regions took place somewhat later. In spite of the difficulty of tracing ethnicity in the complex situation of the country of origin, various indicators suggest that Zurich has a higher share of immigrants from the southern republics of the former Yugoslav federation. The proportion of parents whose childhood language is Albanian or Macedonian is similar in Zurich and Basel (some 10 per cent), but Zurich has a higher share of people with mixed linguistic heritage, a situation which occurs more frequently among people from Kosovo and Macedonia. Zurich has more Muslim SSYU families than Basel. Family reunification is the most important entry ground for SSYU mothers in Zurich. The mean number of household members is also higher in Zurich than in Basel; the highest numbers of household members is to be found in Kosovar and Macedonian families.

Immigrants from the former Yugoslavia initially settled in Basel, though their relative significance in Zurich grew over time. Despite these differences, the level of qualification of immigrants from the SSYU is quite similar in the two agglomerations. SSYU mothers arrived in Switzerland more often as workers than in the frame of family reunification. Mixed marriages at parental level are more frequent in Basel than in Zurich; they appear more frequent in the agglomeration where the immigrant group is less concentrated. In the same vein, naturalisation affects a majority of SSYU parents in Basel but does not reach the same level in Zurich. No significant differences between agglomerations are to be observed in the 
educational background of Yugoslav origin parents, who quite frequently completed education beyond compulsory school.

\subsubsection{Second-generation outcomes in Zurich and Basel}

The two second-generation groups present parallel outcomes if the chosen indicator of educational success is attendance of tertiary education: less than one young person in ten reaches this goal. Yet this result conceals quite different educational trajectories for the two groups. Comparing fathers' and children's educational attainment, the Turkish second-generation experience high intergenerational educational mobility (two out of three). At the same time, however the proportion of youth 'at risk' lacking any post-secondary training or equipped with limited vocational qualification is quite high, three times that observed in the comparison group. The intergenerational educational mobility of the SSYU second generation is much lower (less than one in two) but the share of youth at risk is also lower, double that observed in the comparison group. Descendants of immigrants are more likely to be successful in the labour market than in school, as they manage to close somewhat the gap with youth of the comparison group in terms of prestige and occupational status.

The chance to access extended requirements tracks in lower secondary school in Zurich represents a multiple of the chances of similar school trajectories in Basel; the difference is especially sharp in the case of BaselLand. This early selection is crucial as it prepares the ground for further training and qualifications. Under these preconditions, among respondents who are no longer enrolled in school, Basel youth of any origin tend to be more affected by the lack of post-compulsory qualifications than Zurich youth. Among those who are still completing their education, no systematic polarisation is observed between the two agglomerations.

The labour market position of the second generation does not vary significantly in the two agglomerations. However, a variety of indicators tend to support the idea that the labour market situation is more favourable in Zurich than in Basel in general and for the second generation in particular. The activity rate tends to be higher in Zurich than in Basel for all groups, for fixed contracts as well as occupational prestige. Earnings are also higher in Zurich, especially for the second generation. Zurich appears to be a more receptive labour market than Basel. With equal intermediate educational credentials, the second generation finds comparable access to public sector occupations, though this does not always seem to be the case when they reach higher levels of education. Yet those assets do not benefit the second 
generation of Turkish descent who, in contrast to the comparison group and SSYU second generation, have significantly higher unemployment in Zurich than in Basel.

On the other hand, Basel gives greater access than Zurich to public sector jobs, possibly an effect of a more sensitive integration policy on this issue (Wichmann \& D'Amato 2010). Interethnic face-to-face relations are more frequent in Basel; public social events of an ethnic variety are more frequently attended by autochthonous youth in Basel. Against this background, it comes as no surprise that the second generation shows higher political participation in Basel than in Zurich. Basel has more tightly knit Turkish intra-community networks and a somewhat stronger family hold on the marriage market for the second generation. Nevertheless, attitudes toward gender roles are less traditional in Basel than in Zurich for both the Turkish and SSYU second generation.

The second generation perceives tensions in both contexts, however. Whether in school or the labour market, the feeling of being unwelcome appears stronger in the agglomeration where the migrant group is better represented, that is, Basel for the Turkish origin group and Zurich for the SSYU origin group, as if relations were more tense in the agglomeration where each of the groups has a relatively greater prominence.

It proved easy to identify different patterns of settlement of Turkish and SSYU immigrants in the two agglomerations, but more difficult to design a specific local profile for the second generation's outcomes. And yet, out of the various elements reported a curious contrast appears between the two localities. Structural conditions appear more favourable in Zurich than in Basel, in terms of the educational outcomes and labour market positions of the second generation. Although the reception climate can be equally cool in both places, as reports on perceptions of hostility have shown, interethnic relations and political participation appear somewhat more inclusive in Basel than in Zurich.

This study has shown that socio-economic integration of the new second generation in Switzerland definitely presents areas of success for the great majority both in school and the labour market, yet a significant share of respondents, mainly men, has a hard time in reaching this target. They face a rather unwelcoming context, even in the opinion of comparison group respondents. Yet the children of immigrants show a decisive willingness to participate in social and political life while retaining distinctive family practices. Religion plays an important role in their lives, but the overwhelming majority share the view that religion should be a private matter. 
This contrasting picture means that the conditions which produce boundary blurring at the level of education and the labour market between this new second generation and Swiss society are only partially met in the case of the SSYU and Turkish second generation. The social mobility of part of the second generation and the multiple identifications repeatedly reported by second-generation respondents bear witness to their efforts to take advantage of new opportunities while maintaining continuity. Their difficulties in negotiating acceptance of those tentative, inclusive identities evidence the lasting existence of a 'bright' boundary between majority society and children of Turkish and SSYU descent.

\subsection{Old and new second generations in Switzerland: Structural integration and boundary making}

Switzerland confronted integration when dealing with immigrants from Italy and Spain who came as guest-workers in the fifties and sixties and later settled with their families. Literature on the experience of this older second generation dates from 30 years ago (Gonvers et al. 1980) and continues to grow (Wessendorf 2013). This experience is often implicitly used as a basis for comparison when discussing the current situation of a new second generation entering adulthood, assuming that the process was easier in the past. We take up this issue while highlighting the historical context of integration. For the sake of simplicity, we designate the groups under study as the 'new' second generation (Fibbi et al. 2005: 130) as opposed to the 'old' one, as represented by the Italian and Spanish children of immigrants (see Chapter 1).

Our diachronic comparison between the old and new second generation in Switzerland echoes the intense debate on similar issues which started in the United States (Portes and Zhou 1993) and later developed in Europe (Lucassen 2005). On both continents, the old and new second generation present a contrast between descendants of European origin and non-European origin immigrants or, in the Swiss case, European Union citizens with non-EU citizens. While the old second generation belongs to now-slower immigration streams, new second generations belong to ongoing immigrant flows which enrich the supply side of ethnicity (Alba 1997: 835), so that group processes influence individual attainment. Old second generations are the descendants of workers recruited by an industrial economy who therefore benefitted from a strong foothold in the labour market; new second generations are the descendants of immigrants to a mainly service 
economy which provides a less secure position in the labour market to medium and low-skilled workers.

The historical conditions for the old and the new second-generation groups in Switzerland are different. At the economic level, 'old' immigrant parental flows were less affected by unemployment, as the crisis of the nineties arrived when they were reaching retirement age; the same crisis weakened the labour market position of the younger parents of the new second generation, exposing them to higher risks of unemployment. It has also narrowed avenues of social mobility due to the lack of skilled blue collar positions. At the political level, the new second generation belongs to flows that include a sizable component of asylum seekers; this migrant profile has been targeted in the last twenty years by anti-immigrant movements and stigmatised in Swiss politics as undeserving welfare profiteers. The legal status of these flows has worsened over time. At the cultural level, the new second generation belongs to flows that include a large share of Muslims, considered with suspicion as a potential enemy in the context of the international war on terrorism and suspected as immigrants unwilling or resist to integration. In the meantime, the old second generation has benefitted from the political rapprochement between Switzerland and the EU: they have profited from a consolidated legal regime and an increasingly positive attitude toward immigrants originating from countries increasingly presented as culturally similar.

In Switzerland, guest-workers were not expected to settle; only their functional insertion into the labour market was relevant. Policy has now changed, yet for a long time 'old' immigrants and their children were not expected to integrate. As the new second generation came of age at the beginning of the new century, however - when the new federal integration policy was introduced - such expectations were raised for all immigrant families and children. Now the achievements of the new second generation are readily compared to those of the old second generation as well as those of local youth, creating a sense of judgement as to the degree of their integration. Although understandable, this practice is unfair to the new second generation, as it suggests an explanation in terms of cultural diversity which overshadows the changing historical conditions of the new second generation's insertion into Swiss society.

Against this contrasting historical background, how do Turkish and SSYU second-generation youth compare with the old second generation born in Switzerland to guest-worker families? Educational attainment and unemployment are key indicators. Census 2000 data show that the proportion of native-born Italian youth 'at risk' aged 20-24 with at most 
compulsory schooling is twice that observed among Swiss by birth (Mey et al. 2005). The TIES study documents a comparable gap between the new second generation and the comparison group in this respect; the proportion of youth at risk is three times that of the comparison group for the Turkish second generation and twice that for SSYU origin youth. Census 2000 data also show that the unemployment rate among native-born Italians aged 20-24 is 1.5 times higher than among Swiss by birth (Fibbi et al 2005). The TIES study documents a similar gap for SSYU youth and a larger gap for the Turkish second generation.

We argue that in spite of the harsher economic and political climate, immigrants of these new flows integrated more readily than their peers in previous flows, quickly showing willingness to settle in Switzerland by, among other things, embracing the option to naturalise. Acculturation to local school norms took place quite slowly in the case of the old second generation. The young worker model, entailing early entry into the labour market without proper vocational training, changed slowly for Italians (Fibbi \& De Rham 1988); girls were often left behind and therefore performed significantly worse in education in comparison to boys (Gurny et al. 1984). By contrast, 'Swiss' standards in this respect have been quickly adopted by Turkish and SSYU families for their children despite the difficulties they encounter in realising their goals. In their analysis of the transition to upper secondary school among children of immigrants, Hupka et al. observe that the origin country does not play a role and therefore 'the second generation from south-east Europe and Turkey will be as successful as the previously immigrated groups' (2006: 21). The new second generation may face more problems in terms of structural integration because of the shorter collective immigrant seniority, but the old and new second generations are similarly engaged in social mobility.

This orientation contributes to an explanation of the overall limited gap in school and labour market performance between the old and new second generations. We dismissed the cultural argument in a paper based on analysis of Census 2000 data: '[G]ood school performance, although limited, is not reserved to groups originating from "culturally close" countries. When family social background and language practices are controlled for, patterns of school success do not support the divide between EU and non EU countries'(Fibbi et al. 2011: 130).

Some differences persist as the result of a constellation of related factors, whereby old immigrant flows take advantage of social capital accumulated over time both individually and collectively. In this context, they are able to benefit fully from the succession of ethnic groups in the labour market 
(Lieberson 1980), facilitated by the interruption of immigrant intake from those countries (Alba and Nee 2003). The old second generation whose performance was documented in the late nineties represent the last secondgeneration cohorts of native-born youth originating from Italy and Spain. Their access to the labour market might have benefitted from the inflow of new low-qualified immigrant groups, which may have enhanced their social mobility. By contrast, the second generation of Turkish and SSYU origin is the very first cohort of native-born of that origin; moreover, they are entering the labour market at a time when the Swiss economy is massively recruiting highly skilled labour, thus probably lessening their mobility chances. Such historical considerations show the notable impact of group factors on individual chances of structural integration.

Despite some undeniable differences, the outcomes of the old and new second generation appear similar. There remains at issue why the old second generation is perceived today as successfully integrated while the new second generation is portrayed as problematic (ODM 2006). Official school statistics, which show attainment by nationality and ignore place of birth and length of stay, give a more worrying picture of the situation of more recent groups where the proportion of first-generation youth is quite high.

\subsubsection{Boundary definition}

The theory of boundary-making proposed by Zolberg (1999) and further developed by Alba (2005) and Wimmer (2008) seems most pertinent to this study, based as it is on differentiation between individual and grouplevel integration (Alba 1997: 835). Reflecting on how distinctions between 'insiders' and 'outsiders' might be drawn or erased, Zolberg identifies possible patterns of negotiations between national majorities and immigrant minorities. This process of symbolic struggle and negotiation (Lamont \& Bail 2005) is one of the major aspects of the reciprocity inherent to the integration process between majority and minority; the boundary concept allows transcendence of the static, unidirectional notion of integration.

Boundary crossing designates an individual process of immigrants acquiring some of the attributes of the host identity. Such a process leaves the structure of the society and the distinction between insiders and outsiders unchanged; the boundary remains 'bright'. Boundary blurring, by contrast, affects the legal, social and cultural structure of the immigration society. The social profile of a boundary becomes less distinct through the acceptance of overlapping collective identities previously thought of as 
being mutually exclusive. Boundary shifting finally entails a fundamental redefinition of the situation whereby a group previously considered an 'outsider' group is assigned to the category of 'insider' (Alba 2005).

The management of boundaries is not exclusively but more readily in the hands of the majority. Wimmer rightly notes that whether or not a boundary can be crossed depends on those on the other side as well, who may accept or reject newcomers: "Minority making" will make boundary crossing more difficult and dominant groups may police their boundary against trespassers' (ERS 2008: 1039). To borrow Lamont's (2002) distinction, boundaries are both social and symbolic. The differential legal frame for EU and non-EU citizens is one major aspect of the management of boundaries; their bearing goes beyond the specific legal barriers they present. Though they have no direct effect on naturalised youth, such legal measures have an impact at a symbolic level on the public perception of these groups.

The adult second generation has the potential to challenge boundaries once taken for granted by their parents. The youth of the new second generation now established in Swiss society is engaged in a process of individual boundary crossing, a strategy which does not contest the boundaries of ethnic categories nor the hierarchy between the groups. In other words, 'boundary crossing...thus reproduces the overall hierarchy by reinforcing its empirical significance and normative legitimacy' (Wimmer ERS 2008: 1039). Dual citizenship may have lowered the entry threshold into the majority at an individual level, but collectively the social boundary remains intact, or 'bright' (Alba 2005). The obstacles they encounter in achieving their goals makes 'minority making' a necessary way of protecting their own dignity (Mey and Rorato 2010). Intermarriage can be interpreted as one 'minority making' response to the social closure they experience, all the more so when it coincides with the 'bright' religious divide.

The old second generation has, by contrast, successfully undergone the process of boundary blurring thanks not only to the acceptance of individual overlapping identities (via dual citizenship), but moreover to a redefinition of the categories of insider and outsider. This societal process was crystallised in the institutionalisation of the special status granted to EU citizens in Switzerland since 2002. The new legal status came as the ratification of the 'whitening' of those old immigrant groups and their descendants (Roediger 1991, Lucassen 2005, D'Amato 2005, Fibbi 2011) that demonstrates the wider acceptance of those groups into the majority. 
The TIES study shed light on Turkish and SSYU immigration to Switzerland and offered a comprehensive assessment of the evolution of the new second generation. This evidence is relevant to the integration debate and to policymaking in this country. First, the high proportion of second-generation respondents lacking proper qualifications - two to four times as many as the comparison group - at the entry point to the labour market is disturbing and suggests an area of concern in school achievement which needs to be addressed. Two factors have prevented this educational situation from turning into an occupational hardship: the favourable labour market situation seems to have provided a second avenue of inclusive integration. Measures aimed at easing the transition from school into the labour market have also proved quite effective; those efforts should be continued and intensified. International studies show that the second generation in Switzerland compares favourably with other European countries based on second-generation occupational integration (Liebig et al. 2012; Crul et al 2012).

The development of a middle class of immigrant origin will be crucial for countering risks of ethnic polarisation and therefore for social cohesion in cities. The old second generation largely showed a lack of interest in social activity and political mobilisation (Bednarz 2002) whereas the new second generation appears more assertive, as shown by their involvement in associations and participation in the political process. Both the old and new second generation experienced some hostility, but the offenders differ: the former felt targeted mainly by their peers, while the latter perceive hostility as much from their superiors as from their peers. This weakens identification with the country of residence, where they collectively face harsher socio-economic, political and 'discursive' conditions. The TIES study shows that there is no ground for supposing a lack of willingness to integrate on the part of the new second generation; on the contrary, their high naturalisation rates suggest that they are not only willing but also able to deliver sufficient 'proof' of belonging in the challenging Swiss naturalisation procedure.

Clear purposeful action for promoting members of the new second generation into higher education and public sector occupations will be helpful in ensuring visibility for these groups. This may impact positively on members of their group who need role models to counter the enduring scepticism they face. It would also have positive repercussions for the majority society that must incorporate these groups in established local circles, where a migration background and mixed heritage will increasingly be the norm. 


\section{References}

Alba, Richard \& Victor Nee (1997), 'Rethinking Assimilation Theory for a New Era of Immigration', International Migration Review, 31(4): 826-875.

Alba, Richard \& Victor Nee (2003), Remaking the American mainstream: Assimilation and contemporary immigration. Cambridge: Harvard University Press.

Alba, Richard (2005), 'Bright vs. blurred boundaries: Second-generation assimilation and exclusion in France, Germany and the United States', Ethnic and Racial Studies 28(1): 20-49.

Bednarz, Furio (2002), 'I giovani italiani nel mondo tra integrazione e ricerca delle radici storiche: il modello svizzero', Zurigo: Federazione delle Colonie Libere Italiane in Svizzera, Fondazione ECAP.

Crul, Maurice, Jens Schneider \& Frans Lelie (eds) (2012), The European second generation compared. Does the integration context matter? Amsterdam: Amsterdam University Press.

D'Amato, Gianni (2005), 'How the Italians became blond! Immigration and political rights in France, Switzerland and Germany', Studi Emigrazione XLII (160): 822-847.

Fibbi, Rosita \& Gérard De Rham (1988), 'Switzerland: The position of second generation immigrants on the labour market', in Wilpert Czarina (ed.), Entering the working world. Following the descendants of Europe's immigrant labour force, 24-55. Aldershot: Gower.

Fibbi, Rosita, Mathias Lerch \& Philippe Wanner (2005), 'Processus de naturalisation et caractéristiques socio-économiques des jeunes issus de la migration', in OFS (ed.), L'intégration des populations issues de l'immigration en Suisse: personnes naturalisés et deuxième génération, 57. Neuchâtel: Office fédéral de statistique.

Fibbi, Rosita, Mathias Lerch \& Philippe Wanner (2007), 'Naturalisation and socio-economic characteristics of youth of immigrant descent in Switzerland.'Journal of Ethnic and Migration Studies, 33(7): 1121-1144.

Fibbi, Rosita, Mathias Lerch \& Philippe Wanner (2011), 'School qualifications of children of immigrant descent in Switzerland', in Richard Alba \& Mary Waters (eds), New dimensions of diversity: The children of immigrants in North America and Western Europe. Ithaca: Cornell University Press.

Fibbi, Rosita (2011), 'Come siamo diventati biondi: L'immigrazione italiana in Svizzera', L'importanza di essere Svizzera. I Quaderni speciali di Limes. 3(3): 211-220.

Gonvers, Jean-Pierre, Arlette Mottaz, Laurent Monnier \& Gérard de Rham (1980), Qui sont-ils? Suisses et/ou Espagnols? La deuxième génération d'immigrés espagnols en Suisse. Lausanne: Institut de science politique.

Gurny, Ruth, Paul Cassée, Hans-Peter Hauser \& Andreas Meyer (1984), Karrieren und Sackgassen. Wege ins Berufsleben junger Schweizer und Italiener in der Stadt Zürich. Diessenhofen: Ruegger Verlag.

Hupka, Sandra, Stefan Sacchi \& Barbara E. Stalder (2006)., 'Herkunft oder Leistung? Analyse des Eintritts in eine zertifizierende nachobligatorische Ausbildung anhand der Daten des Jugendlängsschnitts TREE', TREE Working paper: 40.

Lamont, Michèle \& Virág Molnár (2002), 'The study of boundaries in the social sciences', Annual Review of Sociology 28: 167-195.

Lamont, Michèle \& Christopher A. Bail (2005), 'Sur les frontières de la reconnaissance. Les catégories internes et externes de l'identité collective', Revue européenne des migrations internationales 21(2): 61-90.

Lieberson, Stanley (1980), A piece of the pie: Blacks and immigrants since 1880. Berkeley, Los Angeles: University of California Press. 
Liebig, Thomas, Sebastian Kohls \& Karolin Krause (2012), Lintégration des immigrés et de leurs enfants sur le marché du travail en Suisse. Paris: Éditions de l'OCDE.

Lucassen, Leo (2005), The immigrant threat: The integration of old and new migrants in Western Europe since 1850. Urbana and Chicago: University of Illinois Press.

Mey, Eva, Miriam Rorato \& Peter Voll (2005), 'Die soziale Stellung der zweiten Generation. Analysen zur schulischen und beruflichen Integration der zweiten Ausländergeneration', in OFS (ed.), L'intégration des populations issues de l'immigration en Suisse: Personnes naturalisées et deuxième génération, 61-152. Neuchâtel: Office fédéral de la statistique.

Mey, Eva \& Miriam Rorato (2010), Jugendliche mit Migrationshintergrund im Übergang ins Erwachsenenalter - eine biographische Längsschnittstudie. Luzern: Hochschule Luzern Soziale Arbeit.

ODM (2006), Problèmes d'intégration des ressortissants étrangers en Suisse. Berne: Office fédéral des migrations.

Portes, Alejandro \& Min Zhou (1993), 'The new second generation: Segmented assimilation and its variants among post-1965 immigrant youth', Annals of the American Academy of Political and Social Science 530(1): 74-96.

Roediger, David (1991), The wages of whiteness: The making of the American working class. New York: Verso.

Salentin, Kurt \& Frank Wilkening (2003), 'Ausländer, Eingebürgerte und das Problem einer realistischen Zuwanderer-Integrationsbilanz.' Kölner Zeitschrift für Soziologie und Sozialpsychologie, 55(2): 278-298.

Wessendorf, Susanne (2013), Second-generation transnationalism and roots migration: Crossborder lives. Aldershot: Ashgate Publishing.

Wichmann, Nicole \& Gianni D'Amato (2010), Migration und Integration in Basel-Stadt:Ein 'Pionierkanton'unter der Lupe. Neuchâtel: Schweiz. Forum for Migrations- und Bevölkerungsstudien.

Wimmer, Andreas (2008), 'Elementary strategies of ethnic boundary making', Ethnic and racial studies 31(6): 1025-1055.

Wimmer, Andreas (2008), 'The making and unmaking of ethnic boundaries: A multilevel process theory', American Journal of Sociology 113(4): 970-1022.

Zolberg, Aristide \& Litt Woon Long (1999), 'Why Islam is like Spanish: Cultural incorporation in Europe and the United States', Politics and Society 27: 5-38. 



\section{List of contributors}

Rosita Fibbi is coordinator of the Swiss TIES project. She works as a senior researcher and project manager at the Swiss Forum for Migration and Population Studies at the University of Neuchâtel and she is a senior lecturer at the University of Lausanne.

rosita.fibbi@unine.ch

Philippe Wanner is professor of demography at the University of Geneva. Former director of the Swiss Forum for Migration and Population Studies, in 2013 he edited a book on "La démographie de étrangers en Suisse." philippe.wanner@unige.ch

Ceren Topgül obtained her PhD in demography at the University of Geneva in 2013, with a thesis on Partner choice of Turkish originyouth in Switzerland: The underlying mechanisms and social implications for women and men. She holds an MA degree in economic and social demography from Hacettepe University, Ankara, where she worked on schooling and employment of children in Turkey.

cerentopgul@yahoo.com

Dušan Ugrina is an anthropology doctoral candidate at the Florida International University. In Fall 2014 he will defend his thesis: Production, reproduction and of the of integration. He is now working as a consultant responsible for Berlin's part of the Open Society Foundation's project "Engaging Marginalized Majority Populations and Communities."

dusan.ugrina@gmail.com 



\section{Other IMISCOE Research titles}

María Bruquetas-Callejo

EducationalReception in Rotterdam and Barcelona:Policies, Practices and Gaps 2014 ISBN 9789089646446

Philipp Schnell

Educational Mobility of Second-Generation Turks: Cross-NationalPerspectives 2014 ISBN 9789089646514

Franck Düvell, Irina Molodikova and Michael Collyer (eds)

Transit Migration in Europe

2014 ISBN 9789089646491

Michael Bommes, Heinz Fassmann and Wiebke Sievers (eds)

Migration from the Middle Eastand North Africa to Europe: Past Developments, Current Status and Future Potentials

2014 ISBN 9789089646507

Masja van Meeteren

Irregular Migrants in Belgium and the Netherlands: Aspirations and Incorporation

2014 ISBN 9789089646439

Yolande Jansen

Secularism, Assimilation and the Crisis of Multiculturalism:French Modernist Legacies

2013 ISBN 9789089645968

Marlou Schrover and Deidre M. Moloney (eds)

Gender, Migration and Categorisation: Making Distinctions between Migrants in Western Countries, 1945-2010

2013 ISBN 9789089645739

Birgit Glorius, Izabela Grabowska-Lusinska and Aimee Kuvik (eds)

Mobility in Transition: Migration Patterns after EU Enlargement 2013 ISBN 9789089643926 
Joan Font and Mónica Méndez (eds)

Surveying Ethnic Minorities and Immigrant Populations: Methodological Challenges and Research Strategies

2013 ISBN 9789089645432

Marek Okólski (ed.)

European Immigrations: Trends, Structures and Policy Implications

2012 ISBN 9789089644572

Ulbe Bosma (ed.)

Post-Colonial Immigrants and Identity Formations in the Netherlands 2012 ISBN 9789089644541

Christina Boswell and Gianni D'Amato (eds)

Immigration and Social Systems: Collected Essays of Michael Bommes

2012 ISBN 9789089644534

Maurice Crul, Jens Schneider and Frans Lelie (eds)

The European Second Generation Compared: Does the Integration Context Matter?

2012 ISBN 9789089644435

Bram Lancee

Immigrant Performance in the Labour Market: Bonding and Bridging Social Capital

2012 ISBN 9789089643575

Julie Vullnetari

Albania on the Move: Links between Internal and International Migration 2012 ISBN 978 90 $8964355^{1}$

Blanca Garcés-Mascareñas

State Regulation of Labour Migration in Malaysia and Spain: Markets, Citizenship and Rights

2012 ISBN 9789089642868

Albert Kraler, Eleonore Kofman, Martin Kohli and Camille Schmoll (eds) Gender, Generations and the Family in International Migration 2012 ISBN 9789089642851 
Giovanna Zincone, Rinus Penninx and Maren Borkert (eds)

Migration Policymaking in Europe: The Dynamics of Actors and Contexts in Past and Present 2011 ISBN 9789089643704

Michael Bommes and Giuseppe Sciortino (eds)

Foggy Social Structures: Irregular Migration, European Labour Markets and the Welfare State 2011 ISBN 9789089643414

Peter Scholten

Framing Immigrant Integration: Dutch Research-Policy Dialogues in Comparative Perspective 2011 ISBN 9789089642844

\section{Liza Mügge}

Beyond Dutch Borders: Transnational Politics among Colonial Migrants, Guest Workers and the Second Generation

2010 ISBN 9789089642448

Rainer Bauböck and Thomas Faist (eds)

Diaspora and Transnationalism: Concepts, Theories and Methods 2010 ISBN 9789089642387

Cédric Audebert and Mohamed Kamel Dorai (eds)

Migration in a Globalised World: New Research Issues and Prospects 2010 ISBN 9789089641571

Richard Black, Godfried Engbersen, Marek Okólski and Cristina Pantîru (eds) A Continent Moving West? EU Enlargement and Labour Migration from Central and Eastern Europe 2010 ISBN 9789089641564

Charles Westin, José Bastos, Janine Dahinden and Pedro Góis (eds) Identity Processes and Dynamics in Multi-Ethnic Europe 2010 ISBN 9789089640468

Rainer Bauböck, Bernhard Perchinig and Wiebke Sievers (eds) Citizenship Policies in the New Europe: Expanded and Updated Edition 2009 ISBN 9789089641083 
Gianluca P. Parolin

Citizenship in the Arab World: Kin, Religion and Nation-State

2009 ISBN 9789089640451

Maurice Crul and Liesbeth Heering (eds)

The Position of the Turkish and Moroccan Second Generation in Amsterdam and Rotterdam: The TIES Study in the Netherlands

2008 ISBN 9789089640611

Marlou Schrover, Joanne van der Leun, Leo Lucassen and Chris Quispel (eds) Illegal Migration and Gender in a Global and Historical Perspective 2008 ISBN 9789089640475

Corrado Bonifazi, Marek Okólski, Jeannette Schoorl and Patrick Simon (eds) International Migration in Europe: New Trends and New Methods of Analysis 2008 ISBN 9789053568941

Ralph Grillo (ed.)

The Family in Question:Immigrant and Ethnic Minorities in MulticulturalEurope 2008 ISBN 9789053568699

Holger Kolb and Henrik Egbert (eds)

Migrants and Markets: Perspectives from Economics and the Other Social Sciences

2008 ISBN 9789053566848

Veit Bader

Secularism or Democracy? Associational Governance of Religious Diversity 2007 ISBN 9789053569993

Rainer Bauböck, Bernhard Perchinig and Wiebke Sievers (eds)

Citizenship Policies in the New Europe

2007 ISBN 9789053569221

Rainer Bauböck, Eva Ersbøll, Kees Groenendijk and Harald Waldrauch (eds) Acquisition and Loss of Nationality: Policies and Trends in 15 European Countries Volume 1: Comparative Analyses

2006 ISBN 9789053569207

Volume 2: Country Analyses

2006 ISBN 9789053569214 
Leo Lucassen, David Feldman and Jochen Oltmer (eds)

Paths of Integration: Migrants in Western Europe (1880-2004)

2006 ISBN 9789053568835

Rinus Penninx, Maria Berger and Karen Kraal (eds)

The Dynamics of International Migration and Settlement in Europe: A State of the Art

2006 ISBN 9789053568668

\section{IMISCOE Textbooks}

Marco Martiniello and Jan Rath (eds)

An Introduction to Immigrant Incorporation Studies: European Perspectives (Vol. 3)

2014 ISBN 9789089646484

Marco Martiniello and Jan Rath (eds)

An Introduction to International Migration Studies: European Perspectives (Vol. 2)

2012 ISBN 9789089644565

Marco Martiniello and Jan Rath (eds)

Selected Studies in International Migration and Immigrant Incorporation (Vol.1) 2010 ISBN 9789089641601 
